\title{
VINHAÇA COMO POSSÍVEL REDUTOR DA INEILTRAÇÃO EM CANAIS DE TERRA
}

CARLOS BRANCILDES MONTE CALHEIROS

Engenheiro Agrônomo, Mestre

Orientador: Prof. Dr. ANTÔNIO FERNANDO LORDELO OLITTA

Tese apresentada à Escola Superior de Agricultura "Luiz de Queiroz", Universidade de São Paulo, para obtenção do título de Doutor em Agronomia, Área de Concentração: Irrigação e Drenagem.

\author{
PIRACICABA \\ Estado de São Paulo - Brasil \\ Novembro de 1996
}




\section{Dados Internacionais de Catalogação na Publicação (CIP) DIVISĀO DE BIBLIOTECA E DOCUMENTAÇĀO - Campus "Luiz de Queiroz"/USP}

\section{Calheiros, Carlos Brancildes Monte}

Vinhaça como possivel redutor da infiltração em canais de terra / Carlos Brancildes Monte Calheiros. - - Piracicaba, 1996.

137p. : il.

Tese (doutorado) -- Escola Superior de Agricultura Luiz de Queiroz, 1996.

Bibliografia.

1. Condutividade hidráulica 2. Infiltração (taxa) 2. Irrigação 4. Porosidade 5. Solo 6. Vinhaça I. Título 


\section{VINHAÇA COMO POSSÍVEL REDUTOR DA INEILTRAÇÃO EM CANAIS DE TERRA}

CARLOS BRANCIL MS MONTE CALHEIROS

Aprovada em: 16.12.1996

Comissão julgadora:

Prof. Dr. Antônio Fernando Lordelo Olitta

ESALQ/USP

Prof. Dr. Dirceu Brasil Vieira

$\mathrm{EE} / \mathrm{UNICAMP}$

Prof. Dr. José Renato Zanini

Prof. Dr. Joelito de Oliveira Resende

FCAV/UNESP

Prof. Dr. Tarlei Ariel Botrel

$\mathrm{EACA} / \mathrm{UFBA}$

ESALQ/USP

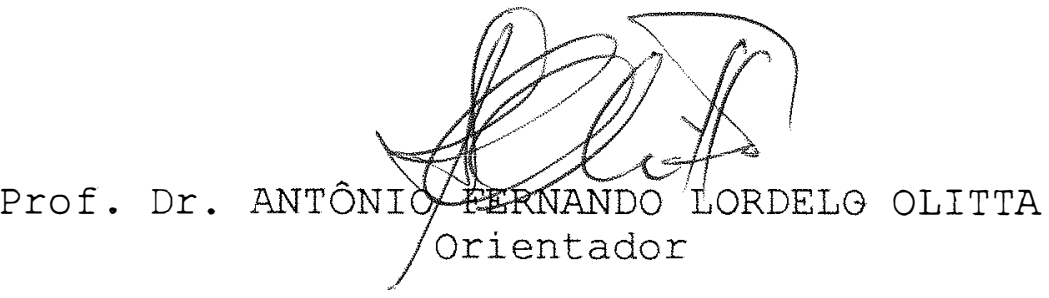


"Vejo, de um lado, a totalidade das experiências sensoriais e, do outro, a totalidade dos conceitos e proposiçōes descritos nos livros. As relaçōes entre os conceitos e as proposiçōes são de natureza lógica, e o processo do pensamento lógico é estritamente limitado à efetivação da conexão entre os conceitos e as proposiçōes entre si, de acordo com regras firmemente estabelecidas, que constituem a matéria da lógica. Os conceitos e proposiçōes adquirem 'sentido' ou 'conteúdo', apenas através das suas conexōes sensoriais. A conexão destas últimas com os primeiros é puramente intuitiva, e não de natureza lógica em si mesma. $O$ grau de certeza com o qual essa conexão ou ligação intuitiva pode ser admitida, é a única diferença entre a fantasia desprovida de conteúdo e a 'verdade' científica. O sistema de conceitos é criação do homem, bem como as regras da sintaxe, que constituem a estrutura dos sistemas conceptuais. Embora esses sistemas sejam logicamente arbitrários na sua totalidade, são restritos pelo objetivo de permitir a mais completa e correta coordenação(intuitiva) com a totalidade das experiência sensoriais; em segundo lugar, objetivam a maior escassez possível dos seus elementos logicamente independentes(conceitos básicos e axiomas), isto é, seus conceitos definidos e proposiçōes não-derivadas[postuladas]."

Albert Einstein

(1879-1955) 
DEDICATÓRICA

A meus pais,

A meus filhos,

Dedico. 


\section{AGRADECIMENTOS}

À Universidade Federal de Alagoas e à Universidade de São Paulo, pelas oportunidades;

À Usina Caeté S/A, Direção, Gerência, Técnicos nos vários níveis, auxiliares de campo e outros, pelo inestimável empenho e presteza nos serviços a nós e a esta pesquisa;

À Usina Coruripe Açúcar e Álcool S/A, Direção, Gerência, Técnicos nos vários níveis, auxiliares de campo e outros, pelos inestimáveis serviços prestados nos primórdios experimentais;

À Estação Experimental Agrícola do Município de Piracicaba-SP, Direção e técnicos, pelo empenho e compromisso demonstrados em nossos contatos para viabilização deste experimento;

Às Unidades Produtoras de Cana, Açúcar e, ou, Álcool do Estado de São Paulo, Região de Piracicaba, por nos ter ouvido;

Ao Núcleo de Absorção e Transferência de Tecnologia(NATT), especialmente aos Engenheiros Luiz Ximenes e Celso Silva Caldas pelas oportunidades de discussão e realização das análises dos líquidos;

Ao Centro de Ciências Agrárias da Universidade Federal de São Carlos, pela elevada contribuição no que se refere ao acervo bibliotecário e ao desprendimento de suas bibliotecárias;

Às bibliotecas e bibliotecárias da Escola Superior de Agricultura "Luiz de Queiroz", Escola de Engenharia de São Carlos, Universidade Federal Rural de Pernambuco, Universidade Estadual de Campinas e Universidade Federal de Alagoas; 
A todos que fazem $\circ$ Departamento de Engenharia Rural da Escola Superior de Agricultura "Luiz de Queiroz", pelas valiosas orientações e serviços prestados;

Ao nosso orientador, Prof. Dr. Antônio Fernando Lordelo Olitta, pela discreta orientação;

À Profa. Sônia Maria de Steffano Piedade, pela disposição e paciência nas nossas discussões sobre o planejamento estatístico e pela presteza na realização das análises estatísticas;

Enfim, a todos aqueles, não citados aqui, porém não menos importantes e não menos considerados, os quais prestaram importantes e significativos serviços na realização deste trabalho. 
DEDICATÓRIA.

AGRADECIMENTOS .

SUMÁRIO.

LISTA DE SÍMBOLOS, TERMOS E CONCEITOS.

vii

LISTA DE FIGURAS.

LISTA DE QUADROS E, OU, TABEIAS.

$x i$

RESUMO.

xiii

SUMMARY.

$x v i$

1. INTRODUÇÃO.

2. REVISÃO BIBLIOGRÁFICA.

2.1. Vinhaça in natura.

2.1.1. Caracterização geral. (Origem, denominação, proporção, composição, tipos e poder poluente) .

2.1.2. Destinação.

2.1.3. Efeitos sobre o solo.

2.2. Infiltração da água em canais de terra.

2.3. Análise crítica.

3. MATERIAIS E MÉTODOS.

3.1. Teorização.

3.1.1. "Teoria".

3.1.2. Condições limites.

3.1.3. Hipóteses e variáveis.

3.2. Planejamento da pesquisa e do experimento.

3.3.1. Localização do experimento.

3.3.2. Solo.

3.3.3. Líquidos.

3.3.4. Trecho de canal.

3.3.5. Acessórios e equipamentos. 
3.4. Método científico. 26

3.5. Técnicas. 26

3.5.1. Processo de amostragem do solo. 26

3.5.2. Preparação e análise das amostras de solo. (Determinações de graus de umidade, massa específica, porosidades e condutividade hidráulica do solo saturado) . 27

3.5.3. Processo de amostragem dos líquidos. 28

3.5.4. Infiltração e taxas de infiltração. 29

3.5.5. Perdas por infiltração. 32

3.5.6. "Lay-out" do experimento. 33

3.5.7. Planejamento estatístico-experimental. 33

3.6. Testes de hipóteses. 35

4. RESULTADOS E DISCUSSÃO. 36

4.1. Líquidos. 37

4.1.1. Características da vinhaça in natura. 37

4.1.2. Características da água comum. 38

4.2. Solo. 40

4.2.1. Graus de umidade atual. 41

4.2.2. Massa específica. 42

4.2.3. Porosidades. (Macro, micro e total). 42

4.2.4. Condutividade hidráulica do solo saturado. 46

4.3. Análises estatísticas. 48

4.3. Infiltração e taxa de infiltração. 49

4.4. Perdas por infiltração. 52

5. CONCLUSÃO.

REFERENNCIAS BIBLIOGRÁEICAS.

APÊNDICES. 62

01- Resultados das análises da água comum e da vinhaça in natura. 63

02- Caracterização geral do solo da área do experimento. 67

03- Trecho de canal concluído. 69

04- Infiltrômetros. $\quad 70$

05- Controladores de nível do líquido no Sub-TCC. 71 
06- Medidores da lâmina de líquido no Sub-TCC. 72

07- Comportas utilizadas para manter o líquido no sub-TCC. 73

08- Massa específcia do solo(Dados originais de campo). 74

09- Valores de porosidades (응). 80

10- Condutividade hidráulica do solo saturado(Dados originais de carmo). 19

11- Resultados das análises estatísticas. 94

12- Infiltração e taxas de infiltração(Dados originais de campo) .

13- Perdas por infiltração(Dados originais de campo). 


\section{LISTA DE SÍMBOLOS, TERMOS E CONCEITOS}

UPCA

Trecho de canal

B

h

$\alpha$

b

Sub-Trecho de canal

Redução

TORI

I

IAC

$\mathrm{VI}$
Unidade Produtora de Cana, Açúcar e, ou Álcool. (TC); Pequena extensão, igual a $3 \mathrm{~m}$, de canal, com seção análoga à contida na figura 1, forma trapezoidal, adotado como o engenho, mais próximo possível da realidade, que condicionou a infiltração dos líquidos;

Base maior do trapézio representativo da seção molhada do TC;

Altura da lâmina de líquido no canal. Assumida, teoricamente, igual a 500 rm. Considerada uma média de 490rm, a qual foi utilizada nos cálculos necessários;

Ângulo de inclinação do talude do canal;

Base menor do trapézio representativo da seção molhada do TC;

(Sub-TCC). Uma das terças partes de um TC; adveem daí os Sub-TC's de canal central(SubTCC) e laterais (Sub-TCL's);

O processo de infiltração em que o líquido vinhaça in natura ou água comum -, atua como redutor de infiltração; a vinhaça in natura é redutor por hipótese e a água comum por comprovação;

Redutor de infiltração

o líquido que promove a redução da infiltração, evidentemente, nas condições desta pesquisa; na condição de redutor de infiltração, o líquido permance no TC durante 2 horas;

Terpo de oportunidade para a redução da infiltração; igual a 2 horas; Infiltração "instantânea"; Infiltração acumulada; Taxa(ou velocidade) de infiltração 
viii

PI

PACI

Infiltrante

TOI

$\rho_{\text {salo }}$
$M$
$m$
$P$
$u$
b.p.s.

$\mathbf{R}_{0}$

Redutor por corlprovação

Redutor por hipótese

Controladores de nível

Registradores de PI

M Conj Na Saturação

M Conj a $50 \mathrm{mca}$

M Conj Seco

Tara

$\mathrm{V}$

1

$\mu_{H_{2} O}\left(15^{\circ} \mathrm{C}\right)$

$\mu_{\mathrm{H}_{2} \mathrm{O}}\left(10^{\circ} \mathrm{C}\right)$

A
Perda "instantânea" por infiltração;

Perda acumulada por infiltração;

- líquido que, ao promover e condicionar 0 processo de infiltração, possibilita as medidas de I e de PI; na condição de infiltrante, o líquido permanece no TC durante 6 horas;

Termo de oportunidade para a infiltração; igual a 6 horas;

Massa específica do solo $\left(\mathrm{g} / \mathrm{cm}^{3}\right)$;

Macroporosidade ( $\left.\frac{0}{0}\right)$;

Microporosidade (o) ;

Porosidade total $\left(\frac{\circ}{\partial}\right)$;

Grau de umidade do solo(b.p.s.);

Base peso seco;

Condutividade hidráulica do solo saturado $(\mathrm{mm} / \mathrm{min})$;

Água comum; líquido que, já, comprovadamente, redutor de infiltração;

Vinhaça in natura; líquido tido, nesta pesquisa, como possível redutor de infiltração;

Dispositivo que controla o nível do líquido no Sub-TCC; (Apêndice 5);

Dispositivo que indica a perda por infiltração no Sub-TCC; (Apêndice 6);

Massa do conjunto na saturação $(\mathrm{g})$;

Massa do conjunto à tensão de 50mca;

Massa do conjunto seco em estufa $\left(105-110^{\circ} \mathrm{C}\right)(\mathrm{g})$;

Massa seca do cilindrotpanotelástico(g);

Volume coletado na proveta, $\mathrm{ml}$;

Comprimento da coluna de solo(cm);

Viscosidade dinâmica da água a $15^{\circ} \mathrm{C}$ (poise);

Viscosidade dinâmica da água a $10^{\circ} \mathrm{C}$ (poise);

Área da seção transversal da amostra de solo $\left(\mathrm{cm}^{2}\right)$; 


\begin{tabular}{|c|c|}
\hline $\mathrm{T}$ & Tempo de fluxo, min; \\
\hline $\mathrm{H}$ & Altura da lâmina de água sobre a amostra, cm; \\
\hline Reposição & $\begin{array}{l}\text { Leitura de complementação do nível do líquido } \\
\text { na caixa-infiltrômetro; }\end{array}$ \\
\hline Leitura anterior & $\begin{array}{l}\text { Leitura inicial, feita na escala da caixa- } \\
\text { infiltrômetro, correspondente ao início de cada } \\
\text { processo de infiltração momentânea; }\end{array}$ \\
\hline Leitura posterior & $\begin{array}{l}\text { Leitura final, feita na escala da caixa- } \\
\text { infiltrômetro, correspondente ao fim de cada } \\
\text { processo de infiltração momentânea; }\end{array}$ \\
\hline ASLC & $\begin{array}{l}\text { Área da superfície do líquido na caixa de medida } \\
\text { de I }\left(\mathrm{cm}^{2}\right)\end{array}$ \\
\hline AOI & Área de oportunidade para a infiltração $\left(\mathrm{cm}^{2}\right)$; \\
\hline$\Delta H_{A S E L}$ & $\begin{array}{l}\text { Altura de líquido medida na caixa de medida de } \\
\text { I(cm); }\end{array}$ \\
\hline$\Delta H_{0 O I}$ & Altura de líquido depletada no Sub-TCC $(\mathrm{cm})$; \\
\hline $\mathrm{n}$ & $\begin{array}{l}\text { Lado do trapézio da seção transversal de fluxo, } \\
\text { cuja altura corresponde a } 0,480 \mathrm{~m} ; 1\end{array}$ \\
\hline $\mathrm{N}$ & $\begin{array}{l}\text { Lado do trapézio da seção transversa de fluxo, } \\
\text { cuja altura corresponde a } 0,500 \mathrm{~m} ;\end{array}$ \\
\hline A & $\begin{array}{l}\text { Área do trapézio da seção transversal de fluxo, } \\
\text { corresponde a } n=0,500 \mathrm{~m} ;\end{array}$ \\
\hline a & $\begin{array}{l}\text { Área do trapézio da seção transversal de fluxo, } \\
\text { correspondente a } n=0,480 \mathrm{~m} \text {. }\end{array}$ \\
\hline $\mathrm{W}$ & Largura média da seção transversal de fluxo(m); \\
\hline$d_{0}$ & Nível do líquido no Sub-TCC, em $t=0,(m)$; \\
\hline$d_{1}$ & Nível do líquido no Sub-TCC, em $t-t_{i},(m)$ \\
\hline L & $\begin{array}{l}\text { Largura do Sub-TCC para efeito de cálculo de I, } \\
\text { VI e PI; L=1m; }\end{array}$ \\
\hline PM & $\begin{array}{l}\text { Perímetro molhado médio do Sub-TCC de medida de } \\
\text { I e PI (m). }\end{array}$ \\
\hline
\end{tabular}




\section{LISTA DE EIGURAS}

Figura

Página

1 Condições básicas de fluxo a partir de una seção de canal, encrustado em meio poroso, sem revestimento. Principais atributos da seção transversal do $\mathrm{TC}(\mathrm{h}=$ $\left.0,490 \mathrm{~m} ; \mathrm{b0}, 490 \mathrm{~m} ; \alpha=52^{\circ} ; B=1,27 \mathrm{~m}\right)$.

Detalhe do TC e Sub-TC's, com seus principais elementos característicos.

4 Seção transversal do TC, com seus elementos característicos principais.

5 Corte transversal da caixa-infiltrômetro, com alguns elementos característicos.

6 Elementos geométricos da figura correspondente à essura de líquido infiltrado no Sub-TCC.

7 Estrutura do experimento no campo.

Apêndices:

3 Eoto do trecho de canal concluído.

5 Foto de um dos dois controladores de nível. Foto de um dois dois registradores da lâmina de líquido no Sub-TCC. 


\section{LISTA DE QUADROS E TABELAS}

Quadro/

Página

Tabela

1
Composição química dos diferentes tipos de vinhaça, segundo vários autores(Glória \& Orlando Eilho, 1984a). Perdas de água por infiltração em canais não revestidos, para vários locais e situações (Kraatz, 1977) .

Composição granulométrica e classificação textural, por horizontes, do solo da área do experimento.

Esquerna da análise de variância.

Valores médios dos principais constituintes e parâmetros da vinhaça in natura utilizada no experimento.

Valores médios dos constituintes e parâmetros da água comum utilizada no experimento. Valores médios do grau de umidade, por bloco experimental.

Valores médios da massa específica do solo, bps, por tratamento, em função da posição e do momento da amostragem.

Valores médios da macroporosidade, microporosidade e porosidade total, em função de tratamentos, posição e momento da amostragem.

Valores médios da condutividade hidráulica do solo saturado, em função de tratamentos, posição e momento da amostragem.

Resumo dos resultados do teste $F$, média geral e coeficiente de variação, em função das variáveis analisadas. 
$x i i$

Valores médios de TACI, Iac e VI por tratamento

e por repetição, a partir dos valores terminais. 


\title{
VINHAÇA COMO POSSÍVEL REDUTOR DA IN- FILTRAÇÃO EM CANAIS DE TERRA
}

\author{
AUTOR : Prof., Ms., Carlos Brancildes Monte Calheiros \\ ORIENTADOR : Prof., Dr., Antônio Fernando Lordelo Olitta
}

\section{RESUMO}

A perda de líquido por infltração nos canais em terra nos projetos de aplicação de efluentes líquidos da agroindústria sucroalcooleira, se constitui num dos grandes fatores de elevação dos custos de operação desses projetos. Esta pesquisa visa comprovar que a vinhaça in natura é um redutor de infiltração de líquidos nesses canais.

Para tanto, fez-se uma adaptação da metodologia atribuída a Kraatz(1977) para medida da infiltração e da perda por infiltração em canais sem revestimento, utilizando-se, comparativamente, a vinhaça in natura e a água comum. Foram estabelecidas as seguintes hipóteses: (1) "ao longo do tempo de oportunidade para a redução e, ou, para a infiltração, ocorre um preenchimento dos poros do solo com materiais minerais e orgânicos, constituintes inerentes dos líquidos; (2) em função dessa obstrução dos poros do solo, ocorre um aumento de sua massa específica, redução de sua macroporosidade, aumento da microporosidade e da porosidade total e redução da condutividade hidráulica; (3) há redução da taxa de infiltração e das perdas por infiltração ao longo do tempo e (4) a vinhaça in natura se constitui num redutor da infiltração de líquidos em canais de terra.

O experimento foi delineado em blocos completos ao acaso, com sete tratamentos e cinco repetições, para analisar os dados de massa específi 
ca, de porosidades e condutividade hidráulica do solo saturado. Esses dados foram analisados e interpretados com base nas técnicas da estatísti ca clássica - análise de variância e teste de comparação de médias. Os dados de infiltração, taxa de infiltração e perdas por infiltração foram submetidos a uma análise de simples confronto de valores médios obtidos, sem utilização das técnicas da estatística clássica.

As controvérsias entre os dados não nos possibilitou conclusões definitivas acerca dos efeitos da vinhaça sobre a massa específica do solo, as porosidades e a condutividade hidráulica na saturação, não corroborando, portanto, a hipótese 2. As taxas de infiltração sofreram reduções variando de 21 a 30 vezes às obitdas com a água comum. As perdas por infiltração foram reduzidas de 7 a 17 vezes. A vinhaça in natura, então, é redutor de infiltração em canais de terra, verificando-se, assim, as hipóteses 1,3 e 4 . 


\section{VINASSE AS POSSIBLE REDUCTER OF THE INFILTRATION IN UNLINED CANALS}

AUTHOR : Prof., Ms., Carlos Brancildes Monte Calheiros

ADVISER: Prof., Dr., Antônio Eernando Lordelo Olitta

\section{SUMMARY}

The infiltration loss in the unlined canals, in the application liquids effluents projects of sugarcane industry, is elevation factor of the operation cost this projects. This research objective verify if the in nature vinasse is reducter of the infiltration of liquids in this canals.

The other than, adapted the ponding method(Kraatz, 1977), for measuring the infiltration and infiltration loss, using, comparatively, the in nature vinasse and ordinary water. The hypothesys of works were: (1) "along of the time of oportunity for reduction and, or, for infiltration, ocurr filling of porous space of soil with minerals and organics materials, inerent constituents of liquids; (2) "on account of this obstruction of the pores of soil, ocurr increase of especyfic gravity, reduction of macroporosity, increase of microporosity and reduction of the full porosity and of the hidraulic condutivity"; (3) "where reduction of infiltration rate and the infiltration losses along of the time" and (4) "the in nature vinasse is in the reducter of the infiltration of liquids in unlined canals".

The experiment was designed in complete blocks randomized, with seven tretments and five replications, for analisys of the specific gravity of soil, porosites and hidraulic condutivity. These datas were analised and interpretads using the technics of classical statistic - 
variance analisys and avarage tests. The datas of the infiltration, infiltration rates and infiltration losses, were subjected to analyse of simple confrontation in the average values obtained, without utilization of the technics of classical statistic.

On account of the differences in the datas, no came possible to conclude definitively as regards the effects of the in nature vinasse about the specific gravity of soil, porosities and hidraulic condutivity in saturaction. The hypothesis 2, therefore, no came corroborated. The infiltration rate reducting of the 21 at 31 times, relatively on the obtined for ordinary water. The infiltration loss reducting of the 7 at 17 times. The in nature vinasse, thus, is reducter of infiltration in inlined canals, it was founding the hypothesis 1,3 and 4. 


\section{INTRODUÇÃO.}

A vinhaça é considerada como o principal resíduo da destilação do álcool (Orlando Filho et al., 1983; Glória \& Orlando Filho, 1984a).

Em virtude de seu enorme volume, efluente das destilarias de álcool, - qual se encontra em torno de 10 a 16 litros por litro de álcool (Almeida, 1952; Valsechi, 1955; Rodella \& Ferrari, 1977; Lima, 1978; Bieske, 1979; Camhi, 1979; Fontes, 1980; Vasconcelos, 1983; Germek \& Feigl, 1987; Ferreira \& Monteiro, 1987; além de outros), e de seu elevado índice BOD ("biochimical oxygen dernand") (Almeida, 1952 e 1955; Tibau, 1973), seu poder poluente tornou-se assustador e intolerável.

Técnicos e pesquisadores passaram, então, a buscar uma solução adequada para a destinação deste resíduo, ocorrendo, em vista disto, um grande volume de publicações científicas abordando este assunto, em seus vários aspectos - agrícola, industrial, econômico, ambiental.

Atualmente há várias formas de destinação da vinhaça; umas de descarte, outras de utilização. A utilização pode ser subdividida em agrícola e industrial.

$\mathrm{Na}$ utilização agrícola, destaca-se a aplicação da vinhaça ao solo como fertilizante e como redutor da deficiência hídrica dos cultivos de cana-de-açúcar. Dentre as técnicas mais difundidas nesta aplicação, sobressai-se a irrigação através do sistema "montagem direta". As características e componentes básicos deste sistema encontram-se muito bern descritos em Leme et al. (1979).

Neste sistema, é difícil definir qual componente é mais importante. Porém, en todas as fases do projeto, a rede de canais em terra deve merecer maior consideração, tanto do ponto de vista técnico quanto econômico. Isto se deve a dois motivos principais: (1) ao elevado custo unitário de 
abertura dos canais e (2) à enorme extensão da rede, em virtude do cultivo da cana-de-açúcar, necessariamente, ocupar áreas superextensas. Ambos fatores convergem no sentido de elevar o custo total de implantação desse sistema.

Todo o volume de líquido aspergido, além daquele inevitavelmente perdido por infiltração e evaporação, é conduzido por essa rede de canais. Se torna evidente, então, o enorme volume de líquido dispendido, principalmente por infiltração, durante a condução, nestes sistemas, encarecendo ainda mais o custo total de operação do projeto. Há necessidade, portanto, de desenvolver-se pesquisas e tecnologias para redução dessas perdas.

Em função disso, este trabalho tem os seguintes objetivos:

1) Quantificar as perdas por infiltração nos canais com e sem a utilização da vinhaça in natura;

2) Estabelecer comparações entre a vinhaça in natura e a água comum, tanto em relação ao processo de infiltração quanto em relação às perdas por infiltração;

3) Verificar se, realmente, a vinhaça reduz as perdas, tanto em água quanto da própria vinhaça, por infiltração em canais de condução desses líquidos para fins de irrigação.

Verificando-se que a vinhaça in natura, realmente, reduz a infiltração da água em canais de terra e que se consiga transfomar este resultado de pesquisa numa tecnologia viável, os benefícios disto serão enormes. Inicialmente, está-se descobrindo mais uma utilidade agrícola deste resíduo, com desdobramentos técnicos e, ou, econômicos dos mais significativos; posteriomente, os seguintes benefícios deverão ser computados aos resultados desta pesquisa:

1) mais uma destinação racional agrícola, das mais viáveis, para a vinhaça, contribuindo ainda mais para a redução dos custos de geração deste resíduo;

2) redução, de importância bastante significativa, das perdas por infiltração em canais de condução de líquido nos projetos de fertirrigação com vinhaça, água de lavagem de cana e, ou, água comum;

3) aumento da eficiência de condução dos líquidos nos projetos, reduzindo a quantidade necessária para fertirrigar uma determinada área; 
4) possibilidade de comercialização deste residuo(vinhaça in natura), aumentando os Iucros, com outros empresários que necessitern da mesma tecnologia;

5) diminuição do tempo de funcionamento da estação de bombeamento na fonte de suprimento de líquidos, reduzindo o custo com energia elétrica;

6) incorporação de novas áreas fertirrigáveis, aumentando a produção.

7) contribuição, bastante significativa, para redução do potencial de poluição ambiental por este resíduo.

Os resultados pretendidos, portanto, potencialmente, são bastante importantes em termos de aplicabilidade, podendo se constituirem em grande contribuição social. 


\section{REVISÃO BIBLIOGRÁEICA.}

\subsection{VINHAÇA IN NATURA.}

2.1.1. Caracterização geral (Origem, denominação, proporção, composição, tipo e poder poluente).

O cultivo da cana-de-açúcar, a partir da colonização do território brasileiro, difundiu-se por várias regiões, destacando-se a Região Sudeste - Estados de São Paulo e Paraná - e a Região Nordeste - Estados de Sergipe, Alagoas e Permambuco, principalmente. Evidentemente, em virtude dessa diversidade de ambientes, tanto os agroecossistemas quanto os costumes das populações desses Estados, determinaram as técnicas de cultivo de cana e, com isto, as características de seus produtos e subprodutos.

O álcool, assim como o açúcar, são produtos da industrialização da cana; a vinhaça e outros resíduos, são subprodutos da destilação do álcool (Camhi, 1979). A partir de cada tonelada de cana esmagada (Álcool, 1977), ocorre a geração de:

1. 1066 litros de vinhaça,

2. 82 litros de álcool e

3. 90 quilos de açúcar.

A vinhaça recebe várias denominações, - "dunder", "stillage", "spent mash", "waste product" - variando de um país para outro(Bieske, 1797; Usher \& Willington, 1979). No Brasil recebe outros nomes, variando de Região para Região, tais como vinhoto, "tiborna", "restilo", "garapão", "caxixi", "cachaça", "calda"(Ranzani, 1955/56; Filgueiras, 1955; Pontes, 1959; Rezende, 1979; Fontes, 1980; Ferreira \& Monteiro, 1987). Neste país os nomes mais difundidos são vinhaça e vinhoto. 
Com o avanço, no aspecto geral, da agroindústria da cana-de-açúcar no país, principalmente após o Proálcool, a vinhaça tornou-se o efluente de maior importânica nas destilarias de álcool(Orlando Filho et al, 1983; Glória \& Orlando Filho, 1984b), em virtude, inicialmente, de seu elevado volume produzido ( Fontes, 1980). Para cada litro de álcool, é gerado 10 a 16 litros de vinhaça (Almeida, 1952; Valsechi, 1955; Rodella \& Ferrari, 1977; Lima, 1978; Bieske, 1979; Camhi, 1979; Fontes, 1980; Germek \& Feigl, 1987; Ferreira \& Monteiro, 1987, além de outros). Vasconcelos(1983), considerou um número médio de 13 litros de vinhaça para cada litro de álcool destilado.

As "matérias-primas" para a fabricação do álcool são o caldo direto, ou mosto de caldo, o mosto misto e o mosto de melaço (Almeida, 1952; Rodella \& Ferrari, 1977; Bolsanello \& Vieira, 1980; Medeiros, 1981). Os tipos de vinhaça recebem os nomes dessas "matérias-primas", quais sejam:

1) vinhaça de "caldo direto", ou de "mosto" de caldo,

2) vinhaça de "mosto" misto e

3) vinhaça de "mosto" de melaço.

De acordo com Almeida(1952), a composição de cada um destes tipos de vinhaça é bastante variável, em função de fatores tais como:

1) natureza e composição da "matéria-prima",

2) natureza e composição do "mosto",

3) natureza e composição do "vinho" e

4) tipo de aparelho destilatório e condução da operação de destilação.

A composição da vinhaça encontra-se exaustivamente determinada, para quase todas as regiões do Brasil, por vários autores: Almeida(1952 e 1962); Glória et al.(1973); Bittencourt et al. (1978); Rodella \& Parazzi(1980); Bolsanello \& Vieira(1980); Medeiros(1981); Vasconcelos(1983). Glória \& Orlando Filho(1984c) compilaram dados de composição química dos três tipos de vinhaça, a partir de pesquisas feitas por vários autores (Quadros 1).

A vinhaça de "mosto" de caldo, menos concentrada, é originada da fermentação alcoólica de "caldo direto", normalmente em destilarias autô 
QUADRO 1 - Composição química dos diferentes tipos de vinhaça, segundo vários autores (Glória \& Orlando Eilho, 1984a).

\begin{tabular}{|c|c|c|c|c|c|c|}
\hline \multirow[t]{2}{*}{ Constituintes } & \multicolumn{5}{|c|}{ Autores } & \multirow[t]{2}{*}{ Média } \\
\hline & A & B & $\mathrm{C}$ & D & $E$ & \\
\hline & \multicolumn{6}{|c|}{ Vinhaça de mosto de melaço } \\
\hline $\mathrm{N} *$ & 1,18 & 0,57 & 0,79 & 0,60 & 0,70 & 0,77 \\
\hline $\mathrm{P}_{2} \mathrm{O}_{5}$ * & 0,15 & 0,10 & 0,14 & 0,22 & 0,34 & 0,19 \\
\hline $\mathrm{K}_{2} \mathrm{O}$ * & 7,87 & 3,95 & 5,50 & 5,08 & 7,59 & 6,00 \\
\hline $\mathrm{CaO}$ * & 3,64 & 1,85 & 2,25 & 2,10 & 2,41 & 2,45 \\
\hline MgO * & 0,98 & 0,98 & 1,02 & 0,84 & 1,40 & 1,04 \\
\hline $\mathrm{SO}_{4}$ * & 6,40 & & & & 1,05 & 3,73 \\
\hline Mat. Orgân. * & 63,64 & 37,30 & 56,90 & 47,40 & 54,68 & 52,04 \\
\hline $\mathrm{Fe} \star \star$ & & & 120 & 52 & 67 & 80 \\
\hline $\mathrm{Cu} \star \star$ & & & 9 & 3 & 3 & 5 \\
\hline $\operatorname{Zn} \star \star$ & & & 3 & 4 & 3 & 3 \\
\hline $\operatorname{Mn} \star \star$ & & & 11 & 7 & 6 & 8 \\
\hline $\mathrm{pH}$ & 4,90 & 4,20 & 4,20 & 4,20 & 4,40 & 4,40 \\
\hline & \multicolumn{6}{|c|}{ Vinhaça de mosto misto } \\
\hline$N \star$ & 0,70 & 0,48 & 0,43 & 0,33 & 0,36 & 0,46 \\
\hline $\mathrm{P}_{2} \mathrm{O}_{5}$ * & 0,11 & 0,09 & 0,14 & 0,24 & 0,61 & 0,24 \\
\hline $\mathrm{K}_{2} \mathrm{O}$ * & 4,59 & 3,34 & 2,61 & 2,18 & 2,59 & 3,06 \\
\hline $\mathrm{CaO}$ * & 1,72 & 1,33 & 1,46 & 0,84 & 0,57 & 1,18 \\
\hline $\mathrm{MgO}$ * & 0,66 & 0,58 & 0,52 & 0,33 & 0,54 & 0,53 \\
\hline $\mathrm{SO}_{4}$ * & 3,74 & & & & 1,60 & 2,67 \\
\hline Mat. Orgân. * & 38,30 & 28,97 & 45,10 & 19,10 & 31,67 & 32,63 \\
\hline $\mathrm{Fe} \star \star$ & & & 130 & 57 & 47 & 78 \\
\hline $\mathrm{Cu} \star \star$ & & & 57 & 4 & 2 & 21 \\
\hline $\operatorname{Zn} \star \star$ & & & 50 & 4 & 3 & 19 \\
\hline $\operatorname{Mn} \star \star$ & & & 5 & 6 & 6 & 6 \\
\hline $\mathrm{pH}$ & 4,6 & 4,4 & 3,8 & 3,6 & 4,1 & 4,1 \\
\hline
\end{tabular}


Continuação do Quadro 1...

\begin{tabular}{|c|c|c|c|c|c|c|}
\hline \multirow[t]{2}{*}{ Constituintes } & \multicolumn{5}{|c|}{ Autores } & \multirow[t]{2}{*}{ Média } \\
\hline & A & B & C & D & $E$ & \\
\hline & \multicolumn{6}{|c|}{ Vinhaça de mosto de caldo } \\
\hline $\mathrm{N} \star$ & 0,28 & 0,28 & 0,35 & 0,25 & 0,26 & 0,28 \\
\hline $\mathrm{P}_{2} \mathrm{O}_{5}$ * & 0,13 & 0,09 & 0,11 & 0,18 & 0,49 & 0,20 \\
\hline $\mathrm{K}_{2} \mathrm{O}$ * & 1,23 & 1,29 & 1,15 & 1,94 & 1,72 & 1,47 \\
\hline $\mathrm{CaO}$ * & 0,69 & 0,13 & 0,76 & 0,56 & 0,17 & 0,46 \\
\hline $\mathrm{MgO}$ * & 0,21 & 0,21 & 0,30 & 0,33 & 0,41 & 0,29 \\
\hline $\mathrm{SO}_{4} \star$ & 0,61 & & & & 2,03 & 1,32 \\
\hline Mat. Orgân. * & 19,65 & 22,31 & 34,70 & 15,30 & 25,24 & 23,24 \\
\hline $\mathrm{Fe} \star \star$ & & & 110 & 45 & 51 & 69 \\
\hline $\mathrm{Cu} \star \star$ & & & 18 & 1 & 1 & 7 \\
\hline $\mathrm{Zn} \star \star$ & & & 2 & 3 & 2 & 2 \\
\hline $\operatorname{Min} \star \star \star$ & & & 10 & 5 & 6 & 7 \\
\hline $\mathrm{pH}$ & 4,3 & 3,7 & 3,6 & 3,5 & 3,6 & 3,7 \\
\hline
\end{tabular}

$\star \mathrm{kg} / \mathrm{m}^{3}$;

$\star \star \mathrm{ppm}$.

A: Glória et al. (1972, 1973);

B: Rodella et al. (1980);

C: Bolsanello \& Vieira(1980);

D: Medeiros (1981);

E: Vasconcelos \& Oliveira(1981).

nomas; a de "mosto" de "melaço", mais concentrada, é produzida, comumente, em destilarias anexas, a partir de "mosto" preparado com "melaço", subproduto da produção de açúcar; a de "mosto" misto, de concentração intermediária, é oriunda do "mosto" preparado com "caldo direto" e "melaço", taruém comum em destilarias anexas.

Um dos comportamentos mais significativos da vinhaça reside no seu poder poluente, elevado (Tibau, 1973; Almeida, 1955; Camhi, 1979; Glória \& Orlando Filho, 1979 e muitos outros). Possui, em média, um indice BOD 
("Biochemical Oxygen Demand") de 12 a $20 \mathrm{mil}$ ppm; a água comum, classe 2, deve conter até $5 \mathrm{mg} / \mathrm{I}$ de oxigênio dissolvido (Benette \& Bidone, 1993).

Enfim, a vinhaça é um efluente líquido, subproduto da destilação do álcool, de cor pardo clara, assim que sai da destilação, tornando-se pardo escura à medida que oxida-se em contato com a atmosfera (Rezende, 1979). Possui alta heterogeneidade (Vasconcelos, 1983).

Tendo em vista as características e comportamentos da vinhaça aqui apresentados, depreende-se que, quando em interação com o sistema solo, também de elevada complexidade, deve ocorrer várias alterações no comportamento do conjunto, modificando, certamente, seu potencial agrícola. Isto, evidentemente, deve determinar significativas modificações no processo de infiltração de líquido no solo, com efeitos sobre a taxa e perda por infiltração.

\subsubsection{Destinação.}

O fim que se dá à vinhaça, após esta efluir da destilação, pode ser enquadrado em duas grandes áreas de atividades dentro de uma Unidade Produtora de Cana, Açúcar e, ou, Álcool (UPCA): (1) a área agrícola e (2) a área industrial. Importa aqui a área agrícola. Nesta há diferentes alternativas de uso e utilização, como define Orlando Filho et al. (1983).

Dentre estas alternativas, encontra-se a utilização da técnica de irrigação por aspersão. Filgueiras(1955), cita que esta técnica já era adotada em destilarias de álcool na França, obtendo-se êxito na destinação de resíduos dessa agroindústria. Ratificando tal êxito, Rennie(1972) afirma que somente quando a irrigação por aspersão for impraticável, deve-se recorrer a meios biológicos de descarte.

No Brasil, já no início da década passada (Vasconcelos, 1983), essa técnica era tida como a mais racional e promissora. Leme et al. (1979) introduziu o sistema de irrigação por aspersão "montagem direta", em sua versão original, na região canavieira do Estado de São Paulo. Estes autores abordaram as características gerais do sistema, aspectos de manejo e aspectos econômicos, através de testes realizados em várias UPCA's deste Estado. Ao longo do tempo, este sistema foi recebendo algumas modificações 
- na realidade, avanços tecnológicos - tanto em relação à engenharia do sistema como um todo, quanto ao manejo e utilização dos resíduos, do solo e da cultura da cana. Atualmente existe, como versão avançada, o sistema "montagem direta extendido", com substanciais diferenças em relação ao original. A utilização racional deste sistema é assegurada hoje por resultados de pesquisas como os obtidos por Matioli(1989), no qual verifica-se que o sistema "montagem direta extendido", combinado ou não com outro sistema de aplicação de resíduos das $\mathrm{UPCA}^{\prime} \mathrm{s}$, é a opção mais viável. Leme (1988), após testes nas UPCA's, conseguiu uma redução de 22,908 no consumo de óleo diesel pelo equipamento.

\subsubsection{Efeitos sobre o solo.}

A preocupação com os efeitos da vinhaça sobre o solo data das primeiras décadas deste século, como constatado em Ross \& Froberville(1928). Segue-se, além de outros, os trabalhos de Almeida et al. (1950), Almeida(1952), Ranzani(1955/56) e Valsechi(1955), os quais são considerados pioneiros no Brasil.

Certamente, a incorporação de vinhaça in natura ao solo, causa, neste, modificações em suas propriedades físicas, químicas e microbiológicas. Nesta pesquisa serão abordadas apenas algumas propriedades físicas e físico-hídricas de interesse.

No estudo desses efeitos, como alertado por Glória \& Orlando Filho(1984), irmorta discernir sobre alguns aspectos fundamentais, tais como:

1) condições ambientais da pesquisa; se em ambiente controlado - laboratório, casa de vegetação, estufa, etc. - ou não-controlado,

2) doses de vinhaça,

3) tipos de vinhaça,

4) tipos de solo, e

5) sistemas de aplicação.

Estes aspectos e suas variações determinam uma grande diversidade de resultados de pesquisa, limitando bastante a aplicabilidade destes. Em virtude disto, segundo estes autores, os resultados até agora obtidos 
acerca dos efeitos da vinhaça in natura sobre as propriedades físicas dos solos, constituem-se, apenas, em cogitações de ordem teórica, não tendo, efetivamente, comprovação nas condições da cultura.

Buscando uma solução para a destinação dos efluentes líquidos de destilarias de álcool em Natal, África do Sul, Ross \& Froberville(1928) afirmaram que qualquer tendência para a formação de "poças" (locais alagados), deve ser imediatamente combatida, do contrário, os poros do solo serão obstruídos, a percolação será sustada e os resultados serão danosos. Indícios deste mesmo fenômeno, foram registrados por Almeida et al.(1950). Estes pesquisadores, experimentando os efeitos da vinhaça in natura e vinhaça neutralizada com leite de cal, nas doses de 50, 100, 250, 500 e $1000 \mathrm{~m}^{3} / \mathrm{ha}$, sobre amostras de solo arenoso, verificaram que a penetração da vinhaça foi muito lenta em ambos os tratamentos. As últimas doses - cremos que significam as maiores doses -, necessitaram de 35 dias para incorporação total. Além desses resultados, os autores verificaram que $\circ$ poder de embebição das amostras aumentou progressivamente com a dosagem de vinhaça e que, ao contrário do que se pensava, este resíduo melhora as propriedades físicas do solo.

Ranzani(1956), trabalhando sob as mesmas condições de Almeida et al.(1950), verificaram que o volume total de poros aumentou $178 \mathrm{com}$ a dose de $1000 \mathrm{~m}^{3} /$ ha de vinhaça. Este autor reconhece, entretanto, que desconhece-se a natureza dos poros do solo, e isto limita a aplicabilidade dos resultados. Por suposição, o autor atribuiu o aumento observado na porosidade total, ao incremento em macroporos; isto, por consequência, reduziu os movimentos capilares. Esta hipótese foi reforçada pela maior facilidade com que a água foi perdida contra a ação centrífuga de 1000 gravidades. Outra verificação importante foi a de que a permeabilidade das amostras de solo pouco se alterou, em função das doses de vinhaça.

Os efeitos da vinhaça sobre algumas propriedades físicas do solo grau de floculação das partículas, retenção de água, porosidade e condutividade hidráulica -, também foram estudados por Rezende (1979). Este autor realizou experimento em campo, num solo de textura franco argilo arenosa, utilizando dois períodos de "incubação" - 60 e 120 dias - e doses de vinhaça de $0,60,120,180,240,300,360$ e $420 \mathrm{~m}^{3} /$ ha. O autor admitiu que o 
estado de floculação das partículas do solo não se modificou com as doses de vinhaça, durante os 120 dias de "incubação".

Para julgar a influência da vinhaça sobre a retenção da água pelo solo, o autor partiu dos seguintes pressupostos:

1. "qualquer alteração na geometria de poros do solo, em decorrência da aplicação da vinhaça, resulta do seu efeito sobre a granulação".

2. "as doses crescentes de matéria orgânica adicionadas ao solo, deveriam contribuir para aumentar sua superfície específica e, tambén, sua capacidade adsortiva".

Durante os 120 dias de "incubação", nenhuma das doses de vinhaça foi suficiente para alterar, significativamente, a geometria dos poros do solo, nem, tampouco, a sua superfície específica; por isto, não contribuíram para modificar a capacidade de retenção de água.

Na avaliação da influência da concentração de vinhaça sobre a porosidade do solo, o autor considerou a seguinte hipótese:

1. "durante o período de "incubação", pré-estabelecido, as possíveis interações entre as partículas minerais do solo com a matéria orgânica e íons do resíduo, contribuem para modificar a distribuição do tamanho de poros da camada arada".

O autor chegou à conclusão de que, num período de 120 dias, nenhuma das doses de vinhaça contribuiu para qualquer modificação significativa nas densidades aparente e real do solo e nas porosidades(total, macro e micro) .

Os efeitos sobre a condutividade hidráulica foram avaliados considerando-se a hipótese de que:

1. "qualquer efeito significativo da vinhaça na granulação do solo, contribuiria para mudanças na sua condutividade hidráulica".

Os dados obtidos não permitiram esboçar uma conclusão acerca dos efeitos da vinhaça sobre este atributo do solo, necessitando de novos estudos.

De acordo com Ribeiro et al.(1983), normalmente se aceita, embora com base em reduzido número de dados experimentais, que a vinhaça tenha efeito dispersante sobre a argila do solo, o que pode resultar na compactação deste. Na busca de respostas para tal afirmativa, esses autores 
avaliaram o efeito de amostras de argila de latossolos, em condições de laboratório. Em comparação com a água, as vinhaças atuaram como floculantes, nos solos de textura mais argilosa, e como dispersante nos solos de textura mais arenosa. Os resultados sugerem que o efeito da vinhaça na dispersão ou floculação da argila de amostras de solo, segue, em linhas gerais, os modelos clássicos, dependendo da concentração e do balanço de cátions nas vizinhanças, além da natureza da fração argila. Ribeiro \& Sengik(1983), nas mesmas condições experimentais, concluíram que tanto no LV quanto no IE, as menores doses promoveram floculação da argila, ao passo que as maiores provocaram dispersão; no LE, porém, estes efeitos foram menos evidentes.

\subsection{INEILTRAÇÃO DA ÁGUA EM CANAIS DE TERRA.}

Nesta parte da revisão serão abordados, apenas, alguns aspectos relacionados com os fatores que influem sobre o processo de infiltração, com os métodos de medida de I e com a magnitude das perdas por infiltração em canais de terra.

De acordo com os estudos de Lauritzen \& Terrel(1967), a taxa de infiltração("seepage rates") depende da permeabilidade do solo, da existência ou não de revestimento natural ou artifical, da lâmina de água, de sua velocidade, da profundidade do lençol freático.

Cremos que pode depender, também, de outros fatores que podem ser, por exemplo, (1) os graus de anisotropia e heterogeneidade do solo, (2) seu teor em matéria orgânica, (3) grau de umidade imediatamente antes do início da infiltração, (3) características do líquido e (4) características da superfície infiltrada.

Kraatz (1977) reuniu esses fatores nos seguintes grupos: (1) características do solo e da região por onde passa o canal, (2) magnitude da lâmina de água no canal, perímetro molhado do canal e profundidade do nível freático e (3) quantidade de sedimentos na água, velocidade desta no canal e espaço de tempo em que o canal está em operação.

Este mesmo autor afinna que se torna praticamente impossível separar os efeitos destes fatores, pois eles se encontram estreitamente interrela- 
cionados, agindo simultaneamente no sentido de variar a magnitude da infiltração.

Por esta afirmação, depreende-se a complexidade existente nos estudos de infiltração, mais ainda nas condições de canais em terra. Isto, evidentemente, dificulta as medidas da infiltração de uma forma precisa.

Alguns métodos de medidas, referidos por Lauritzen \& Terrel(1967), são (1) "inflow-outflow", (2) "ponding", (3) medidores de "seepage" (4) elevações do lençol freático, (5) medidas da permeabilidade in loco, (6) testes de permeabilidade em laboratório e (7) velocímetro elétrico.

Na estimativa das perdas por infiltração, os métodos de medida podem ser agrupados da seguinte forma:(1) fómulas enpiricamente desenvolvidas, (2) soluções oriundas de métodos analíticos, (3) soluções derivadas por analogias elétricas.

Dentre os vários métodos existentes, é largamente usado o método do estancamento("ponding method"). Este consiste em medir a taxa de decréscimo do nível da água no trecho de canal de interesse, calculando a taxa de infiltração pela relação entre o produto da área da superfície líquida pelo comprimento do trecho de canal e a área umedecida neste trecho.

Por este método, as observações podem ser feitas de foma precisa, e os resultados fornecem uma boa indicação da perda média de água no trecho de canal considerado, com a ressalva de que a água estática(ausência de fluxo) pode escoar em taxas diferentes em relação à água fluindo.

o quadro a seguir, compilado por Kraatz(1977), contém magnitudes de perdas de água em sistemas de condução não revestidos, para várias localidades.

Tem sido estimado que $1 / 4$ a $1 / 3$ de toda a água derivada para fins de irrigação é perdida na condução(Lauritzen \& Terrel, 1967). O USBR mostrou que, em 46 projetos, as perdas variaram de 3 a $86 \%$. Se assumirmos que 1/4 dos 20.778.842,57m.ha de água derivados por estes projetos são perdidos, isto representará 5.194.710m.ha(US Senate, 1962a, citado por Lauritzen \& Terrel, 1967). Considerando os Estados Unidos da América como um todo, se apenas $1 / 5$ do total de água derivada para fins de irrigação é perdido pelo usuário, a quantidade de infiltração, a partir dos canais, seria de 29,20 
mihões m.ha/ano. Se os futuros usuários podessem reter esta água, eles poderíam irrigar 13,6 milhões de hectares a mais, utilizando 5,31m.ha/ha.

QUADRO 2 - Perdas de água por infiltração em canais não revestidos, para vários locais e situações (Kraatz, 1977).

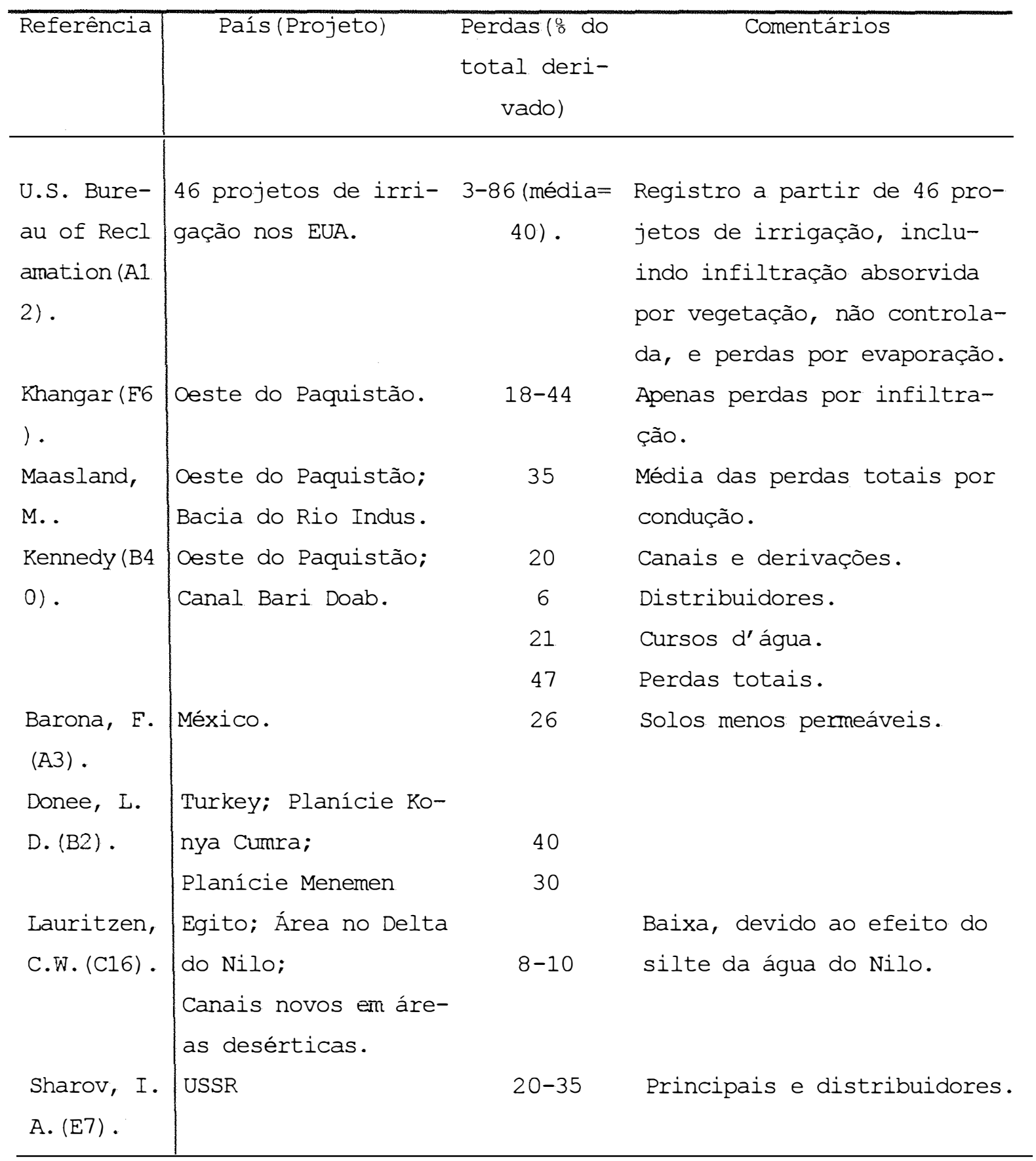




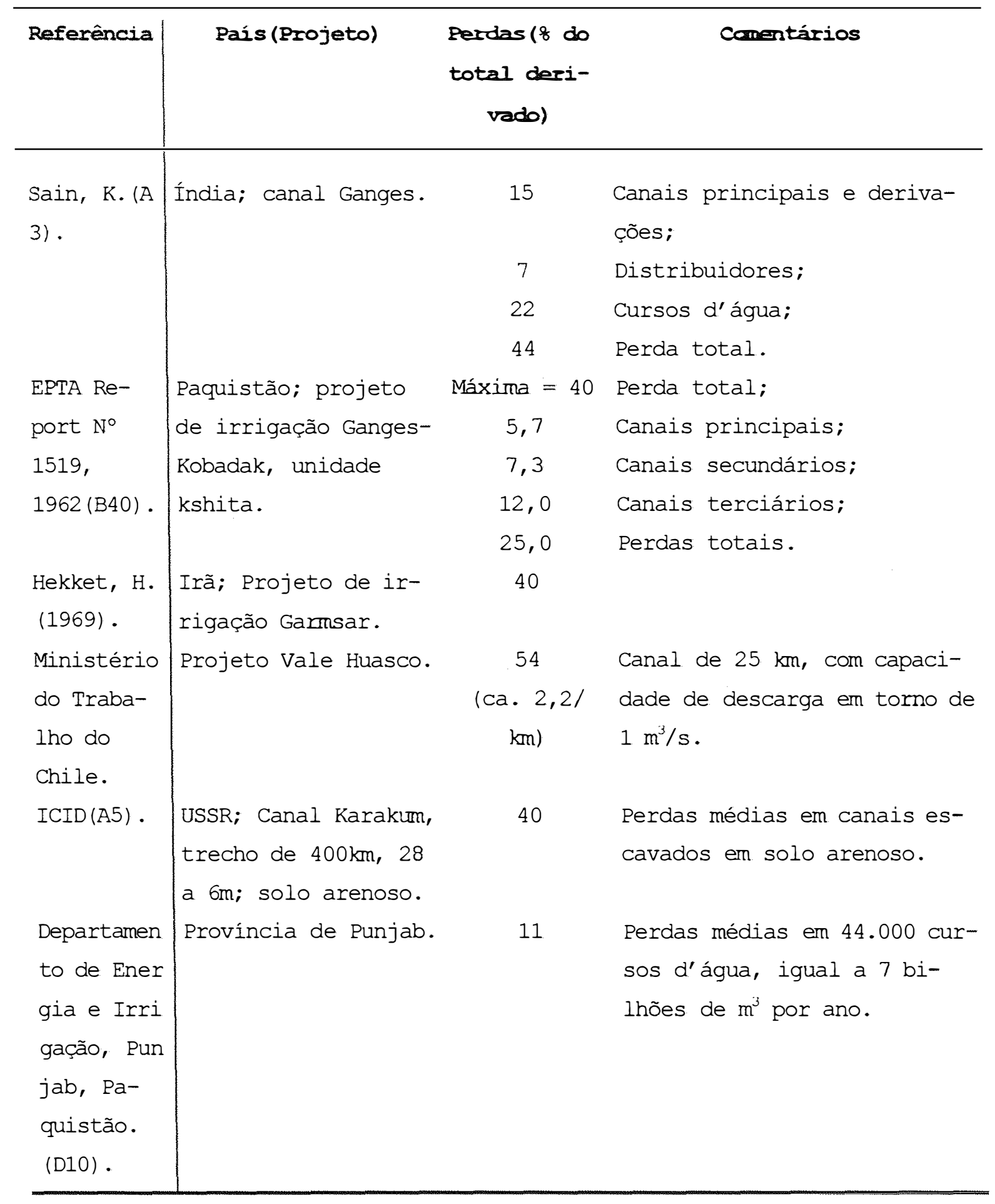

Por afinmação desses mesmos autores, as perdas por evaporação em canais são, comunente, de 1,0 a $1,5 \%$ da água derivada. 


\subsection{ANÁLISE CRÍTICA.}

Primordialmente, houve, de nossa parte, uma preocupação muito grande, talvez até excessiva, em verificar (1) a originalidade e (2) a contribuição social da pesquisa, isto é, a importância e aplicabilidade dos resultados possíveis ao meio produtivo.

Evidentemente, esta análise será feita confrontando-se o "estado da arte", pertinente ao assunto aqui estudado, e o "conjunto científico característico" (problema+hipóteses+variáveis+objetivos+importância/aplicabil idade dos resultados), e está restrita ao conteúdo deste capítulo.

Considerando isto, discernimos, fundamentalmente, quatro fatores de estudo, no arcabouço científico desta pesquisa: (1) a água comum, (2) a vinhaça in natura, (3) a infiltração através do solo, numa condição de canal em terra e, indiretamente, (4) a forma de destinação dos efluentes líquidos das UPCA's.

Dentro do contexto em que se insere esta pesquisa e sob a égide do conteúdo desta revisão bibliográfica, verifica-se uma limitação muito grande na discussão dos resultados pretendidos, isto é, no confronto entre - "conjunto científico característico" e o "estado da arte". O grau de pertinência, principalmente em relação aos dados de I e PI, é insuficiente, ou, mesmo, baixo. Queremos dizer com isto que os contornos e as metodologias nas quais a bibilografia aqui revistas fundamentaram-se, são diferentes daquelas adotadas nesta pesquisa. Cremos que isto se deve ao elevado grau de complexidade que envolve as relações no continuum infiltração(com vinhaça)-solo, além da complexidade intrínseca de cada um destes. 
3. MATERIAIS E MÉTODOS.

3.1. TEORIZAÇÃO.

3.1.1. "Teoria".

Considere-se a situação abaixo, definida por uma seção transversal de canal, de forma trapezoidal - quase sempre a utilizada nos projetos de condução de líquidos para fins de irrigação - e seus elementos característicos principais.

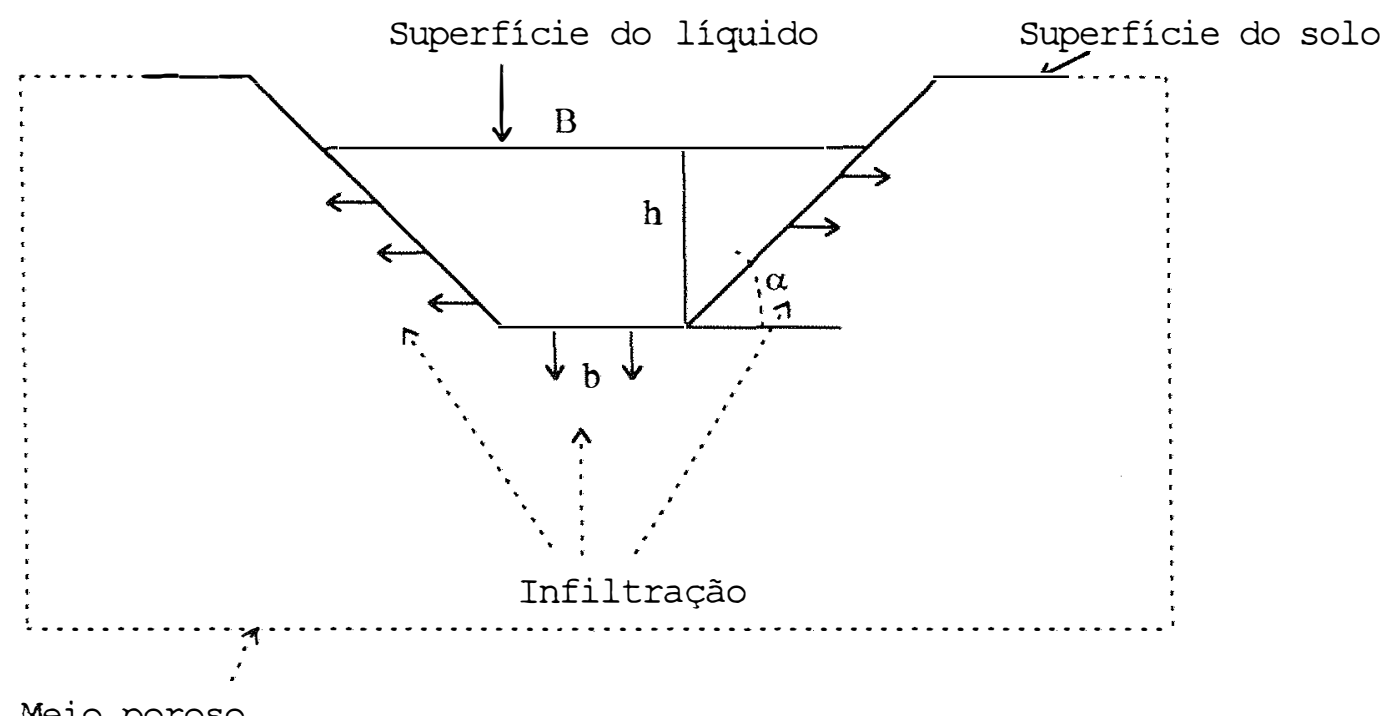

Meio poroso

FIGURA 01 - Condições básicas de fluxo a partir de uma seção de canal, encrustado em meio poroso, sem revestimento. 
O líquido no TC pode ser a vinhaça in natura ou a água comum, dependendo do tratamento considerado; pode, também, permanecer por duas horas ou por seis horas, conforme esteja atuando como redutor ou como infiltrante;

A altura do líquido no $\mathrm{TC}, \mathrm{h}(\mathrm{h}=500 \mathrm{~mm})$, foi assumida teoricamente constante durante todo o tempo de ambos os processos ocorridos: redução e infiltração.

O solo, sendo um meio poroso, possibilita a passagem, por seus poros, de elemento fluido - no caso, um líquido. Tanto a água comum quanto a vinhaça in natura possuem constituintes, minerais e orgânicos, que tanto reagem com a matriz do solo quanto modificam a geometria do espaço poroso.

A quantidade de matéria orgânica, sólidos suspensos e elementos minerais diversos, na vinhaça, é muito grande. Após um certo tempo, $t$, e sob a ação da carga hidráulica, h, o fluxo de líquido da superfície infiltrada do TC para o interior do solo, evidentemente conduzindo todos aqueles materiais minerais e orgânicos, promoveria, progressivamente, a obstrução dos poros do solo, por ações mecânicas de transporte e acumulação. Formar-se-ia, assim, uma camada colmatada - solotelementos infiltrados -, adjacente e ao longo de todo o perímetro do TC, a partir da superfície deste e aprofundando-se no meio poroso. As principais características e propriedades dessa camada colmatada, diferentes, em magnitude, daquelas do meio poroso original, seriam: (1) sua constituição, (2) sua estrutura, (3) maior massa específica, e (4) menor condutividade hidráulica, em solo saturado.

Com a aplicação da vinhaça in natura, certamente, haverá dispersão de argilas, podendo provocar, também, redução do fluxo de líquidos no solo. Este efeito não foi aqui considerado por acreditamos que a acumulação e consequente obstrução dos poros do solo, pelos materiais componentes da vinhaça, contribuir muito mais para o fenômeno de redução do fluxo de líquidos neste meio poroso.

A espessura dessa camada ao longo do perímetro molhado, a quantidade de elementos infiltrados, seu potencial para redução de $\boldsymbol{R}_{0}$, a magnitude desse $\mathbf{R}_{0}$, dependeriam, principalmente, dos seguintes fatores: (1) características do líquido infiltrado, (2) características do solo, (3) magnitude 
de h, (4) tempo de oportunidade para a redução e, ou, para a infiltração e (5) geometria da seção transversal da superfície infiltrante.

Os elementos inerentes a estes fatores interagem, de forma convergente, no sentido de modificar a infiltração,I, a taxa de infiltração,VI e a perda de líquido por infiltração, PI. Nesse caso particular, as modificações em I, VI e PI, seriam determinadas pelas condições limites inerentes ao experimento. Certamente, deve haver algum(ns) fator(es) que não está(ão) sendo controlado(s), dentro desta concepção científica. 0 grau de importância deste(s) último(s), cremos, poderá ser qualificado após a obtenção dos resultados.

\subsubsection{Condições limites.}

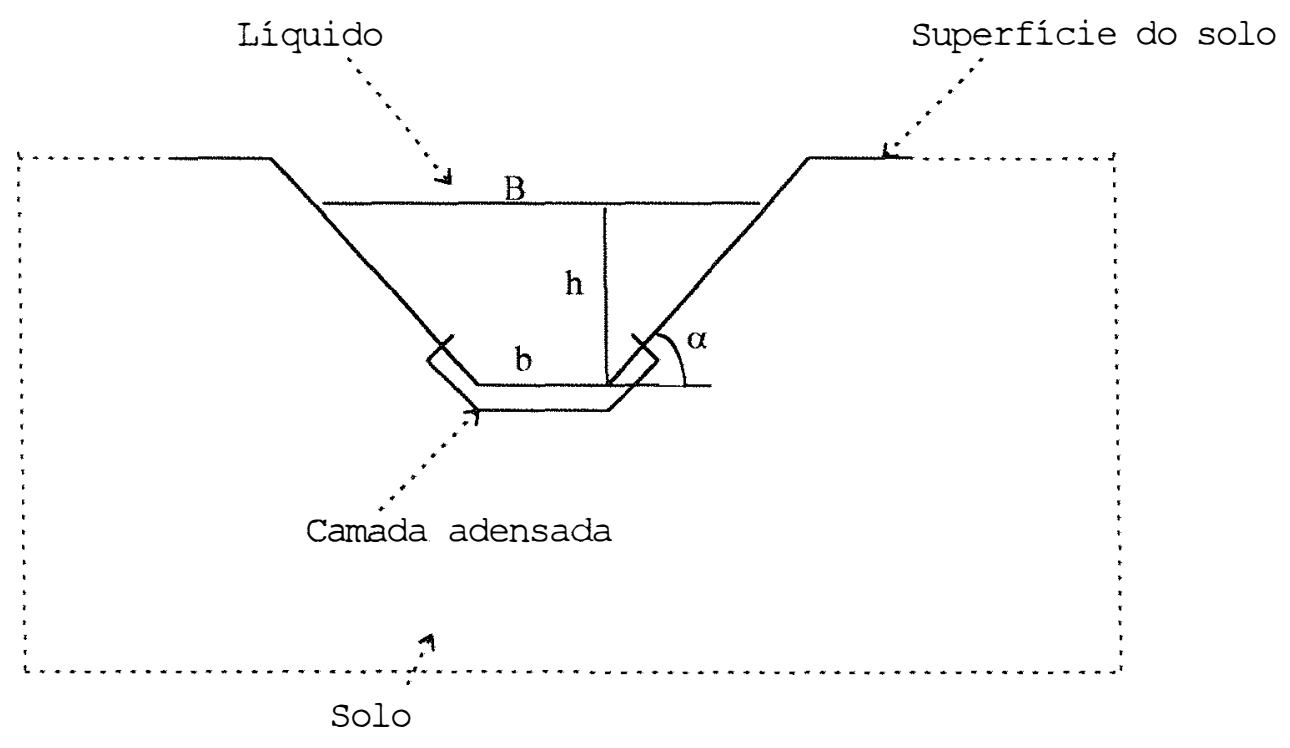

FIGURA 02 - Principais atributos da seção transversal do TC. $(\mathrm{h}=0,490 \mathrm{~m}$; $\left.b=0,490 \mathrm{~m} ; \alpha=52^{\circ} ; B=1,27 \mathrm{~m}\right)$.

As condições limites constituem-se nos contornos da indagação científica que se está pondo à prova com o experimento. É um conjunto de fatores que, direta ou indiretamente, intervem no comportamento dos fenômenos que estão sendo considerados para a obtenção dos dados, os quais 
virão a valorar, qualitativa e, ou, quantitativamente, as variáveis experimentais.

Para esta pesquisa, as condições limites foram as seguintes:

1) A vinhaça in natura, o redutor, por hipótese, de infiltração constitui-se numa mistura complexa de vários elementos minerais e orgânicos, cujas características e, consequentemente, comportamentos, são bastante diferentes daqueles da água comum. Consideramos, para os fins desta pesquisa, como principais características e propriedades da vinhaça, problematizadoras do processo de infiltração, as seguintes: (1) o seu teor em Potássio, (2) o seu teor em matéria orgânica, (3) a sua termperatura, (4) a sua viscosidade dinâmica e (5) seu teor em sólidos suspensos.

2) O grau de sedimentação dos sólidos suspensos na vinhaça é muito alto. A parte mais baixa da superfície infiltrada, o fundo do TC, em pouco termo, deve está coberta com sedimentos;

3) O líquido permaneceu estático - não houve fluxo e a inclinação do fundo era nula - sobre a superfície infiltrada, durante todo o tempo de oportunidade para a redução e, ou, para a infiltração;

4) A forma geométrica da superfície infiltrada foi a de um trapézio isósceles, simulando, evidentemente, a forma da seção de canal mais utilizada nos projetos de condução de efluentes líquidos. Isto estabelece duas sub-superfícies de infiltração, no que respeita à inclinação: (1) duas sub-superfícies inclinadas, definidas pelas paredes do TC e (2) uma horizontal, que se constitui no fundo do TC;

5) Solo anisotrópico; ocorria uma camada sedimentada abrangendo cerca de 1/2 do perímetro molhado do TC, como descrito pela Figura 2, ítem 3.1.2.;

6) Foi mantida uma lâmina média de líquido de $490 \mathrm{~mm}$, sobre o fundo e as paredes do TC, durante todo o tempo de oportunidade para a redução e, ou, para a infiltração;

7. O tempo de oportunidade para a redução foi de duas horas; o de oportunidade para a infiltração, de seis horas.

8) A superfície infiltrada foi submetida ao fluxo imediatamente após preparada, isto é, a infiltração se verificou em trechos de canais (TC's) recém abertos, novos; 
9) O início do processo de redução da infiltração ocorreu, sempre, numa superfície com umidade de 15,52 a 17,74\%(bps); para efeito de medida da infiltração nesta pesquisa, contudo, o início deste processo de infiltração, estava na dependência de, no tratamento de interesse, ter havido, anteriormente, redução ou não.

3.1.3. Hipóteses $(\mathrm{H})$ e variáveis $(\mathrm{V})$.

H1) Ao longo do tempo de oportunidade para a redução e, ou, para a infiltração, ocorre um preenchimento dos poros do solo com materiais minerais e orgânicos, constituintes inerentes dos líquidos;

H2) Em função dessa obstrução dos poros do solo, ocorre um aumento de sua massa específica, redução de sua macroporosidade, aumento da microporosidade e da porosidade total e redução da condutividade hidráulica;

H3) Há redução da taxa de infiltração e das perdas por infiltração ao longo do termo;

H4) A vinhaça in natura se constitui num redutor de infiltração de líquidos em canais de terra.

V1) Porosidades;

V2) Massa específica do solo;

v3) Condutividade hidráulica do solo saturado;

V4) Taxa de infiltração;

V5) Perdas por infiltração.

\subsection{PIANEJAMENTO DA PESQUISA E DO EXPERTMENTO.}

O problema encontra-se inserido nas condições de uma área de cultivo tradicional de cana-de-açúcar, isto é, de uma UPCA, onde está consolidada a técnica de irrigação com sistema "montagem direta", na aplicação de resíduos líquidos que efluem da agroindústria. Este problema, para o qual buscamos resposta, requer o conhecimento de particularidades inerentes (I) à UPCA, (2) à área onde for implantado o experimento, (3) ao solo desta área e (4) aos líquidos utilizados (vinhaça in natura e água comum). Especificamente, é preciso conhecer: 
1) o estágio tecnológico em que se encontra a UPCA, principalmente no que se refere à disposição em fazer pesquisas e, mais ainda, com respeito ao gerenciamento do projeto de aplicação de resíduos;

2) que tipo de estrutura de condução e distribuição dos resíduos é utilizada pela UPCA, como também no transporte e deslocamento de pessoal, material e equipamentos na área do projeto; isto determina, também, a operacionalização das atividades no experimento;

3) que topografia predomina na região; isto é decisivo na seleção da área destinada à implantação do experimento. É indefensável, em termos científicos e de aplicabilidade dos resultados, a instalação deste experimento em área de topografia acidentada;

4) qual o histórico de cultivo da área do experimento; isto importa no fato de que ela não deve ter recebido vinhaça ou outro resíduo estranho, en passado recente;

5) que tipos gerais de solo predominam na região, na UPCA e qual o tipo de solo da área do experimento; isto importa na abrangência dos dados a serem obtidos, inclusive a nível de Estado;

6) que tipos de efluentes líquidos são predominantemente utilizados nas áreas dos projetos, tanto a nível de UPCA quanto de Estado;

7) quantitativamente, quais as características dos elementos da seção, ou das seções, de canal praticadas pela UPCA; qual a profundidade média de escavação dos canais;

Estes elementos, componentes de uma realidade na qual se insere a pesquisa, interagem na fase de planejamento e de alocação de recursos, otimizando a operacionalização do experimento e, em última instância, garantindo a obtenção dos dados pretendidos da forma mais científica e consistente possível.

\subsection{MATERIAIS.}

\subsubsection{Localização do experimento.}

A área experimental está localizada a $9^{\circ} 48^{\prime} \mathrm{LS}, 36^{\circ} 05^{\prime} \mathrm{LO}$ e $40 \mathrm{~m}$, no Estado de Alagoas, Município de São Miguel dos Campos, em terras da Usina Caeté S/A, fazenda São João, lote $\mathrm{n}^{\circ} 4$. A topografia da área é plana a 
levemente ondulada, com 38 de declividade. Outros detalhes encontram-se no apêndice 5 .

\subsubsection{Solo.}

Podzólico Acinzentado Tb distrófico A proeminente textura média (leve)/média; moderadamente a imperfeitametne drenado; uso atual cana-deaçúcar. Através de verificação dos registros históricos de lotes e por informações pessoais dos Engenheiros e Técnicos da UPCA, verificou-se que o lote onde se desenvolveu o experimento não recebeu vinhaça. o quadro 1 contém a composição granulométrica e a classificação textural por horizonte. O Apêndice 2 contém uma caracterização mais detalhada deste solo.

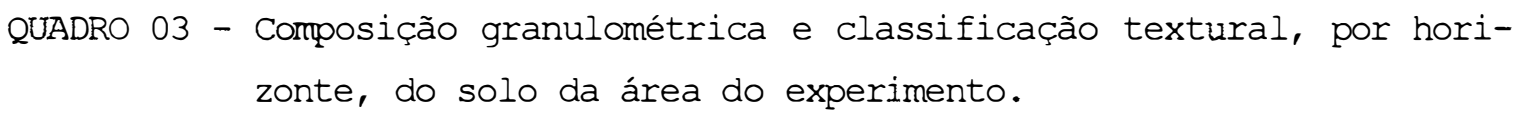
zonte, do solo da área do experimento.

\begin{tabular}{|c|c|c|c|c|c|}
\hline \multirow{3}{*}{$\begin{array}{c}\text { Horizon- } \\
\text { tes }\end{array}$} & \multirow{3}{*}{$\begin{array}{l}\text { Profun- } \\
\text { didade } \\
\text { (cm) }\end{array}$} & \multicolumn{3}{|c|}{ Cormposição granulométrica } & \multirow{3}{*}{$\begin{array}{c}\text { Classificação textu- } \\
\text { ral }\end{array}$} \\
\hline & & Areia & Silte & Argila & \\
\hline & & \multicolumn{3}{|c|}{ 옹 } & \\
\hline Ap & $00-20$ & 73,74 & 6,67 & 19,50 & Franco arenoso \\
\hline A & $20-50$ & 65,09 & 5,73 & 29,18 & Franco argilo arenoso \\
\hline $\mathrm{E}$ & $50-85$ & 57,85 & 9,22 & 32,93 & Eranco argilo arenoso \\
\hline Btxm & $85-195$ & 52,20 & 14,19 & 33,61 & Eranco argilo arenoso \\
\hline
\end{tabular}

\subsubsection{Líquidos.}

Como referido no item 3.1.2., os líquidos utilizados foram a vinhaça in natura e a água comum. Toda a vinhaça in natura usada nos tratamentos experimentais foi de formação instantânea, isto é, recém saída da indústria. A água comum usada adveio parte do açúde da indústria e parte da caixa d’água da garagem do Departamento Agrícola da UPCA. As análises fo- 
ram feitas considerando-se a caracterização química, mineral e orgânica, destes líquidos. Os resultados destas análises encontram-se no Apêndice 1.

\subsubsection{Trecho de canal.}

A figura 3 contém alguns elementos de um TC característico, com alguns detalhes dos corponentes mais importantes.

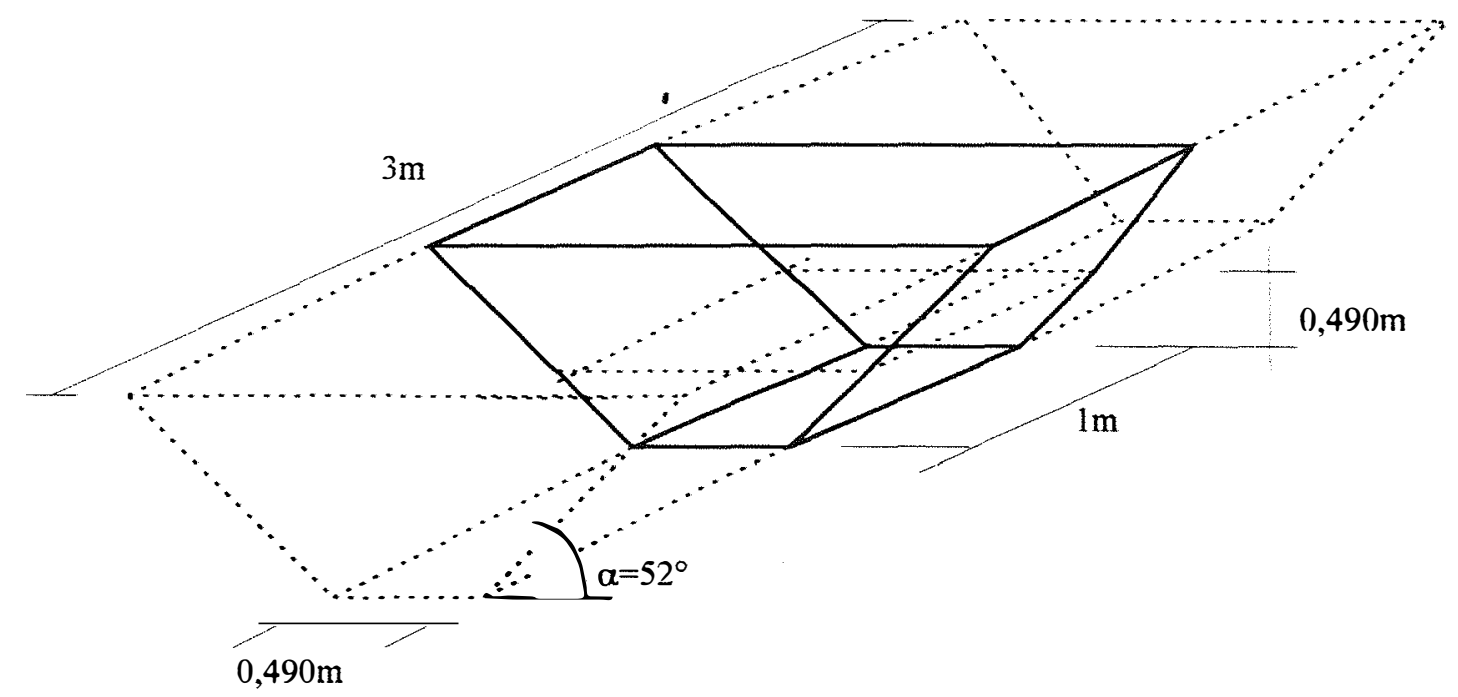

EIGURA 03 - Detalhe do TC e Sub-TC's, com seus principais elementos característicos.

Os TC's foram abertos manualmente, por um grupo de trabalhadores rurais treinados especificamente para este tipo de atividade. Neste experimento foram abertos $35 \mathrm{TC}^{\prime} \mathrm{s}$, os quais se constituíam nas parcelas experimentais. O Apêndice 3, contérn a foto de un TC já concluído.

\subsubsection{Acessórios e equipamentos.}

Para o transporte de água da fonte para a área experimental e, aí estando, para derivação deste líquido para dentro dos TC's, instalando os respectivos tratamentos, foi utilizado um caminhão-tanque, com capacidade 
de 13 mil litros. Posteriormente, em virtude de necessidades da UPCA, este caminhão foi substituído por um tanque, tracionado, com capacidade para sete mil litros. O caminhão-tanque, a partir daí, ficou realizando o abastecimento deste tanque, quando solicitado.

o transporte da vinhaça da fonte para a área experimental e, aí estando, na derivação do líquido para os $\mathrm{TC}^{\prime}$ s, foram feitos utilizando-se outros dois tanques, com capacidades de 2,5 e 4 mil litros, respectivamente, tracionados por trator. Evidentemente, o trator, de média potência, foi outro equipamento imprescindível às atividades no experimento, em virtude da constante necessidade de seus serviços, no deslocamento tanto dos tanques de um TC para outro, instalando os tratamentos, quanto dos infiltrômetros - bastante pesados.

Os infiltrômetros, em número de dois, eram caixas de cimento amianto, com capacidade para 1000 litros, adaptadas para realizar a medida do infiltrado no TC correspondente num determinado tempo. O Apêndice 4, contém uma foto mostrando esses aparelhos.

Outro material imprescindível, embora de simples idealização e confecção, foram as comportas. Em número de quatro eram compostas de chapa e cantoneiras de ferro laminado, na forma trapezoidal, utilizadas para conter o líquido no Sub-TC de interesse (Sub-TCC), dando condições para que se medisse a infiltração de acordo com os objetivos da pesquisa.

Os controladores de nível da lâmina de líquido, também em número de quatro, eram dispositivos de madeira, idealizados e confeccionados de forma a possibilitar a verificação constante da altura da lâmina de líquido no TC, mantendo-a sempre na altura requerida e possibilitando as devidas complementações. Este controle era feito diretamente em uma régua milimétrica, acoplada ao dispositivo de controle. Os Apêndices 5 e 6, contêm fotos mostrando esses materiais.

Vários outros materiais menores, porém de grande importância nas atividades deste experimento, foram: o cronômetro, o termômetro, as ferramentas para escavação dos $\mathrm{TC}^{\prime}$ s, a lona plástica para cobertura dos $\mathrm{TC}^{\prime} \mathrm{s}$ ou dos infiltrômetros, quando necessário, além de outros.

A equipe de trabalho coonstituiu-se de 4 peões, 1 tratorista, 1 motorista, 1 auxiliar de motorista, além do pesquisador. 
3.4. MÉTODO CIENTÍEICO.

Nesta pesquisa buscou-se inferir uma "verdade" geral, expressa nas conclusões, a partir de dados, suficientemente repetidos, constatados, de uma condição particular, específica. Isto, de acordo com Lakatos \& Marconi(1983), Ruiz(1991) e Hühne(1992), caracteriza o método de indução incompleta, ou científica.

De acordo com este sistema de conceitos, os parâmetros de massa específica do solo, porosidades e condutividade hidráulica são tidos como fenômenos particulares, cujos comportamentos induzem a conclusões sobre a infiltração, a taxa de infiltração e sobre as perdas por infiltração, tidos como fenômenos gerais.

\subsection{TÉCNICAS.}

3.5.1. Processo de amostragem do solo.

Com base nos objetivos desta pesquisa, foram feitas amostragens para determinações de grau de umidade do solo(uq), massas específicas ( $\left.\rho_{\text {solo }}\right)$, porosidades (M, m e P), e condutividade hidráulica do solo saturado $\left(\boldsymbol{R}_{0}\right)$.

Para a execução dessas amostragens, foram utilizados os seguintes materiais e equipamentos:

1) conjunto amostrador de Uhland;

2) conjunto amostrador de Kopeck;

3) marretas de madeira;

4) vários acessórios para limpeza;

5) papel alumínio;

6) latas de alumínio;

7) caixas de isopor e gelo;

8) pequenos materiais(foice, enxada, enxadão, facão, pás, lanternas, piquetes, fio de nylon, marretões, etc).

As amostragens para massa específica, porosidade e condutividade hidráulica foram feitas, sempre, antes(Pré-Tratamento) e após(Póstramento) a instalação de cada tratamento, no talude e no fundo dos sub- 
TCL's. Para a determinação dos graus de umidade, as amostragens foram feitas imediatamente antes da implantação do tratamento, na parte mediana de uma das paredes de um dos Sub-TC's, uma para cada tratamento.

As amostras foram, todas, envoltas em papel alumínio, devidamente etiquetadas e colocadas em caixa de isopor com gelo, visando sua preservação e conservação. As amostras para umidade foram mantidas em lugar úmido e fresco, até o momento das análises.

3.5.2. Preparação e análises das amostras de solo.

Referimo-nos aqui às deteminações de graus de umidade, massas específicas, porosidades e condutividades hidráulicas.

Os graus de umidade(u\&), foram obtidos através do método padrão(ABNT, 1969). Foram obtidas médias aritiméticas simples para cada bloco experimental A massa específica do solo( $\left.\rho_{\text {solo }}\right)$, foi obtida utilizandose o método do cilindro central ("core method"), como descrito por Blake \& Hartge(1986). Obteve-se médias aritiméticas simples para cada tratamento, antes e após sua instalação (Apêndice 7). As porosidades, foram determinadas utilizando-se a "mesa de tensão", como descrito por Danielson \& Sutherland(1986) e Oliveira(1988). Foi adotada a tensão de 50mca como a que define a macro e microporosidades, no tipo de solo utilizado(Apêndice 8). A condutividade hidráulica do solo saturado($\left(\boldsymbol{R}_{\mathbf{0}}\right)$, foi obtida utilizando-se um permeâmetro de carga constante, como sugerido por Kraatz (1977) (Apêndice 9) .

Uma mesma amostra foi utilizada para as determinações de porosidade, inicialmente, e de condutividade hidráulica, posteriormente. Ambas as análises foram realizadas no Laboratório de Solos, setor de Hidráulica, Departamento de Engenharia Rural (ESALQ/USP) .

$$
M=\left\{\frac{(M \text { Conj Na Saturaçao-M Conj a 50mca })}{\left[(M \text { Conj Na Saturaçao-M Conj Seco })+\frac{(M \text { Conj Seco }- \text { Tara })}{\rho_{\text {solo }}}\right]}\right\} 100
$$




$$
\begin{gathered}
m=\left\{\frac{(M \operatorname{Conj} \text { a } 50 \mathrm{mca}-M \operatorname{Conj} \text { Seco })}{\left[(M \operatorname{Conj} \text { Na Saturaçao-MConj Seco })+\frac{(M \operatorname{Conj} \text { Seco-Tara })}{\rho_{\text {solo }}}\right]}\right\} 100 \\
P=(M+m) \\
K_{0}=\frac{V L}{A T(H+L)} \frac{\mu_{\mathrm{H}_{2} \mathrm{O}}\left(15^{\circ} \mathrm{C}\right)}{\mu_{\mathrm{H}_{2} \mathrm{O}}\left(10^{\circ} \mathrm{C}\right)}, \mathrm{cm} / \mathrm{mtn} \\
\frac{\mu_{\mathrm{H}_{2} \mathrm{O}}\left(15^{\circ} \mathrm{C}\right)}{\mu_{\mathrm{H}_{2} \mathrm{O}}\left(10^{\circ} \mathrm{C}\right)}=\frac{0,011455 \mathrm{poise}}{0,01309 \mathrm{poise}}=0,875 \\
K_{0}=0,875 \frac{V L}{A T(H+L)}, \mathrm{cm} / \mathrm{min}
\end{gathered}
$$

3.5.3. Processo de amostragem dos líquidos.

Tanto a vinhaça in natura quanto a água comum, foram amostrados e preparados para análises de forma idêntica. Para cada bloco experimental, foram tomadas 3 ou 4 amostras de vinhaça e de água. As amostragens foram feitas no mangote de derivação dos tanques - no caso da vinhaça - e do caminhão-tanque - no caso de água -, de derivação para o TC, no momento de instalação do respectivo tratamento. Elas foram acondicionadas em frascos, hermeticamente fechados, e imediatamente acomodadas em caixas de isopor com gelo.

As amostras individuais coletadas, 10 a 12 para cada líquido, foram misturadas, homogeneizadas e transformadas em uma amostra - amostra composta - para cada líquido. Os resultados das análises encontram-se no Apêndice 6 . Durante todo 0 termo, as amostras foram mantidas em geladeira. As análises dos líquidos foram realizadas pelo laboratório do Núcleo de Absorção e transferência de tecnologia (NATT) .

Apenas para registro, foram tomadas, tambérn, várias medidas de temperatura da vinhaça, em 3 diferentes tempos: (1) Logo quando se estabelecia o tratameto, na metade do tempo de tratamento e (2) no final 
deste. A temperatura média variou de 32 a $45^{\circ} \mathrm{C}$. A água comum manteve-se à temperatura ambiente.

3.5.4. Infiltração e taxas de infltração.

A Infiltração e as taxas de infiltração foram obtidas utilizando-se infiltrômetros, como descrito no ítem 3.3.5. O cálculo de I e de VI foram realizados a partir das fórmulas a seguir.

$$
\begin{aligned}
& I=0,8118(\text { Re posiçao-Leitura Post }), \mathrm{mm} \\
& I=0,8118(\text { Leitura Ant-Leitura Post }), \mathrm{mm} \\
& V I=\frac{I}{T I}, \mathrm{~mm} / \mathrm{min}
\end{aligned}
$$

Estas fórmulas foram obtidas considerando-se as áreas disponíveis para $\circ$ fluxo e as alturas infiltradas correspondentes.

$$
\begin{gathered}
\frac{A S L C}{A O I}=\frac{\Delta H_{A S L C}}{\Delta H_{A O I}} \\
A S L C=\frac{1.342 .768+1.472 .064}{2}=1.407 .416 \mathrm{~mm}^{2}
\end{gathered}
$$

A área de oportunidade para infiltração no Sub-TCC, AOI, figura 4, também é variável, tendo-se que calcular um valor médio aproximado desta.

$$
\begin{aligned}
& n=\frac{480}{\operatorname{sen} 52^{\circ}} ; \\
& \mathrm{n}=609,13 \mathrm{~mm} \\
& \mathrm{~N}=634,51 \mathrm{~mm} \\
& \mathrm{~A}=(2 \mathrm{~N}+490) \mathrm{mm} 1000 \mathrm{~mm} \\
& \mathrm{~A}=1.759 .020 \mathrm{~mm}^{2} \\
& \mathrm{a}=(2 \mathrm{n}+490) \mathrm{mm}^{2} 000 \mathrm{~mm} \\
& \mathrm{a}=1.708 .260 \mathrm{~mm}^{2} \\
& A O I=\frac{a+A}{2} ; \\
& \text { AOI }=1.733 .64 \mathrm{~mm}^{2}
\end{aligned}
$$




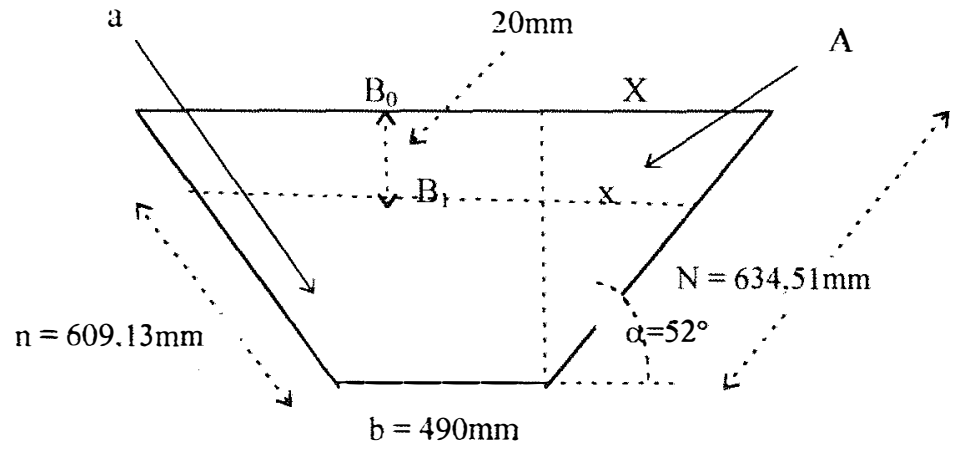

FIGURA 04 - Seção transversal do TC, com os elementos característicos prin cipais.

Verifica-se pela Figura 5 que a área média da caixalou da superfície líquida na caixa) é de, aproximadamente,

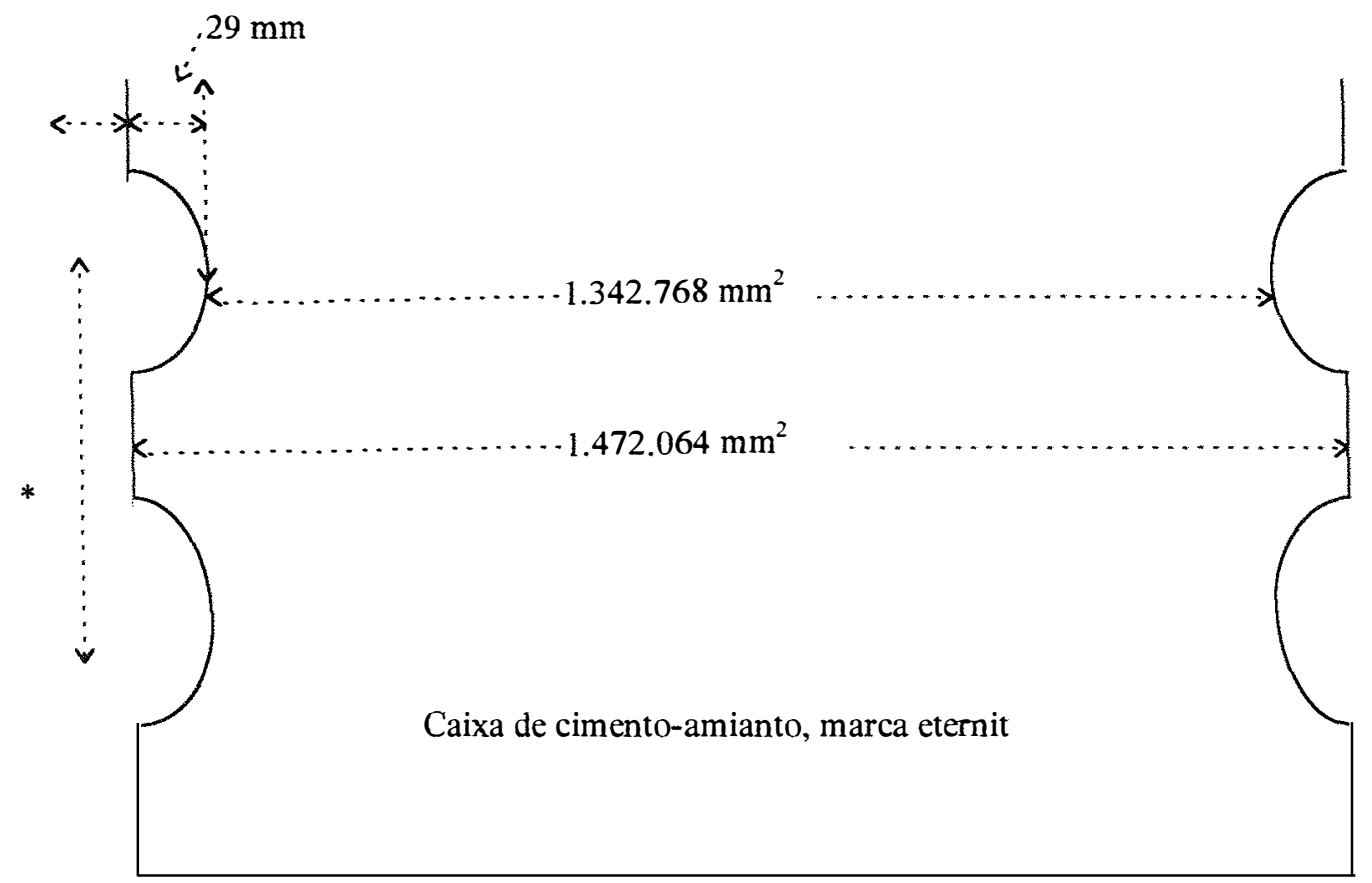

* Faixa onde foram realizadas a quase totalidade das leituras.

FIGURA 05 - Corte transversal da caixa-infiltrômetro, com alguns elementos característicos. 
Da relação matemática entre as áreas e as alturas, pode-se obter:

$$
\begin{aligned}
\Delta H_{A O I} & =\frac{A S L C}{A O I} \Delta H_{A S L C} \\
\Delta H_{A O I} & =\frac{1.407 .416}{1.733 .640} \Delta H_{A S L C} \\
\Delta H_{A O I} & =0,8118 \Delta H_{A S L C}
\end{aligned}
$$

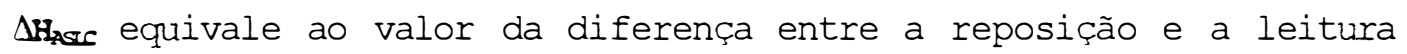
ou entre leituras, do nível da água na caixa-infiltrômetro.

o cálculo das perdas por infiltração, PI, foi feito com base no procedimento atribuído a Kraatz(1977). Este relaciona um volume e uma área de infiltração, como abaixo.

$$
\begin{aligned}
& P I=\frac{\text { Volume }}{\text { Area.Tempo }} \\
& P I=\frac{w\left(d_{0}-d_{1}\right) L}{P M L}
\end{aligned}
$$

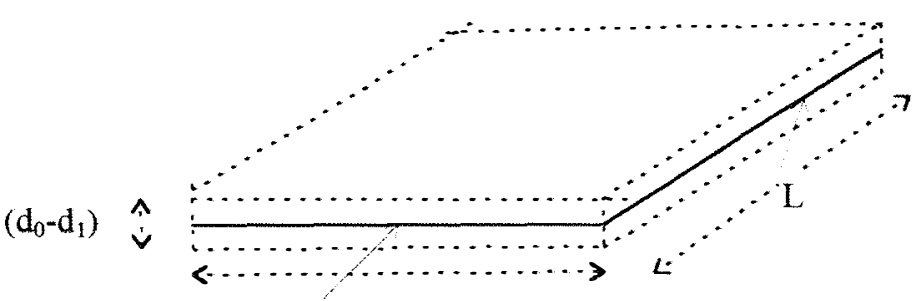

W

FIGURA 06 - Elementos geométricos da figura correspondente à da espessura de líquido infiltrado no sub-TCC.

Considerando-se os elementos geométricos contidos na figura 4, verifica-se as seguintes relações:

$$
\begin{aligned}
& X=\frac{0,500 m}{\tan 52^{\circ}} \\
& x=\frac{0,480 m}{\tan 52^{\circ}}
\end{aligned}
$$




$$
\begin{gathered}
B_{0}=2 X+0,490 m \\
B_{1}=2 x+0,490 m \\
w=\frac{\left(B_{0}+B_{1}\right)}{2} \\
w=1,2556599 m \\
I=1,0 \mathrm{~m} \\
P M=\frac{0,6345+0,6043}{2} 2+0,49=1,7288 m \\
P M L=1,7288 m^{2} \\
P I=\frac{1,2556599}{1,7288}\left(d_{0}-d_{1}\right) \\
P I=0,7263\left(d_{0}-d_{1}\right)
\end{gathered}
$$

Por facilidade de operacionalização das leituras, fez-se o controle do espaço ao invés do de tempo. ou seja, permitiu-se uma depleção máxima do nível do líquido no Sub-TCC, de $20 \mathrm{~mm}$ - até 480 mm -, fazendo-se, neste instante, a complementação e, imediatamente, lendo-se o volume de líquido derivado do infiltrômetro para $\bigcirc$ Sub-TCC. Este volume constituía-se na infiltração naquele espaço/tempo. Este procedimento sucedeu-se até as seis horas, definidas a priori, como o tempo de oportunidade para a infiltração no Sub-TCC, quando encerrava-se o tratamento.

A relação entre a medida de I feita no infiltrômetro - leitura na régua de madeira do nível na mangueira flexível adaptada à caixa de cimento amianto -, e a magnitude de I no sub-TCC, é dada pela expressão a seguir (Apêndice 14):

$$
\Delta H_{A O I}=0,8118 \Delta H_{A S L C}, m m, ~,
$$

na qual, $\Delta \mathbf{H}_{\text {har }}=$ I. Foi calculada também a Velocidade de infiltração, VI, fazendo-se $V I=I / T I$.

\subsubsection{Perdas por infiltração.}

As perdas por infiltração foram determinadas com base no método do estancamento ("ponding method"), conforme descrito por Kraatz(1977). Por este método, as perdas por infiltração, PI, (Apêndice 16), são obtidas pela fórmula: 


$$
P I=\frac{W\left(d_{0}-d_{1}\right) L}{P M L},
$$

onde,

PI = perda por infiltração, em $\mathrm{m}^{3} / \mathrm{m}^{2} / \mathrm{min}$, na distância $\mathrm{L}$;

$\mathrm{W}$ = largura média da superfície da água, no Sub-TCC estancado;

$\mathrm{d}_{2}$ = lâmina de água no início do terpo de medida;

$\mathrm{d}_{\mathrm{i}} \quad=$ lâmina de água no final do termo de medida;

PM = perímetro molhado médio;

$\mathrm{L} \quad=$ comprimento do Sub-TCC.

Neste experimento, O Sub-TCC utilizado teve as dimensões referidas na Figura 3, ítem 3.3.4., e os tempos de oportunidade para a redução e para a infiltração foram de, respectivamente, 2 e 6 horas.

Conforme consta a Figura 3, portanto, a expressão da perda por infiltração assumiu a seguinte expressão:

$$
P I=0,7263\left(d_{0}-d_{1}\right)
$$

3.5.6. "Lay-out" do experimento.

A "parcela experimental" era representada pelo TC, o qual foi subdividido em três Sub-TC's, figura 3(ítem 3.3.4.). O sub-TC central foi destinado às medidas de I, e PI. Os Sub-TC's laterais foram destinados à coleta dos dados referentes às variáveis dependentes e intervenientes. Nestes locais foram realizadas todas as amostragens; um lado antes e outro depois da instalação dos tratamentos. Os detalhes mais importantes da estrutura física do experimento, estão contidos na Figura 4.

3.5.7. Planejamento estatístico-experimental.

o experimento foi executado num delineamento em blocos completos ao acaso, com 7 tratamentos e cinco repetições (Figura 4). En função dos objetivos da pesquisa os tratamentos foram definidos como a seguir: 


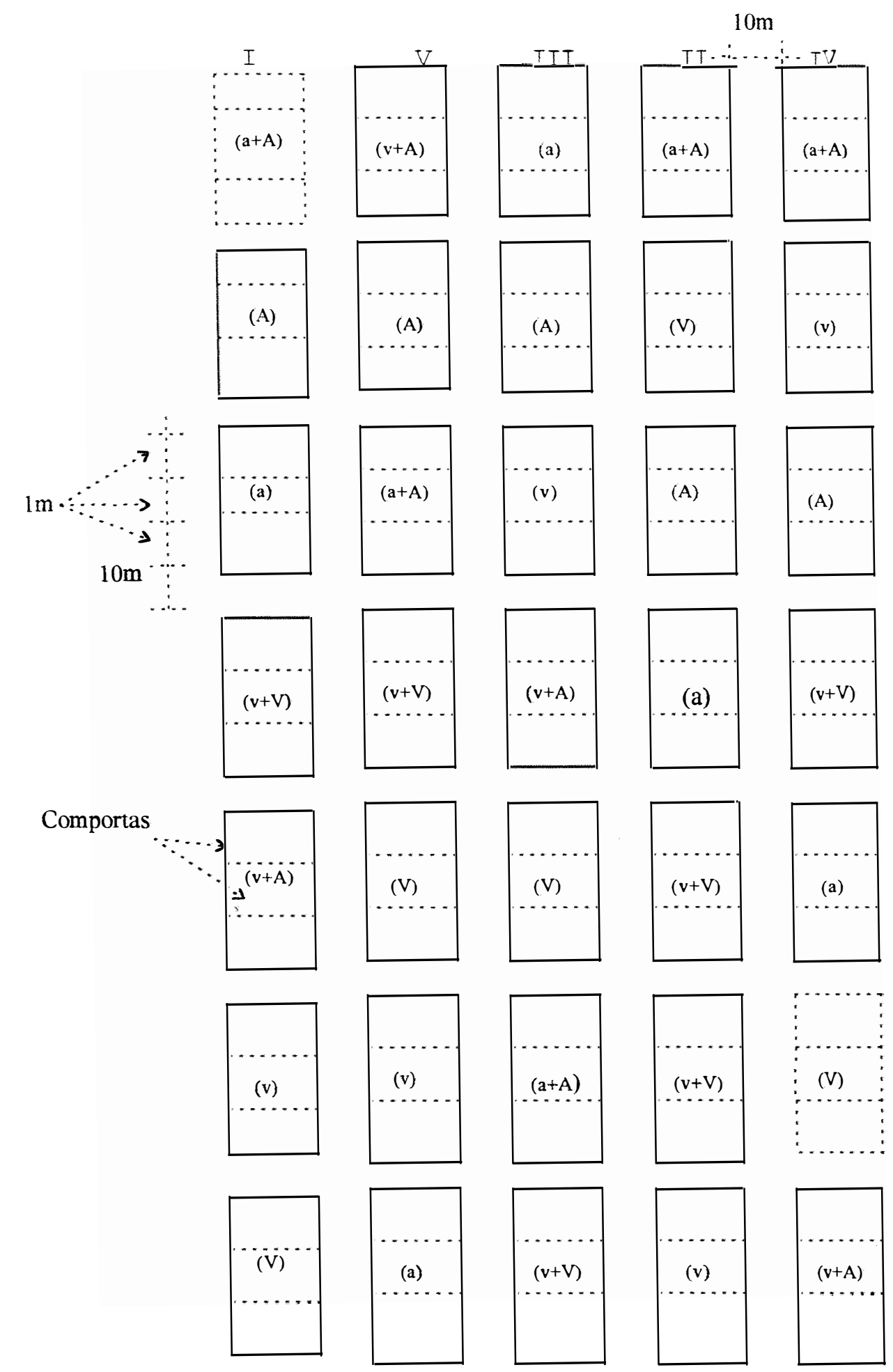

FIGURA 07 - Estrutura do experimento no carmoo. Os retângulos com pe rímetro tracejado correspondem a tratamentos perdidos. 
$(v+\mathbf{A})$ : Vinhaça in natura como redutor, seguida de água comum como infiltrante;

$(v+v)$ : Vinhaça in natura como redutor, seguida de vinhaça in natura como infiltrante;

(v) : Vinhaça in natura como redutor;

(A) : Água comum como infiltrante;

(v) : Vinhaça in natura como infiltrante;

$(\mathbf{a}+\mathbf{A})$ : Água comum como redutor, seguida de água comum como infiltrante;

(a) : Água comum como redutor.

As análises estatísticas, propriamente, foram (1) a análise de variância e teste $\mathrm{E}$, (2) o teste $t$ de comparação entre médias e (3) a análise exploratória dos dados, fazendo-se o confronto entre os valores médios obtidos para cada tratamento, em função dos momentos e das posições de amostragem.

QUADRO 04 - Esquema da análise de variância.

\begin{tabular}{c|c}
\hline Causa de variação & Graus de liberdade \\
\hline Blocos & 4 \\
Tratamentos (T) & 6 \\
Resíduo & $(24)$ \\
\hline Total & 34 \\
\hline
\end{tabular}

\subsection{TESTES DE HIPÓTESES.}

1) Determinações de massa específica do solo, porosidades(macro, micro e total) e condutividade hidráulica do solo saturado, antes e após o estabelecimento de cada tratamento, no talude e no fundo dos $\mathrm{TC}^{\prime} \mathrm{s}$, para testar as hipóteses 1, 2 e 3;

2) Determinações das taxas e perdas de líquido por infiltração, em todos os tratamentos, nas condições com e sem redutor de infiltração, para testar as hipóteses 4 e 5. 


\section{RESULTADOS E DISCUSSÃO.}

A depender da variável considerada, duas a quatro parcelas experimentais foram perdidas, em diferentes tratamentos e repetições. Isto, entretanto, não prejudicou a consistência das análises, pois, o número de repetições continuou suficiente para que os dados apresentassem, pelo menos, uma tendência clara acerca do comportamento dos fenômenos envolvidos. Os respectivos Quadros e Apêndices podem confirmar esta afirmação.

Embora tenhamos tentado, não conseguimos medir a evaporação durante a tomada de dados de infiltração. Cremos, entretanto, que isto não afetou, de forma significativa, as magnitudes de I e PI, pois (1) a área evaporativa era pequena, (2) o termpo de exposição foi curto, (3) trabalhamos, quase sermpre, fora dos horários de maior demanda evaporativa, (4) a vinhaça, caracteristicamente, apresenta elevada tensão superficial e (5) na prática, as irrigações/fertirrigações são intermitentes, minimizando a influência da perda por evaporação, relativamente àquela por infiltração. Saliente-se que estes fatores interferem sobre a magnitude da evaporação de forma cumulativamente, minimizando o efeito desta sobre as magnitudes de $I$ e PI.

Durante todo o período de coleta de dados em campo - janeiro a fevereiro de 1996 - choveu apenas uma única vez e, mesmo assim, em quantidade insignificante, relativamente aos efeitos possíveis sobre as variáveis envolvidas na pesquisa.

Exceto para a variável $\rho_{\text {solor }}$ as análises, interpretações e conclusões foram restritas à posição fundo do TC. Os efeitos sobre o talude não foram quantificados, em virtude de não dispormos de material em quantidade suficiente. 
4.1. LíquIDOS (Apêndice 1).

Hipótese envolvida:

H1 - "Ao longo do tempo de oportunidade para a redução e, ou, para a infiltração, ocorre um preenchimento dos poros do solo com materiais minerais e orgânicos, constituintes inerentes daqueles líquidos".

4.1.1. Características da vinhaça(Apêndice 1).

QUADRO 05 - Valores médios dos principais constituintes e parâmetros da vinhaça in natura utilizada no experimento.

\begin{tabular}{l|c}
\hline Constituintes e parâmetros & Valor médio \\
\hline $\mathrm{pH}$ & 5,33 \\
$\mathrm{~N}^{\star}$ & 0,655 \\
$\mathrm{P}_{2} \mathrm{O}_{5}^{\star}$ & 0,446 \\
$\mathrm{~K}_{2} \mathrm{O}^{\star}$ & 4,950 \\
$\mathrm{C}$ Org.* & 61,00 \\
Matéria orgânica total* & 105,16 \\
CaO* & 2,13 \\
MgO* & 0,87 \\
Residuo sedimentável* & 0,00 \\
Sólidos totais* & 17,50 \\
\hline
\end{tabular}

$\star \mathrm{Kg} / \mathrm{m}^{3}$.

Considerando-se os objetivos desta pesquisa, destacam-se dentre os constituintes e parâmetros da vinhaça, os teores em matéria orgânica e sólidos totais. Estes constituintes importam por se considerar a possibilidade de obstrução mecânica ao fluxo no interior do solo, isto é, redução da área disponível ao fluxo, através da ocupação de parte do espaço poroso. 
Há que se cogitar também do possível efeito dispersante da vinhaça sobre a argila do solo, como discutido por Ribeiro et al.(1983) e Ribeiro e Sengik(1983), podendo causar compactação. Os primeiros salientam, entretanto, que esta afinmação é baseada em reduzido número de dados experimentais. Considerando o aspecto de pertinência, alertamos para a possiblidade desses resultados terem sido oriundos de amostras indefonmadas, extraídas de horizontes superficiais - da camada arável, portanto de experimentos em laboratório e, assim, não ser possível uma comparação com os resultados desta pesquisa.

Ao se considerar o possivel efeito dispersante da vinhaça sobre a argila do solo, e, sabendo-se que tal efeito traduz-se naquele adicional ao causado pela água, ou seja, efeito este causado exclusivamente pelos componenentes característicos da vinhaça, adquirem importância outros componentes característicos da vinhaça, principalmente o potássio. Como já explicado na teoria(ítem 3.1.), esta questão foge aos objetivos desta pesquisa.

4.1.2. Características da água comum (Apêndice 1).

A importância dos resultados das análises da água comum utilizada no experimento, com base nos objetivos desta pesquisa, restringe-se apenas a verificar(comprovar) a existência ou não de um ou mais constituinte em excesso, ou seja, que viesse tornar a água anomal para as atividades em irrigação e drenagem. Caso isto acontecesse, a possbilidade de modificar, tendenciosamente, o comportamento de alguma(s), ou todas, as variáveis experimentais de interesse, seria grande.

Analizando-se o Quadro 5, verifica-se que os valores dos principais constituintes da água comum utilizada no experimento, comprovam a condição nomal desta água. O Apêndice 1 contém a classificação com base na escala americana(SCS/USDA). Com isto, verifica-se que a água comum não deve ter causado modificações significativas no comportamento das variáveis experimentais estudadas.

Falta-nos, aqui, todavia, um quadro com padrões comparativos para os valores dos constituintes e parâmetros da água comum, a exemplo do que foi 
feito para a vinhaça in natura. Contudo, cremos, isto não traz prejuísos a análise destes dados, pois, ao contrário do que acontece com as vinhaças, há uma escala de classificação de águas, científica e universalmente reconhecida (Apêndice 1).

QUADRO 06 - Valores médios dos constituintes e parâmetros da água comum utilizada no experimento.

\begin{tabular}{l|c}
\hline Constituintes e parâmetros & Valores médios \\
\hline $\mathrm{pH}$ & 7,20 \\
$\mathrm{CE}^{\star}$ & 199 \\
$\mathrm{Ca}^{-\star \star}$ & 0,203 \\
$\mathrm{Mg}^{++\star \star}$ & 0,291 \\
$\mathrm{Cl}^{-\star \star}$ & 1,889 \\
$\mathrm{Na}^{+\star \star}$ & 1,478 \\
$\mathrm{CO}_{3}{ }^{-\star \star}$ & 0,00 \\
$\mathrm{HCO}_{3}{ }^{-\star \star}$ & 0,309 \\
$\mathrm{~K}^{+\star \star}$ & Traços \\
$\mathrm{SO}^{-\star \star}$ & Traços \\
$\mathrm{Fe}^{\star \star \star}$ & 1,338 \\
$\mathrm{SiO}_{2}{ }^{* \star}$ & 9,756 \\
$\mathrm{Só}^{*}$ dos totais & 0,128 \\
\hline
\end{tabular}

$$
\begin{aligned}
& \text { * } \mu \mathrm{s} / \mathrm{cm} \text {. } \\
& \text { ** } \mathrm{meq} / \mathrm{l} \text {. } \\
& \star \star \star \mathrm{kg} / \mathrm{m}^{3} \text {. }
\end{aligned}
$$

Chamamos a atenção para os valores de matéria orgânica total da vinhaça in natura e de sólidos totais tanto desta vinhaça quanto da água comum, Quadros 5 e 6. Sugere-se, também, uma comparação com os valores de matéria orgânica da vinhaça, contidos no Apêndice 2. Verifica-se que os valores de sólidos totais de ambos os líquidos, são consideráveis. Infelizmente nos falta um padrão comparativo para os valores de sólidos totais!... A matéria orgânica da vinhaça utilizada neste experimento, pos- 
sui valores duas vezes maiores que aqueles contidos no Apêndice 2. Apesar dessa magnitude ser normal, no que se refere ao ambiente de produção da vinhaça, isto, certamente, acentua o efeito de obstrução mecânica dos poros do solo, como aludido por Ross \& Froberville(1928) - embora com pertinência científica limitada -, induzindo uma redução ainda maior nos valores de I, VI e PI.

Os dados sobre compoentes da vinhaça aqui apresentados, comprovam, "novamente", a elevada variação destes constituintes, justificando, desta forma, um estudo mais aprofundado acerca deste resíduo agroindustrial e confirmando a importância que se deve dar às características da vinhaça gerada pela indústria canavieira, como alertado por Glória \& Orlando FiIho(1984). Os valores de sólidos totais, tanto da vinhaça in natura quanto da água comum, também podem ter contribuído para este efeito de obstrução dos poros do solo. O quanto estes constituintes, particularmente, influenciam as magnitudes de I, VI e PI, depende, cremos, da natureza dos mesmos. E, daí, advém a importância de uma análise rigorosa dos líquidos envolvidos no processo de infiltração, nas condições desta pesquisa ou semelhantes.

Esta evidência, ou seja, o potencial desses líquidos, principalmente da vinhaça in natura, para redução da infiltração desses mesmos líquidos em canais de terra, pela sua própria constituição, já nos induz a pensar na possível confirmação da hipótese 1 .

Em seguida, pelas análises dos comportamentos das variáveis intevenientes consideradas, inerentes ao solo, confirmaremos ou não este potencial.

4.2. SOIO (Apêndice 02) .

Além da hipótese 1(H1), já escrita, está envolvida também a hipótese $2(\mathrm{H} 2)$, transcrita a seguir:

H2 - "Ern função dessa obstrução dos poros do solo, ocorre um aumento de sua massa específica, redução de sua macroporosidade, aumen 
to da microporosidade, e redução da porosidade total e da con dutividade hidráulica na saturação".

4.2.1. Grau de umidade atual (b.p.s.), u(o $)$.

QUADRO 07 - Valores médios do grau de umidade, por bloco experimental, e média geral para o experimento.

\begin{tabular}{c|c}
\hline Bloco & $u\left(\frac{o}{8}\right)$ \\
\hline I & $15,52^{1}$ \\
II & $16,58^{1}$ \\
III & $17,74^{1}$ \\
IV & $17,31^{2}$ \\
V & $16,58^{2}$ \\
Média geral & $16,75^{2}$ \\
\hline
\end{tabular}

1 Médias de 6 repetições.

2 Média de 5 repetições.

Considerando-se este quadro e a depender do bloco experimental referido, o número de repetições - que, para este fim, coincide com o número de tratamentos possíveis (no caso, igual a 7) -, variou de 5 a 7.

A importância do Quadro 7, contendo os valores médios de graus de umidade atual, reside no fato, fundamental, da infiltração, independentemente da natureza do líquido infiltrante, variar, no tempo, com esse grau de umidade do meio poroso. Assim, a importância referida está restrita ao momento inicial do processo de infiltração.

A amplitude total de variação, entre estes valores, foi de 2,22\%, não nos parecendo significativa, podendo-se, portanto, considerar-se qualquer um destes valores como $\circ$ grau de umidade que afetou todo 0 experimento, ou, mesmo, o valor médio, igual a 16,75\%. Enfim, repetimos, para esta pesquisa, o grau de umidade no qual o experimento foi realizado serve apenas como um indicador do estado de energia da solução do solo. Não se constitui em variável experimental. 


\subsubsection{Massa específica do solo ( $\rho_{\text {sojo }}$ ) (Apêndice 08).}

Analizando-se $\circ$ Quadro 8, verifica-se que os valores de $\rho_{\text {solo }}$ em geral, sofreram acréscimos, no momento pós-tratamento, tanto na posição fundo quanto na posição talude, independentemente de ter havido redução ou não. Isto comprova que, realmente, ocorre uma obstrução dos poros do solo ao longo do processo de infiltração.

Esses acréscimos, entretanto, incoerente e inexplicavelmente, não ocorreram para os tratamentos $(\mathrm{v}+\mathrm{V})$ e $(\mathrm{v})$ posição fundo. Ao contrário, houve aumento do valor de psobr com a aplicação dos líquidos. Esta incoerência pode ter sido causada por um excessivo número de batidas no amostrador, provocando una relativa compactação da amostra, como verificada pelos valores de massa seca do solo (Apêndice 08).

Confrontando-se os valores obtidos nos tratamentos ( $v+A) v s(a+A)$, (v) vs(a) e (A)vs(V), não se constata a contribuição da vinhaça in natura para $\bigcirc$ aumento dos valores de psolor comparativamente com a água comum. $\mathrm{Pa}-$ rece haver um efeito sinergístico de ambos os líquidos sobre $\rho_{\text {solor }}$ bem como efeito do tempo de redução e, ou, de infiltração. Na condição real de aplicação de resíduos da agroindústria sucroalcooleira, estes tempos são muito maiores. Talvez, nesta condição, haja significativo efeito da vinhaça sobre a massa específica do solo, relativamente à água comum.

Portanto, considerando-se o referido cojunto de dados, os efeitos da vinhaça in natura sobre a psob não comprovam o potencial da vinhaça para redução dos valores de I e VI. Enfatizamos, entretanto, que, em virtude das fortes tendências verificadas, se faz necessário estudos mais aprofundados, na busca de resultados conclusivos.

\subsubsection{Porosidades (Macro, micro e total) (Apêndice 09).}

Observando-se o Quadro 09, verifica-se que não foram obtidos todos os dados para a posição talude, no TC. Isto aconteceu em virtude da grande escassez do material necessário. As análises, discussões e conclusões envolvendo a posição talude, portanto, encontram-se restritas. 
QUADRO 08 - Valores médios da massa específica do solo(b.p.s.), por tratamento, em função da posição e do momento da amostragem.

\begin{tabular}{|c|c|c|c|}
\hline Tratamento & Posição da amostragem & Momento da amostragem & $\rho_{5010}\left(g / \mathrm{cm}^{3}\right)$ \\
\hline \multirow[t]{4}{*}{$(\mathrm{V}+\mathrm{A})$} & \multirow[t]{2}{*}{ Talude } & Pré-Tratam. & 1,28 \\
\hline & & Pós-Tratam. & 1,41 \\
\hline & \multirow[t]{2}{*}{ Fundo } & Pré-Tratam. & 1,34 \\
\hline & & Pós-Tratam. & 1,45 \\
\hline \multirow[t]{4}{*}{$(v+V)$} & \multirow[t]{2}{*}{ Talude } & Pré-Tratam. & 1,41 \\
\hline & & Pós-Tratam. & 1,41 \\
\hline & \multirow[t]{2}{*}{ Eundo } & Pré-Tratam. & 1,38 \\
\hline & & Pós-Tratam. & 1,39 \\
\hline \multirow[t]{4}{*}{$(v)$} & \multirow[t]{2}{*}{ Talude } & Pré-Tratam. & 1,32 \\
\hline & & Pós-Tratam. & 1,38 \\
\hline & \multirow[t]{2}{*}{ Fundo } & Pré-Tratam. & $1,39^{1}$ \\
\hline & & Pós-Tratam. & $1,36^{1}$ \\
\hline \multirow[t]{4}{*}{ (A) } & \multirow[t]{2}{*}{ Talude } & Pré-Tratam. & 1,32 \\
\hline & & Pós-Tratam. & 1,38 \\
\hline & \multirow[t]{2}{*}{ Fundo } & Pré-Tratam. & $1,36^{1}$ \\
\hline & & Pós-Tratam. & $1,39^{1}$ \\
\hline \multirow[t]{4}{*}{$(\mathrm{V})$} & \multirow[t]{2}{*}{ Talude } & Pré-Tratam. & 1,31 \\
\hline & & Pós-Tratam. & $1,39^{1}$ \\
\hline & \multirow[t]{2}{*}{ Fundo } & Pré-Tratam. & 1,39 \\
\hline & & Pós-Tratam. & $1,43^{1}$ \\
\hline \multirow[t]{4}{*}{$(a+A)$} & \multirow[t]{2}{*}{ Talude } & Pré-Tratam. & 1,29 \\
\hline & & Pós-Tratam. & $1,44^{2}$ \\
\hline & \multirow[t]{2}{*}{ Fundo } & Pré-Tratam. & $1,22^{1}$ \\
\hline & & Pós-Tratam. & 1,43 \\
\hline \multirow[t]{4}{*}{ (a) } & \multirow[t]{2}{*}{ Talude } & Pré-Tratam. & 1,30 \\
\hline & & Pós-Tratam. & 1,38 \\
\hline & \multirow[t]{2}{*}{ Fundo } & Pré-Tratam. & $1,40^{1}$ \\
\hline & & Pós-Tratam. & $1,43^{1}$ \\
\hline
\end{tabular}

${ }^{1}$ Médias de 4 repetições. $\quad{ }^{2}$ Média de 3 repetições. 
QUADRO 09 - Valores médios da macroporosidade, microporosidade e porosidade total, em função de tratamentos, posição e momento da amostragem.

\begin{tabular}{|c|c|c|c|c|c|}
\hline Tratamento & $\begin{array}{l}\text { Posição da } \\
\text { amostragem }\end{array}$ & $\begin{array}{l}\text { Momento da } \\
\text { amostragem }\end{array}$ & $\begin{array}{l}\text { Macroporosi } \\
\text { dade }\left(\frac{o}{\partial}\right), M\end{array}$ & $\begin{array}{l}\text { Microporosi } \\
\text { dade }\left(\frac{o}{0}\right), \mathrm{m}\end{array}$ & $\begin{array}{l}\text { Porosidade } \\
\text { total }\left(\frac{o}{\partial}\right), \mathrm{P}\end{array}$ \\
\hline \multirow[t]{4}{*}{$(\mathrm{V}+\mathrm{A})$} & \multirow[t]{2}{*}{ Talude } & Pré-Tratam. & - & - & - \\
\hline & & Pós-Tratam. & - & - & - \\
\hline & \multirow[t]{2}{*}{ Fundo } & Pré-Tratam. & 7,60 & 24,88 & 32,48 \\
\hline & & Pós-Tratam. & 5,65 & 27,46 & 33,11 \\
\hline \multirow[t]{4}{*}{$(v+V)$} & \multirow[t]{2}{*}{ Talude } & Pré-Tratam. & 11,36 & 20,73 & 32,09 \\
\hline & & Pós-Tratam. & 9,11 & 21,03 & 30,14 \\
\hline & \multirow[t]{2}{*}{ Fundo } & Pré-Tratam. & 10,58 & 24,41 & 34,98 \\
\hline & & Pós-Tratam. & 7,88 & 18,88 & 26,76 \\
\hline \multirow[t]{4}{*}{$(v)$} & \multirow[t]{2}{*}{ Talude } & Pré-Tratam. & 10,92 & 20,02 & 30,94 \\
\hline & & Pós-Tratam. & - & - & - \\
\hline & \multirow[t]{2}{*}{ Fundo } & Pré-Tratam. & 8,75 & 25,19 & 33,94 \\
\hline & & Pós-Tratam. & 7,31 & 23,96 & 31,27 \\
\hline \multirow[t]{4}{*}{ (A) } & \multirow[t]{2}{*}{ Talude } & Pré-Tratam. & - & - & - \\
\hline & & Pós-Tratam. & - & - & - \\
\hline & \multirow[t]{2}{*}{ Fundo } & Pré-Tratam. & 7,67 & 19,32 & 26,99 \\
\hline & & Pós-Tratam. & 7,73 & 23,47 & 31,20 \\
\hline \multirow[t]{4}{*}{$(\mathrm{V})$} & \multirow[t]{2}{*}{ Talude } & Pré-Tratam. & 10,00 & 23,91 & 33,91 \\
\hline & & Pós-Tratam. & 8,47 & 23,00 & 31,47 \\
\hline & \multirow[t]{2}{*}{ Fundo } & Pré-Tratam. & 10,68 & 21,32 & 31,90 \\
\hline & & Pós-Tratam. & 8,72 & 22,35 & 31,07 \\
\hline \multirow[t]{4}{*}{$(a+A)$} & \multirow[t]{2}{*}{ Talude } & Pré-Tratam. & 8,95 & 24,91 & 33,86 \\
\hline & & Pós-Tratam. & 7,71 & 21,69 & 29,40 \\
\hline & \multirow[t]{2}{*}{ Fundo } & Pré-Tratam. & 11,30 & 23,00 & 34,30 \\
\hline & & Pós-Tratam. & 11,23 & 23,27 & 34,50 \\
\hline \multirow[t]{4}{*}{ (a) } & \multirow[t]{2}{*}{ Talude } & Pré-Tratam. & 9,49 & 25,51 & 34,99 \\
\hline & & Pós-Tratam. & - & - & - \\
\hline & \multirow[t]{2}{*}{ Fundo } & Pré-Tratam. & 9,78 & 22,65 & 32,49 \\
\hline & & Pós-Tratam. & 10,07 & 24,63 & 34,70 \\
\hline
\end{tabular}


Mesmo com uma certa limitação dos dados obtidos e algumas incoerências, evidencia-se tendências de redução da macroporosidade, $M$, aumento da microporisidade, $\mathrm{m}$, e da porosidade total, $\mathrm{E}$.

Confrontando-se os tratamentos com vinhaça in natura com os com água comum, independentemente de ser com redutor ou não, constata-se a tendência da vinhaça ter comtribuído, mais que a água comum, para a redução das porosidades. Isto pode ser confimado analisando os valores de porosidades para os tratamentos $(\mathrm{v}+\mathrm{V}),(\mathrm{v})$ e $(\mathrm{V})$.

O espaço poroso do solo foi mais afetado pela vinhaça in natura que pela água comum. Os valores de M diminuíram em todos os tratamentos com vinhaça in natura, em relação aos com água comum. Entretanto, nem todos os mesmos tratamentos tiveram seus valores de $\mathrm{m}$ e $\mathrm{P}$ aumentados, correspondentemente. Isto induz a afimação de que, realmente, há um acúmulo de materiais - orgânicos e minerais - e, neste caso, oriundos exclusivamente da vinhaça, nos poros do solo, podendo ou não reduzir o fluxo de líquidos através dos mesmos. Esta possibilidade deverá ser verificada com os dados de $\boldsymbol{K}_{0}, \mathrm{I}, \mathrm{VI}$ e PI, os quais serão abordados mais adiante. Verifica-se que a redução nos valores de $M$ foi da ordern de $2 \%$. Não quantificamos o quanto representa esta magnitude de redução sobre a redução do fluxo através do solo, pois haveria necessidade de isolarmos os dois fatores. Sugerimos que seja objetivo de outra investigação.

Também com relação aos resultados obtidos para $\mathrm{M}$, $\mathrm{m}$ e $\mathrm{P}$, é válido afimar, considerando-se a importância para a magnitude da redução da infiltração, do termo de permanência da vinhaça in natura, como redutor e, ou, infiltrante, sobre a superfície infiltrada. É importante ter-se conhecimento de como a magnitude destes termpos - de redução e, ou, de infiltração -, influem sobre as magnitudes de I, VI e PI. Que lei matemática rege esta relação. Lembremos que a vinhaça in natura se constitui numa mistura complexa de vários solutos, com elevado potencial de interrelação com os constituintes do solo, podendo, assim, modificar as interações. Estes estudos conduziriam a um maior aprofundamento desta investigação, podendo elucidar, com maior rigorosidade e clareza, as relações vinhaça-solo. Evidentemente, enfatizamos, estes estudos deverão ser realizados numa condição de fluxo em canal, novo, aberto "em terra", e 
na subsuperfície do solo, além de outros contornos, como se verifica numa situação real.

4.2.4. Condutividade hidráulica do solo saturado ( $\left.\boldsymbol{R}_{0}\right)$ (Apêndice 10) .

Os valores de $\boldsymbol{R}_{0}$, quadro 10 , independentemente de qualquer fator interveniente considerado nesta pesquisa, mostraram-se bastante controvertidos. O tratamento ( $\mathrm{V}+\mathrm{A})$, em ambas as posições de amostragem, confirma a hipótese de que a vinhaça reduz a infiltração; há uma redução nos valores dessa condutividade hidráulica da ordern de 3 vezes, para a posição talude, e de 1,6 vezes para a posição fundo. Porém, os tratamentos $(v+V)$ posição fundo, (V) e (V) indicam a tendência inversa, chegando a aumentar essa condutividade hidráulica em 2,5 vezes. Até dentro de um mesmo tratamento, como no $(\mathrm{v}+\mathrm{V})$, quando o normal e coerente seria ocorrer uma maior redução, houve aumento no valor de $\mathrm{K}_{0}$. Mesmo que tenha havido influência do fluxo, em virtude da mesma amostra ter sido utilizada para determinações de porosidade, inicialmente, e, após, condutividade hidráulica, deveria ter ocorrido em todos os tratamentos. O tratamento $(v+A)$, o qual foi submetido a fluxo de água no carmo durante 6 horas, não apresentou esta tendência inversa. Portanto, concluimos, foram obtidos dados com valores e significados físicos completamente antagônicos, para uma mesma variável, submetida "às mesmas condições"! Não conseguimos explicação científica consistente para tal fato. Nos tratamentos apenas com água comum, as incoerências foram ainda maiores, principalmente se houver um confronto com os dados de porosidades.

Enfim, os dados de condutividade hidráulica do solo saturado estabeleceram duas tendências antagônicas. Isto está em desacordo com os dados obtidos para $\rho_{\text {solo }}$ e porosidades, quando, certamente, deveria ter mantido a mesma tendência.

Enfim, com os dados aqui apresentados, não se pode inferir qualquer tendência no comportamento de $\boldsymbol{R}_{0}$. Evidentemente, independente do que tenha acontecido - de qual a causa disto -, estas incoerências trouxeram sérios prejuízos para as análises, discussões e conclusão sobre os resultados desta pesquisa. 
QUADRO 10 - Valores médios da condutividade hidráulica do solo saturado, $\boldsymbol{R}_{0}$, em função de tratamento, posição e momento da amostragem.

\begin{tabular}{|c|c|c|c|}
\hline Tratamento & Posição da amostragem & Momento da amostragem & $\boldsymbol{R}_{0}(\mathrm{~cm} / \mathrm{min})$ \\
\hline \multirow[t]{4}{*}{$(v+A)$} & \multirow[t]{2}{*}{ Talude } & Pré-Tratam. & 0,15717 \\
\hline & & Pós-Tratam. & 0,04893 \\
\hline & \multirow[t]{2}{*}{ Fundo } & Pré-Tratam. & 0,11464 \\
\hline & & Pós-Tratam. & 0,07050 \\
\hline \multirow[t]{4}{*}{$(v+V)$} & \multirow[t]{2}{*}{ Talude } & Pré-Tratam. & 0,11574 \\
\hline & & Pós-Tratam. & 0,07886 \\
\hline & \multirow[t]{2}{*}{ Fundo } & Pré-Tratam. & 0,12451 \\
\hline & & Pós-Tratam. & 0,21342 \\
\hline \multirow[t]{4}{*}{$(v)$} & \multirow[t]{2}{*}{ Talude } & Pré-Tratam. & 0,10996 \\
\hline & & Pós-Tratam. & 0,21625 \\
\hline & \multirow[t]{2}{*}{ Fundo } & Pré-Tratam. & 0,25357 \\
\hline & & Pós-Tratam. & 0,23463 \\
\hline \multirow[t]{4}{*}{ (A) } & \multirow[t]{2}{*}{ Talude } & Pré-Tratam. & 0,21203 \\
\hline & & Pós-Tratam. & 0,08592 \\
\hline & \multirow[t]{2}{*}{ Fundo } & Pré-Tratam. & 0,07716 \\
\hline & & Pós-Tratam. & 0,15536 \\
\hline \multirow[t]{4}{*}{$(\mathrm{V})$} & \multirow[t]{2}{*}{ Talude } & Pré-Tratam. & 0,18510 \\
\hline & & Pós-Tratam. & 0,25986 \\
\hline & \multirow[t]{2}{*}{ Fundo } & Pré-Tratam. & 0,18966 \\
\hline & & Pós-Tratam. & 0,38365 \\
\hline \multirow[t]{4}{*}{$(a+A)$} & \multirow[t]{2}{*}{ Talude } & Pré-Tratam. & 0,16131 \\
\hline & & Pós-Tratam. & 0,19391 \\
\hline & \multirow[t]{2}{*}{ Fundo } & Pré-Tratam. & 0,08996 \\
\hline & & Pós-Tratam. & 0,12720 \\
\hline \multirow[t]{4}{*}{ (a) } & \multirow[t]{2}{*}{ Talude } & Pré-Tratam. & - \\
\hline & & Pós-Tratam. & 0,19983 \\
\hline & \multirow[t]{2}{*}{ Fundo } & Pré-Tratam. & 0,13722 \\
\hline & & Pós-Tratam. & 0,08900 \\
\hline
\end{tabular}


Com o grau de consistência dos resultados aqui apresentados e discutidos, entendemos que as hipóteses H1 e H2, expressando-nos rigorosamente, não devem ser consideradas comprovadas de forma definitiva. Entretanto, as evidências neste sentido são bastante claras e substanciais, nos induzindo e nos obrigando a afimar que necessitamos de outros experimentos, com potencial ainda mais crítico, para que venhamos a lograr conclusões definitivas.

\subsection{Análises estatísticas (Apêndice 11).}

QUADRO 11 - Resumo dos resultados do teste F, média geral e coeficiente de variação, em função das variáveis analisadas.

\begin{tabular}{|c|c|c|c|c|c|c|}
\hline $\begin{array}{l}\text { Vari- } \\
\text { áveis }\end{array}$ & $\begin{array}{l}\text { Posição } \\
\text { da } \\
\text { amos- } \\
\text { tragem }\end{array}$ & $\begin{array}{l}\text { Momento } \\
\text { da amos- } \\
\text { tragem }\end{array}$ & $\begin{array}{l}\text { F } \\
\text { calcu- } \\
\text { lado }\end{array}$ & $\begin{array}{l}\text { Probabi- } \\
\text { lidade > } \\
\text { F }\end{array}$ & $\begin{array}{l}\text { Média } \\
\text { geral } \\
\text { ajus- } \\
\text { tada }\end{array}$ & $\begin{array}{c}\text { Coeficien- } \\
\text { te de va- } \\
\text { riação } \\
\left(\frac{o}{y}\right)\end{array}$ \\
\hline \multirow[t]{4}{*}{$\rho_{s 010}$} & \multirow[t]{2}{*}{ Talude } & Pré-trat. & 0,8665 & $0,53541^{\text {ns }}$ & 1,3162 & 7,559 \\
\hline & & Pós-trat. & 0,1618 & $0,98287^{\mathrm{ns}}$ & 1,3960 & 8,552 \\
\hline & \multirow[t]{2}{*}{ Fundo } & Pré-trat. & 0,6652 & $0,68017^{\mathrm{ns}}$ & 1,3491 & 7,711 \\
\hline & & Pós-trat. & 0,7187 & $0,64097^{\mathrm{ns}}$ & 1,4075 & 6,922 \\
\hline \multirow[t]{2}{*}{$M$} & \multirow[t]{2}{*}{ Eundo } & Pré-trat. & 1,3077 & $0,30081^{n s}$ & 8,9624 & 22,182 \\
\hline & & Pós-trat. & 1,0688 & $0,41903^{\mathrm{ns}}$ & 7,5550 & 23,935 \\
\hline \multirow[t]{2}{*}{$\mathrm{m}$} & \multirow[t]{2}{*}{ Fundo } & Pré-trat. & 1,4763 & $0,23858^{\mathrm{ns}}$ & 24,2282 & 8,187 \\
\hline & & Pós-trat. & 2,1104 & $0,10542^{\mathrm{ns}}$ & 23,7625 & 15,780 \\
\hline \multirow[t]{2}{*}{$\mathrm{P}$} & \multirow[t]{2}{*}{ Fundo } & Pré-trat. & 1,0807 & $0,40884^{\mathrm{ns}}$ & 33,1903 & 10,054 \\
\hline & & Pós-trat. & 1,5302 & $0,22739^{\mathrm{ns}}$ & 31,3183 & 13,176 \\
\hline \multirow[t]{2}{*}{$\boldsymbol{R}_{0}$} & \multirow[t]{2}{*}{ Fundo } & Pré-trat. & 1,3109 & $0,29949^{\mathrm{ns}}$ & 0,1402 & 80,209 \\
\hline & & Pós-trat. & 1,6453 & $0,19504 \mathrm{~ms}^{\mathrm{ns}}$ & 0,1869 & 89,663 \\
\hline
\end{tabular}

O Quadro 11 contém o resumo das análises estatísticas clássicas realizadas para aquelas variáveis anteriormente definidas. O Apêndice 11 traz 
os detalhes de todas estas análises. As duas posições de amostragem - talude e fundo do TC -, foram analizadas apenas para a variável $\rho_{\text {sod. }}$.

Os testes $\mathrm{F}$ foram realizados adnitindo-se uma probabilidade de 18 de que as diferenças entre tratamentos fossem devidas ao fatores não controlados. Verifica-se que não houve significância estatística entre os tratamentos estudados, em nenhuma destas variáveis. Assim, com base nas hipóteses da estatística clássica, a probabilidade das diferenças entre os valores médios obtidos para cada tratamento serem devidas a fatores não controlados, foi superior a $99 \%$.

Por conseguinte, em virtude desses mesmos dados terem evidenciado fortes tendências no sentido de comprovação das hipóteses científicas elaboradas, cumpre-nos chamar a atenção para os seguintes questionamentos: (1) será que as técnicas da estatística clássica são adequadas para estudar o comportamento dessas variáveis nas condições desta pesquisa?; (2) considerando-se as características de comportametno espaço-termporal dessas mesmas variáveis, será que o número de repetições foi suficiente?

\subsection{Infiltração e taxas de infiltração (Apêndice 12) .}

Hipóteses envolvidas:

H3 - "Há redução da infiltração e das perdas por infiltração ao lon go do tempo".

H4 - "A vinhaça in natura se constitui num redutor de infiltração desses líquidos em canais de terra".

Os valores que constam do Quadro 12 são valores teminais, isto é, aqueles que representam a última medida do processo de infiltração. Evidentemente, estes valores, em termos de características físicas deste processo, são limitados pelos tempos considerados no experimento - 2 horas para a redução e $\sigma$ horas para a infiltração.

Verificando-se o Apêndice 12, constata-se que, possivelmente, estes tempos, aqui considerados como terminais, não coincidem com aquele tempo para o qual a infiltração assume valor constante, o qual, numa condição de 
QUADRO 12 - Valores médios de TACI, IAC e VI por tratamento e por repetição, a partir dos valores terminais.

\begin{tabular}{|c|c|c|c|c|}
\hline Tratamento & Repetição & $\operatorname{TACI}(\mathrm{min})$ & IAC (mm) & $\mathrm{VI}(\mathrm{mm} / \mathrm{min}$ \\
\hline \multirow[t]{6}{*}{$(v+A)$} & $\bar{I}$ & 359,0 & 457,0 & 1,6 \\
\hline & V & 375,5 & 309,3 & 0,6 \\
\hline & III & 349,0 & 310,9 & 0,6 \\
\hline & II & 358,0 & 251,7 & 0,5 \\
\hline & IV & 384,5 & 539,8 & 1,1 \\
\hline & Média & 365,2 & 373,7 & 0,9 \\
\hline \multirow[t]{6}{*}{$(v+V)$} & I & 155,0 & 14,6 & 0,1 \\
\hline & $\mathrm{V}$ & 442,0 & 55,2 & 0,1 \\
\hline & III & 359,0 & 142,1 & 0,4 \\
\hline & I I & 300,0 & 52,0 & 0,0 \\
\hline & IV & 360,0 & 51,1 & 0,0 \\
\hline & Média & 323,2 & 63,0 & 0,1 \\
\hline \multirow[t]{6}{*}{ (A) } & I & 236,0 & 1670,0 & 3,7 \\
\hline & V & 362,0 & 404,0 & 0,5 \\
\hline & III & 361,5 & 554,5 & 0,7 \\
\hline & I I & 394,0 & 440,8 & 0,5 \\
\hline & IV & 359,0 & 816,7 & 2,2 \\
\hline & Média & 342,5 & 777,2 & 1,5 \\
\hline \multirow[t]{6}{*}{ (V) } & I & 360,0 & 61,7 & 0,2 \\
\hline & $\mathrm{V}$ & 315,0 & 74,7 & 0,1 \\
\hline & III & 359,0 & 179,4 & 0,0 \\
\hline & II & 309,0 & 160,7 & 0,1 \\
\hline & IV & - & - & - \\
\hline & Média & 335,8 & 119,1 & 0,1 \\
\hline \multirow[t]{6}{*}{$(a+A)$} & I & - & - & - \\
\hline & V & 351,0 & 363,7 & 0,7 \\
\hline & III & 375,0 & 438,4 & 0,8 \\
\hline & II & 372,5 & 2588,0 & 5,2 \\
\hline & IV & 274,0 & 535,8 & 1,8 \\
\hline & Média & 343,1 & 981,5 & 2,1 \\
\hline
\end{tabular}


irrigação por aspersão convencional, é considerado como "velocidade de infiltração básica(VIB)". Enfatizamos que, em função das condições em que se realizou esta pesquisa, esses tempos médios terminais não são comparáveis àqueles correspondentes à "VIB".

Ocorreram vários valores discrepantes ao longo de todo o termpo de oportunidade para a infiltração na maioria dos tratamentos e repetições (Apêndice 12). Como pode ser observado no Quadro 12, os valores médios de VI (mm/min), por tratamento, envolvem esses valores discrepantes. Isto, certamente, causa diferença quantitativa sobre o valor da média. Salientamos, contudo, que, caso optássemos por não considerar esses valores discrepantes, apenas ocorreriam diminuições nos valores das diferenças comparativas entre um e outro trtamento; as tendências sobre o fenômeno pesquisado não mudariam significativamente, ou seja, a vinhaça in natura continuaria a se comportar como um eficaz redutor de infiltração.

A tendência, invariável, é dos valores de I e VI diminuírem com o tempo, como se encontra difundido na literatura. A maior importância reside, contudo, no fato de que quando a vinhaça atua, como redutor, ou, como infiltrante, a diminuição dos valores de I e de VI tornou-se maior ainda, comprovando as hipóteses 3 e 4.

A consistência dos dados, entretanto, num aspecto geral, limita as conclusões a um nível de tendência de ocorrência ou não do fenômeno pesquisado. Isto é, de tendência ou não da vinhaça reduzir a infiltração em canais de terra. Há necessidade, portanto, de novos experimentos, mais específicos, para se alcançar conclusões definitivas.

Os dados do Quadro 12, contendo valores teminais do processo de infiltração, não deixam dúvidas quanto ao potencial redutor de infiltração da vinhaça in natura.

Deve ser ressaltado, também, a importância da magnitude dos tempos de redução e, ou, de infiltração adotados, principalmente quando se sabe que, na prática, estes tempos são muito maiores. Isto nos induz a pensar que a redução nas taxas e nas perdas por infiltração, são bem mais altas que as obtidas por esta pesquisa. Isto, também, tende a confirmar as hipóteses 3 e 4 . 
O efeito redutor da vinhaça in natura é constatado de forma irrefutável, quando se compara os tratamentos $(v+A)$ e $(a+A)$. Estes tratamentos estabelece o confronto claro e direto dos dois líquidos atuando como redutores de infiltração. A vinhaça in natura comportou-se como um redutor de infiltração duas vezes mais eficaz. Quando a vinhaça in natura atua como redutor e como infiltrante, tratamento $(\mathrm{V}+\mathrm{V})$, a eficácia na redução de VI é 21 a 30 vezes maior, conforme se considere os dados discrepantes ou não.

\subsection{Perdas por infiltração (Apêndice 13) .}

As hipóteses envolvidas na discussão desta variável, são as mesmas envolvidas na discussão de I e VI(ítem 4.4.).

A obtenção dos valores constantes do Quadro 13 foi semelhante àquela adotada na obtenção dos valores de I e VI. Foram tomados valores teminais do processo de infiltração - valores de TACI e de PACI -, para cada tratamento e repetição.

Os valores obtidos para a perda de líquido por infiltração em canais de terra, a exemplo dos obtidos para VI, também são valores terminais, a partir de um TAcI terminal respectivo.

Obviamente, os valores de $\operatorname{PACI}\left(\mathrm{m}^{3} / \mathrm{m}^{2} / \mathrm{min}\right)$, para cada metro linear de canal, mantêm a mesma tendência científica daqueles obtidos para a VI (Quadro 13). Ou seja, com a substancial redução das perdas de líquido por infiltração, corroboram a vinhaça in natura como um eficaz redutor de infiltração daqueles líquidos em canais de terra.

Analogamente ao que foi feito para os dados de VI, comfrontando-se os valores de PACI obtidos para os tratamentos $(v+A)$ e $(a+A)$, constata-se que ocorreu uma redução da perda de líquido por infiltração da ordem de 1,21 a 2,26 vezes, conforme se considere ou não os dados discrepantes, para cada $\mathrm{m}^{2} / \mathrm{min} / \mathrm{m}$ linear de canal. Quando se considera a vinhaça in natu ra atuando como redutor e como infiltrante, a magnitude da redução aumenta para 7,35 a 17,36 vezes mais.

Neste ítem, atendonos aos dados que constam do Apêndice 10 e dos valores terminais do Quadro 13, constata-se que a vinhaça in natura é, comprovadamente, um redutor de infiltração desses líquidos em canais de 
QUADRO 13 - Valores médios de PACI, em função de tratamentos e repetições, a partir dos valores terminais.

\begin{tabular}{|c|c|c|c|c|}
\hline Tratamento & Repetição & TACI (min) & $\operatorname{PACI}\left(\mathrm{m}^{3} / \mathrm{m}^{2}\right)$ & $\operatorname{PACI}\left(\mathrm{m}^{3} / \mathrm{m}^{2} / \mathrm{min}\right.$ \\
\hline \multirow[t]{6}{*}{$A,(v+A)$} & I & 352,0 & 0,365866 & 0,001039 \\
\hline & V & 375,5 & 0,293417 & 0,000781 \\
\hline & III & 349,0 & 0,246326 & 0,000706 \\
\hline & II & 358,0 & 0,217346 & 0,000607 \\
\hline & IV & 384,5 & 0,641171 & ד \\
\hline & Média & 363,8 & 0,352825 & 0,000960 \\
\hline \multirow[t]{6}{*}{$B,(v+V)$} & I & 155,0 & 0,010867 & 0,000070 \\
\hline & V & - & - & - \\
\hline & III & 359,0 & 0,094183 & 0,000262 \\
\hline & II & 300,0 & 0,043469 & 0,000145 \\
\hline & IV & 360,5 & 0,047092 & 0,000130 \\
\hline & Média & 339,8 & 0,061581 & 0,000125 \\
\hline \multirow[t]{6}{*}{$D, \quad(A)$} & I & 236,0 & 1,278719 & 0,005418 \\
\hline & V & 362,0 & 0,307907 & 0,000850 \\
\hline & $\operatorname{III}$ & 361,5 & 0,470917 & 0,001303 \\
\hline & II & 394,0 & 0,365866 & 0,000929 \\
\hline & IV & 359,0 & 0,746222 & 0,002079 \\
\hline & Média & 342,5 & 0,633926 & 0,002116 \\
\hline \multirow[t]{6}{*}{$\mathrm{E}, \quad(\mathrm{V})$} & I & 360,0 & 0,036224 & 0,000101 \\
\hline & V & 315,0 & 0,043469 & 0,000138 \\
\hline & III & 359,0 & 0,123162 & 0,000343 \\
\hline & I I & 309,0 & 0,123162 & 0,000399 \\
\hline & IV & - & - & - \\
\hline & Média & 335,8 & 0,081504 & 0,000245 \\
\hline \multirow[t]{6}{*}{$E,(a+A)$} & I & - & - & - \\
\hline & V & 351,0 & 0,264437 & 0,000753 \\
\hline & III & 375,0 & 0,351376 & 0,000937 \\
\hline & II & 360,5 & 1,875697 & 0,005203 \\
\hline & IV & 359,5 & 0,641895 & 0,001785 \\
\hline & Média & 361,5 & 0,783351 & 0,002170 \\
\hline
\end{tabular}


terra. Comparativamente vinhaça in natura vs água comum, as perdas chegaram a ser reduzidas de 17 vezes, aproximadamente, quando a vinhaça atua tanto como redutor quanto como infiltrante, que é a situação mais comum nos projetos de aplicação de resíduos líquidos das UPCA's.

Após as análises e discussões aqui desenvolvidas, evidentemente sob a ótica dos dados obtidos no experimento, constata-se que a vinhaça, realmente, se constitui num redutor eficaz da infiltração de líquidos vinhaça e água comum -, em canais de terra. Isto, certamente, se constitui numa outra forma de utilização da vinhaça, aumentando seu potencial para ser utilizada, racionalmetne, em atividades agrícolas. Se esta perspectiva virá a se concretizar ou não, isto é, se estes resultados de pesquisa virão a ser transformados ou não em tecnologia viável, dependerá de outros fatores. Isto é inerente a uma outra fase do processo de desenvolvimento tecnológico.

Por outro lado, como consequência da redução das perdas desses líquidos por infiltração, há uma redução na quantidade de horas de funcionamento do conjunto motor-bomba, com redução do volume aduzido e redução de custos. Com a diminuição do volume de líquido aduzido, há possibilidade de, com este volume que deixou de ser perdido, fertirrigar novas áreas, elevando a produção e, também, os lucros.

Enfim, a comprovação de que a vinhaça in natura, realmente, reduz as perdas por infiltração em canais de terra, traz significativos benefícios ao setor produtivo sucroalcooleiro.

Entretanto, devemos salientar que há, ainda, uma série de questões a serem respondidas dentro deste mesmo assunto, pois, parafraseando Kraatz (1977), o número de fatores que interveem sobre o comportamento do continuum solo-vinhaça é enorme e estes interagem, de forma bastante complexa, no sentido de modificar a magnitude de I, VI e PI. Portanto, ainda existem um grande número de pesquisas a serem desenvolvidas, principalmente considerando-se o aspecto químico das interrelações vinhaça-solo, para que tenhamos um domínio mais amplo e, ao mesmo tempo, mais profundo, deste problena.

Outras questões que carecem de pesquisas e esclarecimentos, referemse aos aspectos físicos da infiltração, os quais, entendemos, se constitui 
num campo de estudos teóricos bastante importante em dinâmica de solutos no solo. 


\section{CONCLUSÕES .}

A vinhaça in natura contém componentes - matéria orgânica total e sólidos totais - que a potencializam como um eficaz redutor da infiltração em canais de terra. Esta potencialidade tende a corroborar a hipótese hipótese 1 - de que "ao longo do tempo de oportunidade para a redução e, ou, para a infiltração, ocorre um preenchimento dos poros do solo com materiais minerais e orgânicos, constituintes inerentes desses líquidos".

Não foi possível concluir, definitivamente, acerca dos efeitos da vinhaça sobre a massa específica do solo, as porosidades e a condutividade hidráulica do solo saturado. A hipótese 2 - "em função dessa obstrução dos poros do solo, ocorre um aumento de sua massa específica, redução de sua macroporosidade, aumento da microporosidade e redução da porosidade total e de sua condutividade hidráulica na saturação" -, então, não foi verificada.

Tanto a infiltração, quanto a taxa de infiltração e as perdas por infiltração foram significativamente reduzidas pela vinhaça in natura, relativamente à água comum. As taxas de infiltração sofreram reduções variando de 21 a 30 vezes às obtidas com a água comum. As perdas por infiltração foram reduzidas de 7 a 17 vezes. A vinhaça in natura, portanto, é um eficaz redutor de infiltração em canais de terra. Com isto, ficam corroboradas as hipóteses 3 - "há redução da infiltração e das perdas por infiltração ao longo do tempo" - e 4 - "a vinhaça in natura se constitui num redutor de infiltração desses líquidos em canais de terra". 
REEERÊNCIAS BIBLIOGRÁEICAS.

ASSOCIAÇÃO BRASILEIRA DE NORMAS TÉCNICAS. Procedimentoo de ensaio para determinação do grau de umidade de solos: NBR 069. Rio de Janeiro, 1989. 4p.

ÁLCOOL combustível: um desafio à estrutura agrícola. Brasil Açucareiro, v.90, n.1, p.7-19, jul. 1977.

ALMEIDA, J. R.; RANZANI, G. \& VALSECHI, O. La vinasse dans l'agriculture. Piracicaba-IZ, 1950. 21p. (Boletim Técnico, $n^{\circ} 1$ ).

ALMEIDA, J. R. O problema da vinhaça São Paulo. Piracicaba-IZ, s.d. 24p. (Boletim Técnico, $\mathrm{n}^{\circ} 3$ ).

- O problema da vinhaça. Brasil Acreareiro, 46:72-4, Ago/1955.

ALMEIDA, J. R. Composição, proporção e aplicação da vinhaça. Brasil Açucareiro, n.59, p.196-208. maio-jun. 1962.

BENETTI, A. \& BIDONE, F. O meio ambiente e os recursos hídricos. In: TUCCI, C. E. M. (Organ.). Hidrologia: ciência e aplicação. Porto Alegre: Ed. Universitária/ABRH/EDUSP, 1993. p. 849-75

BIESKE, G. C. Agriculture use of dunder. Proc. of the Aust. Soc. of sugar Care Techn., Machay, april, 1979. p. 139-141.

BITTENCOURT, V. C.; CASTR, L. J. B. de; FIGUEIREDO, A. D. M.; PAIXÃO, A. C. S.; POLLI, D. M. Composição da vinhaça. Brasil Açucareiro, V.92, n.4, p.25-37, out, 1978.

BIAKE, G. R.; HARTGE, K. H. Bulk density. In: KLUTE, A., ed. Methods of soil analysis. Madison, ASA/SSSA, 1986a, pt. 1: Physical and mineralogical methods, cap. 13, p.373-75. (Agronomy. A Ser. of Monographs, 9). BOLSANELLO, J.; VIEIRA, J. R. Caracterização da composição química dos diferentes tipos de vinhaça da região de campos. In: SIMPÓSIO DE TECNO 
IOGIA DO AÇÚCAR E DO ÁLCOOL - STAB/SUL, 3, Águas de São Pedro-SP, set/1980. p. 257-276.

CAMHI, J. D. Tratamento do vinhoto, subproduto da destilação do álcool.

Brasil Açucareiro, v.4, n.1, p.18-23, jul/1979.

CAMPOS, H. de; PIEDADE, S. M. S. Planejamento de experimentos. Piracicaba: FEALQ, s.d., p. 1-43, 102-14.

DANIELSON, R. E. \& SUTHERIAND, P. L. Porosity. In: KLUTE, A., ed. Methods of soil analysis. Madison, ASA/SSSA, 1986. pt. 1: Physical and mineralogical methods, cap. 18, p.443-61. (Agronomy. A Ser. of Monographs, 9) .

FERREIRA, E. da S. \& MONTEIRO, A. de O. Efeitos da aplicação de vinhaça nas propriedades físicas, químicas e biológicas do solo. Bol. Téc. CoFERSUCAR: São Paulo, n.35, p.3-7, 1987.

EILGUEIRAS, G. Novo processo para utilização das águas residuais das indústrias agrícolas. Brasil Açueareiro, n.46, p.96-8, ago, 1955.

FONTES, J. B. Reciclagem do vinhoto(total e a quente). Brasil Açucareiro, v.95, n.1, p.31-4, jan, 1980.

GERMEK, H. A. \& FEIGL, G. F. Processos de redução de vinhaça. STAB/Açúcar, Álcool e Subprodutos, V.4, p.42-50, maio-abril/1987.

GLÓRIA, N. A. da; SANT'ANA, A. G.; BIAGI, E. Composição dos resíduos de usinas de açúcar e destilarias. Brasil Açncareizo, n.81, p.78-87. jun, 1973.

GLÓRIA, N. da; ORIANDO FILHO, J.. Aplicação de vinhaça: um resumo e discussões sobre $\circ$ que foi pesquisado. Parte 1. Álcool e Afúcar, v.4, n.14, p. 24-35, $1984 a$.

- Aplicação de vinhaça: um resumo e discussões sobre o que foi pesquisado. Parte 2. Álcool e Açúcar, v.4, n.14, p. ?, jan-fev, 1984b. - Aplicação de vinhaça: um resumo e discussões sobre o que foi pesquisado. Parte 3. Álcool e Açúcar, v.4, n.14, p.32-9, jan-fev, $1984 \mathrm{c}$.

HÜHNE, L. M. (Organ.). Metodologia cientifica; cadernos de textos e técnicas. Agir: 1992, p.149-189. 
KRAATZ, D. B. Irrigation canal lining. Food and Agriculture Organization of the United Nations. Rome, 1977. (FAO Land and Water Development Series, 1). p.18-50.

LAKATOS, E. M.; MARCONI, M. de A. Metodologia cientifica. Atlas: São Pau10, p.40-85, 1983.

IAAUITZEN, C. W. \& TERREL, P. W. Reducing water losses in conveyance and storage. In: HAGAN, R. M.; HAISE, H. R. (Ed.) Irrigation of agricuitural lands. Madison: American Society of Agronomy, 1967. cap. 60, p. 1105-1119.

LEME, E. J. de A.; ROSENEED, U. \& BAPTISTELIA, J. R. Aplicação de vinhaça en cana-de-açúcar por aspersão. Piracicaba-PIANALSUCAR, 1979, 42p. (Boletim Técnico, $n^{\circ} 4$ ).

LEME, E. J. de A. Montagem direta otimizado - O sistema para reduzir consumo de energia. In: CONGRESSO BRASILEIRO DE ENGENHARIA AGRÍCOIA, 17, Anais, Sorocaba-SP, 1988. Sorocaba: CENEA, 1988. p. 72-101.

LIMA, U. D. Lugar de vinhaça é no solo. Química e Derivados, v.14, n.151, p.37, dez. 1978.

MATIOLI, C. S. Aspectos técnicos-econômicos e critérios básicos para otimização de sistemas de fertirrigação de lavouras canavieiras com vinhaça. Piracicaba, 1989. 195p. Dissertação. (Mestrado) - Escola Superior de Agricultura "Luiz de Queiroz", Universidade de São Paulo.

MEDEIROS, A. P.. Composição química dos diferentes tipos de vinhaça nos Estados de Pernambuco, Paraíba e Rio Grande do Norte. Sacharm-STAB, v.4, n.12, p.36-40, jan/1981.

OLIVEIRA, L. B. de. Detenninação da macro e microporosidades pela "mesa de tensão" em amostras de solo com estrutura indeformada. Pesq. Agrop. Bras., v.?, n.3, p.197-200, 1978.

ORIANDO FIIHO, J.; SILVA, L. C. F. da; ZAMBELLO JúNIOR, E. Agricultural utilization of vinasse in Brazil by means of tank-trucks. sugar cane, v.?, n.2, p.4-8, jul-aug, 1983.

PONTES, J. F. A "calda" e seus principais elementos minerais. Brasil Açucareiro, v.53/54, n.12, p.11-15, jan. 1959.

RANZANI, G. Consequencias da aplicação do restilo ao solo(I). Anais da ESALQ, V.12/13, n.?, p.57-68, 1955/56. 
RENNIE, L. L. A good look at the problem of dunder disposal. In: ANNUAL CONGRESS OF THE SOUTH AFRICAN SUGAR TECHNOLOGISTS ASSOCIATION, 46, Mount Edgecombe, 1972. Procedings. p.37-39. june, 1972.

REZENDE, J. de $O$. Consequências da aplicação de vinhaça sobre algumas propriedades físicas de um solo aluvial (Estudo de um caso). Piracicaba, 1979, 112p. Tese. (Doutorado) - Escola Superior de Agricultura "Luiz de Queiroz", Universidade de São Paulo.

RIBEIRO, A. C.; NOVAIS, R. F. de; BAHIA FILHO, A. F. de C. Efeitos da vinhaça sobre a dispersão de argila de amostras de Latossolos. Revista Ceres, V.30, n.167, p.12-18, 1983.

RIBEIRO, A. C.; SENGIK, E. Efeitos da aplicação de vinhaça nas propriedades físicas e químicas de duas amostras de latossolos. Ceres, v.30, n.167, p.25-31, 1983.

RODELLA, A. A.; EERRART, S. E. A composição da vinhaça e efeitos de sua aplicação como fertilizante na cana-de-açúcar. Brasil Acareareiro, v.90, n.1, p.6-13, jul, 1977.

RODELIA, A. A.; PARAZZI, C.. Composição de vinhaça de destilarias autônomas. Brasil Acueareiro, v.96, n.4, p.25-8, out, 1980.

ROSS, P.; EROBERVILLE, L. F. de. Disposal of waste waters. Proceedings of the Annual Meeting and Congress. Natal: South African Sugar Technologists Association, 1928, p.35-42.

RUIZ, J. A. Metodologia cientifica; guia para eficiência nos estudos. Atlas: 1991. p.137-60.

TIBAU, A. O. Projeto de aproveitamento do vinhoto. Brasil Açucareiro, v.81, p.57-65, fev/1973.

USHER, J. F.; WILLINGTON, I. P. The potential of distillery waste as sugar cane fertiliser. Mackay: Proceedings of Australian Society of Sugar Cane Technologists, 1979. p.143-6.

VALSECHI, O. Alguns aspectos do problema da vinhaça. Brasil Açueareiro, v.46, p.57-62, nov/1955.

VASCONCELOS, J. N. de; OLIVEIRA, C. G. de. Composição quírica dos diferentes tipos de vinhaça das destilarias de álcool de Alagoas - Safra 1978/79. Saccharma/STAB, V.4, n.14, p.32-6, maio/1981. 
VASCONCELOS, J. N. de. Estudo sobre a composição química da vinhaça de diferentes procedências no Estado de alagoas. Saccharm/APC, V.6, n.29, p.40-8, nov-dez, 1983. 
APÊNDICES 
APENDICE 1

Resultados das análises da água comum e da vinhaça in natura

- NATT -

Núcleo de Absorção e Transferência de Tecnologia

- DACQ -

Divisão Analítica de Controle de Qualidade

Procedência: Usina Caeté SA

Setor: Vinhaça
Maceió, 14 de maio de 1996

Amostra recebida em : 07/05/96

\section{Repetições}

\begin{tabular}{|l|c|c|c|c|}
\hline \multicolumn{1}{|c|}{ Determinações } & $\mathbf{0 1}$ & $\mathbf{0 2}$ & $\mathbf{0 3}$ & $\mathbf{m}$ \\
\hline $\mathrm{pH}$ & 5,33 & 5,34 & 5,33 & 5,33 \\
\hline $\mathrm{N}^{*}$ & 0,658 & 0,655 & 0,652 & 0,655 \\
\hline $\mathrm{P}_{2} \mathrm{O}_{5}{ }^{*}$ & 0,448 & 0,443 & 0,448 & 0,446 \\
\hline $\mathrm{K}_{2} \mathrm{O}^{*}$ & 4,920 & 4,980 & 4,940 & 4,950 \\
\hline $\mathrm{C}$ Org. & 60,00 & 61,20 & 60,90 & 61,00 \\
\hline $\mathrm{Matéria} \mathrm{Org.} \mathrm{Total*}^{*}$ & 103,44 & 105,51 & 104,99 & 105,16 \\
\hline $\mathrm{CaO}^{*}$ & 2,120 & 2,160 & 2,110 & 2,130 \\
\hline $\mathrm{MgO}^{*}$ & 0,870 & 0,890 & 0,850 & 0,870 \\
\hline Resíduo Sedimentável** & 0,000 & 0,000 & 0,000 & 0,000 \\
\hline Sólidos Totais* & 17,750 & 17,740 & 17,750 & 17,750 \\
\hline
\end{tabular}

$* \mathrm{Kg} / \mathrm{m}^{3}$

$* * \mathrm{ml} / \mathrm{l}$

Obs.: Os resultados deste ensaio têm significação restrita e se aplicam tão so mente a amostra trazida pelo interessado.

Celso Silva Caldas

Eng ${ }^{\circ}$ Químico

Reg. $N^{\circ} 01.301 .496$

CRQ $1^{\text {a }}$ Região 
- NATT -

Núcleo de Absorção e Transferência de Tecnologia

- DACQ -

Divisão Analítica de Controle de Qualidade

Procedência: Usina Caeté SA

Setor: Água para Irrigação
Maceió, 14 de maio de 1996

Amostra recebida em : 07/05/96

\begin{tabular}{|c|c|c|c|c|}
\hline & \multicolumn{4}{|c|}{ Repetições } \\
\hline Determinações & 01 & 02 & 03 & $\mathbf{m}$ \\
\hline $\mathrm{pH}$ & 7,20 & 7,19 & 7,20 & 7,20 \\
\hline CE* & 195 & 199 & 203 & 199 \\
\hline $\mathrm{Ca}^{++* *}$ & 0,203 & 0,207 & 0,199 & 0,203 \\
\hline $\mathrm{Mg}^{++} * *$ & 0,291 & 0,291 & 0,292 & 0,291 \\
\hline $\mathrm{Cl}^{-* *}$ & 1,889 & 1,888 & 1,900 & 1,889 \\
\hline $\mathrm{Na}^{+} * *$ & 1,478 & 1,479 & 1,478 & 1,478 \\
\hline $\mathrm{CO}_{3}^{-\cdots *}$ & 0,000 & 0,000 & 0,000 & 0,000 \\
\hline $\mathrm{HCO}_{3}{ }^{-* *}$ & 0,306 & 0,311 & 0,309 & 0,309 \\
\hline $\mathrm{K}^{+* *}$ & Traços & Traços & Traços & Traços \\
\hline $\mathrm{SO}_{4}{ }^{-* *}$ & Traços & Traços & Traços & Traços \\
\hline $\mathrm{Fe}^{* * *}$ & 1,332 & 1,341 & 1,341 & 1,338 \\
\hline $\mathrm{SiO}_{2} * * *$ & 9,457 & 9,457 & 10,350 & 9,756 \\
\hline Sólidos Totais $* * *$ & 128 & 128 & 127 & 128 \\
\hline
\end{tabular}

* $\mu \mathrm{S} / \mathrm{cm}$

** meq/l

$* * * \mathrm{mg} / \mathrm{l}$

Obs.: Os resultados deste ensaio têm significação restrita e se aplicam tão so mente a amostra trazida pelo interessado.

Celso Silva Caldas

Eng ${ }^{\circ}$ Químico

Reg. $N^{\circ} 01.301 .496$

CRQ $1^{\mathrm{a}} \mathrm{Re}$ 


\section{METODOLOGIAS UTILIZADAS NAS DETERMINAÇÕES DAS AMOSTRA DE VINHAÇA E ÁGUA PARA IRRIGAÇÃO}

\section{I - VINHAÇA}

\begin{tabular}{|c|c|}
\hline DETERMINAÇÕES & MÉTODOS \\
\hline $\mathrm{pH}$ & Potenciométrico \\
\hline Nitrogênio & Kjedahl \\
\hline Fósforo & Espectrofotométrico, com sol. vanadomolibídica \\
\hline Potássio & Fotometria de chama \\
\hline Carbono & Titulometria de oxiredução \\
\hline Mat. Org. Total & Estequiométrico, utilizando o fator de Waksman ${ }^{1}$ \\
\hline Cálcio & Titulometria de complexação \\
\hline Magnésio & Titulometria de complexação \\
\hline Res. Sedimentável & Volumétrico, com cone Imhoff \\
\hline Res. Total & Gravimetria \\
\hline
\end{tabular}

KIEHL, E.J. Fertilizantes orgânicos. Piracicaba. Ed. Agronômica "Ceres" Ltda. 1985. p.91-102; 419$20 ; 422-24 ; 455-58$.

\section{II - ÁGUA PARA IRRIGAÇÃo}

\begin{tabular}{|c|l|}
\hline DETERMINAÇÕES & \multicolumn{1}{|c|}{ MÉTTODOS } \\
\hline pH & Potenciométrico \\
\hline Condutividade & | \\
\hline Cálcio & Titulometrimétrico de complexação \\
\hline Magnésio & Titulometria de complexação \\
\hline Cloretos & Titulometria de precipitação \\
\hline Sódio & Fotometria de chama \\
\hline Carbonatos & Titulometria de neutralização \\
\hline Bicarbonatos & Titulometria de neutralização \\
\hline Potássio & Fotometria de chama \\
\hline Sulfato & Espectrofotométrico, com sol. cloreto de bário \\
\hline Ferro & Espectrofotométrico, com sol. de fenantrolina \\
\hline Sílica & Espectrofotométrico, com sol. de molibidato de amônio \\
\hline Sólidos Totais & Gravimetria \\
\hline
\end{tabular}

Eng $^{\circ}$ Celso Silva Caldas CRQ No 01301946

$1^{\mathrm{a}} \mathrm{REGI} \tilde{\mathrm{A} O}$ 


\section{CLASSIFICAÇÃO DA ÁGUA PARA IRRIGAÇÃO}

\section{Risco de Salinização.}

Classificação feita pela condutividade elétrica

Classificação : $1^{\text {a }}$ classe - pouco risco para salinização

Água com pouca salinidade, pode-se usar na irrigação da maior parte dos solos, com pouca possibilidade de desenvolver salinização.

\section{Risco de Alcalinização}

Classificação feita pela Relação de Absorção do Sódio ( RAS )

Classificação : $1^{\text {a }}$ classe - pouco risco para alcalinização

Água com pouco sódio, pode-se usar em todos os solos com pouco perigo de acumulação de quantidades nocivas de sódio.

\section{Risco de Carbonatação}

Classificação feita pelo teor de Carbonato de Sódio Residual ( CSR )

Classificação : $1^{\text {a }}$ classe - adequada

Água adequada, pode-se usar na irrigação da maioria dos solos e de todas as culturas. 


\section{APÊNDICE 2}

Caracterização geral do solo da área do experimento.

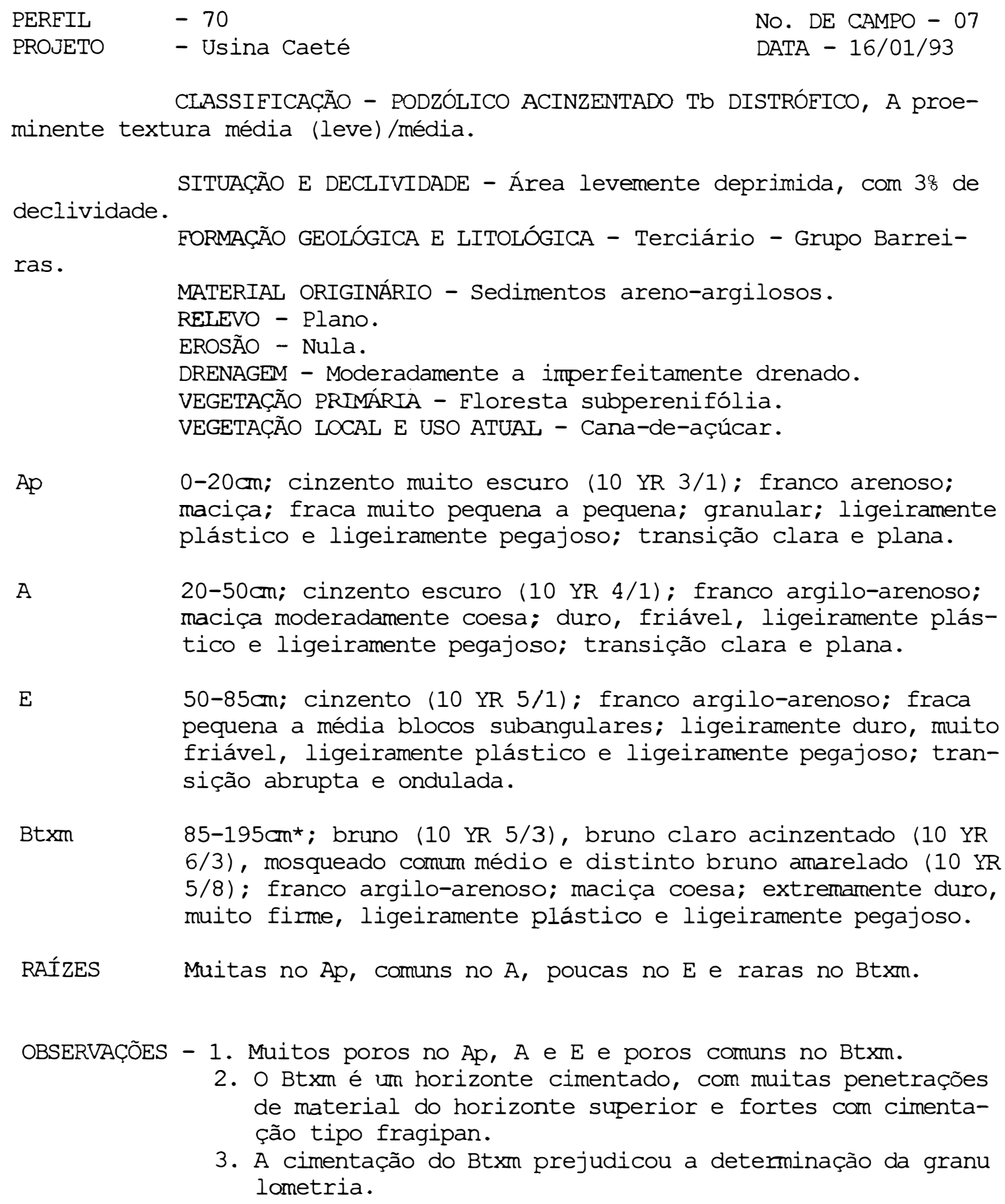

3. A cimentação do Btxm prejudicou a determinação da granu lometria. 


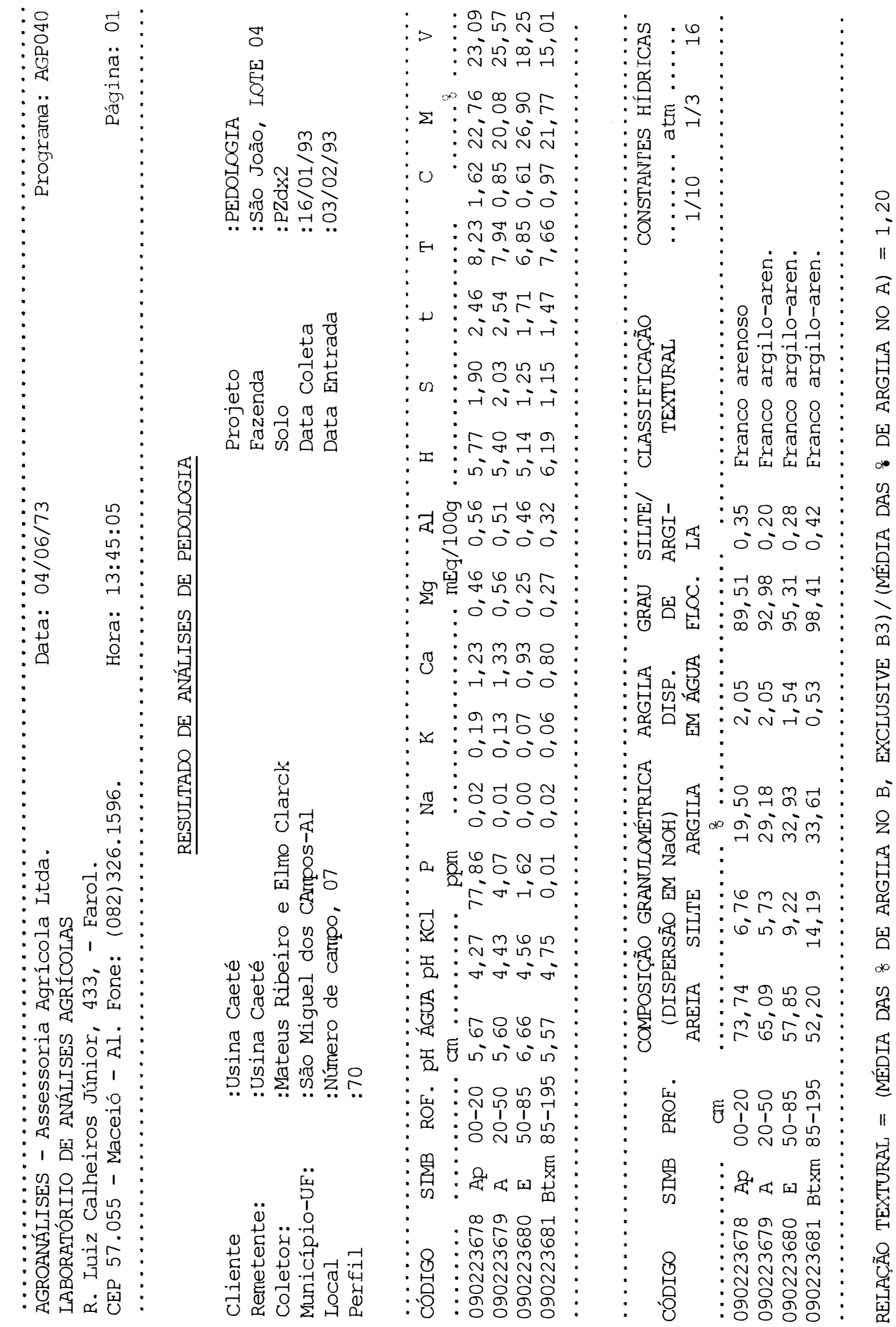




\section{APÊNDICE 3}

Trecho de canal concluído

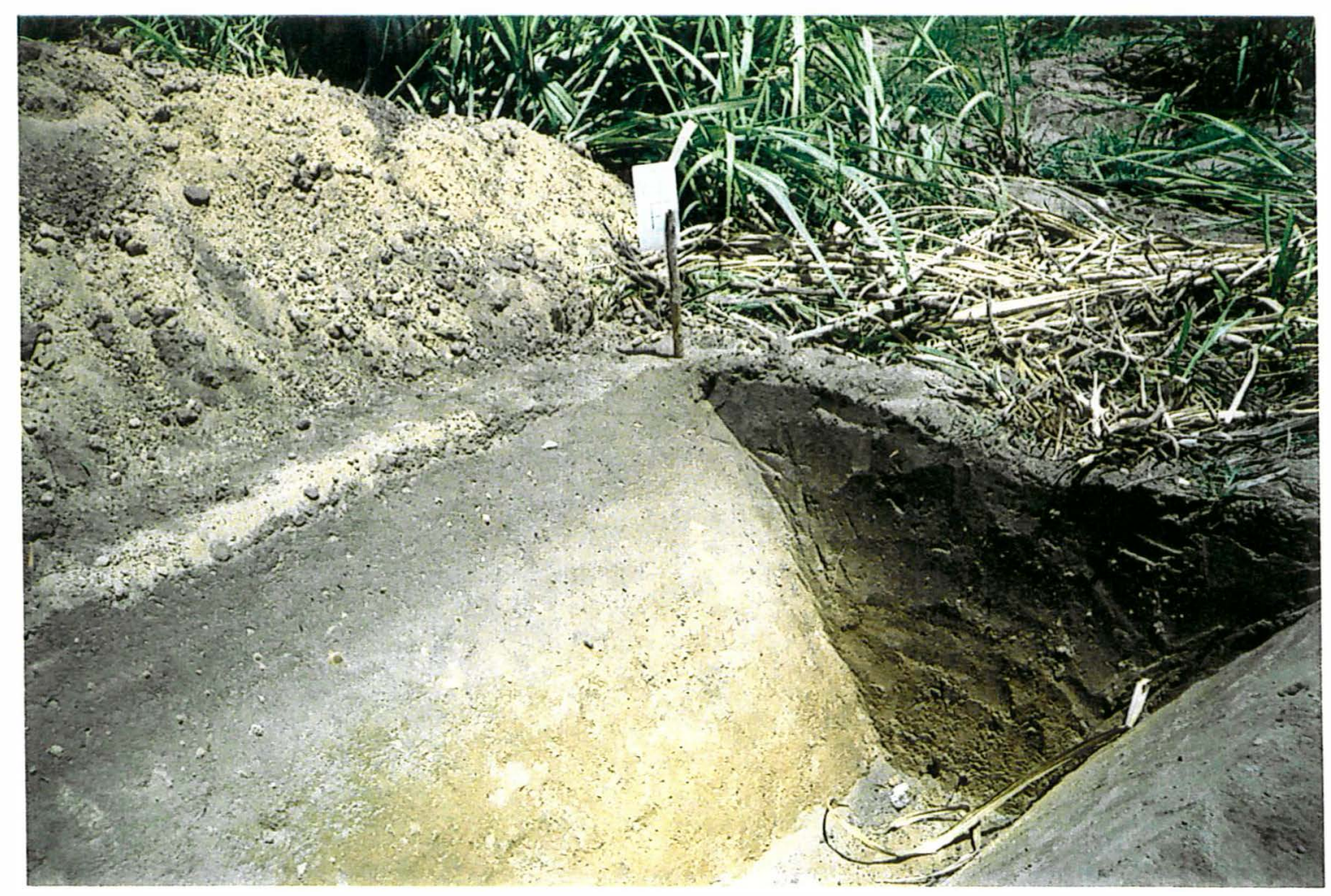




\section{APÊNDICE 4}

Reservatórios utilizados para medidas de I

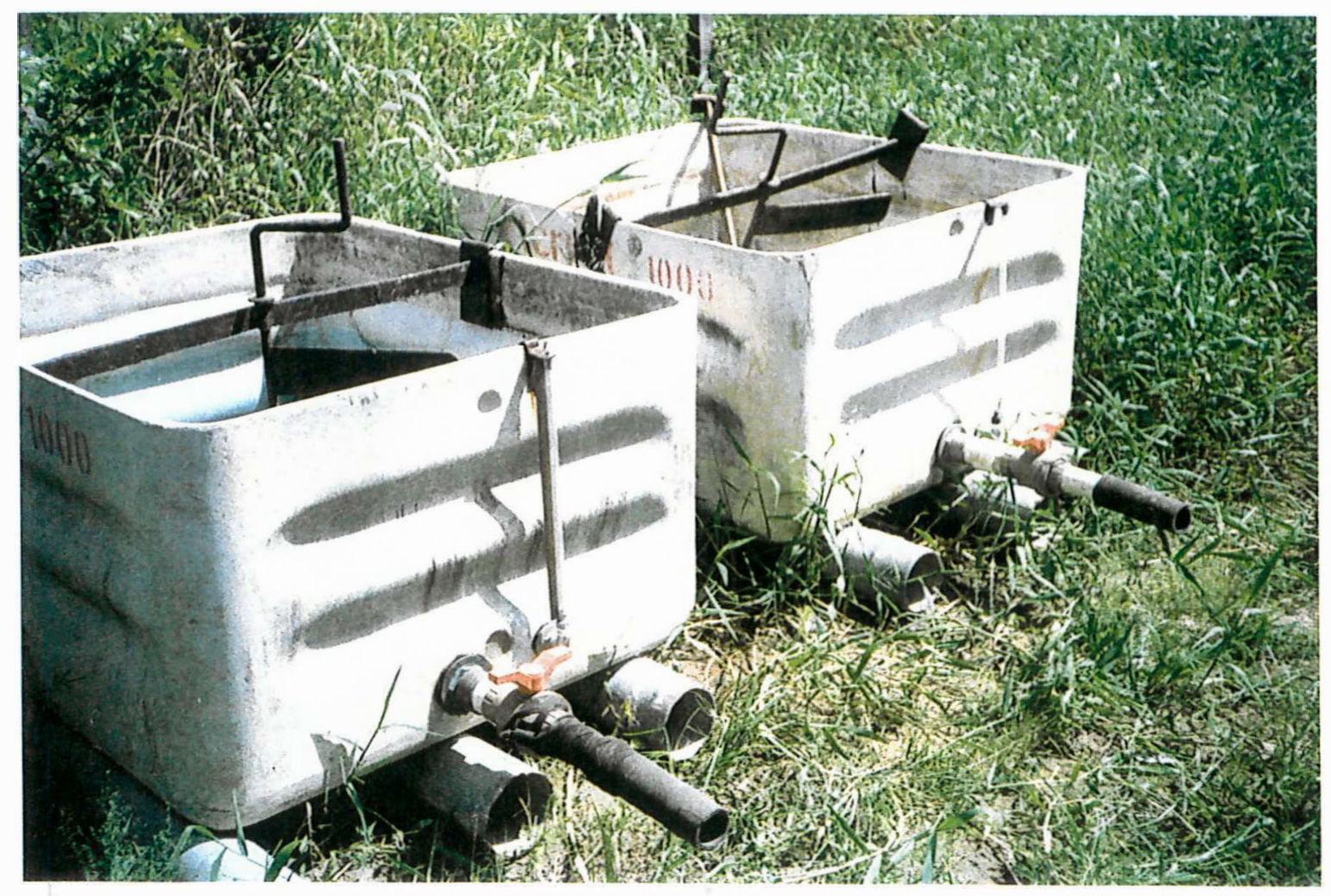


APÊNDICE 5

Controladores do nível do líquido no TC

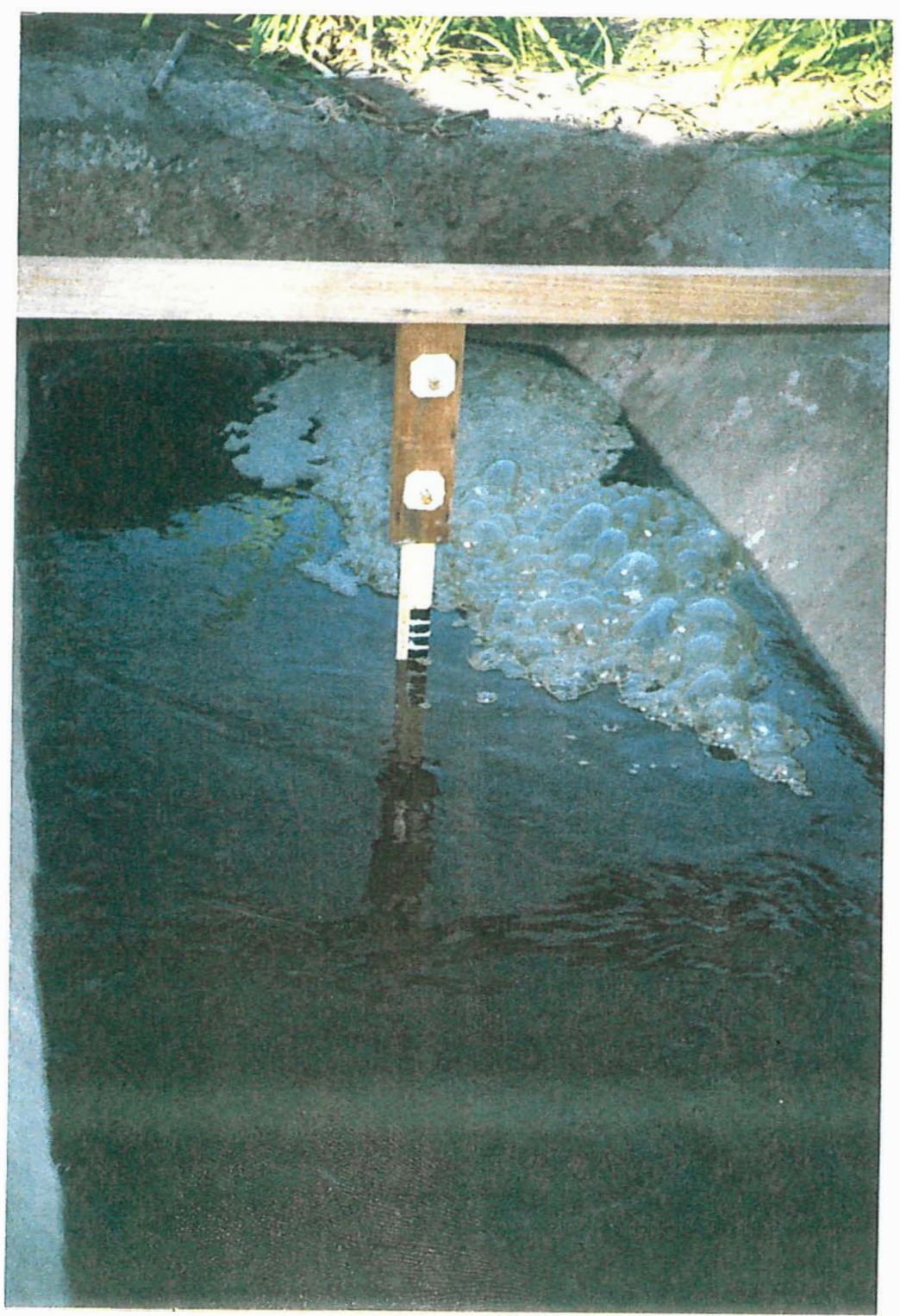


APÊNDICE 6

Medidores/controladores da lâmina de líquido no Sub-TCC.

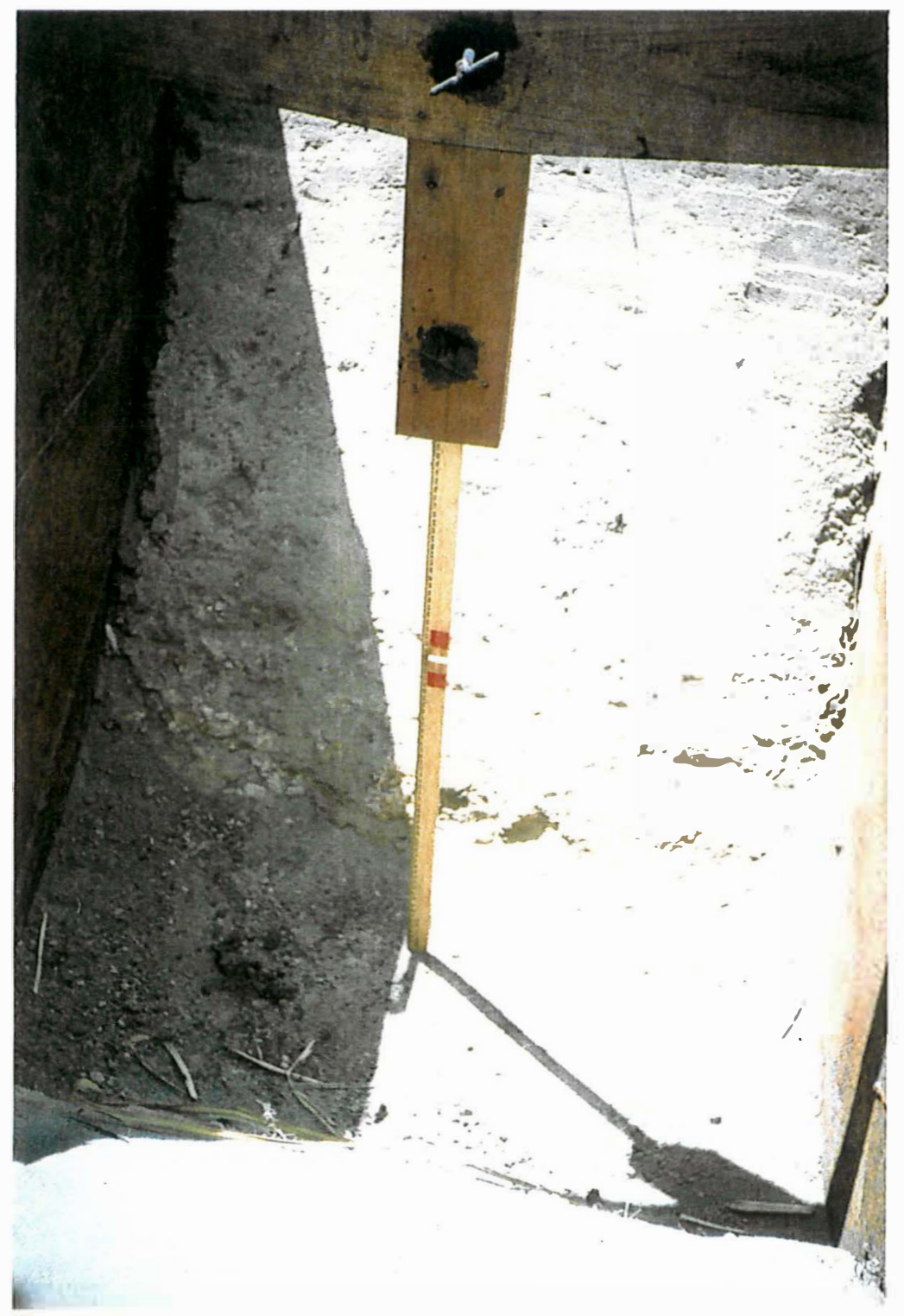




\section{APÊNDICE 7}

Comportas utilizadas para reter o líquido no Sub-TCC

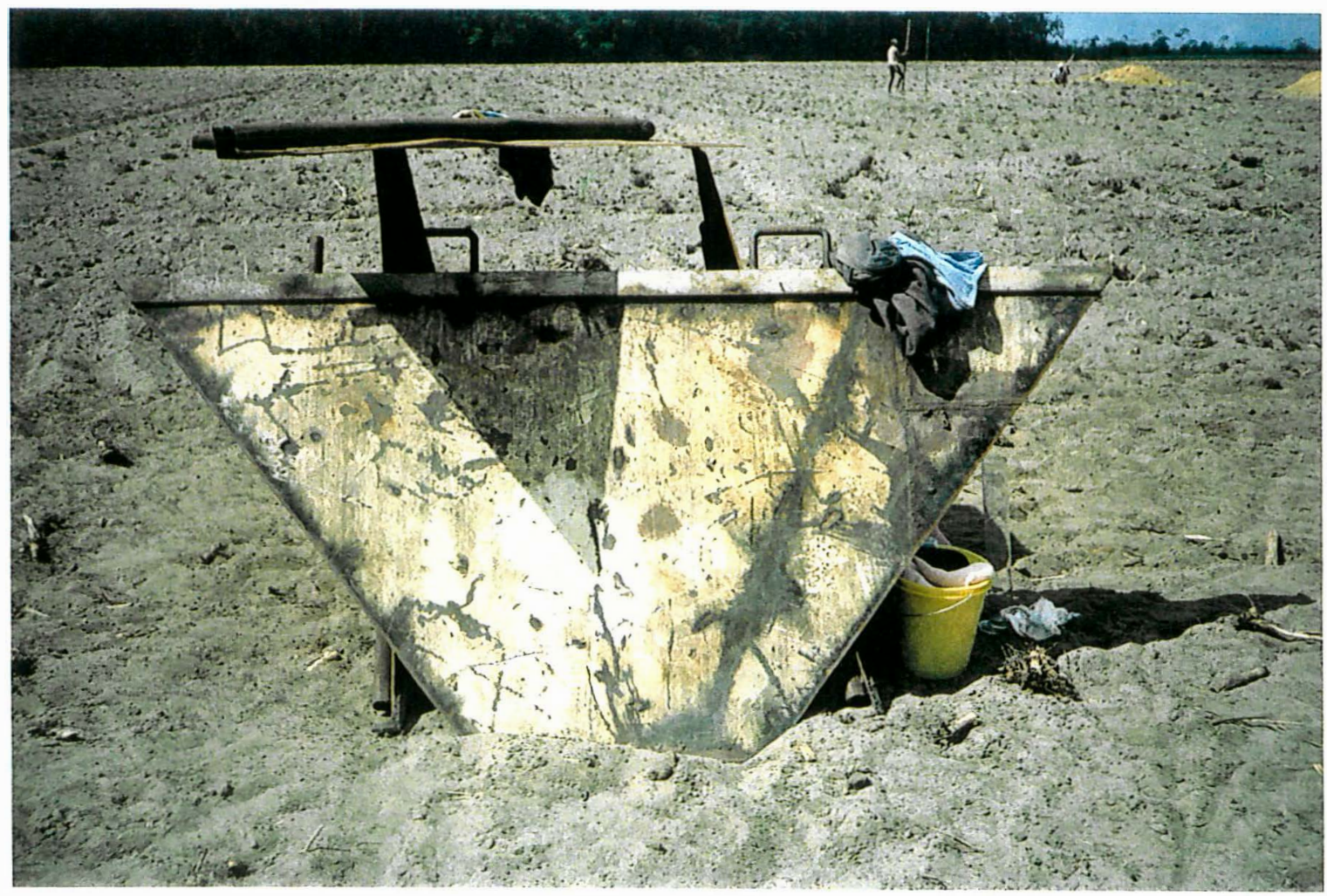




\section{APÊNDICE 8 \\ Deterninaçāo do volume médio do cillndro de Uhtand e da massa especifica do solo(pat)}

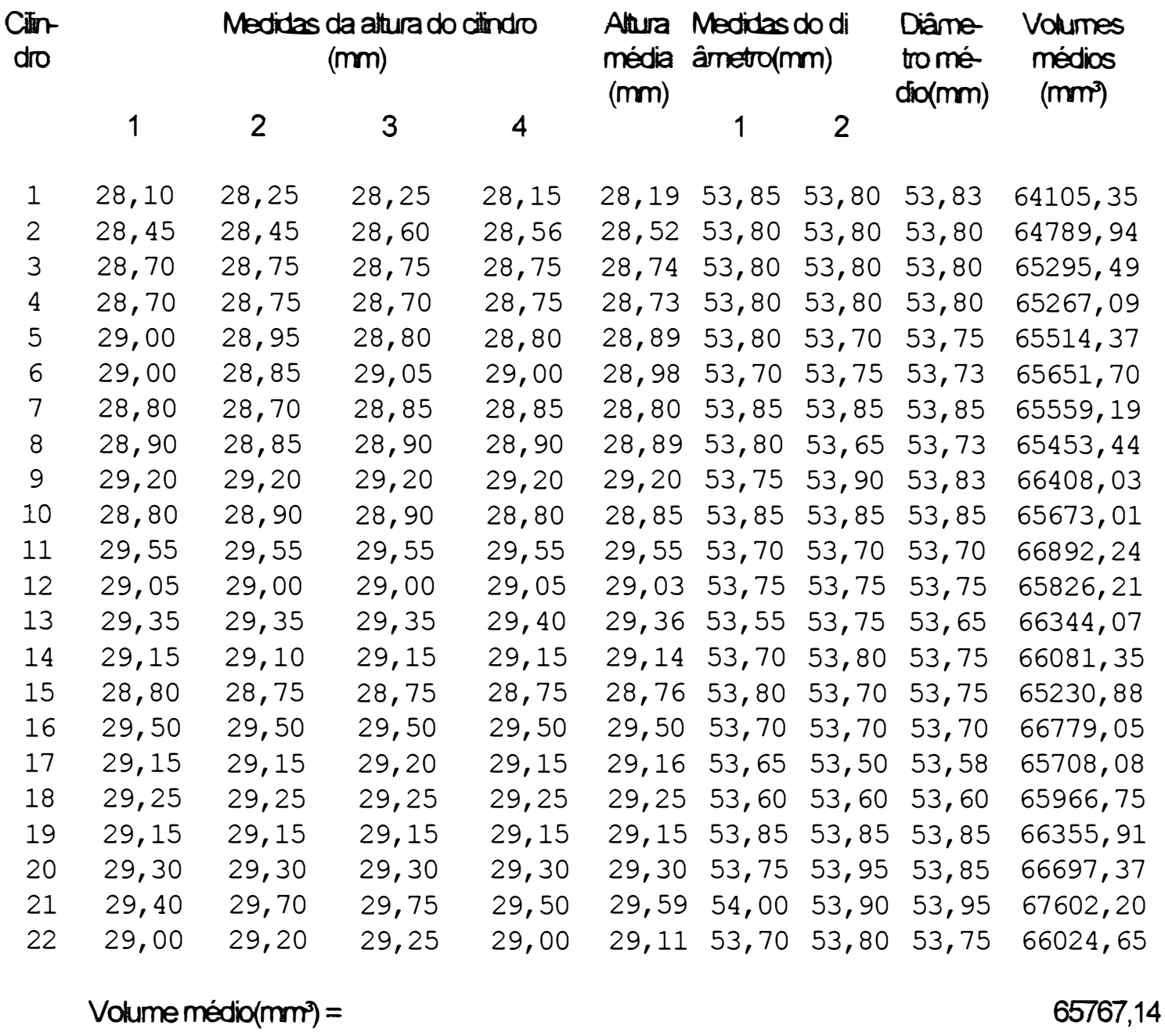

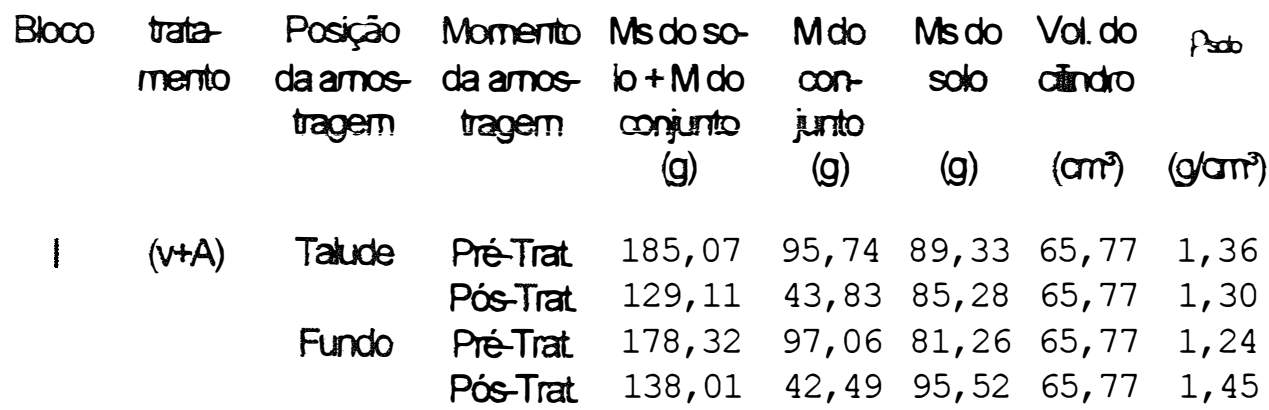




\begin{tabular}{|c|c|c|c|c|c|c|c|}
\hline$(v+V)$ & Talude & Pré-Trat & 171,86 & 88,59 & 83,27 & 65,77 & 1,27 \\
\hline & & Pós-Trat & 170,32 & 82,97 & 87,35 & 65,77 & 1,33 \\
\hline & Fundo & Pré-Trat & 177,1 & 85,25 & 91,85 & 65,77 & 1,40 \\
\hline & & Pós-Trat & 127,94 & 33,59 & 94,35 & 65,77 & 1,43 \\
\hline (v) & Talude & Pré-Trat & 168,72 & 85,13 & 83,59 & 65,77 & 1,27 \\
\hline & & Pós-Trat & 172,85 & 84,69 & 88,16 & 65,77 & 1,34 \\
\hline & Fundo & Pré-Trat & 171,03 & 86,23 & 84,8 & 65,77 & 1,29 \\
\hline & & Pós-Trat & 168,74 & 85,4 & 83,34 & 65,77 & 1,27 \\
\hline (A) & Talude & Pré-Trat & 161,34 & 83,85 & 77,49 & 65,77 & 1,18 \\
\hline & & Pós-Trat & 174,07 & 85,41 & 88,66 & 65,77 & 1,35 \\
\hline & Fundo & Pré-Trat & - & - & - & 65,77 & - \\
\hline & & Pós-Trat & - & - & - & 65,77 & - \\
\hline$M$ & Talude & Pré-Trat & 184,61 & 98,28 & 86,33 & 65,77 & 1,31 \\
\hline & & Pós-Trat & 138,82 & 44,71 & 94,11 & 65,77 & 1,43 \\
\hline & Fundo & Pré-Trat & 194,12 & 94,5 & 99,62 & 65,77 & 1,51 \\
\hline & & Pós-Trat & 150,49 & 44,21 & 106,3 & 65,77 & 1,62 \\
\hline$+A$ & Tahode & Pré-Trat & - & - & - & 65,77 & - \\
\hline & & Pós-Trat & - & - & - & 65,77 & - \\
\hline & Fundo & Pré-Trat & - & - & - & 65,77 & - \\
\hline & & Pós-Trat & - & - & - & 65,77 & - \\
\hline (a) & Tahode & Pré-Trat & 182,57 & 94,84 & 87,73 & 65,77 & 1,33 \\
\hline & & Pós-Trat & 187,74 & 93,68 & 94,06 & 65,77 & 1,43 \\
\hline & Fundo & Pré-Trat & 194,76 & 96,4 & 98,36 & 65,77 & 1,50 \\
\hline & & Pós-Trat & 182,53 & 95,87 & 86,66 & 65,77 & 1,32 \\
\hline$(v+A)$ & Tahode & Pré-Trat & & & & 65,77 & \\
\hline & & Pós-Trat & 184,6 & 93,54 & 91,06 & 65,77 & 1,38 \\
\hline & Fundo & Pré-Trat & 170,82 & 91,94 & 78,88 & 65,77 & 1,20 \\
\hline & & Pós-Trat & 184,08 & 94,68 & 89,4 & 65,77 & 1,36 \\
\hline$(v+V)$ & Tahode & Pré-Trat & 186,26 & 95,13 & 91,13 & 65,77 & 1,39 \\
\hline & & Pós-Trat & 186,31 & 91,61 & 94,7 & 65,77 & 1,44 \\
\hline & Fundo & Pré-Trat & 179 & 95,7 & 83,3 & 65,77 & 1,27 \\
\hline & & Pós-Trat & 182,91 & 99,15 & 83,76 & 65,77 & 1,27 \\
\hline (v) & Tahode & Pré-Trat & 182,65 & 94,37 & 88,28 & 65,77 & 1,34 \\
\hline & & Pós-Trat & 181,73 & 95,99 & 85,74 & 65,77 & 1,30 \\
\hline & Fundo & Pré-Trat & - & - & - & 65,77 & - \\
\hline & & Pós-Trat & - & - & - & 65,77 & - \\
\hline (A) & Tahode & Pré-Trat & 180 & 95,28 & 84,72 & 65,77 & 1,29 \\
\hline & & Pós-Trat & 180,75 & 92,5 & 88,25 & 65,77 & 1,34 \\
\hline & Fundo & Pré-Trat & 183,92 & 99,27 & 84,65 & 65,77 & 1,29 \\
\hline & & Pós-Trat & 181,68 & 91,62 & 90,06 & 65,77 & 1,37 \\
\hline$M$ & Tahode & Pré-Trat & 175,18 & 94,34 & 80,84 & 65,77 & 1,23 \\
\hline & & Pós-Trat & 181,3 & 91,71 & 89,59 & 65,77 & 1,36 \\
\hline & Fundo & PréTrat & 174 & 93,44 & 80,56 & 65,77 & 1,22 \\
\hline & & Pós-Trat & 171,17 & 93,29 & 77,88 & 65,77 & 1,18 \\
\hline$(a+A)$ & Tahode & Pré-Trat & 176,71 & 95,86 & 80,85 & 65,77 & 1,23 \\
\hline & & Pós-Trat & 176,99 & - & - & 65,77 & - \\
\hline & Fundo & Pré-Trat & 172,74 & 95,11 & 77,63 & 65,77 & 1,18 \\
\hline
\end{tabular}




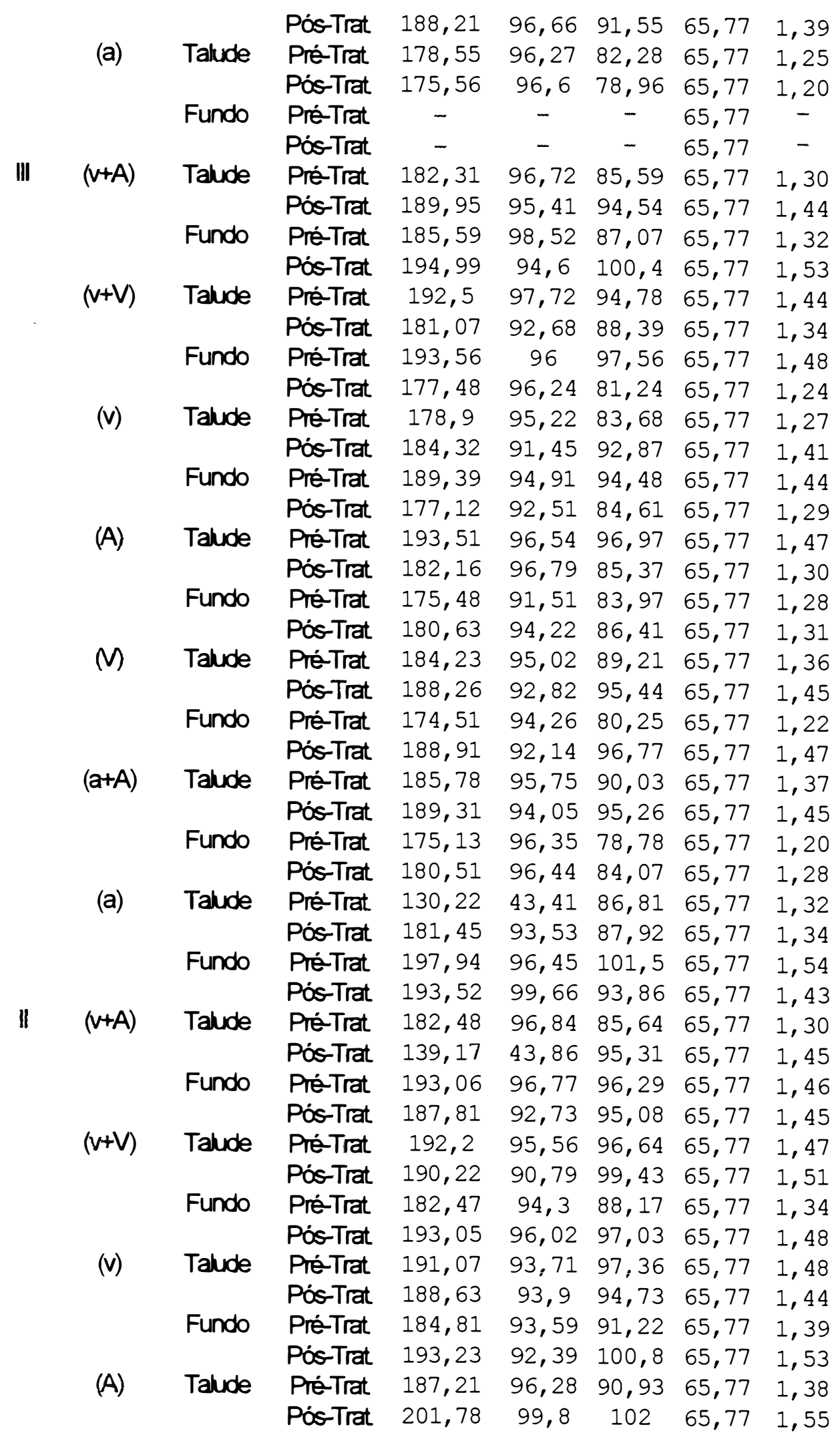




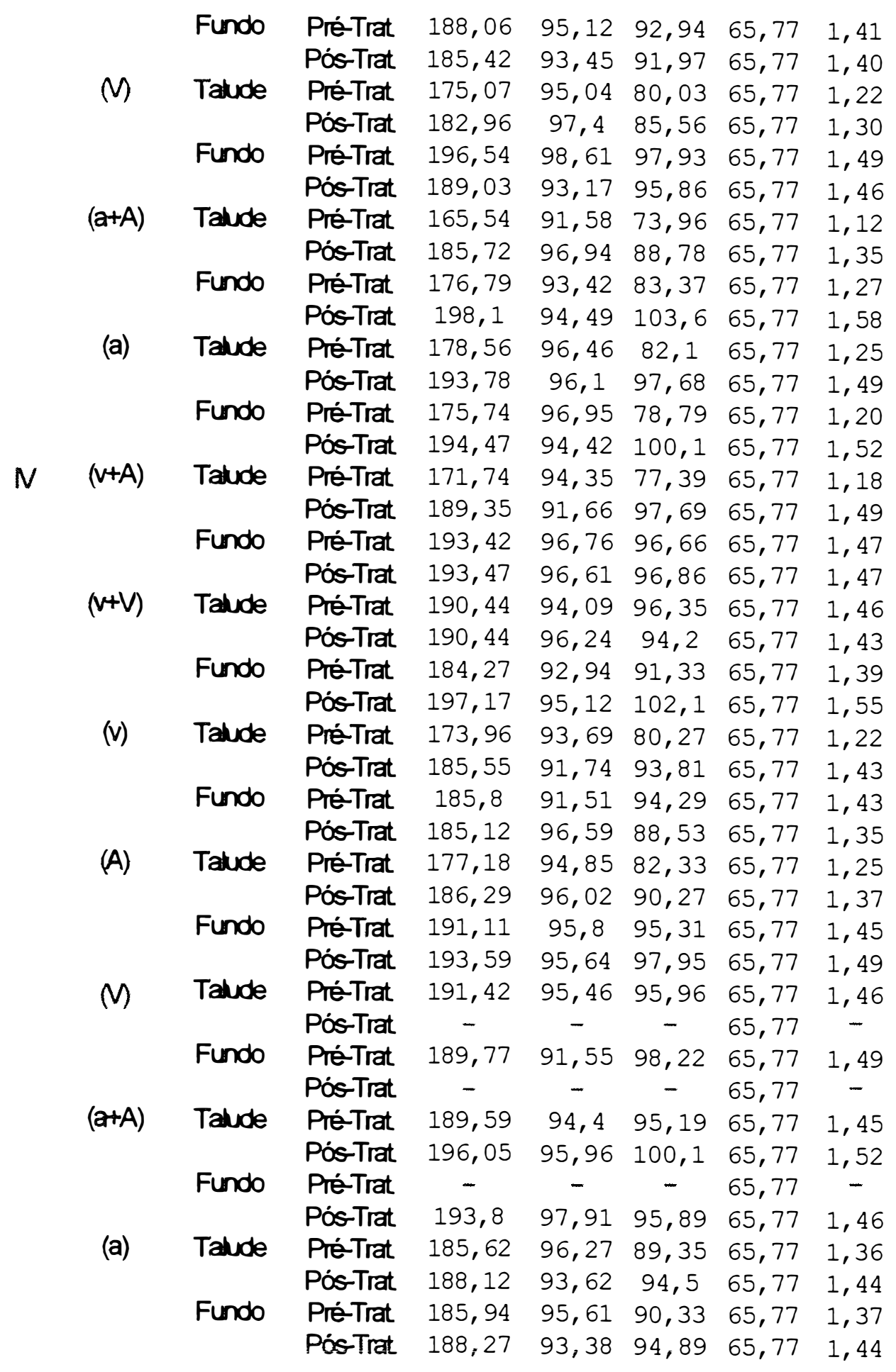

Média (v+A) Taude Pré-Trat

1,28

Pós-Trat

1,41

Fundo

Pré-Trat

1,34 


\begin{tabular}{|c|c|c|c|}
\hline & & Pós-Trat & 1,45 \\
\hline \multirow[t]{4}{*}{$(v+V)$} & Talude & Pré-Trat & 1,41 \\
\hline & & Pós-Trat & 1,41 \\
\hline & Fundo & Pré-Trat & 1,38 \\
\hline & & Pós-Trat & 1,39 \\
\hline \multirow[t]{4}{*}{ (v) } & Talude & Pré-Trat & 1,32 \\
\hline & & Pós-Trat & 1,38 \\
\hline & Fundo & Pré-Trat & 1,39 \\
\hline & & Pós-Trat & 1,36 \\
\hline \multirow[t]{4}{*}{ (A) } & Talude & Pré-Trat & 1,32 \\
\hline & & Pós-Trat & 1,38 \\
\hline & Fundo & Pré-Trat & 1,36 \\
\hline & & Pós-Trat & 1,39 \\
\hline \multirow[t]{4}{*}{$M$} & Talude & Pré-Trat & 1,31 \\
\hline & & Pós-Trat & 1,39 \\
\hline & Fundo & Pré-Trat & 1,39 \\
\hline & & Pós-Trat & 1,4 \\
\hline \multirow[t]{4}{*}{$(a+A)$} & Talude & Pré-Trat & 1,29 \\
\hline & & Pós-Trat & 1,4 \\
\hline & Fundo & Pré-Trat & 1,2 \\
\hline & & Pós-Trat & 1,4 \\
\hline \multirow[t]{4}{*}{ (a) } & Talude & Pré-Trat & 1,3 \\
\hline & & Pós-Trat & 1,3 \\
\hline & Fundo & Pré-Trat & 1,40 \\
\hline & & Pós-Trat & 1,4 \\
\hline
\end{tabular}

\begin{tabular}{|c|c|c|c|c|c|}
\hline \multicolumn{6}{|c|}{$\rho_{s c d}\left(g / a m^{3}\right)^{*}$} \\
\hline $3 b c$ & I & V & III & $\|$ & $N$ \\
\hline léd & 1,34 & 1,30 & 1,37 & 1,40 & 1,42 \\
\hline
\end{tabular}

*Vabores médios tomados por tratamento, na posição talude e no momento prétrotamento.

Trata Posição Momento

mento da amos da amos tragern tragem

(v+A) Talude Pré-Trat

Pós-Trat 1,30

Fundo Pré-Trat 1,24

Pós-Trat 1,45

1

Brocos

Média

V

H N N

$-$

1,30

1,44

$1,30 \quad 1,18$

1,38

1,20

1,36

1,53

$1,46 \quad 1,47$

$1,45 \quad 1,47$ 


\begin{tabular}{|c|c|c|c|c|c|c|c|}
\hline \multirow[t]{4}{*}{$(v+v)$} & Talude & Pré-Trat & 1,27 & 1,39 & 1,44 & 1,47 & 1,46 \\
\hline & & Pós-Trat & 1,33 & 1,44 & 1,34 & 1,51 & 1,43 \\
\hline & Fundo & Pré-Trat & 1,40 & 1,27 & 1,48 & 1,34 & 1,39 \\
\hline & & Pós-Trat & 1,43 & 1,27 & 1,24 & 1,48 & 1,55 \\
\hline \multirow[t]{4}{*}{ (v) } & Talude & Pré-Trat & 1,27 & 1,34 & 1,27 & 1,48 & 1,22 \\
\hline & & Pós-Trat & 1,34 & 1,30 & 1,41 & 1,44 & 1,43 \\
\hline & Fundo & Pré-Trat & 1,29 & - & 1,44 & 1,39 & 1,43 \\
\hline & & PósTrat & 1,27 & - & 1,29 & 1,53 & 1,35 \\
\hline \multirow[t]{4}{*}{ (A) } & Talude & Pré-Trat & 1,18 & 1,29 & 1,47 & 1,38 & 1,25 \\
\hline & & PósTrat & 1,35 & 1,34 & 1,30 & 1,55 & 1,3 \\
\hline & Fundo & Pré-Trat & - & 1,29 & 1,28 & 1,41 & 1,45 \\
\hline & & Pós-Trat & - & 1,37 & 1,31 & 1,40 & 1,49 \\
\hline \multirow[t]{4}{*}{$M$} & Talude & Pré-Trat & 1,31 & 1,23 & 1,36 & 1,22 & 1,46 \\
\hline & & PósTrat & 1,43 & 1,36 & 1,45 & 1,30 & - \\
\hline & Fundo & Pré-Trat & 1,51 & 1,22 & 1,22 & 1,49 & 1,49 \\
\hline & & Pós-Trat & 1,62 & 1,18 & 1,47 & 1,46 & - \\
\hline \multirow[t]{4}{*}{$(a+A)$} & Talude & Pré-Trat & - & 1,23 & 1,37 & 1,12 & 1,45 \\
\hline & & Pós-Trat & - & - & 1,45 & 1,35 & 1,52 \\
\hline & Findo & Pré-Trat & - & 1,18 & 1,20 & 1,27 & - \\
\hline & & PósTrat & - & 1,39 & 1,28 & 1,58 & 1,46 \\
\hline \multirow[t]{4}{*}{ (a) } & Talude & Pré-Trat & 1,33 & 1,25 & 1,32 & 1,25 & 1,36 \\
\hline & & Pós-Trat & 1,43 & 1,20 & 1,34 & 1,49 & 1,44 \\
\hline & Findo & Pré-Trat & 1,50 & - & 1,54 & 1,20 & 1,37 \\
\hline & & Pós-Trat & 1,32 & - & 1,43 & 1,52 & 1,4 \\
\hline
\end{tabular}

Média 


\section{APÊNDICE 9}

Valores de porosidades, \%, em função de tratarnentus, posição e momento da amos tagem.

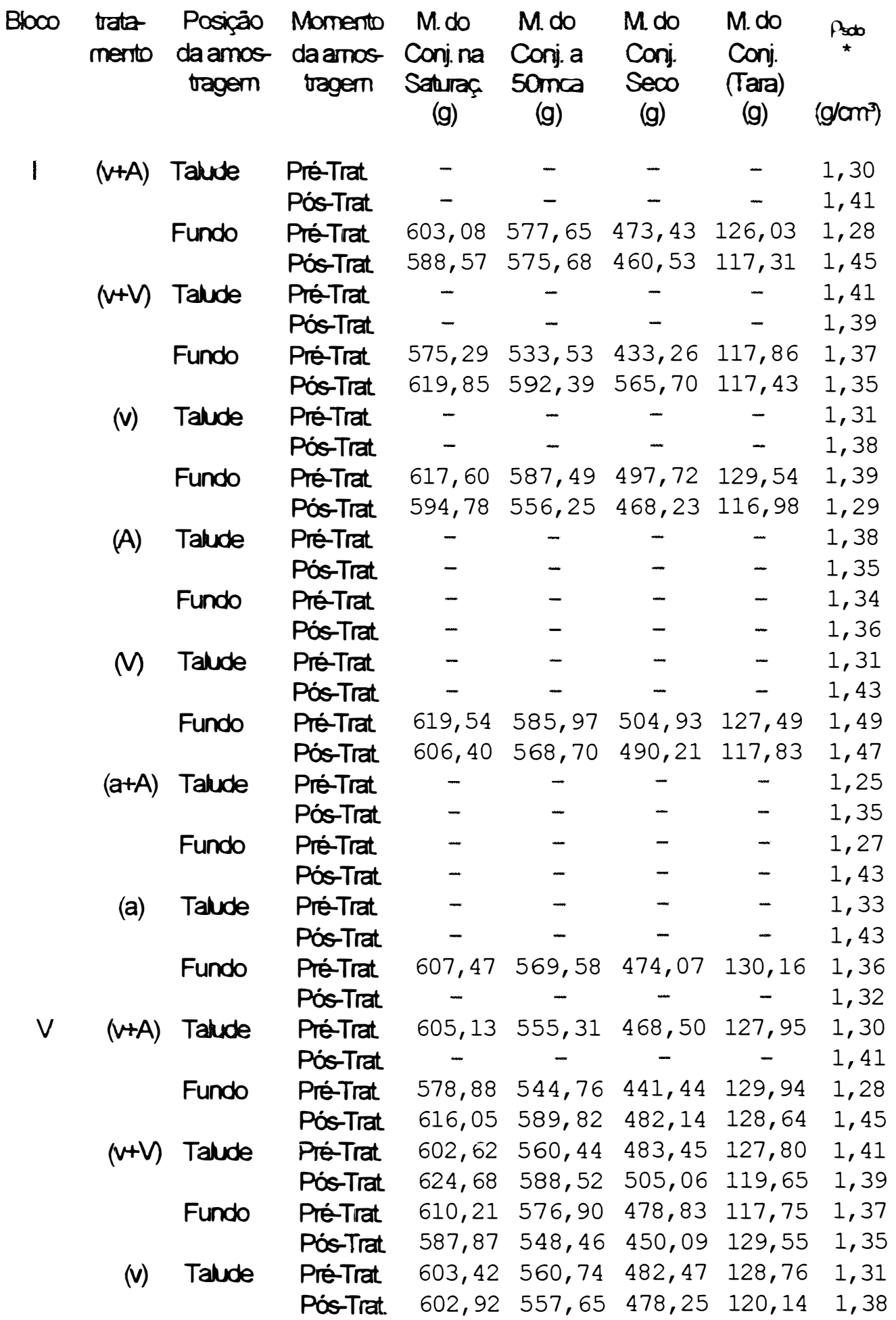




\begin{tabular}{|c|c|c|c|c|c|c|c|c|}
\hline & & Fundo & Pré-Trat & - & - & - & - & 1,39 \\
\hline & & & Pós-Trat & - & - & - & - & 1,29 \\
\hline & (A) & Tahude & Pré-Trat & 593,82 & 542,96 & 466,08 & 116,38 & 1,38 \\
\hline & & & PósTrat & 608,05 & 573,25 & 486,23 & 117,51 & 1,35 \\
\hline & & Fundo & Pré-Trat & 575,33 & 538,74 & 435,13 & 117,79 & 1,34 \\
\hline & & & Pós-Trat & 629,95 & 599,20 & 512,70 & 129,86 & 1,36 \\
\hline & $M$ & Talude & Pré-Trat & 611,25 & 558,55 & 477,30 & 126,52 & 1,31 \\
\hline & & & Pós-Trat & 601,30 & 549,79 & 464,83 & 117,39 & 1,43 \\
\hline & & Fundo & Pré-Trat & 606,19 & 579,09 & 479,25 & 119,24 & 1,49 \\
\hline & & & Pós-Trat & - & - & - & - & 1,47 \\
\hline & $(a+A)$ & Talude & Pré-Trat & 593,77 & 543,02 & 468,31 & 119,97 & 1,25 \\
\hline & & & Pós-Trat & 601,26 & 557,39 & 475,16 & 113,98 & 1,35 \\
\hline & & Fundo & Pré-Trat & 609,00 & 582,49 & 482,60 & 117,64 & 1,27 \\
\hline & & & PósTrat & 613,76 & 587,55 & 486,39 & 129,58 & 1,43 \\
\hline & (a) & Tahude & Pré-Trat & - & - & - & - & 1,33 \\
\hline & & & Pós-Trat & 596,63 & 554,26 & 465,91 & 116,65 & 1,43 \\
\hline & & Fundo & PréTrat & - & - & - & - & 1,36 \\
\hline & & & Pós-Trat & - & - & - & - & 1,32 \\
\hline III & $(v+A)$ & Tahude & Pré-Trat & - & - & - & - & 1,30 \\
\hline & & & Pós-Trat & - & - & - & - & 1,41 \\
\hline & & Fundo & Pré-Trat & 606,81 & 578,76 & 480,96 & 128,77 & 1,28 \\
\hline & & & Pós-Trat & 631,63 & 605,81 & 522,89 & 129,64 & 1,45 \\
\hline & $(v+V)$ & Tahude & Pré-Trat & - & - & - & - & 1,41 \\
\hline & & & Pós-Trat & - & - & - & - & 1,39 \\
\hline & & Fundo & Pré-Trat & 600,52 & 561,15 & 469,07 & 118,78 & 1,37 \\
\hline & & & Pós-Trat & - & - & - & - & 1,35 \\
\hline & (v) & Tahude & PréTrat & - & - & - & - & 1,31 \\
\hline & & & Pós-Trat & - & - & - & - & 1,38 \\
\hline & & Fundo & PréTrat & 598,72 & 566,60 & 471,09 & 117,95 & 1,39 \\
\hline & & & Pós-Trat & 606,06 & 582,43 & 482,78 & 128,33 & 1,29 \\
\hline & (A) & Tahude & Pré-Trat & - & - & - & - & 1,38 \\
\hline & & & Pós-Trat & - & - & - & - & 1,35 \\
\hline & & Fundo & Pré-Trat & 645,83 & 627,81 & 554,12 & 130,73 & 1,34 \\
\hline & & & Pós-Trat & 624,08 & 598,76 & 505,26 & 117,91 & 1,36 \\
\hline & $M$ & Tahude & PréTrat & - & - & - & - & 1,31 \\
\hline & & & Pós-Trat & - & - & - & - & 1,43 \\
\hline & & Fundo & PréTrat & 608,22 & 584,35 & 483,27 & 128,97 & 1,49 \\
\hline & & & Pós-Trat & 607,98 & 579,12 & 478,03 & 118,13 & 1,47 \\
\hline & $(a+A)$ & Tahude & PréTrat & - & - & - & - & 1,25 \\
\hline & & & Pós-Trat & - & - & - & - & 1,35 \\
\hline & & Fundo & PréTrat & 587,03 & 541,12 & 442,42 & 130,13 & 1,27 \\
\hline & & & Pós-Trat & 605,93 & 577,23 & 480,17 & 128,71 & 1,43 \\
\hline & (a) & Talude & Pré-Trat & - & - & - & - & 1,33 \\
\hline & & & Pós-Trat & - & - & - & - & 1,43 \\
\hline & & Fundo & PréTrat & 623,12 & 598,77 & 504,78 & 128,05 & 1,36 \\
\hline & & & Pós-Trat & 619,63 & 592,32 & 499,92 & 128,38 & 1,3 \\
\hline & $(v+A)$ & Talude & PréTrat & - & - & - & - & 1,3 \\
\hline
\end{tabular}




\begin{tabular}{|c|c|c|c|c|c|c|c|}
\hline & & Pós-Trat & - & - & - & - & 1,41 \\
\hline & Fundo & Pré-Trat & 597,52 & 566,62 & 470,09 & 129,81 & 1,28 \\
\hline & & Pós-Trat & 614,92 & 598,77 & 488,56 & 130,27 & 1,45 \\
\hline$(v+V)$ & Talude & Pré-Trat & - & - & - & - & 1,41 \\
\hline & & Pós-Trat & - & - & - & - & 1,39 \\
\hline & Fundo & Pré-Trat & 603,77 & 560,84 & 472,76 & 129,03 & 1,37 \\
\hline & & js-Trat & 630,70 & 605,98 & 509,55 & 119,28 & 1,35 \\
\hline (v) & Talude & Pré-Trat & - & - & - & - & 1,31 \\
\hline & & Pós-Trat & - & - & - & - & 1,38 \\
\hline & Fundo & Pré-Trat & 597,70 & 559,96 & 457,29 & 128,07 & 1,39 \\
\hline & & Pós-Trat & 600,59 & 575,05 & 475,26 & 117,42 & 1,29 \\
\hline (A) & Talude & Pré-Trat & - & - & - & - & 1,38 \\
\hline & & Pós-Trat & - & - & - & - & 1,35 \\
\hline & Fundo & Pré-Trat & 606,14 & 563,93 & 484,49 & 129,71 & 1,34 \\
\hline & & Pós-Trat & 609,16 & 573,58 & 481,44 & 128,21 & 1,36 \\
\hline$M$ & Talude & Pré-Trat & - & - & - & - & 1,31 \\
\hline & & Pós-Trat & - & - & - & - & 1,43 \\
\hline & Fundo & Pré-Trat & - & - & - & - & 1,49 \\
\hline & & Pós-Trat & 617,41 & 599,03 & 494,44 & 120,07 & 1,47 \\
\hline$(a+A)$ & Talude & Pré-Trat & - & - & - & - & 1,25 \\
\hline & & Pós & - & - & - & - & 1,35 \\
\hline & Fundo & Pré-Trat & 604,43 & 571,54 & 480,26 & 117,32 & 1,27 \\
\hline & & Pós-Trat & 596,49 & 556,96 & 468,98 & 118,60 & 1,43 \\
\hline (a) & Talude & Pré-Trat & - & - & - & - & 1,33 \\
\hline & & Pós-Trat & - & - & - & - & 1,43 \\
\hline & Fundo & Pré-Trat & 597,66 & 554,87 & 461,01 & 116,05 & 1,36 \\
\hline & & Pós-Trat & 607,86 & 573,11 & 480,55 & 117,64 & 1,32 \\
\hline$(v+A)$ & Talude & Pré-Trat & - & - & - & - & 1,30 \\
\hline & & Pós-Trat & - & - & - & - & 1,41 \\
\hline & Fundo & Plé-Trat & 618,38 & 586,39 & 495,10 & 129,87 & 1,28 \\
\hline & & Pós-Trat & 611,88 & 586,76 & 488,59 & 117,75 & 1,45 \\
\hline$(v+V)$ & Talude & Pré-Trat & - & - & - & - & 1,41 \\
\hline & & Pós-Trat & - & - & - & - & 1,39 \\
\hline & Fundo & Pré-Trat & 596,08 & 550,51 & 460,17 & 117,98 & 1,37 \\
\hline & & Pós-Trat & 626,39 & 596,93 & 504,56 & 118,69 & 1,35 \\
\hline (v) & Talude & Pré-Trat & - & - & - & - & 1,31 \\
\hline & & Pós-Trat & - & - & - & - & 1,38 \\
\hline & Fundo & Pré-Trat & 609,28 & 570,17 & 476,66 & 117,36 & 1,39 \\
\hline & & Pós-Trat & 620,01 & 585,33 & 491,18 & 129,42 & 1,29 \\
\hline (A) & Talude & Pré-Trat & - & - & - & - & 1,38 \\
\hline & & Pós-Trat & - & - & - & - & 1,35 \\
\hline & Fundo & Plé-Trat & 630,28 & 602,60 & 514,44 & 117,93 & 1,34 \\
\hline & & Pós-Trat & 606,49 & 574,36 & 486,88 & 116,95 & 1,36 \\
\hline$M$ & Talude & PréTrat & - & - & - & - & 1,31 \\
\hline & & Pós-Trat & - & - & - & - & 1,43 \\
\hline & Fundo & Pré-Trat & 600,35 & 558,16 & 468,46 & 117,32 & 1,4 \\
\hline & & Pós-Trat & 599,10 & 568,07 & 468,42 & 130,80 & 1,4 \\
\hline
\end{tabular}




\begin{tabular}{cllccccc} 
(a+A) Talude & Pré-Trat & - & - & - & - & 1,25 \\
& Pós-Trat & - & - & - & - & 1,35 \\
Fundo & Pré-Trat & 602,28 & 545,15 & 452,19 & 119,56 & 1,27 \\
& Pós-Trat & 630,89 & 603,29 & 512,7 & 117,67 & 1,43 \\
(a) Talude & Pré-Trat & - & - & - & - & 1,33 \\
& Pós-Trat & - & - & - & - & 1,43 \\
\multirow{2}{*}{ Fundo } & Pré-Trat & 603,48 & 566,50 & 479,98 & 129,19 & 1,36 \\
& & Pós-Trat & 607,29 & 579,91 & 487,45 & 119,06 & 1,32
\end{tabular}

* Média de tratamentos, por posição e por mornento de amostagem,

\begin{tabular}{|c|c|c|c|c|c|c|}
\hline Bloco & $\begin{array}{l}\text { trata } \\
\text { mento }\end{array}$ & $\begin{array}{c}\text { Posição } \\
\text { da arnos } \\
\text { tragem }\end{array}$ & $\begin{array}{c}\text { Momento } \\
\text { da armos } \\
\text { tagem }\end{array}$ & $\begin{array}{l}\text { Macra } \\
\text { porosi } \\
\text { dade } \\
(\%)\end{array}$ & $\begin{array}{l}\text { Micro } \\
\text { porosi- } \\
\text { dade } \\
(\%)\end{array}$ & $\begin{array}{l}\text { Porosi } \\
\text { dade } \\
\text { total } \\
(\%)\end{array}$ \\
\hline \multirow[t]{28}{*}{ I } & \multirow[t]{4}{*}{$(v+A)$} & \multirow[t]{2}{*}{ Talude } & PréTrat & - & - & - \\
\hline & & & Pós-Trat & - & - & - \\
\hline & & \multirow[t]{2}{*}{ Fundo } & Pré-Trat & 6,34 & 25,99 & 32,33 \\
\hline & & & PósTrat & 3,53 & 31,57 & 35,10 \\
\hline & \multirow[t]{4}{*}{$(v+V)$} & \multirow[t]{2}{*}{ Talude } & Pré-Trat & - & - & - \\
\hline & & & Pós-Trat & - & - & - \\
\hline & & \multirow[t]{2}{*}{ Fundo } & Pré-Trat & 11,22 & 26,94 & 38,15 \\
\hline & & & Pós-Trat & 7,11 & 6,91 & 14,02 \\
\hline & \multirow[t]{4}{*}{ (v) } & \multirow[t]{2}{*}{ Talude } & Pré-Trat & - & - & - \\
\hline & & & Pós-Trat & - & - & - \\
\hline & & \multirow[t]{2}{*}{ Fundo } & Pré-Trat & 7,83 & 23,33 & 31,16 \\
\hline & & & PósTrat & 9,66 & 22,07 & 31,73 \\
\hline & \multirow[t]{4}{*}{ (A) } & \multirow[t]{2}{*}{ Tahude } & Pré-Trat & - & - & - \\
\hline & & & Pós-Trat & - & - & - \\
\hline & & \multirow[t]{2}{*}{ Fundo } & Pré-Trat & - & - & - \\
\hline & & & Pós-Trat & - & - & - \\
\hline & \multirow[t]{4}{*}{$M$} & \multirow[t]{2}{*}{ Tahude } & Pré-Trat & - & - & - \\
\hline & & & Pós-Trat & - & - & - \\
\hline & & \multirow[t]{2}{*}{ Fundo } & Pré-Trat & 9,12 & 22,03 & 31,15 \\
\hline & & & Pós-Trat & 10,20 & 21,24 & 31,44 \\
\hline & \multirow[t]{4}{*}{$(a+A)$} & \multirow[t]{2}{*}{ Talude } & Pré-Trat & - & - & - \\
\hline & & & Pós-Trat & - & - & - \\
\hline & & \multirow[t]{2}{*}{ Fundo } & Pré-Trat & - & - & - \\
\hline & & & Pós-Trat & - & - & - \\
\hline & \multirow[t]{4}{*}{ (a) } & \multirow[t]{2}{*}{ Tahude } & Pré-Trat & - & - & - \\
\hline & & & Pós-Trat & - & - & - \\
\hline & & \multirow[t]{2}{*}{ Fundo } & Pré-Trat & 9,81 & 24,73 & 34,53 \\
\hline & & & Pós-Trat & - & - & - \\
\hline V & ) & Tahude & Pré-Trat & 12,50 & 21,78 & 34,28 \\
\hline
\end{tabular}




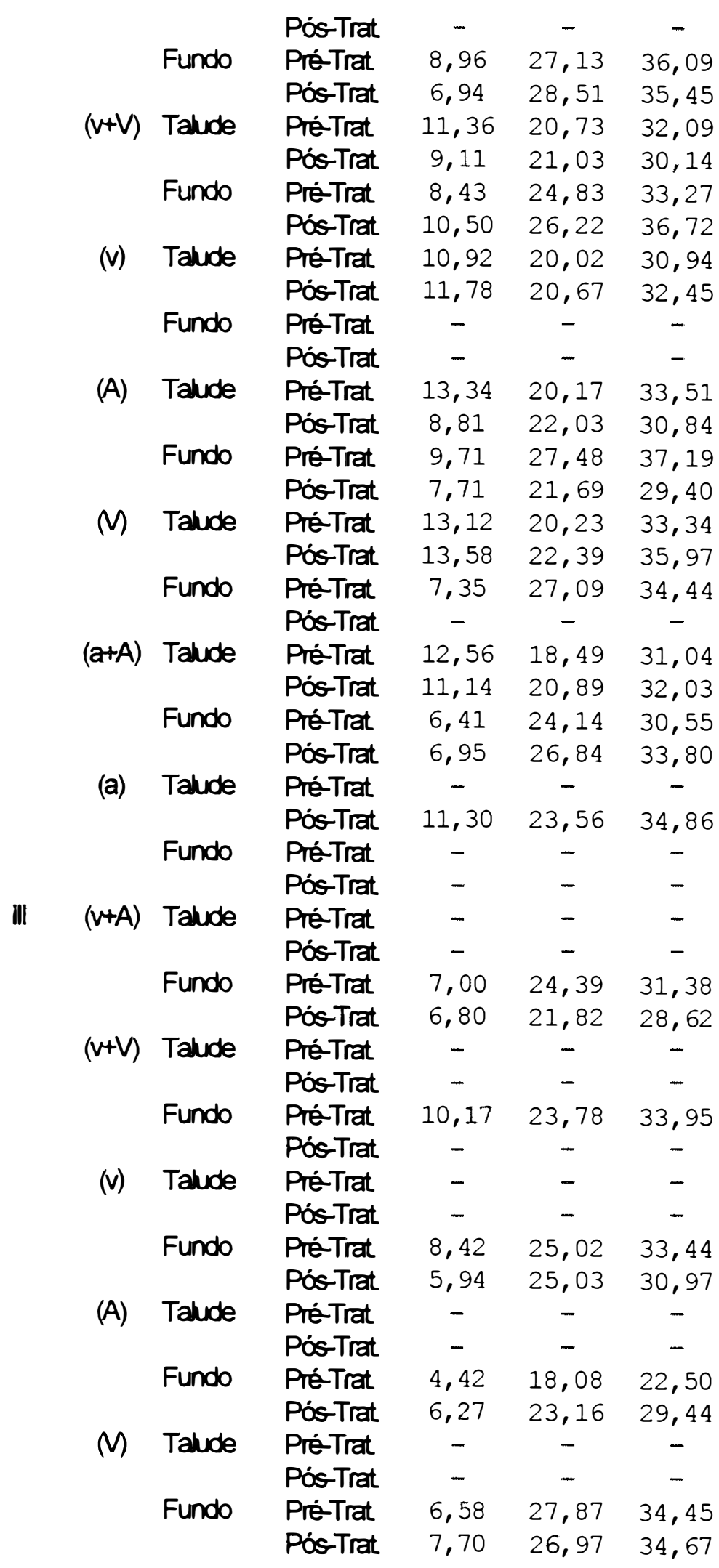




\begin{tabular}{|c|c|c|c|c|c|c|}
\hline & $(a+A)$ & Talude & Pré-Trat & - & - & - \\
\hline & & & Pós-Trat & - & - & - \\
\hline & & Fundo & Pré-Trat & 11,76 & 25,27 & 37,03 \\
\hline & & & Pós-Trat & 7,72 & 26,12 & 33,85 \\
\hline & (a) & Talude & Pré-Trat & - & - & - \\
\hline & & & Pós-Trat & - & - & - \\
\hline & & Fundo & Pré-Trat & 6,16 & 23,77 & 29,93 \\
\hline & & & Pós-Trat & 6,81 & 23,03 & 29,84 \\
\hline ॥ & $(v+A)$ & Talude & Pré-Trat & - & - & - \\
\hline & & & Pós-Trat & - & - & - \\
\hline & & Fundo & PréTrat & 7,86 & 24,55 & 32,40 \\
\hline & & & Pós-Trat & 4,32 & 29,51 & 33,84 \\
\hline & $(v+V)$ & Talude & Pré-Trat & - & - & - \\
\hline & & & Pós-Trat & - & - & - \\
\hline & & Fundo & Pré-Trat & 11,24 & 23,06 & 34,30 \\
\hline & & & Pós-Trat & 6,03 & 23,51 & 29,53 \\
\hline & (v) & Talude & Pré-Trat & - & - & - \\
\hline & & & Pós-Trat & - & - & - \\
\hline & & Fundo & Pré-Trat & 10,00 & 27,21 & 37,22 \\
\hline & & & Pós-Trat & 6,34 & 24,78 & 31,12 \\
\hline & (A) & Talude & Pré-Trat & - & - & - \\
\hline & & & Pós-Trat & - & - & - \\
\hline & & Fundo & Pré-Trat & 10,92 & 20,56 & 31,48 \\
\hline & & & Pós-Trat & 9,18 & 23,78 & 32,96 \\
\hline & $M$ & Talude & Pré-Trat & - & - & - \\
\hline & & & Pós-Trat & - & - & - \\
\hline & & Fundo & Pré-Trat & - & - & - \\
\hline & & & Pós-Trat & 4,87 & 27,70 & 32,56 \\
\hline & $(a+A)$ & Talude & Pré-Trat & - & - & - \\
\hline & & & Pós-Trat & - & - & - \\
\hline & & Fundo & Pré-Trat & 8,02 & 22,27 & 30,29 \\
\hline & & & Pós-Trat & 10,61 & 23,62 & 34,23 \\
\hline & (a) & Talude & Pré-Trat & - & - & - \\
\hline & & & Pós-Trat & - & - & - \\
\hline & & Fundo & Pré-Trat & 10,96 & 24,05 & 35,01 \\
\hline & & & Pós-Trat & 8,64 & 23,01 & 31,65 \\
\hline & $(v+A)$ & Talude & Pré-Trat & - & - & - \\
\hline & & & Pós-Trat & - & - & - \\
\hline & & Fundo & Pré-Trat & 7,83 & 22,34 & 30,17 \\
\hline & & & Pós-Trat & 6,63 & 25,90 & 32,53 \\
\hline & $(v+V)$ & Talude & Pré-Trat & - & - & - \\
\hline & & & Pós-Trat & - & - & - \\
\hline & & Fundo & Pré-Trat & 11,82 & 23,42 & 35,24 \\
\hline & & & Pós-Trat & 7,23 & 22,66 & 29,89 \\
\hline & (v) & Talude & Pré-Trat & - & - & - \\
\hline & & & Pós-Trat & - & - & - \\
\hline & & Fundo & Pré-Trat & 10,00 & 23,91 & 33,91 \\
\hline
\end{tabular}




\begin{tabular}{|c|c|c|c|c|c|}
\hline & & Pós-Trat & 8,47 & 23,00 & 31,48 \\
\hline \multirow{4}{*}{ (A) } & Tahude & Pré-Trat & - & - & - \\
\hline & & Pós-Trat & - & - & - \\
\hline & Fundo & Pré-Trat & 6,72 & 21,41 & 28,13 \\
\hline & & Pós-Trat & 8,20 & 22,34 & 30,54 \\
\hline \multirow[t]{4}{*}{$M$} & Talude & Pré-Trat & - & - & - \\
\hline & & Pós-Trat & - & - & - \\
\hline & Fundo & Pré-Trat & 11,48 & 24,40 & 35,88 \\
\hline & & Pós-Trat & 8,61 & 27,65 & 36,26 \\
\hline \multirow[t]{4}{*}{$(a+A)$} & Talude & PréTrat & - & - & - \\
\hline & & Pós-Trat & - & - & - \\
\hline & Fundo & Pré-Trat & 13,87 & 22,56 & 36,43 \\
\hline & & Pós-Trat & 7,00 & 22,97 & 29,96 \\
\hline \multirow[t]{4}{*}{ (a) } & Talude & Pré-Trat & - & - & - \\
\hline & & Pós-Trat & - & - & - \\
\hline & Fundo & Pré-Trat & 9,69 & 22,68 & 32,38 \\
\hline & & PósTrat & 6,86 & 23,18 & 30,04 \\
\hline
\end{tabular}

\begin{tabular}{|c|c|c|c|c|c|c|}
\hline \multirow{4}{*}{\multicolumn{2}{|c|}{ Média }} & \multirow[t]{2}{*}{ Talude } & Pré-Trat & - & - & - \\
\hline & & & Pós-Trat & - & - & - \\
\hline & & \multirow[t]{2}{*}{ Fundo } & Pré-Trat & 7,60 & 24,88 & 32,48 \\
\hline & & & Pós-Trat & 5,65 & 27,46 & 33,11 \\
\hline & \multirow[t]{4}{*}{$(v+V)$} & \multirow[t]{2}{*}{ Talude } & Pré-Trat & - & - & - \\
\hline & & & Pós-Trat & - & - & - \\
\hline & & \multirow[t]{2}{*}{ Fundo } & Pié-Trat & 10,58 & 24,41 & 34,98 \\
\hline & & & Pós-Trat & 7,72 & 19,82 & 27,54 \\
\hline & \multirow[t]{4}{*}{ (v) } & \multirow[t]{2}{*}{ Talude } & Pré-Trat & - & - & - \\
\hline & & & Pós-Trat & - & - & - \\
\hline & & \multirow[t]{2}{*}{ Fundo } & Pié-Trat & 9,06 & 24,87 & 33,93 \\
\hline & & & Pós-Trat & 7,60 & 23,72 & 31,32 \\
\hline & \multirow[t]{4}{*}{ (A) } & \multirow[t]{2}{*}{ Talude } & Pré-Trat & - & - & - \\
\hline & & & Pós-Trat & - & - & - \\
\hline & & \multirow[t]{2}{*}{ Fundo } & Pié-Trat & 7,94 & 21,88 & 29,82 \\
\hline & & & Pós-Trat & 7,84 & 22,74 & 30,59 \\
\hline & \multirow[t]{4}{*}{$M$} & \multirow[t]{2}{*}{ Talude } & Pré-Trat & - & - & - \\
\hline & & & Pós-Trat & - & - & - \\
\hline & & \multirow[t]{2}{*}{ Fundo } & Pré-Trat & 8,63 & 25,35 & 33,98 \\
\hline & & & Pós-Trat & 7,85 & 25,89 & 33,74 \\
\hline & \multirow[t]{4}{*}{$(a+A)$} & \multirow[t]{2}{*}{ Talude } & Pré-Trat & - & - & - \\
\hline & & & PósTrat & - & - & - \\
\hline & & \multirow[t]{2}{*}{ Fundo } & Pié-Trat & 10,01 & 23,56 & 33,57 \\
\hline & & & Pós-Trat & 8,07 & 24,89 & 32,96 \\
\hline & \multirow[t]{4}{*}{ (a) } & \multirow[t]{2}{*}{ Talude } & Pré-Trat & - & - & - \\
\hline & & & Pós-Trat & - & - & - \\
\hline & & \multirow[t]{2}{*}{ Fundo } & Pré-Trat & 9,16 & 23,81 & 32,96 \\
\hline & & & Pós-Trat & 7,44 & 23,07 & 30,51 \\
\hline
\end{tabular}


Macoporasidad $=$ \%).

\begin{tabular}{|c|c|c|c|c|c|c|c|c|}
\hline \multirow[t]{2}{*}{ Bloco } & \multirow{2}{*}{$\begin{array}{l}\text { Trata } \\
\text { mento }\end{array}$} & \multirow{2}{*}{$\begin{array}{c}\text { Posicão } \\
\text { da amos } \\
\text { tagem }\end{array}$} & \multirow{2}{*}{$\begin{array}{c}\text { Momento } \\
\text { da amos } \\
\text { tragem }\end{array}$} & \multicolumn{5}{|c|}{ Blocos } \\
\hline & & & & 1 & V & III & $\|$ & $N$ \\
\hline \multirow[t]{14}{*}{ Média } & \multirow[t]{2}{*}{$(v+A)$} & \multirow[t]{2}{*}{ Fundo } & Pré-Trat & 6,34 & 8,96 & 7,00 & 7,86 & 7,83 \\
\hline & & & Pós-Trat & 3,53 & 6,94 & 6,80 & 4,32 & 6,63 \\
\hline & \multirow[t]{2}{*}{$(v+V)$} & \multirow[t]{2}{*}{ Fundo } & Pré-Trat & 11,22 & 8,43 & 10,17 & 11,24 & 11,82 \\
\hline & & & Pós-Trat & 7,11 & 10,50 & - & 6,03 & 7,23 \\
\hline & \multirow[t]{2}{*}{ (v) } & \multirow[t]{2}{*}{ Fundo } & PréTrat & 7,83 & - & 8,42 & 10,00 & 10,00 \\
\hline & & & Pós-Trat & 9,66 & - & 5,94 & 6,34 & 8,47 \\
\hline & \multirow[t]{2}{*}{ (A) } & \multirow[t]{2}{*}{ Fundo } & Pré-Trat & - & 9,71 & 4,42 & 10,92 & 6,72 \\
\hline & & & Pós-Trat & - & 7,71 & 6,27 & 9,18 & 8,20 \\
\hline & \multirow[t]{2}{*}{$M$} & \multirow[t]{2}{*}{ Fundo } & Pré-Trat & 9,12 & 7,35 & 6,58 & - & 11,48 \\
\hline & & & Pós-Trat & 10,20 & - & 7,70 & 4,87 & 8,61 \\
\hline & \multirow[t]{2}{*}{$(a+A)$} & \multirow[t]{2}{*}{ Fundo } & Pré-Trat & - & 6,41 & 11,76 & 8,02 & 13,87 \\
\hline & & & Pós-Trat & - & 6,95 & 7,72 & 10,61 & 7,00 \\
\hline & \multirow[t]{2}{*}{ (a) } & \multirow[t]{2}{*}{ Fundo } & Pré-Trat & 9,81 & - & 6,16 & 10,96 & 9,69 \\
\hline & & & Pós-Trat & - & - & 6,81 & 8,64 & 6,86 \\
\hline
\end{tabular}

Mugoprasitade(\%).

\begin{tabular}{|c|c|c|c|c|c|c|c|c|}
\hline \multirow[t]{2}{*}{ Bboo } & \multirow{2}{*}{$\begin{array}{l}\text { Trata } \\
\text { mento }\end{array}$} & Posição & Mormerto & \multicolumn{5}{|c|}{ Blocos } \\
\hline & & tagem & tragem & 1 & V & III & $\|$ & $N$ \\
\hline \multirow[t]{12}{*}{ Média } & \multirow[t]{2}{*}{$(v+A)$} & \multirow[t]{2}{*}{ Fundo } & Pré-Trat & 25,99 & 27,13 & 24,39 & 24,55 & 22,34 \\
\hline & & & Pós-Trat & 31,57 & 28,51 & 21,82 & 29,51 & 25,90 \\
\hline & \multirow[t]{2}{*}{$(v+V)$} & \multirow[t]{2}{*}{ Fundo } & Pré-Trat & 26,94 & 24,83 & 23,78 & 23,06 & 23,42 \\
\hline & & & Pós-Trat & 6,91 & 26,22 & - & 23,51 & 22,66 \\
\hline & \multirow[t]{2}{*}{ (v) } & \multirow[t]{2}{*}{ Fundo } & Pré-Trat & 23,33 & - & 25,02 & 27,21 & 23,91 \\
\hline & & & Pós-Trat & 22,07 & - & 25,03 & 24,78 & 23,00 \\
\hline & \multirow[t]{2}{*}{ (A) } & \multirow[t]{2}{*}{ Fundo } & Pré-Trat & - & 27,48 & 18,08 & 20,56 & 21,41 \\
\hline & & & Pós-Trat & - & 21,69 & 23,16 & 23,78 & 22,34 \\
\hline & \multirow[t]{2}{*}{$M$} & \multirow[t]{2}{*}{ Fundo } & Pré-Trat & 22,03 & 27,09 & 27,87 & - & 24,40 \\
\hline & & & PósTrat & 21,24 & - & 26,97 & 27,70 & 27,65 \\
\hline & \multirow[t]{2}{*}{$(a+A)$} & \multirow[t]{2}{*}{ Fundo } & Pré-Trat & - & 24,14 & 25,27 & 22,27 & 22,56 \\
\hline & & & Pós-Trat & - & 26,84 & 26,12 & 23,62 & 22,97 \\
\hline
\end{tabular}

Média 


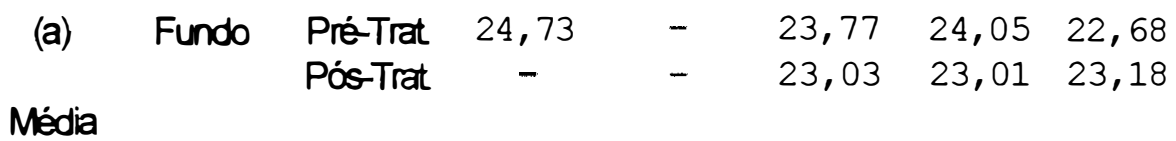

Porosidade total(\%).

\begin{tabular}{|c|c|c|c|c|c|c|c|c|}
\hline \multirow[t]{2}{*}{ Bloco } & \multirow{2}{*}{$\begin{array}{l}\text { Trata } \\
\text { mento }\end{array}$} & \multirow{2}{*}{$\begin{array}{l}\text { Posição } \\
\text { da amos } \\
\text { tagem }\end{array}$} & \multirow{2}{*}{$\begin{array}{l}\text { Momento } \\
\text { da amos } \\
\text { tragem }\end{array}$} & \multicolumn{5}{|c|}{ Blocos } \\
\hline & & & & 1 & V & III & $\|$ & $N$ \\
\hline \multirow[t]{14}{*}{ Média } & \multirow[t]{2}{*}{$(v+A)$} & \multirow[t]{2}{*}{ Fundo } & Pré-Trat & 32,33 & 36,09 & 31,38 & 32,40 & 30,17 \\
\hline & & & Pós-Trat & 35,10 & 35,45 & 28,62 & 33,84 & 32,53 \\
\hline & \multirow[t]{2}{*}{$(v+V)$} & \multirow[t]{2}{*}{ Fundo } & Pré-Trat & 38,15 & 33,27 & 33,95 & 34,30 & 35,24 \\
\hline & & & Pós-Trat & 14,02 & 36,72 & - & 29,53 & 29,89 \\
\hline & \multirow[t]{2}{*}{ (v) } & \multirow[t]{2}{*}{ Fundo } & Pré-Trat & 31,16 & - & 33,44 & 37,22 & 33,91 \\
\hline & & & Pós-Trat & 31,73 & - & 30,97 & 31,12 & 31,48 \\
\hline & \multirow[t]{2}{*}{ (A) } & \multirow[t]{2}{*}{ Fundo } & Pré-Trat & - & 37,19 & 22,50 & 31,48 & 28,13 \\
\hline & & & Pós-Trat & - & 29,40 & 29,44 & 32,96 & 30,54 \\
\hline & \multirow[t]{2}{*}{$M$} & \multirow[t]{2}{*}{ Fundo } & Pré-Trat & 31,15 & 34,44 & 34,45 & - & 35,88 \\
\hline & & & Pós-Trat & 31,44 & - & 34,67 & 32,56 & 36,26 \\
\hline & \multirow[t]{2}{*}{$(a+A)$} & \multirow[t]{2}{*}{ Fundo } & Pré-Trat & - & 30,55 & 37,03 & 30,29 & 36,43 \\
\hline & & & Pós-Trat & - & 33,80 & 33,85 & 34,23 & 29,96 \\
\hline & \multirow[t]{2}{*}{ (a) } & \multirow[t]{2}{*}{ Fundo } & PréTrat & 34,53 & - & 29,93 & 35,01 & 32,38 \\
\hline & & & Pós-Trat & - & - & 29,84 & 31,65 & 30,04 \\
\hline
\end{tabular}


APÊNDICE 10

Determinação da condustividade hidráufica. (Dados originas de laboratónio).

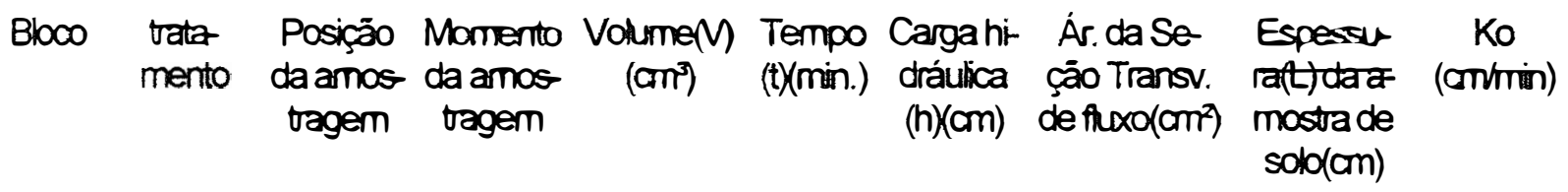

\begin{tabular}{|c|c|c|c|c|c|c|c|c|}
\hline$(v+A)$ & Talude & Pré-Trat & - & 10 & - & 38,5945 & 7,17 & - \\
\hline & & Pós-Trat & - & 10 & - & 38,5945 & 7,17 & - \\
\hline & Fundo & PréTrat & 77 & 10 & 1,7 & 38,5945 & 7,17 & 0,1411136 \\
\hline & & Pós-Trat & 6 & 10 & 1,6 & 38,5945 & 7,17 & 0,0111212 \\
\hline$(v+v)$ & Talude & Pré-Trat & - & 10 & - & 38,5945 & 7,17 & - \\
\hline & & Pós-Trat & - & 10 & - & 38,5945 & 7,17 & - \\
\hline & Fundo & Pré-Trat & 72 & 10 & 2,3 & 38,5945 & 7,17 & 0,1235903 \\
\hline & & Pós-Trat & 190 & 10 & 1,8 & 38,5945 & 7,17 & 0,3443206 \\
\hline (v) & Talude & Pré-Trat & - & 10 & - & 38,5945 & 7,17 & - \\
\hline & & Pós-Trat & - & 10 & - & 38,5945 & 7,17 & - \\
\hline & Fundo & PréTrat & 82 & 10 & 1,7 & 38,5945 & 7,17 & 0,1502768 \\
\hline & & Pós-Trat & 186 & 10 & 1,7 & 38,5945 & 7,17 & 0,3408718 \\
\hline (A) & Talude & Pré-Trat & - & 10 & - & 38,5945 & 7,17 & - \\
\hline & & Pós-Trat & - & 10 & - & 38,5945 & 7,17 & - \\
\hline & Fundo & Pré-Trat & - & 10 & - & 38,5945 & 7,17 & - \\
\hline & & Pós-Trat & - & 10 & - & 38,5945 & 7,17 & - \\
\hline$M$ & Talude & Pré-Trat & - & 10 & - & 38,5945 & 7,17 & - \\
\hline & & Pós-Trat & - & 10 & - & 38,5945 & 7,17 & - \\
\hline & Fundo & PréTrat & 55 & 10 & 1,4 & 38,5945 & 7,17 & 0,1043239 \\
\hline & & Pós-Trat & 135 & 10 & 1,9 & 38,5945 & 7,17 & 0,2419515 \\
\hline$(a+A)$ & Talude & Pré-Trat & - & 10 & - & 38,5945 & 7,17 & - \\
\hline & & PósTrat & - & 10 & - & 38,5945 & 7,17 & - \\
\hline & Fundo & Pré-Trat & - & 10 & - & 38,5945 & 7,17 & - \\
\hline & & PósTrat & - & 10 & - & 38,5945 & 7,17 & - \\
\hline (a) & Talude & Pré-Trat & - & 10 & - & 38,5945 & 7,17 & - \\
\hline & & Pós-Trat & - & 10 & - & 38,5945 & 7,17 & - \\
\hline & Fundo & PréTrat & 80 & 10 & 1,8 & 38,5945 & 7,17 & 0,1449771 \\
\hline & & PósTrat & - & 10 & - & 38,5945 & 7,17 & - \\
\hline$(v+A)$ & Talude & Pré-Trat & 105 & 10 & 2,3 & 38,5945 & 7,17 & 0,1802358 \\
\hline & & Pós-Trat & 27 & 10 & 1,8 & 38,5945 & 7,17 & 0,0489298 \\
\hline & Fundo & PréTrat & 16 & 10 & 2,0 & 38,5945 & 7,17 & 0,028363 \\
\hline & & Pós-Trat & 19 & 10 & 1,7 & 38,5945 & 7,17 & 0,0348202 \\
\hline$(n+V)$ & Talude & Pré-Trat & 66 & 10 & 2,1 & 38,5945 & 7,17 & 0,1157353 \\
\hline & & Pós-Trat & 44 & 10 & 1,9 & 38,5945 & 7,17 & 0,0788583 \\
\hline & Fundo & PréTrat & 42 & 10 & 1,7 & 38,5945 & 7,17 & 0,0769711 \\
\hline & & PósTrat & 45 & 10 & 1,8 & 38,5945 & 7,17 & 0,0815496 \\
\hline (v) & Talude & Pré-Trat & 60 & 10 & 1,7 & 38,5945 & 7,17 & 0,1099587 \\
\hline & & Pós-Trat & 118 & 10 & 1,7 & 38,5945 & 7,17 & 0,216252 \\
\hline
\end{tabular}




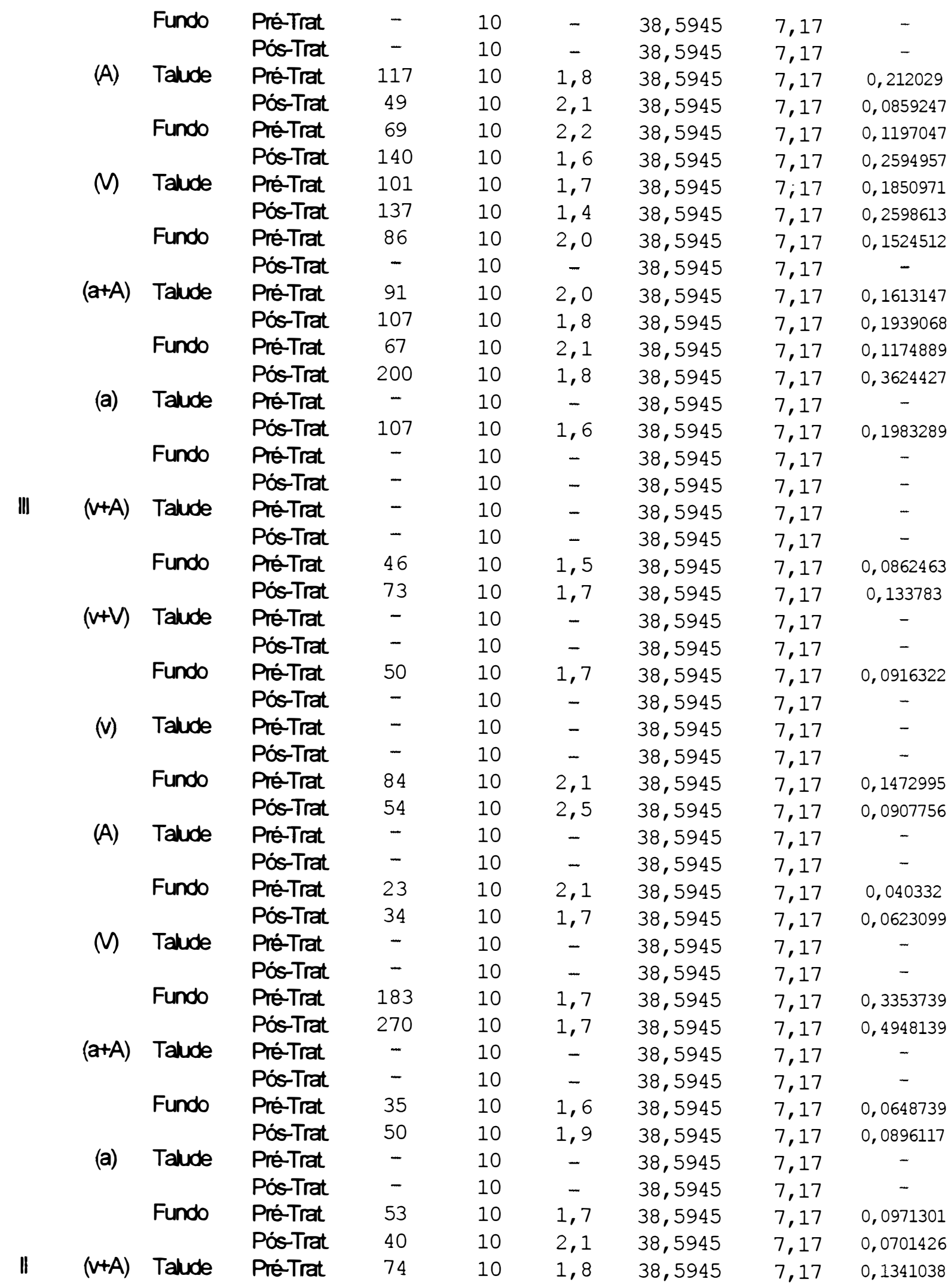




\begin{tabular}{|c|c|c|c|c|c|c|c|c|}
\hline & & Pós-Trat & - & 10 & - & 38,5945 & 7,17 & - \\
\hline & Fundo & Pré-Trat & 96 & 10 & 2,0 & 38,5945 & 7,17 & 0,1701781 \\
\hline & & Pós-Trat & 22 & 10 & 2,0 & 38,5945 & 7,17 & 0,0389991 \\
\hline \multirow[t]{4}{*}{$(v+v)$} & Talude & Pré-Trat & - & 10 & - & 38,5945 & 7,17 & - \\
\hline & & Pós-Trat & - & 10 & - & 38,5945 & 7,17 & - \\
\hline & Fundo & Pré-Trat & 61 & 10 & 2,0 & 38,5945 & 7,17 & 0,108134 \\
\hline & & Pós-Trat & 187 & 10 & 1,9 & 38,5945 & 7,17 & 0,3351476 \\
\hline \multirow[t]{4}{*}{ (v) } & Talude & Pré-Trat & - & 10 & - & 38,5945 & 7,17 & - \\
\hline & & Pós-Trat & - & 10 & - & 38,5945 & 7,17 & - \\
\hline & Fundo & Pré-Trat & 350 & 10 & 1,7 & 38,5945 & 7,17 & 0,6414255 \\
\hline & & Pós-Trat & 112 & 10 & 1,5 & 38,5945 & 7,17 & 0,209991 \\
\hline \multirow[t]{4}{*}{ (A) } & Talude & Pré-Trat & - & 10 & - & 38,5945 & 7,17 & - \\
\hline & & Pós-Trat & - & 10 & - & 38,5945 & 7,17 & - \\
\hline & Fundo & Pré-Trat & 57 & 10 & 2,6 & 38,5945 & 7,17 & 0,0948379 \\
\hline & & Pós-Trat & 17 & 10 & 1,8 & 38,5945 & 7,17 & 0,0308076 \\
\hline \multirow[t]{4}{*}{$M$} & Tahude & Pré-Trat & - & 10 & - & 38,5945 & 7,17 & - \\
\hline & & Pós-Trat & - & 10 & - & 38,5945 & 7,17 & - \\
\hline & Fundo & Pré-Trat & - & 10 & - & 38,5945 & 7,17 & - \\
\hline & & Pós-Trat & 15 & 10 & 1,8 & 38,5945 & 7,17 & 0,0271832 \\
\hline \multirow[t]{4}{*}{$(a+A)$} & Talude & Pré-Trat & - & 10 & - & 38,5945 & 7,17 & - \\
\hline & & Pós-Trat & - & 10 & - & 38,5945 & 7,17 & - \\
\hline & Fundo & Pré-Trat & 66 & 10 & 2,3 & 38,5945 & 7,17 & 0,1132911 \\
\hline & & Pós-Trat & $74 ?$ & 10 & 1,8 & 38,5945 & 7,17 & 0,0018122 \\
\hline \multirow[b]{5}{*}{$(v+A)$} & Talude & Pré-Trat & - & 10 & - & 38,5945 & 7,17 & - \\
\hline & & Pós-Trat & - & 10 & - & 38,5945 & 7,17 & - \\
\hline & Fundo & Pré-Trat & 43 & 10 & 1,7 & 38,5945 & 7,17 & 0,0788037 \\
\hline & & Pós-Trat & 70 & 10 & 2,2 & 38,5945 & 7,17 & 0,1214396 \\
\hline & Talude & Pré-Trat & - & 10 & - & 38,5945 & 7,17 & - \\
\hline \multirow{7}{*}{$(v+A)$} & & Pós-Trat & - & 10 & - & 38,5945 & 7,17 & - \\
\hline & Fundo & Pré-Trat & 84 & 10 & 2,1 & 38,5945 & 7,17 & 0,1472995 \\
\hline & & Pós-Trat & 73 & 10 & 1,7 & 38,5945 & 7,17 & 0,133783 \\
\hline & Talude & Pré-Trat & - & 10 & - & 38,5945 & 7,17 & - \\
\hline & & Pós-Trat & - & 10 & - & 38,5945 & 7,17 & - \\
\hline & Fundo & Pré-Trat & 124 & 10 & 1,9 & 38,5945 & 7,17 & 0,2222369 \\
\hline & & Pós-Trat & 50 & 10 & 1,6 & 38,5945 & 7,17 & 0,092677 \\
\hline \multirow[t]{4}{*}{ (v) } & Talude & Pré-Trat & - & 10 & - & 38,5945 & 7,17 & - \\
\hline & & Pós-Trat & - & 10 & - & 38,5945 & 7,17 & - \\
\hline & Fundo & Pré-Trat & 42 & 10 & 1,9 & 38,5945 & 7,17 & 0,0752738 \\
\hline & & Pós-Trat & 162 & 10 & 1,7 & 38,5945 & 7,17 & 0,2968884 \\
\hline \multirow[t]{4}{*}{ (A) } & Tahude & Pré-Trat & - & 10 & - & 38,5945 & 7,17 & - \\
\hline & & Pós-Trat & - & 10 & - & 38,5945 & 7,17 & - \\
\hline & Fundo & Pré-Trat & 30 & 10 & 1,9 & 38,5945 & 7,17 & 0,053767 \\
\hline & & Pós-Trat & 150 & 10 & 1,9 & 38,5945 & 7,17 & 0,268835 \\
\hline \multirow[t]{4}{*}{$M$} & Tahude & Pré-Trat & - & 10 & - & 38,5945 & 7,17 & - \\
\hline & & Pós-Trat & - & 10 & - & 38,5945 & 7,17 & - \\
\hline & Fundo & Pré-Trat & 97 & 10 & 2,3 & 38,5945 & 7,17 & 0,1665036 \\
\hline & & Pós-Trat & 430 & 10 & 1,9 & 38,5945 & 7,17 & 0,7706602 \\
\hline
\end{tabular}




\begin{tabular}{cclcccccc} 
(a+A) Taude & Pré-Trat & - & 10 & - & 38,5945 & 7,17 & - \\
& Pós-Trat & - & 10 & - & 38,5945 & 7,17 & - \\
& Fundo & Pré-Trat & 37 & 10 & 2,2 & 38,5945 & 7,17 & 0,0641895 \\
& Pós-Trat & 31 & 10 & 2,0 & 38,5945 & 7,17 & 0,0549533 \\
(a) Tahude & Pré-Trat & - & 10 & - & 38,5945 & 7,17 & - \\
& Pós-Trat & - & 10 & - & 38,5945 & 7,17 & - \\
& \multirow{2}{*}{ Fundo } & Pré-Trat & 130 & 10 & 2,1 & 38,5945 & 7,17 & 0,2279635 \\
& & Pós-Trat & 43 & 10 & 2,1 & 38,5945 & 7,17 & 0,0754033
\end{tabular}

\section{Vabores médios de Ko}

trata Posição Mornento Ko

mento da amos da amos

tragem tagem

(crminin)

\begin{tabular}{|c|c|c|c|}
\hline \multirow[t]{4}{*}{$(v+A)$} & \multirow[t]{2}{*}{ Talude } & Pré-Trat & 0,15717 \\
\hline & & Pós-Trat & 0,04893 \\
\hline & \multirow[t]{2}{*}{ Fundo } & Pré-Trat & 0,11464 \\
\hline & & Pós-Trat & 0,07050 \\
\hline \multirow[t]{4}{*}{$(v+v)$} & \multirow[t]{2}{*}{ Talude } & Pré-Trat & 0,11574 \\
\hline & & Pós-Trat & 0,07886 \\
\hline & \multirow[t]{2}{*}{ Fundo } & Pré-Trat & 0,12451 \\
\hline & & Pós-Trat & 0,21342 \\
\hline \multirow[t]{4}{*}{ (v) } & \multirow[t]{2}{*}{ Talude } & Pré-Trat & 0,10996 \\
\hline & & Pós-Trat & 0,21625 \\
\hline & \multirow[t]{2}{*}{ Fundo } & Pré-Trat & 0,25357 \\
\hline & & Pós-Trat & 0,23463 \\
\hline \multirow[t]{4}{*}{ (A) } & \multirow[t]{2}{*}{ Talude } & Pré-Trat & 0,21203 \\
\hline & & Pós-Trat & 0,08592 \\
\hline & \multirow[t]{2}{*}{ Fundo } & Pré-Trat & 0,07716 \\
\hline & & Pós-Trat & 0,15536 \\
\hline \multirow[t]{4}{*}{ (V) } & \multirow[t]{2}{*}{ Talude } & Pré-Trat & 0,18510 \\
\hline & & Pós-Trat & 0,25986 \\
\hline & \multirow[t]{2}{*}{ Fundo } & PréTrat & 0,18966 \\
\hline & & PósTrat & 0,38365 \\
\hline \multirow[t]{4}{*}{$(a+A)$} & \multirow[t]{2}{*}{ Talude } & Pré-Trat & 0,16131 \\
\hline & & Pós-Trat & 0,19391 \\
\hline & \multirow[t]{2}{*}{ Fundo } & Pré-Trat & 0,08996 \\
\hline & & Pós-Trat & 0,12720 \\
\hline \multirow[t]{4}{*}{ (a) } & \multirow[t]{2}{*}{ Talude } & Pré-Trat & - \\
\hline & & Pós-Trat & 0,19833 \\
\hline & \multirow[t]{2}{*}{ Fundo } & Pré-Trat & 0,13722 \\
\hline & & Pós-Trat & 0,08900 \\
\hline
\end{tabular}


Condutividade hidráulica do solo saturado, Ko(antmin).

\begin{tabular}{|c|c|c|c|c|c|c|c|}
\hline \multirow{2}{*}{$\begin{array}{l}\text { Trata } \\
\text { mento }\end{array}$} & \multirow{2}{*}{$\begin{array}{l}\text { Posição } \\
\text { da amos } \\
\text { tragem }\end{array}$} & \multirow{2}{*}{$\begin{array}{l}\text { Momento } \\
\text { da amos } \\
\text { vagem }\end{array}$} & \multicolumn{5}{|c|}{ Blocos } \\
\hline & & & I & V & III & $\|$ & N \\
\hline \multirow[t]{2}{*}{$(v+A)$} & Fundo & Pré-Trat & 0,14111 & 0,02836 & 0,0863 & 0,17018 & 0,1473 \\
\hline & & Pós-Trat & 0,01112 & 0,03482 & 0,1338 & 0,039 & 0,13378 \\
\hline \multirow[t]{2}{*}{$(v+V)$} & Fundo & Pré-Trat & 0,12359 & 0,07697 & 0,0916 & 0,10813 & 0,22224 \\
\hline & & Pós-Trat & 0,34432 & 0,08155 & - & 0,33515 & 0,09268 \\
\hline \multirow[t]{2}{*}{ (v) } & Fundo & Pré-Trat & 0,15128 & - & 0,1473 & 0,64143 & 0,07527 \\
\hline & & PósTrat & 0,34087 & - & 0,0908 & 0,20999 & 0,29689 \\
\hline \multirow[t]{2}{*}{ (A) } & Fundo & Pré-Trat & - & 0,1197 & 0,0403 & 0,09484 & 0,05377 \\
\hline & & PósTrat & - & 0,2595 & 0,0623 & 0,03081 & 0,26883 \\
\hline \multirow{2}{*}{$M$} & Fundo & Pré-Trat & 0,10432 & 0,15245 & 0,3354 & - & 0,1665 \\
\hline & & Pós-Trat & 0,24195 & - & 0,4948 & 0,02718 & 0,77066 \\
\hline \multirow[t]{2}{*}{$(a+A)$} & Fundo & Pré-Trat & - & 0,11749 & 0,0649 & 0,11329 & 0,06419 \\
\hline & & Pós-Trat & - & 0,36244 & 0,0896 & 0,00181 & 0,05495 \\
\hline \multirow[t]{2}{*}{ (a) } & Fundo & Pré-Trat & 0,14498 & - & 0,0971 & 0,0788 & 0,22796 \\
\hline & & Pós-Trat & - & - & 0,0701 & 0,12144 & 0,0754 \\
\hline
\end{tabular}

Média 


\section{APÊNDICE 11 \\ Resultados das análises estatísticas}

1. Análises da variância(ANAVA) para os dados de massa específica do solo( $\rho_{\text {ando) }}$

1.1. Quadros da ANAVA e teste de Tukey para os dados de $\rho_{\text {salor }}$ talude e pré-tratamento.

\begin{tabular}{|c|c|c|c|c|c|}
\hline Causa da variação & $\begin{array}{l}\text { Graus } \\
\text { de } 1 i- \\
\text { berdade }\end{array}$ & $\begin{array}{c}\text { Soma de qua- } \\
\text { drados }\end{array}$ & $\begin{array}{l}\text { Quadrados } \\
\text { médios }\end{array}$ & $\begin{array}{c}\text { Valor de } \\
\text { E }\end{array}$ & $\begin{array}{c}\text { Probabi- } \\
\text { dade > } \\
\text { que } \mathrm{E}\end{array}$ \\
\hline Blocos não ajustados & 4 & 0,0275427 & & & \\
\hline Tratamentos ajustados & 6 & 0,0514655 & 0,0085776 & 0,8665 & 0,53541 \\
\hline Resíduo & 22 & 0,2177798 & 0,0098991 & & \\
\hline Total & 32 & 0,2967880 & & & \\
\hline
\end{tabular}

Média geral ajustada

: 1,316297

Coeficiente de variação

Soma de quadrados não ajustada

: 7,5598

$: 0,0468529$

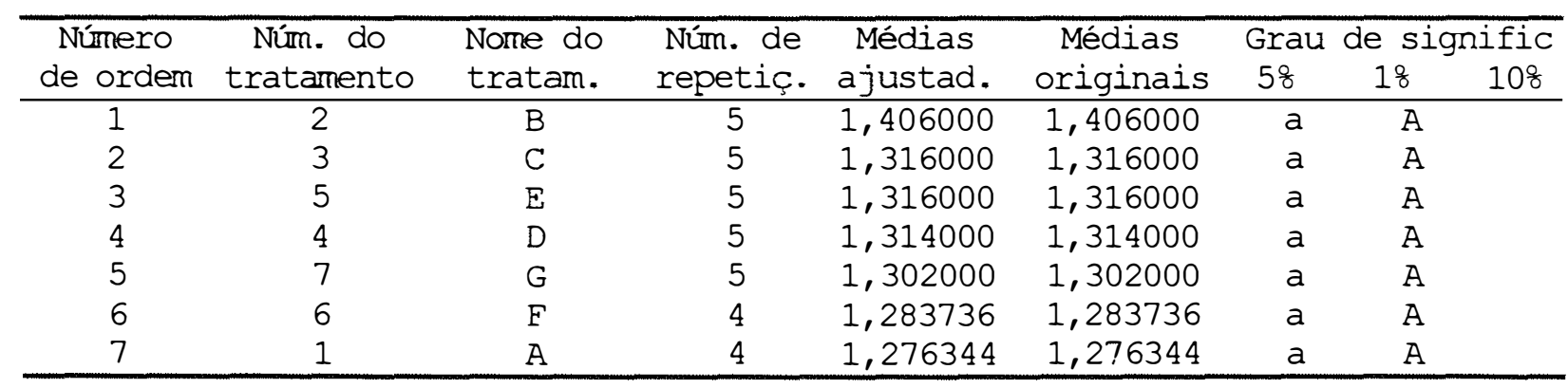

Médias seguidas por letras distintas, diferem entre si ao grau de significância indicado.

1.2. Quadros da ANAVA e teste de Tukey para os dados de psol talude e pós-tratamento.

\begin{tabular}{|c|c|c|c|c|c|}
\hline Causa da variação & $\begin{array}{c}\text { Graus } \\
\text { de li- } \\
\text { berdade }\end{array}$ & $\begin{array}{c}\text { Soma de qua- } \\
\text { drados }\end{array}$ & $\begin{array}{l}\text { Quadrados } \\
\text { médios }\end{array}$ & $\begin{array}{c}\text { Valor de } \\
E\end{array}$ & $\begin{array}{c}\text { Probabi- } \\
\text { dade > } \\
\text { que } \mathrm{F}\end{array}$ \\
\hline Blocos não ajustados & 4 & 0,0576018 & & & \\
\hline Tratamentos ajustados & 6 & 0,0058379 & 0,0009730 & 0,1618 & 0,98287 \\
\hline Resíduo & 21 & 0,1262479 & 0,0060118 & & \\
\hline Total & 31 & 0,2967880 & & & \\
\hline
\end{tabular}

Média geral ajustada Coeficiente de variação

Soma de quadrados não ajustada

$: 1,396580$

$: 5,552 \frac{8}{8}$

$: 0,0115075$ 


\begin{tabular}{|c|c|c|c|c|c|c|c|c|}
\hline \multirow{2}{*}{$\begin{array}{l}\text { Número } \\
\text { de ordem }\end{array}$} & \multirow{2}{*}{$\begin{array}{l}\text { Núm. do } \\
\text { tratamento }\end{array}$} & \multirow{2}{*}{$\begin{array}{l}\text { Nome do } \\
\text { tratam. }\end{array}$} & \multirow{2}{*}{$\begin{array}{l}\text { Núm. de } \\
\text { repetiç. }\end{array}$} & \multirow{2}{*}{$\begin{array}{l}\text { Médias } \\
\text { ajustad. }\end{array}$} & \multirow{2}{*}{$\begin{array}{c}\text { Médias } \\
\text { originais }\end{array}$} & \multicolumn{3}{|c|}{ Grau de signific } \\
\hline & & & & & & 58 & 18 & 108 \\
\hline 1 & 1 & A & 5 & 1,412000 & 1,412000 & $a$ & A & \\
\hline 2 & 6 & E & 3 & 1,410493 & 1,410493 & a & A & \\
\hline 3 & 2 & B & 5 & 1,410000 & 1,410000 & a & A & \\
\hline 4 & 5 & $E$ & 4 & 1,397563 & 1,397563 & a & A & \\
\hline 5 & 3 & $\mathrm{C}$ & 5 & 1,384000 & 1,384000 & a & A & \\
\hline 6 & 4 & $\mathrm{D}$ & 5 & 1,382000 & 1,382000 & a & A & \\
\hline 7 & 7 & G & 5 & 1,380000 & 1,380000 & a & A & \\
\hline
\end{tabular}

Médias seguidas por letras distintas, diferem entre si ao grau de significância indicado.

1.3. Quadros da ANAVA e teste de Tukey para os dados de psolor fundo e pré-tratamento.

\begin{tabular}{l|ccccc}
\hline Causa da variação & $\begin{array}{c}\text { Graus } \\
\text { de li- } \\
\text { berdade }\end{array}$ & $\begin{array}{c}\text { Soma de qua- } \\
\text { drados }\end{array}$ & $\begin{array}{c}\text { Quadrados } \\
\text { médios }\end{array}$ & $\begin{array}{c}\text { Valor de } \\
\text { F }\end{array}$ & $\begin{array}{c}\text { Probabi- } \\
\text { dade }> \\
\text { que F }\end{array}$ \\
\hline Blocos não ajustados & 4 & 0,1184438 & & \\
Tratamentos ajustados & 6 & 0,0431991 & 0,0071998 & 0,6652 & 0,68017 \\
Resíduo & 19 & 0,2056371 & 0,1082301 & & \\
\hline Total & 29 & 0,3672800 & & & \\
\hline
\end{tabular}

Média geral ajustada Coeficiente de variação

$: 1,3491294$

Soma de quadrados não ajustada

$: 7,7118$

: 0,0788683

\begin{tabular}{ccccccccc}
\hline $\begin{array}{c}\text { Número } \\
\text { de ordem }\end{array}$ & $\begin{array}{c}\text { Núm. do } \\
\text { tratamento }\end{array}$ & $\begin{array}{c}\text { Nome do } \\
\text { tratam. }\end{array}$ & $\begin{array}{c}\text { Núm. de } \\
\text { repetiç. }\end{array}$ & ajédias & \multicolumn{2}{c}{ Médias } & \multicolumn{2}{c}{ Grau de signific } \\
\hline 1 & 5 & E & 5 & 1,386000 & 1,386000 & a & A & \\
2 & 2 & B & 5 & 1,376000 & 1,376000 & a & A \\
3 & 7 & G & 4 & 1,375063 & 1,375063 & a & A \\
4 & 4 & D & 4 & 1,362744 & 1,362744 & a & A \\
5 & 3 & C & 4 & 1,360063 & 1,360063 & a & A \\
6 & 1 & A & 5 & 1,338000 & 1,338000 & a & A \\
7 & 6 & F & 3 & 1,245999 & 1,245999 & a & A \\
\hline
\end{tabular}

Médias seguidas por letras distintas, diferem entre si ao grau de significância indicado. 
1.4. Quadros da ANAVA e teste de Tukey para os dados de $\rho_{\text {salo }}$ fundo e pós-tratamento.

\begin{tabular}{l|ccccc}
\hline Causa da variação & $\begin{array}{c}\text { Graus } \\
\text { de li- } \\
\text { berdade }\end{array}$ & $\begin{array}{c}\text { Soma de qua- } \\
\text { drados }\end{array}$ & $\begin{array}{c}\text { Quadrados } \\
\text { médios }\end{array}$ & $\begin{array}{c}\text { Valor de } \\
\text { F }\end{array}$ & $\begin{array}{c}\text { Probabi- } \\
\text { dade }> \\
\text { que F }\end{array}$ \\
\hline Blocos não ajustados & 4 & 0,1189729 & & \\
Tratamentos ajustados & 6 & 0,0409265 & 0,0068211 & 0,7187 & 0,64097 \\
Resíduo & 19 & 0,1803306 & 0,0094911 & & \\
\hline Total & 29 & 0,3402301 & & & \\
\hline
\end{tabular}

Média geral ajustada

$: 1,407463$

Coeficiente de variação

Soma de quadrados não ajustada

: $6,922 \%$

: 0,0255300

\begin{tabular}{ccccccccc}
\hline $\begin{array}{c}\text { Número } \\
\text { de ordem }\end{array}$ & $\begin{array}{c}\text { Núm. do } \\
\text { tratamento }\end{array}$ & $\begin{array}{c}\text { Nome do } \\
\text { tratam. }\end{array}$ & $\begin{array}{c}\text { Núm. de } \\
\text { repetiç. }\end{array}$ & Médias & \multicolumn{2}{c}{ Médias } & \multicolumn{3}{c}{ Grau de signific } \\
\hline 1 & 1 & A & 5 & 1,452000 & 1,452000 & a & A & \\
2 & 5 & E & 4 & 1,447294 & 1,447294 & a & A \\
3 & 6 & F & 4 & 1,430709 & 1,430709 & a & A \\
4 & 7 & G & 4 & 1,400014 & 1,400014 & a & A \\
5 & 4 & D & 4 & 1,395709 & 1,395709 & a & A \\
6 & 2 & B & 5 & 1,394000 & 1,394000 & a & A \\
7 & 3 & C & 4 & 1,332514 & 1,332514 & a & A \\
\hline
\end{tabular}

Médias seguidas por letras distintas, diferem entre si ao grau de significância indicado.

2. Análises da variância(ANAVA) para os dados de macroporosidade do solo(M) .

2.1. Quadros da ANAVA e teste de Tukey para os dados de M, fundo e prétratamento.

\begin{tabular}{l|ccccc}
\hline Causa da variação & $\begin{array}{c}\text { Graus } \\
\text { de li- } \\
\text { berdade }\end{array}$ & $\begin{array}{c}\text { Soma de qua- } \\
\text { drados }\end{array}$ & $\begin{array}{c}\text { Quadrados } \\
\text { médios }\end{array}$ & $\begin{array}{c}\text { Valor de } \\
\mathrm{F}\end{array}$ & $\begin{array}{c}\text { Probabi- } \\
\text { dade }> \\
\text { que } \mathrm{F}\end{array}$ \\
\hline Blocos não ajustados & 4 & 28,0879008 & & \\
Tratamentos ajustados & 6 & 31,0105531 & 5,1684255 & 1,3077 & 0,30081 \\
Resíduo & 19 & 75,0958104 & 3,9524111 & & \\
\hline Total & 29 & 134,1942642 & & & \\
\hline
\end{tabular}

Média geral ajustada

: 8,962393

Coeficiente de variação

Soma de quadrados não ajustada

: 22,1828

: 31,492643 


\begin{tabular}{ccccccccc}
\hline $\begin{array}{c}\text { Número } \\
\text { de ordem }\end{array}$ & $\begin{array}{c}\text { Núm. do } \\
\text { tratamento }\end{array}$ & $\begin{array}{c}\text { Nome do } \\
\text { tratam. }\end{array}$ & $\begin{array}{c}\text { Núm. de } \\
\text { repetiç. }\end{array}$ & Médias & \multicolumn{2}{c}{ Médias } & \multicolumn{2}{c}{ Grau de signific } \\
\hline 1 & 2 & B & 5 & 10,575999 & 10,575999 & a & A & \\
2 & 6 & F & 4 & 9,989486 & 9,989486 & a & A \\
3 & 7 & G & 4 & 8,951708 & 8,951708 & a & A \\
4 & 3 & C & 4 & 8,859208 & 8,859208 & a & A \\
5 & 5 & E & 4 & 8,845358 & 8,845358 & a & A \\
6 & 4 & D & 4 & 7,916986 & 7,916986 & a & A \\
7 & 1 & A & 5 & 7,547999 & 7,547999 & a & A \\
\hline
\end{tabular}

Médias seguidas por letras distintas, diferem entre si ao grau de significância indicado.

2.2. Quadros da ANAVA e teste de Tukey para os dados de M, fundo e póstratamento.

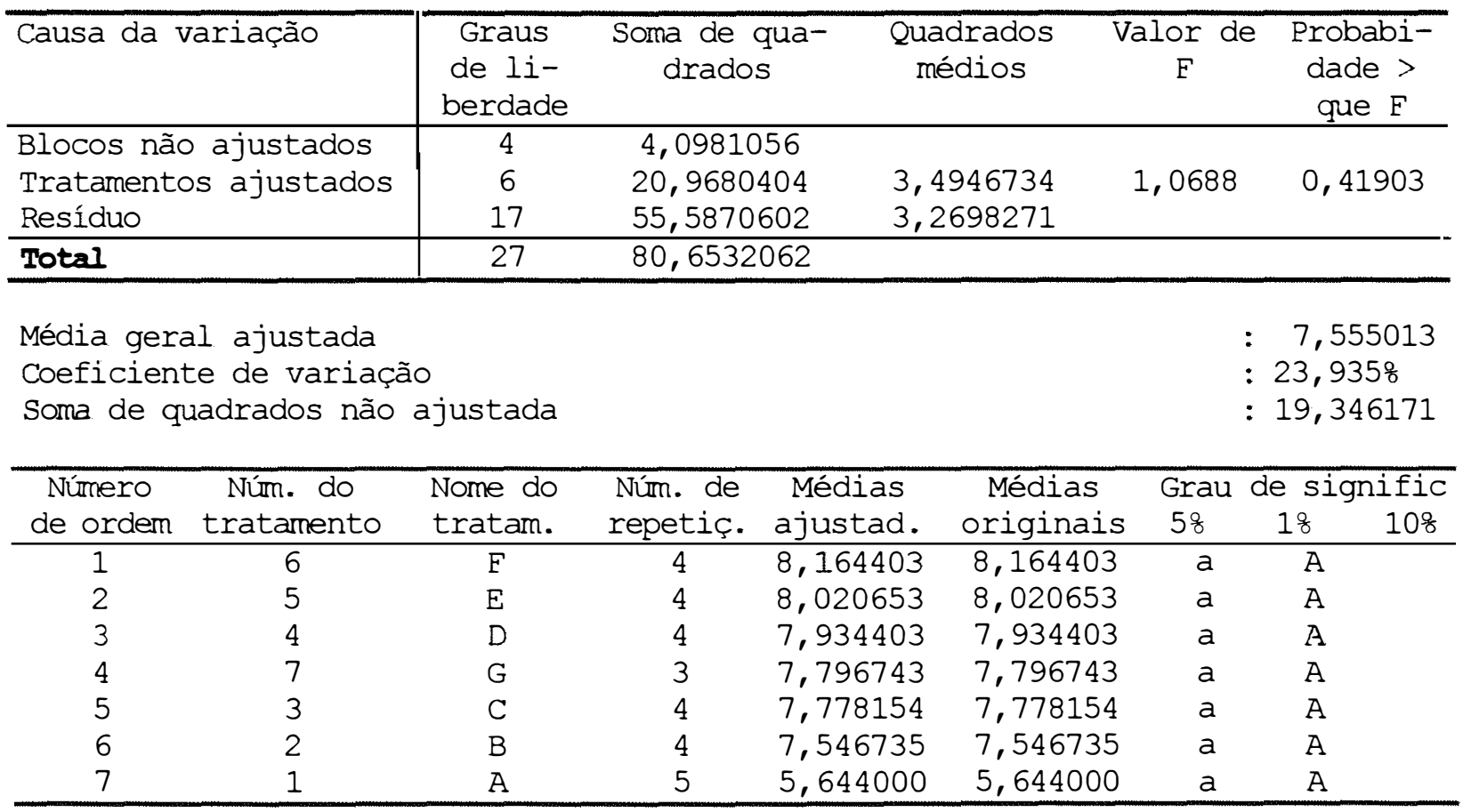

Médias seguidas por letras distintas, diferem entre si ao grau de significância indicado.

3 Análises da variância(ANAVA) para os dados de mioporosidade do solo(m)

3.1. Quadros da ANAVA e teste de Tukey para os dados de $m$, fundo e prétratamento. 


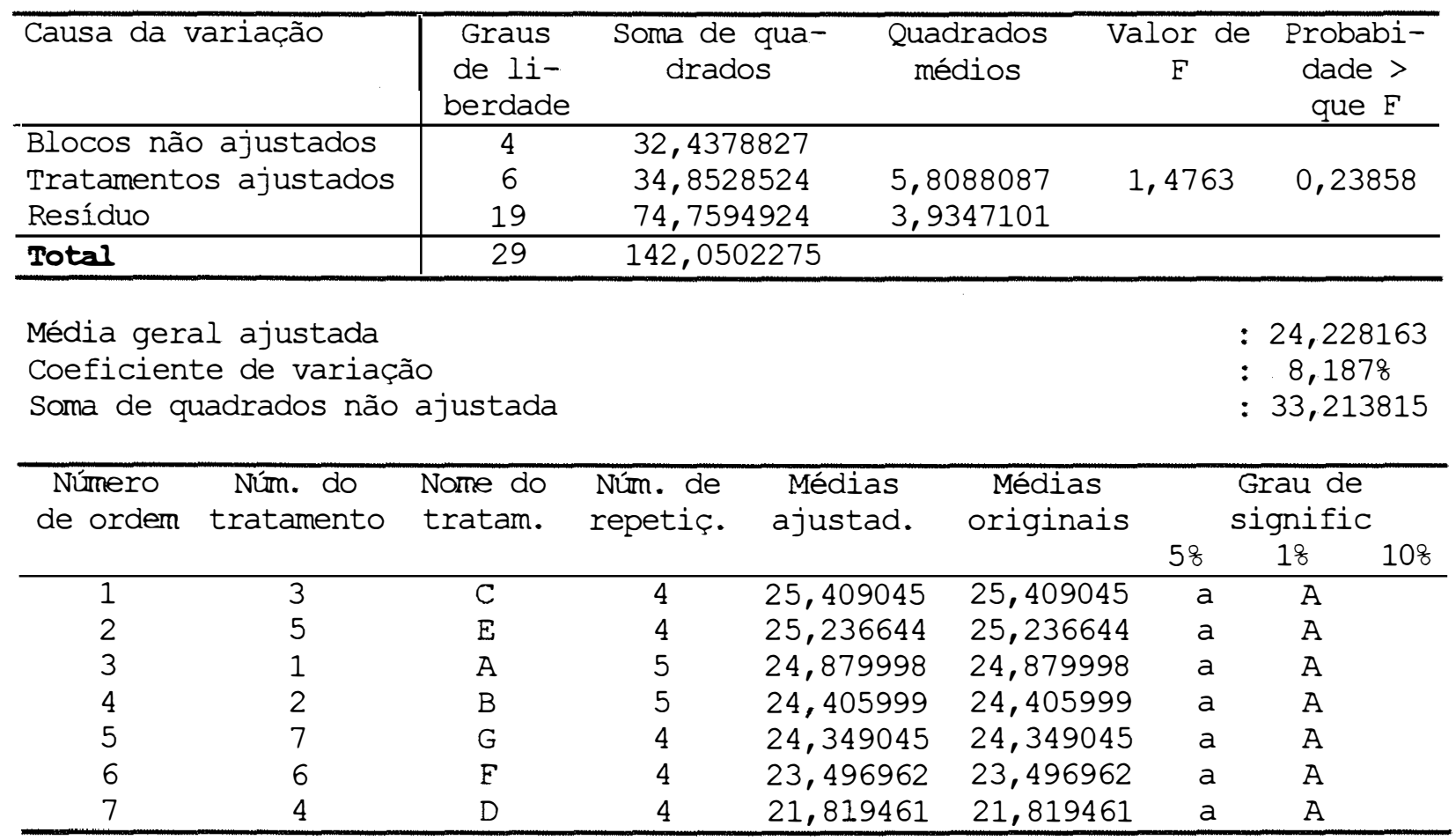

Médias seguidas por letras distintas, diferem entre si ao grau de significância indicado.

3.2. Quadros da ANAVA e teste de Tukey para os dados de $m$, fundo e póstratamento.

\begin{tabular}{l|ccccc}
\hline Causa da variação & $\begin{array}{c}\text { Graus } \\
\text { de li- } \\
\text { berdade }\end{array}$ & $\begin{array}{c}\text { Soma de qua- } \\
\text { drados }\end{array}$ & $\begin{array}{c}\text { Quadrados } \\
\text { médios }\end{array}$ & $\begin{array}{c}\text { Valor de } \\
\text { F }\end{array}$ & $\begin{array}{c}\text { Probabi- } \\
\text { dade }> \\
\text { que } F\end{array}$ \\
\hline Blocos não ajustados & 4 & 73,0872450 & \\
Tratamentos ajustados & 6 & 178,0470275 & 29,6745046 & 2,1104 & 0,10542 \\
Resíduo & 17 & 239,0370291 & 14,0610017 & \\
\hline Total & 27 & 490,1713017 & & $: 23,76247$ \\
\hline & & & $: 15,7808$ \\
Média geral ajustada & & & $: 156,025696$
\end{tabular}




\begin{tabular}{|c|c|c|c|c|c|c|c|c|}
\hline \multirow[t]{2}{*}{$\begin{array}{l}\text { Número } \\
\text { de ordem }\end{array}$} & \multirow[t]{2}{*}{$\begin{array}{l}\text { Núm. do } \\
\text { tratamento }\end{array}$} & \multirow[t]{2}{*}{$\begin{array}{l}\text { Nome do } \\
\text { tratam. }\end{array}$} & \multirow[t]{2}{*}{$\begin{array}{l}\text { Núm. de } \\
\text { repetiç. }\end{array}$} & \multirow[t]{2}{*}{$\begin{array}{l}\text { Médias } \\
\text { ajustad. }\end{array}$} & \multirow[t]{2}{*}{$\begin{array}{c}\text { Médias } \\
\text { originais }\end{array}$} & \multicolumn{3}{|c|}{$\begin{array}{l}\text { Grau de } \\
\text { signific }\end{array}$} \\
\hline & & & & & & 5 울 & 18 & $10 \frac{8}{8}$ \\
\hline 1 & $\overline{1}$ & $\bar{A}$ & 5 & 27,461999 & 27,461999 & $\bar{a}$ & $\bar{A}$ & \\
\hline 2 & 5 & $E$ & 4 & 26,540534 & 26,540534 & a & A & \\
\hline 3 & 3 & C & 4 & 24,370534 & 24,370534 & a & A & \\
\hline 4 & 6 & $F$ & 4 & 23,863034 & 23,863034 & a & A & \\
\hline 5 & 7 & G & 3 & 22,574759 & 22,574759 & a & A & \\
\hline 6 & 4 & D & 4 & 21,718034 & 21,718034 & a & I & \\
\hline 7 & 2 & B & 4 & 19,808379 & 19,808379 & a & F & \\
\hline
\end{tabular}

Médias seguidas por letras distintas, diferem entre si ao grau de significância indicado.

4 Análises da variância (ANAVA) para os dados de porosidade total do solo(P).

41. Quadros da ANAVA e teste de Tukey para os dados de P, fundo e prétratamento.

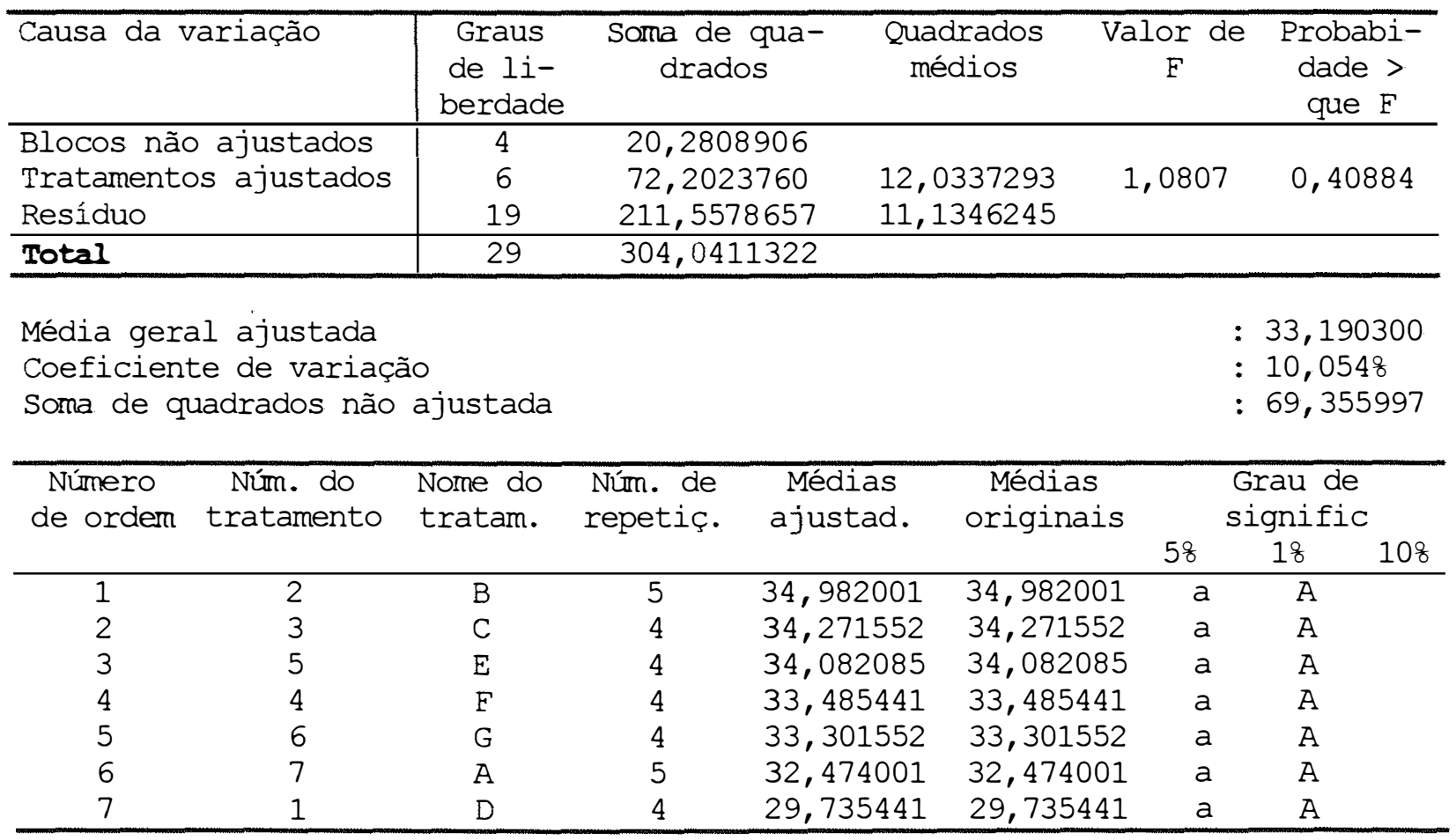

Médias seguidas por letras distintas, diferem entre si ao grau de significância indicado. 
4.2. Quadros da ANAVA e teste de Tukey para os dados de P, fundo e póstratamento.

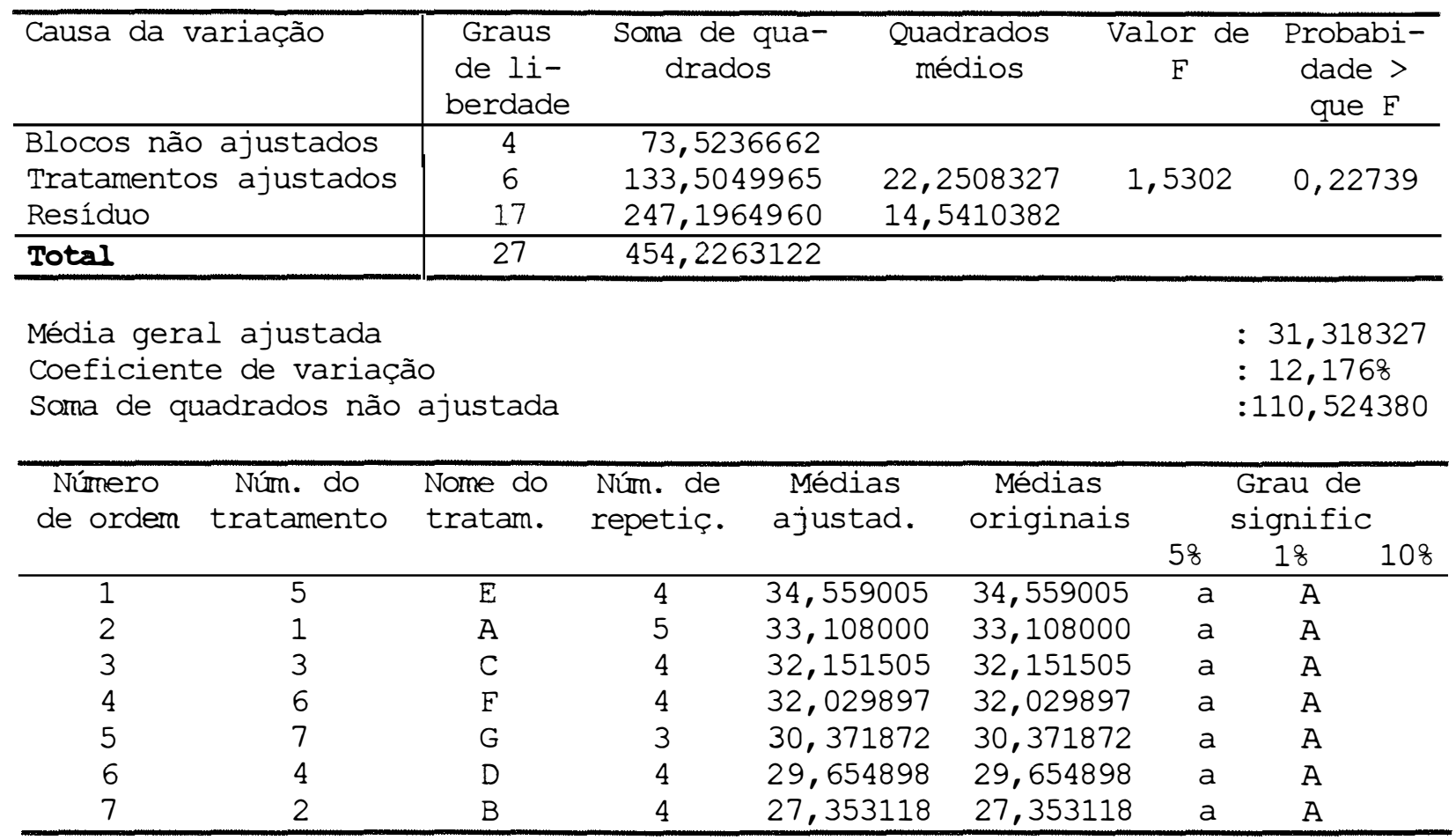

Médias seguidas por letras distintas, diferem entre si ao grau de significância indicado.

5. Análises da variância(ANAVA) para os dados de condutividade hidráulica do solo saturado $\left(\boldsymbol{R}_{\mathbf{0}}\right)$.

5.1. Quadros da ANAVA e teste de Tukey para os dados de $\boldsymbol{R}_{\mathbf{0}}$, fundo e prétratamento.

\begin{tabular}{l|ccccc}
\hline Causa da variação & $\begin{array}{c}\text { Graus } \\
\text { de li- } \\
\text { berdade }\end{array}$ & $\begin{array}{c}\text { Soma de qua- } \\
\text { drados }\end{array}$ & $\begin{array}{c}\text { Quadrados } \\
\text { médios }\end{array}$ & $\begin{array}{c}\text { Valor de } \\
\text { F }\end{array}$ & $\begin{array}{c}\text { Probabi- } \\
\text { dade }> \\
\text { que F }\end{array}$ \\
\hline Blocos não ajustados & 4 & 0,0329708 & & \\
Tratamentos ajustados & 6 & 0,0995155 & 0,0165859 & 1,3109 & 0,29949 \\
Resíduo & 19 & 0,2403981 & 0,0126525 & \\
\hline Total & 29 & 0,3728844 & & 0,140239 \\
\hline & & & 80,2098 \\
Média geral ajustada & & & 0,094243
\end{tabular}




\begin{tabular}{ccccccccc}
\hline $\begin{array}{c}\text { Número } \\
\text { de ordem }\end{array}$ & $\begin{array}{c}\text { Núm. do } \\
\text { tratamento }\end{array}$ & $\begin{array}{c}\text { Nome do } \\
\text { tratam. }\end{array}$ & $\begin{array}{c}\text { Núm. de } \\
\text { repetiç. }\end{array}$ & Médias & \multicolumn{2}{c}{ Médias } & \multicolumn{3}{c}{ Grau de signific } \\
\hline 1 & 3 & $\mathrm{C}$ & 4 & 0,251144 & 0,251144 & $\mathrm{a}$ & $\mathrm{A}$ \\
2 & 5 & $\mathrm{E}$ & 4 & 0,207689 & 0,207689 & $\mathrm{a}$ & $\mathrm{A}$ \\
3 & 7 & $\mathrm{G}$ & 4 & 0,132042 & 0,132042 & $\mathrm{a}$ & $\mathrm{A}$ \\
4 & 2 & $\mathrm{~B}$ & 5 & 0,124512 & 0,124512 & $\mathrm{a}$ & $\mathrm{A}$ \\
5 & 1 & $\mathrm{~A}$ & 5 & 0,114640 & 0,114640 & $\mathrm{a}$ & $\mathrm{A}$ \\
6 & 6 & $\mathrm{~F}$ & 4 & 0,082223 & 0,082223 & $\mathrm{a}$ & $\mathrm{A}$ \\
7 & 4 & $\mathrm{D}$ & 4 & 0,069423 & 0,069423 & $\mathrm{a}$ & $\mathrm{A}$ \\
\hline
\end{tabular}

Médias seguidas por letras distintas, diferem entre si ao grau de significância indicado.

5.2. Quadros da ANAVA e teste de Tukey para os dados de $\boldsymbol{R}_{0}$, fundo e póstratamento.

\begin{tabular}{l|ccccc}
\hline Causa da variação & $\begin{array}{c}\text { Graus } \\
\text { de li- } \\
\text { berdade }\end{array}$ & $\begin{array}{c}\text { Soma de qua- } \\
\text { drados }\end{array}$ & $\begin{array}{c}\text { Quadrados } \\
\text { médios }\end{array}$ & $\begin{array}{c}\text { Valor de } \\
\text { F }\end{array}$ & $\begin{array}{c}\text { Probabi- } \\
\text { dade }> \\
\text { que } F\end{array}$ \\
\hline Blocos não ajustados & 4 & 0,0769032 & & \\
Tratamentos ajustados & 6 & 0,2771261 & 0,0461877 & 1,6453 & 0,19504 \\
Resíduo & 17 & 0,4772454 & 0,0280733 & & \\
\hline Total & 27 & 0,8312747 & & & \\
\hline
\end{tabular}

Média geral ajustada Coeficiente de variação

Soma de quadrados não ajustada

\begin{tabular}{cccccccc}
\hline $\begin{array}{c}\text { Número } \\
\text { de ordem }\end{array}$ & $\begin{array}{c}\text { Núm. do } \\
\text { tratamento }\end{array}$ & $\begin{array}{c}\text { Nome do } \\
\text { tratam. }\end{array}$ & Núm. de & Médias & \multicolumn{2}{c}{ Médias } & \multicolumn{2}{c}{ Grau de signific } \\
\hline 1 & 5 & E & 4 & 0,394643 & 0,394643 & a & A \\
2 & 3 & C & 4 & 0,245626 & 0,245626 & a & A \\
3 & 2 & B & 4 & 0,206764 & 0,206764 & a & A \\
4 & 4 & D & 4 & 0,156658 & 0,156658 & a & A \\
5 & 6 & F & 4 & 0,128498 & 0,128498 & a & A \\
6 & 7 & G & 3 & 0,105378 & 0,105378 & a & A \\
7 & 1 & A & 5 & 0,070500 & 0,070500 & a & A \\
\hline
\end{tabular}

Médias seguidas por letras distintas, diferem entre si ao grau de significância indicado. 
6. Quadro resumo com os resultados do teste F, média geral e coeficiente de variação, para as variáveis estudadas.

\begin{tabular}{|c|c|c|c|c|c|c|}
\hline $\begin{array}{c}\text { Variáve- } \\
\text { is }\end{array}$ & $\begin{array}{l}\text { Posição } \\
\text { da amos- } \\
\text { tragem }\end{array}$ & $\begin{array}{l}\text { Momento } \\
\text { da amos- } \\
\text { tragem }\end{array}$ & $\begin{array}{c}\mathrm{F} \\
\text { calcu- } \\
\text { lado }\end{array}$ & $\begin{array}{l}\text { Probabilida } \\
\text {-de > F }\end{array}$ & $\begin{array}{l}\text { Média } \\
\text { geral } \\
\text { ajustada }\end{array}$ & $\begin{array}{l}\text { Coeficiente } \\
\text { de variação } \\
\left(\frac{o}{\partial}\right)\end{array}$ \\
\hline \multirow[t]{4}{*}{$\rho_{\text {solo }}$} & \multirow[t]{2}{*}{ Talude } & Pré-trat. & 0,8665 & 0,53541 & 1,316297 & 7,559 \\
\hline & & Pós-trat. & 0,1618 & 0,98287 & 1,396580 & 8,552 \\
\hline & \multirow[t]{2}{*}{ Fundo } & Pré-trat. & 0,6652 & 0,68017 & 1,349124 & 7,711 \\
\hline & & Pós-trat. & 0,7187 & 0,64097 & 1,407463 & 6,922 \\
\hline \multirow[t]{2}{*}{ M } & \multirow[t]{2}{*}{ Fundo } & Pré-trat. & 1,3077 & 0,30081 & 8,962393 & 22,182 \\
\hline & & Pós-trat. & 1,0688 & 0,41903 & 7,555013 & 23,935 \\
\hline \multirow[t]{2}{*}{$\mathrm{m}$} & \multirow[t]{2}{*}{ Fundo } & Pré-trat. & 1,4763 & 0,23858 & 24,228163 & 8,187 \\
\hline & & Pós-trat. & 2,1104 & 0,10542 & 23,762466 & 15,780 \\
\hline \multirow[t]{2}{*}{$\mathrm{P}$} & \multirow[t]{2}{*}{ Fundo } & Pré-trat. & 1,0807 & 0,40884 & 33,190300 & 10,054 \\
\hline & & Pós-trat. & 1,5302 & 0,22739 & 31,318327 & 13,176 \\
\hline \multirow[t]{2}{*}{$K_{0}$} & \multirow[t]{2}{*}{ Fundo } & Pré-trat. & 1,3109 & 0,29949 & 0,140239 & 80,209 \\
\hline & & Pós-trat. & 1,6453 & 0,19504 & 0,186867 & 89,663 \\
\hline
\end{tabular}




\section{APÊNDICE 12}

Dados de T, I, lace V..(Dados originais de campo).

Tratanento

hh:mm

16:20

16:30

$16: 39$

$16: 49$

16:58

$17: 06$

$17: 13$

$17: 24$

$17: 30$

17:37

$17: 47$

$17: 59$

18:11

18:17

$18: 27$

$18: 40$

18:52

19:06

19:16

19:37

19:52

20:00

20:15

20:20

20:35

20:45

20:58

21:11

21:24

$21: 45$

22:00

22:10

$22 \cdot 20$
: (v+A); Vinhaça in natura como redutor de infituação, seguida de água comum corno infitivante.

\begin{tabular}{|c|c|c|c|c|c|c|}
\hline$\pi$ & $\begin{array}{l}\text { TAC } \\
\text { (min.) }\end{array}$ & $\begin{array}{l}\text { Leitura } \\
\text { (mm) }\end{array}$ & $\begin{array}{l}\text { Repa } \\
\text { siçäo } \\
\text { (mm) }\end{array}$ & $\begin{array}{c}1 \\
(\mathrm{~mm})\end{array}$ & $\begin{array}{l}\mathrm{AC} \\
(\mathrm{mm})\end{array}$ & $\begin{array}{c}\text { V } \\
\text { (m) } 1 \text { minin) }\end{array}$ \\
\hline & & & petic & & & \\
\hline
\end{tabular}

458

$\begin{array}{rrr}20,3 & 20,3 & 2,0 \\ 11,4 & 31,7 & 1,3 \\ 9,7 & 41,4 & 1,0 \\ 9,7 & 51,1 & 1,1 \\ 7,3 & 58,4 & 0,9 \\ 13,8 & 72,3 & 2,0 \\ 11,4 & 83,6 & 1,6 \\ 8,1 & 91,7 & 1,4 \\ 9,7 & 101,5 & 1,4 \\ 14,6 & 116,1 & 1,5 \\ 11,4 & 127,5 & 0,9 \\ 14,6 & 142,1 & 1,2 \\ 10,6 & 152,6 & 1,3 \\ 12,2 & 164,8 & 1,2 \\ 18,7 & 183,5 & 1,4 \\ 14,6 & 198,1 & 1,2 \\ 22,7 & 220,8 & 1,6 \\ \star & \star & \star \\ 13,8 & 234,6 & 0,7 \\ 24,4 & 259,0 & 1,6 \\ 2,4 & 261,4 & 0,3 \\ 15,4 & 276,8 & 1,0 \\ 12,2 & 289,0 & 2,4 \\ 17,0 & 306,0 & 1,1 \\ 15,4 & 321,5 & 1,5 \\ 21,1 & 342,6 & 1,6 \\ 17,0 & 359,6 & 1,3 \\ 19,5 & 379,1 & 1,5 \\ 21,9 & 401,0 & 1,0 \\ 21,9 & 422,9 & 1,5 \\ 17,9 & 440,8 & 1,8 \\ 16,2 & 457,0 & 1,6\end{array}$


* Dados perdidos

Repetição V

$\begin{array}{lrrr}9: 35 & & & \\ 9: 44 & 9,0 & 9,0 & 393 \\ 9: 50 & 6,0 & 15,0 & 378 \\ 9: 57 & 7,0 & 22,0 & 365 \\ 10: 02 & 5,0 & 27,0 & 358 \\ 10: 09 & 7,0 & 34,0 & 348 \\ 10: 19 & 10,0 & 44,0 & 334 \\ 10: 26 & 7,0 & 51,0 & 323 \\ 10: 32,5 & 6,5 & 57,5 & 314 \\ 10: 40 & 7,5 & 65,0 & 305 \\ 10: 48,5 & 8,5 & 73,5 & 278 \\ 11: 08 & 20,5 & 94,0 & 263 \\ 11: 24 & 16,0 & 110,0 & 245 \\ 11: 35 & 11,0 & 121,0 & 233 \\ 11: 45 & 10,0 & 131,0 & 223 \\ 11: 55,5 & 10,5 & 141,5 & 212 \\ 12: 05 & 5,0 & 146,5 & 186 \\ 12: 47 & 42,0 & 188,5 & 165 \\ 12: 56,5 & 19,5 & 208,0 & 153 \\ 13: 09 & 12,5 & 220,5 & 139 \\ 13: 22 & 13,0 & 233,5 & 127 \\ 13: 33,5 & 11,5 & 245,0 & \star \\ 13: 47 & 13,5 & 258,5 & \star \\ 14: 05 & 18,0 & 276,5 & 267 \\ 14: 16 & 11,0 & 287,5 & 253 \\ 14: 35 & 19,0 & 306,5 & 240 \\ 14: 48,5 & 13,5 & 320,0 & 226 \\ 15: 00 & 11,5 & 331,5 & 216 \\ 15: 16 & 16,0 & 347,5 & 203 \\ 15: 32 & 16,0 & 363,5 & 188 \\ 15: 44 & 12,0 & 375,5 & 179 \\ & & & \\ & * & & \end{array}$

405

$\begin{array}{rrr}9,7 & 9,7 & 1,1 \\ 12,2 & 21,9 & 2,0 \\ 10,6 & 32,5 & 1,5 \\ 5,7 & 38,2 & 1,1 \\ 8,1 & 46,3 & 1,2 \\ 11,4 & 57,6 & 1,1 \\ 8,9 & 66,6 & 1,3 \\ 7,3 & 73,9 & 1,1 \\ 7,3 & 81,2 & 1,0 \\ 21,9 & 103,1 & 2,6 \\ 12,2 & 115,3 & 0,6 \\ 14,6 & 129,9 & 0,9 \\ 9,7 & 139,6 & 0,9 \\ 8,1 & 147,7 & 0,8 \\ 8,9 & 156,7 & 0,9 \\ 21,1 & 177,8 & 4,2 \\ 17,0 & 194,8 & 0,4 \\ 9,7 & 204,6 & 0,5 \\ 11,4 & 215,9 & 0,9 \\ 9,7 & 225,7 & 0,7 \\ \star & \star & \star \\ \star & \star & \star \\ 12,2 & 237,9 & 0,7 \\ 11,4 & 249,2 & 1,0 \\ 10,6 & 259,8 & 0,6 \\ 11,4 & 271,1 & 0,8 \\ 8,1 & 279,3 & 0,7 \\ 10,6 & 289,8 & 0,7 \\ 12,2 & 302,0 & 0,8 \\ 7,3 & 309,3 & 0,6\end{array}$

\section{Repeţ̧ão III}

9:57

10:00 10:04,5

10:10

$10: 20,5$

$10: 32,5$

$\begin{array}{rrr}3,0 & 3,0 & 412 \\ 4,5 & 7,5 & 398 \\ 5,5 & 13,0 & 376 \\ 10,5 & 23,5 & 355 \\ 12,0 & 35,5 & 343\end{array}$

423

$\begin{array}{rrr}8,9 & 8,9 & 3,0 \\ 11,4 & 20,3 & 2,5 \\ 17,9 & 38,2 & 3,2 \\ 17,0 & 55,2 & 1,6 \\ 9,7 & 64,9 & 0,8\end{array}$




$\begin{array}{lrrr}10: 40,5 & 8,0 & 43,5 & 333 \\ 10: 50,5 & 10,0 & 53,5 & 317 \\ 11: 05 & 11,0 & 64,5 & 301 \\ 11: 19,5 & 8,0 & 72,5 & 282 \\ 11: 42,5 & 23,0 & 95,5 & 258 \\ 11: 54 & 11,5 & 107,0 & 246 \\ 12: 05 & 6,5 & 113,5 & 218 \\ 12: 52,5 & 47,5 & 161,0 & 193 \\ 13: 11 & 18,5 & 179,5 & 183 \\ 13: 34 & 23,0 & 202,5 & 158 \\ 13: 59 & 25,0 & 227,5 & 140 \\ 14: 15 & 16,0 & 243,5 & 126 \\ 14: 38,5 & 25,5 & 269,0 & 111 \\ 14: 56 & 17,5 & 286,5 & 96 \\ 15: 11 & 15,0 & 301,5 & 84 \\ 15: 31 & 20,0 & 321,5 & 195 \\ 15: 58,5 & 27,5 & 349,0 & 176\end{array}$

$\begin{array}{rrr}8,1 & 73,1 & 1,0 \\ 13,0 & 86,1 & 1,3 \\ 13,0 & 99,0 & 1,2 \\ 15,4 & 114,5 & 1,9 \\ 19,5 & 133,9 & 0,8 \\ 9,7 & 143,7 & 0,8 \\ 22,7 & 166,4 & 3,5 \\ 20,3 & 186,7 & 0,4 \\ 8,1 & 194,8 & 0,4 \\ 20,3 & 215,1 & 0,9 \\ 14,6 & 229,7 & 0,6 \\ 11,4 & 241,1 & 0,7 \\ 12,2 & 253,3 & 0,5 \\ 12,2 & 265,5 & 0,7 \\ 9,7 & 275,2 & 0,6 \\ 20,3 & 295,5 & 1,0 \\ 15,4 & 310,9 & 0,6\end{array}$

Repetição II

$\begin{array}{lrrr}9: 28 & & & \\ 9: 34 & 6,0 & 6,0 & 424 \\ 9: 41 & 7,0 & 13,0 & 414 \\ 9: 49 & 8,0 & 21,0 & 403 \\ 10: 05 & 16,0 & 37,0 & 381 \\ 10: 16,5 & 11,5 & 48,5 & 373 \\ 10: 32 & 15,5 & 64,0 & 356 \\ 10: 44 & 10,0 & 74,0 & 340 \\ 10: 58 & 14,0 & 88,0 & 328 \\ 11: 19 & 21,0 & 109,0 & 308 \\ 11: 34,5 & 15,5 & 124,5 & 292 \\ 12: 00 & 25,5 & 150,0 & 253 \\ 12: 48,5 & 48,5 & 198,5 & 232 \\ 13: 17 & 28,5 & 227,0 & 212 \\ 13: 38 & 21,0 & 248,0 & 198 \\ 13: 53,5 & 15,5 & 263,5 & 189 \\ 14: 15 & 21,5 & 285,0 & 171 \\ 14: 47,5 & 32,5 & 317,5 & 417 \\ 15: 28 & 40,5 & 358,0 & 393\end{array}$

432

$\begin{array}{rrr}6,5 & 6,5 & 1,1 \\ 8,1 & 14,6 & 1,2 \\ 8,9 & 23,5 & 1,1 \\ 17,9 & 41,4 & 1,1 \\ 6,5 & 47,9 & 0,6 \\ 13,8 & 61,7 & 0,9 \\ 13,0 & 74,7 & 1,3 \\ 9,7 & 84,4 & 0,7 \\ 16,2 & 100,7 & 0,8 \\ 13,0 & 113,7 & 0,8 \\ 31,7 & 145,3 & 1,2 \\ 17,0 & 162,4 & 0,4 \\ 16,2 & 178,6 & 0,6 \\ 11,4 & 190,0 & 0,5 \\ 7,3 & 197,3 & 0,5 \\ 14,6 & 211,9 & 0,7 \\ 20,3 & 232,2 & 0,6 \\ 19,5 & 251,7 & 0,5\end{array}$

\section{Repetição N}

9:14

$09: 17,5$

$09: 20,5$

$09: 25,5$

$09: 28,5$

$\begin{array}{rrr}3,5 & 3,5 & 416 \\ 3,0 & 6,5 & 400 \\ 5,0 & 11,5 & 383 \\ 3,0 & 14,5 & 362\end{array}$

428

$\begin{array}{rrr}9,7 & 9,7 & 2,8 \\ 13,0 & 22,7 & 4,3 \\ 13,8 & 36,5 & 2,8 \\ 17,0 & 53,6 & 5,7\end{array}$




\begin{tabular}{|c|c|c|c|c|c|c|c|}
\hline $09: 39,5$ & 11,0 & 25,5 & 338 & & 19,5 & 73,1 & 1,8 \\
\hline $09: 41,5$ & 2,0 & 27,5 & 326 & & 9,7 & 82,8 & 4,9 \\
\hline $9: 45$ & 3,5 & 31,0 & 312 & & 11,4 & 94,2 & 3,2 \\
\hline $09: 49,5$ & 4,5 & 35,5 & 297 & & 12,2 & 106,3 & 2,7 \\
\hline $09: 54,5$ & 5,0 & 40,5 & 286 & & 8,9 & 115,3 & 1,8 \\
\hline 9:59 & 4,5 & 45,0 & 270 & & 13,0 & 128,3 & 2,9 \\
\hline 10:05 & 6,0 & 51,0 & 254 & & 13,0 & 141,3 & 2,2 \\
\hline 10:11 & 6,0 & 57,0 & 238 & & 13,0 & 154,2 & 2,2 \\
\hline 10:16,5 & 5,5 & 62,5 & 223 & & 12,2 & 166,4 & 2,2 \\
\hline 10:22,5 & 6,0 & 68,5 & 212 & & 8,9 & 175,3 & 1,5 \\
\hline $10: 27$ & 4,5 & 73,0 & 201 & & 8,9 & 184,3 & 2,0 \\
\hline 10:31,5 & 4,5 & 77,5 & 188 & & 10,6 & 194,8 & 2,3 \\
\hline 10:36,5 & 5,0 & 82,5 & 177 & & 8,9 & 203,8 & 1,8 \\
\hline 10:42 & 5,5 & 88,0 & 162 & & 12,2 & 215,9 & 2,2 \\
\hline $10: 47,5$ & 5,5 & 93,5 & 147 & & 12,2 & 228,1 & 2,2 \\
\hline $10: 54$ & 6,5 & 100,0 & 130 & & 13,8 & 241,9 & 2,1 \\
\hline 11:00 & 6,0 & 106,0 & 118 & & 9,7 & 251,7 & 1,6 \\
\hline 11:06 & 6,0 & 112,0 & $\star$ & 435 & $\star$ & * & $\star$ \\
\hline $11: 21,5$ & 15,5 & 127,5 & 394 & & 33,3 & 284,9 & 2,1 \\
\hline 11:38 & 16,5 & 144,0 & 372 & & 17,9 & 302,8 & 1,1 \\
\hline $11: 45$ & 7,0 & 151,0 & 357 & & 12,2 & 315,0 & 1,7 \\
\hline 11:51 & 6,0 & 157,0 & 346 & & 8,9 & 323,9 & 1,5 \\
\hline $11: 57,5$ & 6,5 & 163,5 & 328 & & 14,6 & 338,5 & 2,2 \\
\hline $12: 04$ & 6,5 & 170,0 & 315 & & 10,6 & 349,1 & 1,6 \\
\hline $12: 09$ & 5,0 & 175,0 & 300 & & 12,2 & 361,3 & 2,4 \\
\hline $12: 17$ & 8,0 & 183,0 & 280 & & 16,2 & 377,5 & 2,0 \\
\hline $12: 26$ & 9,0 & 192,0 & $\star$ & & * & * & * \\
\hline 13:10 & 44,0 & 236,0 & 180 & & $\star$ & * & * \\
\hline $13: 19,5$ & 9,5 & 245,5 & 167 & & 10,6 & 388,0 & 1,1 \\
\hline $13: 26,5$ & 7,0 & 252,5 & 155 & & 9,7 & 397,8 & 1,4 \\
\hline 13:36 & 9,5 & 262,0 & 145 & $\star$ & 8,1 & 405,9 & 0,9 \\
\hline $13: 42,5$ & 6,5 & 268,5 & 410 & & $\star$ & * & * \\
\hline $13: 49,5$ & 7,0 & 275,5 & 400 & & 8,1 & 414,0 & 1,2 \\
\hline 13:54 & 4,5 & 280,0 & 388 & & 9,7 & 423,8 & 2,2 \\
\hline $14: 01$ & 7,0 & 287,0 & 377 & & 8,9 & 432,7 & 1,3 \\
\hline $14: 06,5$ & 5,5 & 292,5 & 364 & & 10,6 & 443,2 & 1,9 \\
\hline $14: 14$ & 17,5 & 310,0 & 353 & & 8,9 & 452,2 & 0,5 \\
\hline 14:31 & 17,0 & 327,0 & 323 & & 24,4 & 476,5 & 1,4 \\
\hline $14: 39$ & 18,0 & 345,0 & 308 & & 12,2 & 488,7 & 0,7 \\
\hline 14:48 & 9,0 & 354,0 & 293 & & 12,2 & 500,9 & 1,4 \\
\hline 14:55 & 7,0 & 361,0 & 283 & & 8,1 & 509,0 & 1,2 \\
\hline 15:03 & 8,0 & 369,0 & 267 & & 13,0 & 522,0 & 1,6 \\
\hline 15:11 & 8,0 & 377,0 & 255 & & 9,7 & 531,7 & 1,2 \\
\hline $15: 18,5$ & 7,5 & 384,5 & 245 & & 8,1 & 539,8 & 1,1 \\
\hline
\end{tabular}


Tratamento

hh:mm
: (v+V); Vinhaça in natu ra como redutor de infituação, seguida de vinhaça in natura cormo influturte.

$\begin{array}{ccccccc}\text { TI } & \text { TIAC } & \text { Leitura } & \begin{array}{c}\text { Repo } \\ \text { sição }\end{array} & \text { I } & \text { IAC } & \text { V } \\ (\mathrm{min}) & (\mathrm{min}) & (\mathrm{mm}) & (\mathrm{mm}) & (\mathrm{mm}) & (\mathrm{mm}) & (\text { monvinin) }\end{array}$

Repetição I

19:54

21:23

$22: 29$

$\begin{array}{lll}89 & 381 \\ 66 & 155 \quad 372\end{array}$

390

$66 \quad 155 \quad 372$

$7,3 \quad 7,3 \quad 0,1$

$\begin{array}{lll}7,3 & 14,6 & 0,1\end{array}$

Repetição V

13:45

18:25

$21: 07$

280

162

$280,0 \quad 370$

420

347

40,6

40,6

0,1

$442,0 \quad 329$

$14,6 \quad 55,2 \quad 0,1$

Repetição III

$10: 44$

11:02

11:35

$12: 55$

13:37

$14: 25$

$15: 21$

15.53

16:44

$\begin{array}{rrr}18 & 18,0 & 398 \\ 33 & 51,0 & 384 \\ 80 & 131,0 & 361 \\ 42 & 173,0 & 349 \\ 48 & 221,0 & 325 \\ 56 & 277,0 & 287 \\ 31 & 308,0 & 263 \\ 51 & 359,0 & 235\end{array}$

410

$\begin{array}{rrr}9,7 & 9,7 & 0,5 \\ 11,4 & 21,1 & 0,3 \\ 18,7 & 39,8 & 0,2 \\ 9,7 & 49,5 & 0,2 \\ 19,5 & 69,0 & 0,4 \\ 30,8 & 99,9 & 0,6 \\ 19,5 & 119,3 & 0,6 \\ 22,7 & 142,1 & 0,4\end{array}$

Repetição II

10:42

$11: 25$

$11: 47,5$

$13: 06$

$14: 47$

16:42

$\begin{array}{rrr}43,0 & 43,0 & 410 \\ 22,5 & 65,5 & 398 \\ 18,5 & 84,0 & 380 \\ 101,0 & 185,0 & 364 \\ 115,0 & 300,0 & 359\end{array}$

423

$\begin{array}{rll}10,6 & 10,6 & 0,2 \\ 9,7 & 20,3 & 0,4 \\ 14,6 & 34,9 & 0,8 \\ 13,0 & 47,9 & 0,1 \\ 4,1 & 52,0 & 0,0\end{array}$

Repetição N

$12: 58$

442 


$\begin{array}{lrrrrrr}13: 24,5 & 26,5 & 26,5 & 427 & 12,2 & 12,2 & 0,5 \\ 13: 44,5 & 20,0 & 46,5 & 410 & 13,8 & 26,0 & 0,7 \\ 14: 16 & 31,5 & 78,0 & \star & \star & \star & * \\ 15: 01,5 & 45,5 & 123,5 & 382 & \star & \star & * \\ 16: 10 & 68,5 & 192,0 & 367 & 12,2 & 38,2 & 0,2 \\ 18: 01,5 & 111,5 & 303,5 & 351 & 13,0 & 51,1 & 0,1 \\ 18: 58,5 & 57,0 & 360,5 & 351 & 0,0 & 51,1 & 0,0\end{array}$

* Dados perdidos

Tratamento

:(A); Água comum corno infivante.

hh:mm

\begin{tabular}{|c|c|c|c|c|c|c|}
\hline $\begin{array}{c}\pi \\
\text { (min.) }\end{array}$ & $\begin{array}{l}\text { TAC } \\
\text { (min.) }\end{array}$ & $\begin{array}{l}\text { Leitura } \\
\text { (mm) }\end{array}$ & $\begin{array}{l}\text { Repa } \\
\text { siçäo } \\
\text { (mm) }\end{array}$ & $\begin{array}{c}1 \\
(\mathrm{~mm})\end{array}$ & $\begin{array}{l}\mathrm{AC} \\
(\mathrm{mm})\end{array}$ & $\begin{array}{c}\text { M } \\
\text { (mminin) }\end{array}$ \\
\hline & & & tic & & & \\
\hline
\end{tabular}

$12: 31$

$12: 32,5$

$12: 34$

$12: 35$

$12: 37$

$12: 39$

$12: 40$

$12: 42$

$12: 43,5$

$12: 45,5$

$12: 50$

$12: 52$

12.54

$12: 55$

$12: 57$

$12: 59$

13:01

$13: 03$

13.05

13:07

$13: 08,5$

$13: 10$

13:15

13:17

13:19

13:21
1,5

1,5

1,0

2,0

2,0

1,0

2,0

1,5

2,0

4,5

2,0

2,0

3,0

2,0

2,0

2,0

2,0

2,0

2,0

1,5

1,5

5,0

2,0

2,0

2,0
1,5

3,0

4,0

6,0

8,0

9,0

11,0

12,5

14,5

19,0

21,0

$23,0 \quad 362$

$26,0 \quad 338$

$28,0 \quad 305$

$30,0 \quad 280$

$32,0 \quad 254$

$34,0 \quad 228$

$36,0 \quad 202$

$38,0 \quad 180$

$39,5 \quad 155$

$41,0 \quad 140$

46,0 *

$48,0 \quad 332$

$50,0 \quad 306$

$52,0 \quad 281$

473

$$
\begin{array}{rrr}
10,6 & 10,6 & 7,0 \\
4,1 & 14,6 & 2,7 \\
24,4 & 39,0 & 24,4 \\
17,9 & 56,8 & 8,9 \\
34,9 & 91,7 & 17,5 \\
107,2 & 198,9 & 107,2 \\
18,7 & 217,6 & 9,3 \\
21,1 & 238,7 & 14,1 \\
\star & \star & \star \\
\star & \star & \star \\
21,9 & 260,6 & 11,0 \\
21,1 & 281,7 & 10,6 \\
19,5 & 301,2 & 6,5 \\
26,8 & 328,0 & 13,4 \\
20,3 & 348,3 & 10,1 \\
21,1 & 369,4 & 10,6 \\
21,1 & 390,5 & 10,6 \\
21,1 & 411,6 & 10,6 \\
17,9 & 429,4 & 8,9 \\
20,3 & 449,7 & 13,5 \\
12,2 & 461,9 & 8,1
\end{array}
$$$$
445
$$

392

$\begin{array}{rrr}* & \star & \star \\ \star & * & \star \\ 21,1 & 483,0 & 10,6 \\ 20,3 & 503,3 & 10,1\end{array}$




\begin{tabular}{|c|c|c|c|c|c|c|c|}
\hline $13: 23,5$ & 2,5 & 54,5 & 253 & & 22,7 & 526,0 & 9,1 \\
\hline $13: 25$ & 1,5 & 56,0 & 222 & & 25,2 & 551,2 & 16,8 \\
\hline $13: 27,5$ & 2,5 & 58,5 & 200 & & 17,9 & 569,1 & 7,1 \\
\hline $13: 30$ & 2,5 & 61,0 & 180 & & 16,2 & 585,3 & 6,5 \\
\hline $13: 35$ & 5,0 & 66,0 & 153 & & 21,9 & 607,2 & 4,4 \\
\hline $13: 37,5$ & 2,5 & 68,5 & 117 & & 29,2 & 636,5 & 11,7 \\
\hline $13: 42$ & 4,5 & 73,0 & 412 & 442 & 24,4 & 660,8 & 5,4 \\
\hline $13: 44,5$ & 2,5 & 75,5 & 387 & & 20,3 & 681,1 & 8,1 \\
\hline $13: 46,0$ & 2,0 & 77,5 & 360 & & 21,9 & 703,0 & 11,0 \\
\hline $13: 49$ & 2,5 & 80,0 & 335 & & 20,3 & 723,3 & 8,1 \\
\hline 13:51 & 2,0 & 82,0 & 303 & & 26,0 & 749,3 & 13,0 \\
\hline $13: 53,5$ & 2,5 & 84,5 & 286 & & 13,8 & 763,1 & 5,5 \\
\hline $13: 56$ & 2,5 & 87,0 & 260 & & 21,1 & 784,2 & 8,4 \\
\hline $14: 01$ & 5,0 & 92,0 & 206 & & 43,8 & 828,0 & 8,8 \\
\hline $14: 05$ & 4,0 & 96,0 & 184 & & 17,9 & 845,9 & 4,5 \\
\hline $14: 07$ & 2,0 & 98,0 & 158 & & 21,1 & 867,0 & 10,6 \\
\hline $14: 10,5$ & 3,5 & 101,5 & 112 & 430 & 37,3 & 904,3 & 10,7 \\
\hline $14: 14,5$ & 4,0 & 105,5 & 404 & & 21,1 & 925,5 & 5,3 \\
\hline $14: 16,5$ & 2,0 & 107,5 & 384 & & 16,2 & 941,7 & 8,1 \\
\hline $14: 19,5$ & 3,0 & 110,5 & 357 & & 21,9 & 963,6 & 7,3 \\
\hline $14: 22,5$ & 3,0 & 113,5 & 333 & & 19,5 & 983,1 & 6,5 \\
\hline $14: 26,5$ & 4,0 & 117,5 & 305 & & 22,7 & 1005,8 & 5,7 \\
\hline $14: 29$ & 2,5 & 120,0 & 280 & & 20,3 & 1026,1 & 8,1 \\
\hline $14: 31,5$ & 2,5 & 122,5 & 257 & & 18,7 & 1044,8 & 7,5 \\
\hline $14: 34,5$ & 3,0 & 125,5 & 230 & & 21,9 & 1066,7 & 7,3 \\
\hline $14: 37,5$ & 3,0 & 128,5 & 205 & & 20,3 & 1087,0 & 6,8 \\
\hline $14: 40,5$ & 3,0 & 131,5 & 185 & & 16,2 & 1103,2 & 5,4 \\
\hline $14: 44,0$ & 3,5 & 135,0 & 150 & & 28,4 & 1131,6 & 8,1 \\
\hline $14: 46,5$ & 2,5 & 137,5 & 132 & & 14,6 & 1146,3 & 5,8 \\
\hline $14: 50$ & 3,5 & 141,0 & 97 & & 28,4 & 1174,7 & 8,1 \\
\hline $14: 55$ & 5,0 & 146,0 & 420 & 448 & 22,7 & 1197,4 & 4,5 \\
\hline $14: 58,5$ & 3,5 & 149,5 & 396 & & 19,5 & 1216,9 & 5,6 \\
\hline $15: 01$ & 2,5 & 152,0 & 374 & & 17,9 & 1234,7 & 7,1 \\
\hline $15: 06$ & 5,0 & 157,0 & 349 & & 20,3 & 1255,0 & 4,1 \\
\hline $15: 08$ & 3,0 & 160,0 & 322 & & 21,9 & 1277,0 & 7,3 \\
\hline $15: 12$ & 4,0 & 164,0 & 294 & & 22,7 & 1299,7 & 5,7 \\
\hline $15: 16$ & 4,0 & 168,0 & 270 & & 19,5 & 1319,2 & 4,9 \\
\hline $15: 19$ & 3,0 & 171,0 & 245 & & 20,3 & 1339,5 & 6,8 \\
\hline $15: 22$ & 3,0 & 174,0 & 220 & & 20,3 & 1359,8 & 6,8 \\
\hline $15: 26$ & 4,0 & 178,0 & 196 & & 19,5 & 1379,2 & 4,9 \\
\hline $15: 30,5$ & 4,5 & 182,5 & 167 & & 23,5 & 1402,8 & 5,2 \\
\hline $15: 34$ & 3,5 & 186,0 & 147 & & 16,2 & 1419,0 & 4,6 \\
\hline 15:37 & 3,0 & 189,0 & 110 & & 30,0 & 1449,1 & 10,0 \\
\hline $15: 43,5$ & 6,5 & 195,5 & 408 & 428 & 16,2 & 1465,3 & 2,5 \\
\hline $15: 46,5$ & 3,0 & 198,5 & 383 & & 20,3 & 1485,6 & 6,8 \\
\hline $15: 50$ & 3,5 & 202,0 & 359 & & 19,5 & 1505,1 & 5,6 \\
\hline $15: 54,5$ & 4,5 & 206,5 & 330 & & 23,5 & 1528,6 & 5,2 \\
\hline
\end{tabular}




$\begin{array}{lrrrrrr}15: 59,5 & 5,0 & 211,5 & 305 & 20,3 & 1548,9 & 4,1 \\ 16: 01 & 1,5 & 213,0 & 275 & 24,4 & 1573,3 & 16,2 \\ 16: 08 & 7,0 & 220,0 & 248 & 21,9 & 1595,2 & 3,1 \\ 16: 12 & 4,0 & 224,0 & 225 & 18,7 & 1613,9 & 4,7 \\ 16: 15,5 & 3,5 & 227,5 & 200 & 20,3 & 1634,2 & 5,8 \\ 16: 20 & 4,5 & 232,0 & 173 & 21,9 & 1656,1 & 4,9 \\ 16: 24 & 4,0 & 236,0 & 155 & 14,6 & 1670,7 & 3,7\end{array}$

* Dados perdidos.

\section{Repetiçāo V}

424

$\begin{array}{lrrr}9: 54 & 1,0 & 1,0 & 405 \\ 10: 00 & 6,0 & 7,0 & 390 \\ 10: 01,5 & 1,5 & 8,5 & 378 \\ 10: 05 & 3,5 & 12,0 & 362 \\ 10: 08,5 & 3,5 & 15,5 & 350 \\ 10: 11,5 & 3,0 & 18,5 & 335 \\ 10: 15 & 3,5 & 22,0 & 322 \\ 10: 18,5 & 3,5 & 25,5 & 310 \\ 10: 24,5 & 6,0 & 31,5 & 294 \\ 10: 28,5 & 4,0 & 35,5 & 281 \\ 10: 33,5 & 5,0 & 40,5 & 269 \\ 10: 38,5 & 5,0 & 45,5 & 257 \\ 10: 44 & 5,5 & 51,0 & 243 \\ 10: 51 & 7,0 & 58,0 & 232 \\ 10: 59,5 & 8,5 & 66,5 & 215 \\ 11: 13 & 13,5 & 80,0 & 196 \\ 11: 21 & 8,0 & 88,0 & 184 \\ 11: 31,5 & 10,5 & 98,5 & 170 \\ 11: 42 & 10,5 & 109,0 & 157 \\ 11: 54 & 12,0 & 121,0 & 144 \\ 12: 03 & 9,0 & 130,0 & 115 \\ 12: 48 & 45,0 & 175,0 & 67 \\ 13: 35 & 47,0 & 222,0 & 377 \\ 13: 48,5 & 13,5 & 235,5 & 360 \\ 14: 04 & 15,5 & 251,0 & 348 \\ 14: 21 & 17,0 & 268,0 & 335 \\ 14: 40 & 19,0 & 287,0 & 320 \\ 15: 00 & 20,0 & 307,0 & 302 \\ 15: 16 & 16,0 & 323,0 & 290 \\ 15: 32,5 & 16,5 & 339,5 & 278 \\ 15: 55 & 22,5 & 362,0 & 263\end{array}$

$\begin{array}{rrr}15,4 & 15,4 & 15,4 \\ 12,2 & 27,6 & 2,0 \\ 9,7 & 37,3 & 6,5 \\ 13,0 & 50,3 & 3,7 \\ 9,7 & 60,1 & 2,8 \\ 12,2 & 72,3 & 4,1 \\ 10,6 & 82,8 & 3,0 \\ 9,7 & 92,5 & 2,8 \\ 13,0 & 105,5 & 2,2 \\ 10,6 & 116,1 & 2,6 \\ 9,7 & 125,8 & 1,9 \\ 9,7 & 135,6 & 1,9 \\ 11,4 & 146,9 & 2,1 \\ 8,9 & 155,9 & 1,3 \\ 13,8 & 169,7 & 1,6 \\ 15,4 & 185,1 & 1,1 \\ 9,7 & 194,8 & 1,2 \\ 11,4 & 206,2 & 1,1 \\ 10,6 & 216,8 & 1,0 \\ 10,6 & 227,3 & 0,9 \\ 23,5 & 250,8 & 2,6 \\ 39,0 & 289,8 & 0,9 \\ 21,9 & 311,7 & 0,5 \\ 13,8 & 325,5 & 1,0 \\ 9,7 & 335,3 & 0,6 \\ 10,6 & 345,8 & 0,6 \\ 12,2 & 358,0 & 0,6 \\ 14,6 & 372,6 & 0,7 \\ 9,7 & 382,4 & 0,6 \\ 9,7 & 392,1 & 0,6 \\ 12,2 & 404,3 & 0,5 \\ & & \end{array}$

Repetiçäo III 
10:34

10:35,5

10:37,5

10:39

$10: 40,5$

$10: 42$

$10: 44,5$

10:46

10:50

$10: 52,5$

10:55

$10: 59$

11:01

11:05

$11: 08,5$

11:11

$11: 13,5$

11:18

$11: 21$

$11: 25$

11:29

11:33

$11: 38,5$

$11: 43,5$

$11: 48$

$11: 52,5$

$12: 00$

$12: 52$

$12: 57,5$

13:05

13:26

13:40

$13: 49,5$

$14: 00$

14:08

$14: 22$

$14: 35$

$14: 47$

$14: 59,5$

15:17

15:31

15:48

16:04

$16: 22,5$

$16: 39$
1,5

2,0

1,5

1,5

2,5

1,5

4,0

2,5

2,5

4,0

2,0

4,0

3,5

2,5

2,5

4,5

3,0

4,0

4,0

4,0

5,5

5,0

4,5

4,5

7,5

52,0

5,5

3,0

21,0

14,0

9,5

10,5

8,0

14,0

13,0

12,0

12,5

17,5

14,0

17,0

16,0

18,5

17,5
1,5

3,5

5,0

6,5

416

402

390

378

362

$10,5 \quad 352$

$12,0 \quad 337$

$16,0 \quad 316$

$18,5 \quad 304$

$21,0 \quad 288$

$25,0 \quad 273$

$27,0 \quad 263$

$31,0 \quad 243$

$34,5 \quad 232$

$37,0 \quad 224$

$39,5 \quad 216$

$44,0 \quad 197$

$47,0 \quad 187$

$51,0 \quad 175$

$55,0 \quad 162$

$59,0 \quad 154$

$64,5 \quad 378$

$69,5 \quad 369$

$74,0 \quad 355$

$78,5 \quad 341$

$86,0 \quad 314$

$138,0 \quad 237$

$143,5 \quad 228$

$146,5 \quad 220$

$167,5 \quad 190$

$181,5 \quad 172$

$191,0 \quad 162$

$201,5 \quad 154$

$209,5 \quad 141$

$223,5 \quad 127$

$236,5 \quad 414$

$248,5 \quad 402$

$261,0 \quad 387$

$278,5 \quad 371$

$292,5 \quad 357$

$309,5 \quad 343$

$325,5 \quad 329$

$344,0 \quad 313$

$361,5 \quad 298$
434

$\begin{array}{rll}14,6 & 14,6 & 9,7 \\ 11,4 & 26,0 & 5,7 \\ 9,7 & 35,7 & 6,5 \\ 9,7 & 45,5 & 6,5 \\ 13,0 & 58,4 & 8,7 \\ 8,1 & 66,6 & 3,2\end{array}$

$12,2 \quad 78,7 \quad 8,1$

$17,0 \quad 95,8 \quad 4,3$

$9,7 \quad 105,5 \quad 3,9$

$13,0 \quad 118,5 \quad 5,2$

$12,2 \quad 130,7 \quad 3,0$

$8,1 \quad 138,8 \quad 4,1$

$16,2 \quad 155,1 \quad 4,1$

$8,9 \quad 164,0 \quad 2,6$

$6,5 \quad 170,5 \quad 2,6$

$6,5 \quad 177,0 \quad 2,6$

$15,4 \quad 192,4 \quad 3,4$

$8,1 \quad 200,5 \quad 2,7$

$9,7 \quad 210,3 \quad 2,4$

$10,6 \quad 220,8 \quad 2,6$

$6,5 \quad 227,3 \quad 1,6$

$14,6 \quad 241,9 \quad 2,7$

$7,3 \quad 249,2 \quad 1,5$

$11,4 \quad 260,6 \quad 2,5$

$11,4 \quad 272,0 \quad 2,5$

$21,9 \quad 293,9 \quad 2,9$

$62,5 \quad 356,4 \quad 1,2$

$7,3 \quad 363,7 \quad 1,3$

$6,5 \quad 370,2 \quad 2,2$

$24,4 \quad 394,5 \quad 1,2$

$14,6 \quad 409,1 \quad 1,0$

$8,1 \quad 417,3 \quad 0,9$

$6,5 \quad 423,8 \quad 0,6$

$10,6 \quad 434,3 \quad 1,3$

432

$11,4 \quad 445,7 \quad 0,8$

$14,6 \quad 460,3 \quad 1,1$

$9,7 \quad 470,0 \quad 0,8$

$12,2 \quad 482,2 \quad 1,0$

$13,0 \quad 495,2 \quad 0,7$

$11,4 \quad 506,6 \quad 0,8$

$11,4 \quad 517,9 \quad 0,7$

$11,4 \quad 529,3 \quad 0,7$

$13,0 \quad 542,3 \quad 0,7$

$12,2 \quad 554,5 \quad 0,7$

Repetção II 
10:30

10:31

10:34

10:37,5

$10: 42,5$

$10: 48$

$10: 54$

$11: 01$

11:09

$11: 20$

11:27

11:35

$11: 45$

$11: 54,5$

12:02

12:12

13:04

13:20

$13: 32,5$

$13: 47$

14:00

$14: 16$

$14: 33$

$14: 50,5$

15:05

$15: 19,5$

15:36

16:10

16:39

17:04

$\begin{array}{rrr}1,0 & 1,0 & 413 \\ 3,0 & 4,0 & 392 \\ 3,5 & 7,5 & 369 \\ 5,0 & 12,5 & 349 \\ 5,5 & 18,0 & 330 \\ 6,0 & 24,0 & 312 \\ 7,0 & 31,0 & 290 \\ 8,0 & 39,0 & 269 \\ 11,0 & 50,0 & 243 \\ 7,0 & 57,0 & 231 \\ 8,0 & 65,0 & 214 \\ 10,0 & 75,0 & 195 \\ 9,5 & 84,5 & 182 \\ 7,5 & 92,0 & 400 \\ 10,0 & 102,0 & 397 \\ 52,0 & 154,0 & 347 \\ 16,0 & 170,0 & 333 \\ 13,0 & 183,0 & 316 \\ 14,0 & 197,0 & 304 \\ 13,0 & 210,0 & 290 \\ 16,0 & 226,0 & 278 \\ 16,5 & 242,5 & 263 \\ 18,0 & 260,5 & 247 \\ 14,5 & 275,0 & 236 \\ 14,5 & 289,5 & 223 \\ 16,5 & 306,0 & 211 \\ 34,0 & 340,0 & 184 \\ 29,0 & 369,0 & 166 \\ 25,0 & 394,0 & 150\end{array}$

433

$\begin{array}{rrr}16,2 & 16,2 & 16,2 \\ 17,0 & 33,3 & 5,7 \\ 18,7 & 52,0 & 5,3 \\ 16,2 & 68,2 & 3,2 \\ 15,4 & 83,6 & 2,8 \\ 14,6 & 98,2 & 2,4 \\ 17,9 & 116,1 & 2,6 \\ 17,0 & 133,1 & 2,1 \\ 21,1 & 154,2 & 1,9 \\ 9,7 & 164,0 & 1,4 \\ 13,8 & 177,8 & 1,7 \\ 15,4 & 193,2 & 1,5 \\ 10,6 & 203,8 & 1,1 \\ 34,1 & 237,9 & 4,5 \\ 2,4 & 240,3 & 0,2 \\ 40,6 & 280,9 & 0,8 \\ 11,4 & 292,2 & 0,7 \\ 13,8 & 306,0 & 1,1 \\ 9,7 & 315,8 & 0,7 \\ 11,4 & 327,2 & 0,9 \\ 9,7 & 336,9 & 0,6 \\ 12,2 & 349,1 & 0,7 \\ 13,0 & 362,1 & 0,7 \\ 8,9 & 371,0 & 0,6 \\ 10,6 & 381,5 & 0,7 \\ 9,7 & 391,3 & 0,6 \\ 21,9 & 413,2 & 0,6 \\ 14,6 & 427,8 & 0,5 \\ 13,0 & 440,8 & 0,5\end{array}$

Repetição N

453

$\begin{array}{rrr}17,9 & 17,9 & 11,9 \\ 19,5 & 37,3 & 19,5 \\ 27,6 & 64,9 & 7,9 \\ 15,4 & 80,4 & 7,7 \\ 13,0 & 93,4 & 6,5 \\ 23,5 & 116,9 & 11,8 \\ 52,0 & 168,9 & 5,5 \\ 15,4 & 184,3 & 5,1 \\ 14,6 & 198,9 & 4,2 \\ 16,2 & 215,1 & 4,6 \\ 16,2 & 231,4 & 4,6 \\ 17,0 & 248,4 & 3,8\end{array}$

1,5

1,0

3,5

2,0

2,0

2,0

9,5

3,0

3,5

3,5

3,5

4,5
1,5

2,5

431

$6,0 \quad 373$

$8,0 \quad 354$

$10,0 \quad 338$

$12,0 \quad 309$

$21,5 \quad 245$

$24,5 \quad 226$

$28,0 \quad 208$

$31,5 \quad 188$

$35,0 \quad 168$

$39,5 \quad 147$
$12: 18,5$

12:20

12:21

$12: 24,5$

$12: 26,5$

$12: 28,5$

$12: 30,5$

$12: 40$

$12: 43$

$12: 46,5$

$12: 50$

$12: 53,5$

$12: 58$ 


\begin{tabular}{|c|c|c|c|c|c|c|c|}
\hline $13: 01,5$ & 3,5 & 43,0 & 131 & 451 & 13,0 & 261,4 & 3,7 \\
\hline $13: 05,5$ & 4,0 & 47,0 & 436 & & 12,2 & 273,6 & 3,0 \\
\hline $13: 09$ & 3,5 & 50,5 & 413 & & 18,7 & 292,2 & 5,3 \\
\hline $13: 14,5$ & 5,5 & 56,0 & 396 & & 13,8 & 306,0 & 2,5 \\
\hline $13: 18,5$ & 4,0 & 60,0 & 378 & & 14,6 & 320,7 & 3,7 \\
\hline $13: 23,5$ & 5,0 & 65,0 & 357 & & 17,0 & 337,7 & 3,4 \\
\hline $13: 29$ & 5,5 & 70,5 & 334 & & 18,7 & 356,4 & 3,4 \\
\hline $13: 35,5$ & 6,5 & 77,0 & * & 457 & * & * & * \\
\hline $13: 42$ & 6,5 & 83,5 & 436 & & 17,0 & 373,4 & 2,6 \\
\hline $13: 47,5$ & 5,5 & 89,0 & 420 & & 13,0 & 386,4 & 2,4 \\
\hline $13: 54$ & 6,5 & 95,5 & 400 & & 16,2 & 402,7 & 2,5 \\
\hline $14: 01,5$ & 7,5 & 103,0 & 380 & & 16,2 & 418,9 & 2,2 \\
\hline $14: 07,5$ & 6,0 & 109,0 & 361 & & 15,4 & 434,3 & 2,6 \\
\hline $14: 15$ & 7,5 & 116,5 & 344 & & 13,8 & 448,1 & 1,8 \\
\hline $14: 22,5$ & 7,5 & 124,0 & 327 & & 13,8 & 461,9 & 1,8 \\
\hline $14: 29$ & 6,5 & 130,5 & 307 & & 16,2 & 478,2 & 2,5 \\
\hline $14: 37$ & 8,0 & 138,5 & 286 & & 17,0 & 495,2 & 2,1 \\
\hline $14: 47$ & 10,0 & 148,5 & 262 & & 19,5 & 514,7 & 1,9 \\
\hline $14: 56,5$ & 9,5 & 158,0 & 240 & & 17,9 & 532,5 & 1,9 \\
\hline 15:06 & 9,5 & 167,5 & 223 & & 13,8 & 546,3 & 1,5 \\
\hline $15: 15$ & 9,0 & 176,5 & 204 & & 15,4 & 561,8 & 1,7 \\
\hline $15: 23,0$ & 8,0 & 184,5 & 190 & & 11,4 & 573,1 & 1,4 \\
\hline $15: 37$ & 14,0 & 198,5 & 161 & & 23,5 & 596,7 & 1,7 \\
\hline $15: 52$ & 5,0 & 203,5 & 134 & 454 & 21,9 & 618,6 & 4,4 \\
\hline $16: 05,5$ & 13,5 & 217,0 & 431 & & 18,7 & 637,3 & 1,4 \\
\hline $16: 16,5$ & 11,0 & 228,0 & 409 & & 17,9 & 655,1 & 1,6 \\
\hline $16: 30,5$ & 14,0 & 242,0 & 386 & & 18,7 & 673,8 & 1,3 \\
\hline $16: 44$ & 13,5 & 255,5 & 362 & & 19,5 & 693,3 & 1,4 \\
\hline $16: 59,5$ & 15,5 & 271,0 & 337 & & 20,3 & 713,6 & 1,3 \\
\hline $17: 12$ & 12,5 & 283,5 & 318 & & 15,4 & 729,0 & 1,2 \\
\hline $17: 28$ & 16,0 & 299,5 & 293 & & 20,3 & 749,3 & 1,3 \\
\hline $17: 45$ & 17,0 & 316,5 & 269 & & 19,5 & 768,8 & 1,1 \\
\hline 18:14,5 & 29,5 & 346,0 & 246 & & 18,7 & 787,4 & 0,6 \\
\hline $18: 27,5$ & 13,0 & 359,0 & 210 & & 29,2 & 816,7 & 2,2 \\
\hline
\end{tabular}

* Dados perdidos

Tratamento

M); Vinhaça in natura corno invitrante.

hh:mm

\begin{tabular}{|c|c|c|c|c|c|c|}
\hline $\begin{array}{c}\pi \\
(\min )\end{array}$ & $\begin{array}{l}\text { MAC } \\
\text { (min.) }\end{array}$ & $\begin{array}{l}\text { Leitura } \\
\text { (mm) }\end{array}$ & $\begin{array}{l}\text { Repa } \\
\text { sição } \\
\text { (mm) }\end{array}$ & $\begin{array}{c}1 \\
(\mathrm{~mm})\end{array}$ & $\begin{array}{l}\mathrm{AC} \\
(\mathrm{mm})\end{array}$ & $\begin{array}{c}\text { M } \\
\text { (mm/rin) }\end{array}$ \\
\hline & & & epetic & & & \\
\hline
\end{tabular}




$\begin{array}{lrrrrrrr}10: 00 & & & 440 & & & \\ 10: 24,5 & 24,5 & 24,5 & 428,0 & 402 & 9,7 & 9,7 & 0,4 \\ 11: 19 & 54,5 & 79,0 & 387,0 & & 12,2 & 21,9 & 0,2 \\ 12: 59 & 100,0 & 179,0 & 367,0 & & 16,2 & 38,2 & 0,2 \\ 14: 36 & 97,0 & 276,0 & 354,0 & & 10,6 & 48,7 & 0,1 \\ 16: 00 & 84,0 & 360,0 & 338,0 & & 13,0 & 61,7 & 0,2\end{array}$

Repetção V

15:12

$15: 21$

$15: 43,5$

16:21

$17: 47$

$20: 27$

$\begin{array}{rrr}9,0 & 9,0 & 389 \\ 22,5 & 31,5 & 370 \\ 37,5 & 69,0 & 357 \\ 86,0 & 155,0 & 332 \\ 160,0 & 315,0 & 302\end{array}$

406

$\begin{array}{cccc} & 13,8 & 13,8 & 1,5 \\ & 15,4 & 29,2 & 0,7 \\ 320 & 10,6 & 39,8 & 0,3 \\ 20,3 & 60,1 & 0,2 \\ 14,6 & 74,7 & 0,1\end{array}$

Repetição III

13:56

440

14:00

$14: 06,5$

$\begin{array}{rrr}4,0 & 4,0 & 424 \\ 6,5 & 10,5 & 410\end{array}$

$13,0 \quad 13,0 \quad 3,2$

$14: 17$

$11,5 \quad 22,0 \quad 393$

$14: 26$

$14: 33,5$

$9,0 \quad 31,0 \quad 383$

$7,5 \quad 38,5 \quad 372$

$11,0 \quad 49,5 \quad 360$

$10,5 \quad 60,0 \quad 345$

$14: 55$

$15: 13$

15:31

18,0

$78,0 \quad 334$

$18,0 \quad 96,0 \quad 317$

$15: 59$

$28,0 \quad 124,0 \quad 304$

$28,0 \quad 152,0 \quad 290$

$34,0 \quad 186,0 \quad 272$

$38,0 \quad 224,0 \quad 257$

$38,0 \quad 262,0 \quad 240$

$69,0 \quad 331,0 \quad 219$

$28,0 \quad 359,0 \quad 219$

$11,4 \quad 24,4 \quad 1,7$

$13,8 \quad 38,2 \quad 1,2$

$8,1 \quad 46,3 \quad 0,9$

$8,9 \quad 55,2 \quad 1,2$

$9,7 \quad 64,9 \quad 0,9$

$12,2 \quad 77,1 \quad 1,2$

$8,9 \quad 86,1 \quad 0,5$

$13,8 \quad 99,9 \quad 0,8$

$10,6 \quad 110,4 \quad 0,4$

$11,4 \quad 121,8 \quad 0,4$

$14,6 \quad 136,4 \quad 0,4$

$12,2 \quad 148,6 \quad 0,3$

$13,8 \quad 162,4 \quad 0,4$

$17,0 \quad 179,4 \quad 0,2$

19.54

Repetiçäo II

16:34

$16: 42$

16:53

17:05

$17: 39$

18:02

18:30,5

19:22

21:11

22:35

$\begin{array}{rrr}8,0 & 8,0 & 410 \\ 19,0 & 27,0 & 386 \\ 12,0 & 39,0 & 371 \\ 34,0 & 73,0 & 325 \\ 23,0 & 96,0 & 300 \\ 28,5 & 124,5 & 282 \\ 51,5 & 176,0 & 261 \\ 49,0 & 225,0 & 242 \\ 84,0 & 309,0 & 235\end{array}$

433

$\begin{array}{rrr}18,7 & 18,7 & 2,3 \\ 19,5 & 38,2 & 1,0 \\ 12,2 & 50,3 & 1,0 \\ 37,3 & 87,7 & 1,1 \\ 20,3 & 108,0 & 0,9 \\ 14,6 & 122,6 & 0,5 \\ 17,0 & 139,6 & 0,3 \\ 15,4 & 155,1 & 0,3 \\ 5,7 & 160,7 & 0,1\end{array}$


Repetição N

(Perdida)

Tratamento

thimm

15:35

15:41

$15: 53,5$

16:00

16:07

16:14

16:21,5

16:30

16:35

16.53

17:05

$17: 17,5$

$17: 30$

$17: 44$

$17: 55,5$

18:05

18:16

18:27

18:40

18:53

19:05

19:37,5

19:57,5

20:08

20:44

21:15

21:35
: (a+A); Água cornum corno redutor de influaşão, seguida de água comum corro infituante.

\begin{tabular}{|c|c|c|c|c|c|c|}
\hline $\begin{array}{c}\pi \\
(\min .)\end{array}$ & $\begin{array}{l}\text { TAC } \\
\text { (min.) }\end{array}$ & $\begin{array}{l}\text { Leitura } \\
\text { (mm) }\end{array}$ & $\begin{array}{l}\text { Repa } \\
\text { siçáo } \\
(\mathrm{mm})\end{array}$ & $\begin{array}{c}1 \\
(\mathrm{~mm})\end{array}$ & $\begin{array}{l}\mathrm{AC} \\
(\mathrm{mm})\end{array}$ & $\begin{array}{c}M \\
(m \pi / m i n)\end{array}$ \\
\hline & & & $\begin{array}{l}\text { epetição } \\
\text { Perdida) }\end{array}$ & & & \\
\hline
\end{tabular}

Repetição V

403

$\begin{array}{rrr}6,0 & 6,0 & 384 \\ 12,5 & 18,5 & 362 \\ 6,5 & 25,0 & 345 \\ 7,0 & 32,0 & 330 \\ 7,0 & 39,0 & 318 \\ 7,5 & 46,5 & 303 \\ 8,5 & 55,0 & 292 \\ 5,0 & 60,0 & 267 \\ 8,0 & 68,0 & 247 \\ 12,0 & 80,0 & 233 \\ 12,5 & 92,5 & 217 \\ 12,5 & 105,0 & 406 \\ 14,0 & 119,0 & 390 \\ 11,5 & 130,5 & 377 \\ 9,5 & 140,0 & 366 \\ 11,0 & 151,0 & 351 \\ 11,0 & 162,0 & 341 \\ 13,0 & 175,0 & 325 \\ 13,0 & 188,0 & 312 \\ 13,0 & 201,0 & 302 \\ 32,5 & 233,5 & 264 \\ 20,0 & 253,5 & 245 \\ 10,5 & 264,0 & 220 \\ 36,0 & 300,0 & 200 \\ 31,0 & 331,0 & 178 \\ 20,0 & 351,0 & 160\end{array}$

$\begin{array}{rrr}15,4 & 15,4 & 2,6 \\ 17,9 & 33,3 & 1,4 \\ 13,8 & 47,1 & 2,1 \\ 12,2 & 59,3 & 1,7 \\ 9,7 & 69,0 & 1,4 \\ 12,2 & 81,2 & 1,6 \\ 8,9 & 90,1 & 1,1 \\ 20,3 & 110,4 & 4,1 \\ 16,2 & 126,6 & 2,0 \\ 11,4 & 138,0 & 0,9 \\ 13,0 & 151,0 & 1,0 \\ 13,0 & 164,0 & 1,0 \\ 13,0 & 177,0 & 0,9 \\ 10,6 & 187,5 & 0,9 \\ 8,9 & 196,5 & 0,9 \\ 12,2 & 208,6 & 1,1 \\ 8,1 & 216,8 & 0,7 \\ 13,0 & 229,7 & 1,0 \\ 10,6 & 240,3 & 0,8 \\ 8,1 & 248,4 & 0,6 \\ 30,8 & 279,3 & 0,9 \\ 15,4 & 294,7 & 0,8 \\ 20,3 & 315,0 & 1,9 \\ 16,2 & 331,2 & 0,5 \\ 17,9 & 349,1 & 0,6 \\ 14,6 & 363,7 & 0,7\end{array}$


13:37

$13: 41$

$13: 44,5$

$13: 54,5$

$13: 58,5$

$14: 03$

14:09,5

$14: 17,5$

$14: 22,5$

$14: 26,5$

$14: 34,5$

$14: 41,5$

$14: 48,5$

$14: 57,5$

15:06

15:16,5

15:27

15:37

$15: 45,5$

15:55

16:10

16:25

16:38

16:49

16:57

17:10

17:24

$17: 33,5$

$17: 44,5$

$17: 56,5$

18:05

18:15

18:55

19:25

19:51

$\begin{array}{rrr}4,0 & 4,0 & 387 \\ 3,5 & 7,5 & 362 \\ 10,0 & 17,5 & 350 \\ 4,0 & 21,5 & 344 \\ 4,5 & 26,0 & 332 \\ 6,5 & 32,5 & 315 \\ 8,0 & 40,5 & 314 \\ 5,0 & 45,5 & 302 \\ 4,5 & 50,0 & 282 \\ 8,0 & 58,0 & 272 \\ 6,5 & 64,5 & 258 \\ 7,5 & 72,0 & 247 \\ 8,5 & 80,5 & 230 \\ 9,5 & 90,0 & 218 \\ 10,5 & 100,5 & 202 \\ 10,5 & 111,0 & 192 \\ 10,0 & 121,0 & 177 \\ 8,5 & 129,5 & 163 \\ 9,5 & 139,0 & 148 \\ 15,0 & 154,0 & 126 \\ 15,0 & 169,0 & 405 \\ 13,0 & 182,0 & 388 \\ 10,5 & 192,5 & 373 \\ 8,5 & 201,0 & 359 \\ 13,0 & 214,0 & 336 \\ 14,0 & 228,0 & 322 \\ 9,5 & 237,5 & 308 \\ 11,0 & 248,5 & 293 \\ 12,0 & 260,5 & 278 \\ 8,5 & 269,0 & 264 \\ 10,0 & 279,0 & 236 \\ 40,0 & 319,0 & 192 \\ 30,0 & 349,0 & 176 \\ 26,0 & 375,0 & 151\end{array}$

\section{Repetição II}

14:00

14:01

$14: 02,5$

$14: 04$

14:05,5

14:07

14:10

$14: 12,5$

$14: 14,5$
400

\begin{tabular}{|c|c|c|}
\hline 10,6 & 10,6 & 2,6 \\
\hline 20,3 & 30,8 & 5,8 \\
\hline 9,7 & 40,6 & 1,0 \\
\hline 4,9 & 45,5 & 1,2 \\
\hline 9,7 & 55,2 & 2,2 \\
\hline 13,8 & 69,0 & 2,1 \\
\hline 0,8 & 69,8 & 0,1 \\
\hline 9,7 & 79,6 & 1,9 \\
\hline 16,2 & 95,8 & 3,6 \\
\hline 8,1 & 103,9 & 1,0 \\
\hline 11,4 & 115,3 & 1,7 \\
\hline 8,9 & 124,2 & 1,2 \\
\hline 13,8 & 138,0 & 1,6 \\
\hline 9,7 & 147,7 & 1,0 \\
\hline 13,0 & 160,7 & 1,2 \\
\hline 8,1 & 168,9 & 0,8 \\
\hline 12,2 & 181,0 & 1,2 \\
\hline 11,4 & 192,4 & 1,3 \\
\hline 12,2 & 204,6 & 1,3 \\
\hline 17,9 & 222,4 & 1,2 \\
\hline 12,2 & 234,6 & 0,8 \\
\hline 11,4 & 246,0 & 0,9 \\
\hline 12,2 & 258,2 & 1,2 \\
\hline 11,4 & 269,5 & 1,3 \\
\hline 18,7 & 288,2 & 1,4 \\
\hline 11,4 & 299,6 & 0,8 \\
\hline 11,4 & 310,9 & 1,2 \\
\hline 12,2 & 323,1 & 1,1 \\
\hline 12,2 & 335,3 & 1,0 \\
\hline 11,4 & 346,6 & 1,3 \\
\hline 22,7 & 369,4 & 2,3 \\
\hline 35,7 & 405,1 & 0,9 \\
\hline 13,0 & 418,1 & 0,4 \\
\hline 20,3 & 438,4 & 0,8 \\
\hline
\end{tabular}

336

$\begin{array}{rrr}21,1 & 21,1 & 21,1 \\ 17,9 & 39,0 & 11,9 \\ 22,7 & 61,7 & 9,1 \\ 21,9 & 83,6 & 14,6 \\ 19,5 & 103,1 & 7,8 \\ 18,7 & 121,8 & 6,2 \\ 22,7 & 144,5 & 9,1 \\ 17,9 & 162,4 & 8,9\end{array}$




\begin{tabular}{|c|c|c|c|c|c|c|c|}
\hline $14: 19$ & 4,5 & 21,0 & 445 & & 19,5 & 181,8 & 4,3 \\
\hline $14: 21$ & 2,0 & 23,0 & 422 & & 18,7 & 200,5 & 9,3 \\
\hline $14: 23$ & 2,0 & 25,0 & 380 & & 34,1 & 234,6 & 17,0 \\
\hline $14: 29$ & 6,0 & 31,0 & 296 & & 68,2 & 302,8 & 11,4 \\
\hline $14: 32,5$ & 3,5 & 34,5 & 219 & & 62,5 & 365,3 & 17,9 \\
\hline $14: 36,5$ & 4,0 & 38,5 & 170 & & 39,8 & 405,1 & 9,9 \\
\hline $14: 38,5$ & 2,0 & 40,5 & 140 & & 24,4 & 429,4 & 12,2 \\
\hline $14: 40$ & 1,5 & 42,0 & 108 & & 26,0 & 455,4 & 17,3 \\
\hline $14: 42$ & 2,0 & 44,0 & 65 & 285 & 34,9 & 490,3 & 17,5 \\
\hline $14: 43$ & 1,0 & 45,0 & 251 & & 27,6 & 517,9 & 27,6 \\
\hline $14: 45$ & 2,0 & 47,0 & 230 & & 17,0 & 535,0 & 8,5 \\
\hline $14: 47$ & 2,0 & 49,0 & 209 & & 17,0 & 552,0 & 8,5 \\
\hline $14: 49$ & 2,0 & 51,0 & 180 & & 23,5 & 575,6 & 11,8 \\
\hline $14: 51$ & 2,0 & 53,0 & 148 & & 26,0 & 601,5 & 13,0 \\
\hline $14: 53,5$ & 2,5 & 55,5 & 108 & * & 32,5 & 634,0 & 13,0 \\
\hline $14: 59,5$ & 6,0 & 61,5 & 436 & & * & $\star$ & * \\
\hline $15: 01$ & 6,0 & 67,5 & 416 & & 16,2 & 650,3 & 2,7 \\
\hline $15: 03$ & 2,0 & 69,5 & 393 & & 18,7 & 668,9 & 9,3 \\
\hline $15: 04,5$ & 1,5 & 71,0 & 370 & & 18,7 & 687,6 & 12,4 \\
\hline $15: 06$ & 1,5 & 72,5 & 345 & & 20,3 & 707,9 & 13,5 \\
\hline $15: 07,5$ & 1,5 & 74,0 & 323 & & 17,9 & 725,7 & 11,9 \\
\hline $15: 09$ & 1,5 & 75,5 & 293 & & 24,4 & 750,1 & 16,2 \\
\hline $15: 11$ & 2,0 & 77,5 & 268 & & 20,3 & 770,4 & 10,1 \\
\hline $15: 21$ & 10,0 & 87,5 & 240 & & 22,7 & 793,1 & 2,3 \\
\hline $15: 26$ & 5,0 & 92,5 & 189 & & 41,4 & 834,5 & 8,3 \\
\hline $15: 28$ & 2,0 & 94,5 & 158 & & 25,2 & 859,7 & 12,6 \\
\hline $15: 29,5$ & 1,5 & 96,0 & 129 & & 23,5 & 883,2 & 15,7 \\
\hline $15: 31$ & 1,5 & 97,5 & 100 & & 23,5 & 906,8 & 15,7 \\
\hline $15: 33$ & 2,0 & 99,5 & 61 & 444 & 31,7 & 938,4 & 15,8 \\
\hline $15: 35$ & 2,0 & 101,5 & 412 & & 26,0 & 964,4 & 13,0 \\
\hline $15: 42$ & 9,0 & 110,5 & 392 & & 16,2 & 980,7 & 1,8 \\
\hline $15: 44$ & 2,0 & 112,5 & 364 & & 22,7 & 1003,4 & 11,4 \\
\hline $15: 46$ & 2,0 & 114,5 & 336 & & 22,7 & 1026,1 & 11,4 \\
\hline $15: 48$ & 2,0 & 116,5 & 308 & & 22,7 & 1048,8 & 11,4 \\
\hline $15: 50$ & 2,0 & 118,5 & 271 & & 30,0 & 1078,9 & 15,0 \\
\hline $15: 52$ & 2,0 & 120,5 & 240 & & 25,2 & 1104,0 & 12,6 \\
\hline $15: 54$ & 2,0 & 122,5 & 205 & & 28,4 & 1132,5 & 14,2 \\
\hline $15: 57$ & 3,0 & 125,5 & 171 & & 27,6 & 1160,1 & 9,2 \\
\hline $16: 02$ & 5,0 & 130,5 & 114 & 187 & 46,3 & 1206,3 & 9,3 \\
\hline $16: 06,5$ & 4,5 & 135,0 & 160 & 399 & 21,9 & 1228,3 & 4,9 \\
\hline $16: 08,5$ & 3,0 & 138,0 & 366 & & 26,8 & 1255,0 & 8,9 \\
\hline $16: 12,5$ & 3,0 & 141,0 & 333 & & 26,8 & 1281,8 & 8,9 \\
\hline $16 ; 14$ & 1,5 & 142,5 & 305 & & 22,7 & 1304,6 & 15,2 \\
\hline $16: 16,5$ & 2,5 & 145,0 & 266 & & 31,7 & 1336,2 & 12,7 \\
\hline $16: 21$ & 4,5 & 149,5 & 217 & & 39,8 & 1376,0 & 8,8 \\
\hline
\end{tabular}




\begin{tabular}{|c|c|c|c|c|c|c|c|}
\hline $16: 22,5$ & 1,5 & 151,0 & 186 & & 25,2 & 1401,2 & 16,8 \\
\hline $16: 25$ & 2,5 & 153,5 & 154 & & 26,0 & 1427,1 & 10,4 \\
\hline $16: 27,5$ & 2,5 & 156,0 & 120 & & 27,6 & 1454,7 & 11,0 \\
\hline $16: 30,5$ & 3,0 & 159,0 & 77 & 405 & 34,9 & 1489,7 & 11,6 \\
\hline $16: 36,5$ & 6,0 & 165,0 & 378 & & 21,9 & 1511,6 & 3,7 \\
\hline $16: 42$ & 5,5 & 170,5 & 341 & & 30,0 & 1541,6 & 5,5 \\
\hline 16:52 & 10,0 & 180,5 & 298 & & 34,9 & 1576,5 & 3,5 \\
\hline $16: 58,5$ & 6,5 & 187,0 & 269 & & 23,5 & 1600,1 & 3,6 \\
\hline 17:02 & 3,5 & 190,5 & 231 & & 30,8 & 1630,9 & 8,8 \\
\hline 17:09 & 7,0 & 197,5 & 206 & & 20,3 & 1651,2 & 2,9 \\
\hline $17: 18,0$ & 8,5 & 206,0 & 153 & 410 & 43,0 & 1694,2 & 5,1 \\
\hline $17: 38$ & 20,5 & 226,5 & 292 & & 95,8 & 1790,0 & 4,7 \\
\hline $17: 43,5$ & 5,5 & 232,0 & 264 & & 22,7 & 1812,7 & 4,1 \\
\hline $17: 47$ & 3,5 & 235,5 & 231 & & 26,8 & 1839,5 & 7,7 \\
\hline $17: 50$ & 3,0 & 238,5 & 194 & & 30,0 & 1869,6 & 10,0 \\
\hline $17: 55,5$ & 5,5 & 244,0 & 170 & 433 & 19,5 & 1889,1 & 3,5 \\
\hline 17:59 & 3,5 & 247,5 & 402 & & 25,2 & 1914,2 & 7,2 \\
\hline 18:06 & 7,0 & 254,5 & 379 & & 18,7 & 1932,9 & 2,7 \\
\hline $18: 10,5$ & 4,5 & 259,0 & 343 & & 29,2 & 1962,1 & 6,5 \\
\hline $18: 12,5$ & 2,0 & 261,0 & 312 & & 25,2 & 1987,3 & 12,6 \\
\hline $18: 14,5$ & 2,0 & 263,0 & 288 & & 19,5 & 2006,8 & 9,7 \\
\hline 18:17 & 2,5 & 265,5 & 255 & & 26,8 & 2033,6 & 10,7 \\
\hline 18:19,5 & 2,5 & 268,0 & 229 & & 21,1 & 2054,7 & 8,4 \\
\hline $18: 26$ & 6,5 & 274,5 & 204 & & 20,3 & 2075,0 & 3,1 \\
\hline $18 \cdot 28,5$ & 2,5 & 277,0 & 175 & & 23,5 & 2098,5 & 9,4 \\
\hline 18:33 & 4,5 & 281,5 & 137 & & 30,8 & 2129,4 & 6,9 \\
\hline $18: 35,5$ & 2,5 & 284,0 & 110 & 425 & 21,9 & 2151,3 & 8,8 \\
\hline $18: 38,5$ & 3,0 & 287,0 & 392 & & 26,8 & 2178,1 & 8,9 \\
\hline 18:48 & 9,5 & 296,5 & 362 & & 24,4 & 2202,4 & 2,6 \\
\hline 19:02 & 14,0 & 310,5 & 320 & & 34,1 & 2236,5 & 2,4 \\
\hline 19:05,5 & 3,5 & 314,0 & 310 & & 8,1 & 2244,6 & 2,3 \\
\hline $19: 16$ & 11,5 & 325,5 & 207 & & 83,6 & 2328,2 & 7,3 \\
\hline $19 \cdot 20$ & 4,0 & 329,5 & 182 & & 20,3 & 2348,5 & 5,1 \\
\hline $19: 23,5$ & 3,5 & 333,0 & 154 & & 22,7 & 2371,3 & 6,5 \\
\hline $19: 34$ & 10,5 & 343,5 & 111 & & 34,9 & 2406,2 & 3,3 \\
\hline 19:36,5 & 2,5 & 346,0 & 70 & & 33,3 & 2439,5 & 13,3 \\
\hline $19: 39,5$ & 3,0 & 349,0 & 38 & 312 & 26,0 & 2465,4 & 8,7 \\
\hline $19: 44,5$ & 5,0 & 354,0 & 275 & & 30,0 & 2495,5 & 6,0 \\
\hline 19:52,5 & 8,0 & 362,0 & 228 & & 38,2 & 2533,6 & 4,8 \\
\hline $20: 03$ & 10,5 & 372,5 & 161 & & 54,4 & 2588,0 & 5,2 \\
\hline
\end{tabular}

\section{* Dados perdidos}

\section{Repetiçâo N}




\begin{tabular}{|c|c|c|c|c|c|c|c|}
\hline $15: 49$ & 4,0 & 4,0 & 423 & & 16,2 & 16,2 & 4,1 \\
\hline $15: 53,5$ & 4,5 & 8,5 & 400 & & 18,7 & 34,9 & 4,1 \\
\hline $15: 57$ & 3,5 & 12,0 & 384 & & 13,0 & 47,9 & 3,7 \\
\hline $16: 00$ & 3,0 & 15,0 & 367 & & 13,8 & 61,7 & 4,6 \\
\hline $16: 04$ & 4,0 & 19,0 & * & & * & $\star$ & $\star$ \\
\hline $16: 09$ & 5,0 & 24,0 & 323 & & * & * & * \\
\hline $16: 15$ & 6,0 & 30,0 & 304 & & 15,4 & 77,1 & 2,6 \\
\hline $15: 20,5$ & 5,5 & 35,5 & 276 & & 22,7 & 99,9 & 4,1 \\
\hline $15: 28$ & 7,5 & 43,0 & 256 & & 16,2 & 116,1 & 2,2 \\
\hline $15: 35$ & 7,0 & 50,0 & 236 & & 16,2 & 132,3 & 2,3 \\
\hline $15: 42$ & 7,0 & 57,0 & 219 & & 13,8 & 146,1 & 2,0 \\
\hline $15: 48$ & 6,0 & 63,0 & 199 & & 16,2 & 162,4 & 2,7 \\
\hline $15: 55$ & 7,0 & 70,0 & 180 & & 15,4 & 177,8 & 2,2 \\
\hline 17:01 & 6,0 & 76,0 & 166 & & 11,4 & 189,1 & 1,9 \\
\hline $17: 07,5$ & 6,5 & 82,5 & 147 & & 15,4 & 204,6 & 2,4 \\
\hline $17: 15$ & 7,5 & 90,0 & 113 & 451 & 27,6 & 232,2 & 3,7 \\
\hline 18:10 & 55,0 & 145,0 & 358 & & 75,5 & 307,7 & 1,4 \\
\hline 18:17 & 7,0 & 152,0 & 340 & & 14,6 & 322,3 & 2,1 \\
\hline $18: 24$ & 7,0 & 159,0 & 323 & & 13,8 & 336,1 & 2,0 \\
\hline $18: 31,5$ & 7,5 & 166,5 & 303 & & 16,2 & 352,3 & 2,2 \\
\hline $18: 38$ & 6,5 & 173,0 & 289 & & 11,4 & 363,7 & 1,7 \\
\hline $18: 45$ & 7,0 & 180,0 & 270 & & 15,4 & 379,1 & 2,2 \\
\hline $18: 51,5$ & 6,5 & 186,5 & 252 & & 14,6 & 393,7 & 2,2 \\
\hline $19: 00$ & 8,5 & 195,0 & 237 & & 12,2 & 405,9 & 1,4 \\
\hline $19: 10$ & 10,0 & 205,0 & 219 & & 14,6 & 420,5 & 1,5 \\
\hline 19:18 & 8,0 & 213,0 & 200 & & 15,4 & 435,9 & 1,9 \\
\hline $19: 56,5$ & 38,5 & 251,5 & 127 & & 59,3 & 495,2 & 1,5 \\
\hline 20:08 & 11,5 & 263,0 & 102 & & 20,3 & 515,5 & 1,8 \\
\hline 20:19 & 11,0 & 274,0 & 77 & * & 20,3 & 535,8 & 1,8 \\
\hline 20:31 & 12,0 & 286,0 & 417 & & * & $\star$ & * \\
\hline $20: 43$ & 12,0 & 298,0 & 394 & & 18,7 & 554,5 & 1,6 \\
\hline $20: 58,5$ & 15,5 & 313,5 & 367 & & 21,9 & 576,4 & 1,4 \\
\hline $21: 14,5$ & 16,0 & 329,5 & 343 & & 19,5 & 595,9 & 1,2 \\
\hline 21:32 & 17,5 & 347,0 & 322 & & 17,0 & 612,9 & 1,0 \\
\hline $21: 44,5$ & 12,5 & 359,5 & 302 & & 16,2 & 629,1 & 1,3 \\
\hline
\end{tabular}

\section{* Dados perdidos}

\begin{tabular}{|c|c|c|c|c|}
\hline $\begin{array}{l}\text { Trata } \\
\text { mento }\end{array}$ & $\begin{array}{c}\text { Repet- } \\
\text { ção }\end{array}$ & $\begin{array}{l}\text { TAd } \\
\text { (min) }\end{array}$ & $\begin{array}{l}\text { AC } \\
(\mathrm{mm})\end{array}$ & $\begin{array}{c}\mathrm{V} \\
\text { (mm/nin) }\end{array}$ \\
\hline \multirow[t]{5}{*}{$(v+A)$} & 1 & 359,0 & 457,0 & 1,6 \\
\hline & V & 375,5 & 309,3 & 0,6 \\
\hline & III & 349,0 & 310,9 & 0,6 \\
\hline & $\|$ & 358,0 & 251,7 & 0,5 \\
\hline & $N$ & 384,5 & 539,8 & 1,1 \\
\hline
\end{tabular}




$\begin{array}{ccrrr} & \text { Média } & 365,2 & 373,7 & 0,9 \\ \text { (v+V) } & \text { I } & 155,0 & 14,6 & 0,1 \\ & \text { V } & 442,0 & 55,2 & 0,1 \\ & \text { III } & 359,0 & 142,1 & 0,4 \\ & \text { II } & 300,0 & 52,0 & 0,0 \\ & \text { N } & 360,0 & 51,1 & 0,0 \\ \text { (A) } \quad \text { Média } & 323,2 & 63,0 & 0,1 \\ & \text { I } & 236,0 & 1670,0 & 3,7 \\ & \text { V } & 362,0 & 404,0 & 0,5 \\ & \text { III } & 361,5 & 554,5 & 0,7 \\ & \text { II } & 394,0 & 440,8 & 0,5 \\ & \text { N } & 359,0 & 816,7 & 2,2 \\ \text { M) Média } & 342,5 & 777,2 & 1,5 \\ & \text { I } & 360,0 & 61,7 & 0,2 \\ & \text { V } & 315,0 & 74,7 & 0,1 \\ & \text { III } & 359,0 & 179,4 & 0,0 \\ & \text { II } & 309,0 & 160,7 & 0,1 \\ & \text { N } & - & - & - \\ & \text { Média } & 335,8 & 119,1 & 0,1 \\ \text { (a+A) } & \text { I } & - & - & - \\ & \text { V } & 351,0 & 363,7 & 0,7 \\ & \text { III } & 375,0 & 438,4 & 0,8 \\ & \text { II } & 372,5 & 2588,0 & 5,2 \\ & \text { N } & 274,0 & 535,8 & 1,8 \\ & \text { Média } & 343,1 & 981,5 & 2,1\end{array}$


APENNDICE 13

Dados de PI e PIAc.(Dados oniginais de campo).

Tratamento

hh:mm

16:20

16:30

16:39

16:49

16:58

17:06

17:13

17:24

17:30

17:37

17:47

17:59

18:11

18:17

18:27

$18: 40$

18:52

19:06

19:16

19:37

19:52

20:00

20:15

20:20

20:35

20:45

20:58

21:11

21:24

21:45

22:00

22:10

22:20
:(v+A); Vinhaça in natura corno redutor de infftuação, seguida de água cornum corno infivante.

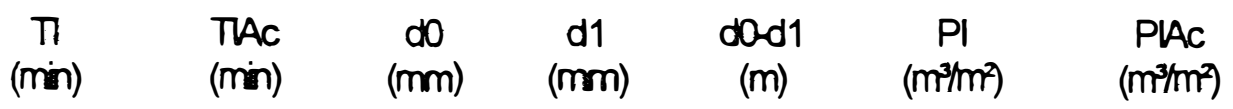

Repetição 1

500

$10 \quad 10 \quad 505$

505

500

500

500

505

500

500

500

500

500

500

500

500

500

500

500

500

500

505

500

500

500

500

500

500

500

500

500

500

500

500

490
490
490
490
490
490
485
490
490
485
490
485
490
485
480
480
475
490
490
480
490
480
490
475
490
480
485
480
470
475
480
485

$\begin{array}{lll}0,010 & 0,007245 & 0,007245 \\ 0,015 & 0,010867 & 0,018112 \\ 0,015 & 0,010867 & 0,028980 \\ 0,010 & 0,007245 & 0,036224 \\ 0,010 & 0,007245 & 0,043469 \\ 0,010 & 0,007245 & 0,050714 \\ 0,020 & 0,014490 & 0,065204 \\ 0,010 & 0,007245 & 0,072449 \\ 0,010 & 0,007245 & 0,079694 \\ 0,015 & 0,010867 & 0,090561 \\ 0,010 & 0,007245 & 0,097806 \\ 0,015 & 0,010867 & 0,108673 \\ 0,010 & 0,007245 & 0,115918 \\ 0,015 & 0,010867 & 0,126785 \\ 0,020 & 0,014490 & 0,141275 \\ 0,020 & 0,014490 & 0,155765 \\ 0,025 & 0,018112 & 0,173877 \\ 0,010 & 0,007245 & 0,181122 \\ 0,010 & 0,007245 & 0,188367 \\ 0,020 & 0,014490 & 0,202856 \\ 0,015 & 0,010867 & 0,213724 \\ 0,020 & 0,014490 & 0,228214 \\ 0,010 & 0,007245 & 0,235458 \\ 0,025 & 0,018112 & 0,253571 \\ 0,010 & 0,007245 & 0,260815 \\ 0,020 & 0,014490 & 0,275305 \\ 0,015 & 0,010867 & 0,286172 \\ 0,020 & 0,014490 & 0,300662 \\ 0,030 & 0,021735 & 0,322397 \\ 0,025 & 0,018112 & 0,340509 \\ 0,020 & 0,014490 & 0,354999 \\ 0,015 & 0,010867 & 0,365866\end{array}$


Repetição V

$09: 35,0$

$09: 44,0$

$09: 50,0$

$09: 57,0$

10:02,0

10:09,0

10:19,0

$10: 26,0$

10:32,5

$10: 40,0$

$10: 48,5$

11:08,0

$11: 11,5$

$11: 35,0$

$11: 45,0$

$11: 55,5$

$12: 05,0$

$12: 47,0$

$12: 56,5$

13:09,0

$13 \cdot 22,0$

$13: 35,5$

$13: 47,0$

14:05,0

$14: 16,0$

$14: 35,0$

$14: 48,5$

$15: 00,0$

$15: 16,0$

15:32,0

$15: 44,0$

$\begin{array}{rrrr}9,0 & 9,0 & 500 & 490 \\ 6,0 & 15,0 & 500 & 490 \\ 7,0 & 22,0 & 505 & 490 \\ 5,0 & 27,0 & 500 & 490 \\ 7,0 & 34,0 & 500 & 490 \\ 10,0 & 44,0 & 500 & 485 \\ 7,0 & 51,0 & 500 & 490 \\ 6,5 & 57,5 & 500 & 490 \\ 7,5 & 65,0 & 500 & 490 \\ 8,5 & 73,5 & 520 & 490 \\ 20,5 & 94,0 & 500 & 490 \\ 16,0 & 110,0 & 500 & 480 \\ 11,0 & 121,0 & 500 & 490 \\ 10,0 & 131,0 & 500 & 490 \\ 10,5 & 141,5 & 500 & 490 \\ 5,0 & 146,5 & 520 & 490 \\ 42,0 & 188,5 & 500 & 470 \\ 19,5 & 208,0 & 500 & 485 \\ 12,5 & 220,5 & 500 & 490 \\ 13,0 & 233,5 & 500 & 490 \\ 11,5 & 245,0 & 500 & 490 \\ 13,5 & 258,5 & 500 & 490 \\ 18,0 & 276,5 & 500 & 485 \\ 11,0 & 287,5 & 500 & 490 \\ 19,0 & 306,5 & 500 & 485 \\ 13,5 & 320,0 & 500 & 490 \\ 11,5 & 331,5 & 500 & 490 \\ 16,0 & 347,5 & 500 & 485 \\ 16,0 & 363,5 & 500 & 485 \\ 12,0 & 375,5 & 500 & 490\end{array}$

$$
\begin{array}{ll}
0,010 & 0,007245 \\
0,010 & 0,007245 \\
0,010 & 0,007245 \\
0,015 & 0,010867 \\
0,010 & 0,007245 \\
0,015 & 0,010867 \\
0,010 & 0,007245 \\
0,010 & 0,007245 \\
0,010 & 0,007245 \\
0,010 & 0,007245 \\
0,030 & 0,021735 \\
0,020 & 0,014490 \\
0,010 & 0,007245 \\
0,010 & 0,007245 \\
0,010 & 0,007245 \\
0,010 & 0,007245 \\
0,050 & 0,036224 \\
0,015 & 0,010867 \\
0,010 & 0,007245 \\
0,010 & 0,007245 \\
0,010 & 0,007245 \\
0,010 & 0,007245 \\
0,015 & 0,010867 \\
0,010 & 0,007245 \\
0,015 & 0,010867 \\
0,010 & 0,007245 \\
0,010 & 0,007245 \\
0,015 & 0,010867 \\
0,015 & 0,010867 \\
0,010 & 0,007245
\end{array}
$$

0,007245

0,014490

0,021735

0,032602

0,039847

0,050714

0,057959

0,065204

0,072449

0,079694

0,101428

0,115918

0,123163

0,130408

0,137653

0,144898

0,181122

0,191989

0,199234

0,206479

0,213724

0,220969

0,231836

0,239081

0,249948

0,257193

0,264438

0,275305

0,286172

0,293417

Repetição III

$09: 57,0$
$10: 00,0$
$10: 04,5$
$10: 10,0$
$10: 20,5$
$10: 32,5$
$10: 40,5$
$10: 50,5$
$11: 05,0$
$11: 19,5$
$11: 42,5$
$11: 54,0$
$12: 05,0$

$\begin{array}{rrrr}3,0 & 3,0 & 500 & 490 \\ 4,5 & 7,5 & 500 & 490 \\ 5,5 & 13,0 & 510 & 490 \\ 10,5 & 23,5 & 510 & 490 \\ 12,0 & 35,5 & 500 & 490 \\ 8,0 & 43,5 & 500 & 490 \\ 10,0 & 53,5 & 500 & 490 \\ 11,0 & 64,5 & 500 & 485 \\ 8,0 & 72,5 & 500 & 485 \\ 23,0 & 95,5 & 500 & 480 \\ 11,5 & 107,0 & 500 & 490 \\ 6,5 & 113,5 & 520 & 490\end{array}$

$$
\begin{aligned}
& 0,010 \\
& 0,010 \\
& 0,010 \\
& 0,020 \\
& 0,020 \\
& 0,010 \\
& 0,010 \\
& 0,015 \\
& 0,015 \\
& 0,020 \\
& 0,010
\end{aligned}
$$

0,007245

0,007245

0,014490

0,021735

0,036224

0,050714

0,057959

0,065204

0,076071

0,086939

0,101428

0,108673

$0,010 \quad 0,007245$

0,115918 


$\begin{array}{llllllll}12: 52,5 & 47,5 & 161,0 & 500 & 470 & 0,050 & 0,036224 & 0,152142 \\ 13: 11,0 & 18,5 & 179,5 & 500 & 485 & 0,015 & 0,010867 & 0,163010 \\ 13: 34,0 & 23,0 & 202,5 & 500 & 480 & 0,020 & 0,014490 & 0,177499 \\ 13: 59,0 & 25,0 & 227,5 & 500 & 485 & 0,015 & 0,010867 & 0,188367 \\ 14: 15,0 & 16,0 & 243,5 & 500 & 490 & 0,010 & 0,007245 & 0,195612 \\ 14: 38,5 & 25,5 & 269,0 & 500 & 485 & 0,015 & 0,010867 & 0,206479 \\ 14: 56,0 & 17,5 & 286,5 & 500 & 485 & 0,015 & 0,010867 & 0,217346 \\ 14: 15,5 & 15,0 & 301,5 & 500 & 490 & 0,010 & 0,007245 & 0,224591 \\ 14: 31,0 & 20,0 & 321,5 & 500 & 490 & 0,010 & 0,007245 & 0,231836 \\ 14: 58,5 & 27,5 & 349,0 & 500 & 480 & 0,020 & 0,014490 & 0,246326\end{array}$

Repetição II

$\begin{array}{rrrrr}09: 28,0 & & & 500 & \\ 09: 34,0 & 6,0 & 6,0 & 500 & 490 \\ 09: 41,0 & 7,0 & 13,0 & 500 & 490 \\ 09: 49,0 & 8,0 & 21,0 & 500 & 490 \\ 10: 05,0 & 16,0 & 37,0 & 500 & 480 \\ 10: 16,5 & 11,5 & 48,5 & 500 & 490 \\ 10: 32,0 & 15,5 & 64,0 & 500 & 485 \\ 10: 44,0 & 10,0 & 74,0 & 500 & 485 \\ 10: 58,0 & 14,0 & 88,0 & 500 & 490 \\ 11: 19,0 & 21,0 & 109,0 & 500 & 480 \\ 11: 34,5 & 15,5 & 124,5 & 500 & 490 \\ 12: 00,0 & 25,5 & 150,0 & 520 & 480 \\ 12: 48,5 & 48,5 & 198,5 & 500 & 480 \\ 13: 17,0 & 28,5 & 227,0 & 500 & 480 \\ 13: 38,0 & 21,0 & 248,0 & 500 & 485 \\ 13: 53,5 & 15,5 & 263,5 & 500 & 490 \\ 14: 15,0 & 21,5 & 285,0 & 500 & 480 \\ 14: 47,5 & 32,5 & 317,5 & 505 & 480 \\ 15: 28,0 & 40,5 & 358,0 & 500 & 480\end{array}$

$\begin{array}{lll}0,010 & 0,007245 & 0,007245 \\ 0,010 & 0,007245 & 0,014490 \\ 0,010 & 0,007245 & 0,021735 \\ 0,020 & 0,014490 & 0,036224 \\ 0,010 & 0,007245 & 0,043469 \\ 0,015 & 0,010867 & 0,054337 \\ 0,015 & 0,010867 & 0,065204 \\ 0,010 & 0,007245 & 0,072449 \\ 0,020 & 0,014490 & 0,086939 \\ 0,010 & 0,007245 & 0,094183 \\ 0,020 & 0,014490 & 0,108673 \\ 0,040 & 0,028979 & 0,137653 \\ 0,020 & 0,014490 & 0,152142 \\ 0,015 & 0,010867 & 0,163010 \\ 0,010 & 0,007245 & 0,170255 \\ 0,020 & 0,014490 & 0,184744 \\ 0,020 & 0,014490 & 0,199234 \\ 0,025 & 0,018112 & 0,217346\end{array}$

\section{Repetição N}

$09: 14,0$
$09: 17,5$
$09: 20,5$
$09: 25,5$
$09: 28,5$
$09: 39,5$
$09: 41,5$
$09: 45,0$
$09: 49,5$
$09: 54,5$
$09: 59,0$
$10: 05,0$
$10: 11,0$
$10: 16,5$

$\begin{array}{rrr}3,5 & 3,5 & 500 \\ 3,0 & 6,5 & 500 \\ 5,0 & 11,5 & 500 \\ 3,0 & 14,5 & 510 \\ 11,0 & 25,5 & 500 \\ 2,0 & 27,5 & 500 \\ 3,5 & 31,0 & 500 \\ 4,5 & 35,5 & 500 \\ 5,0 & 40,5 & 500 \\ 4,5 & 45,0 & 500 \\ 6,0 & 51,0 & 500 \\ 6,0 & 57,0 & 500 \\ 5,5 & 62,5 & 500\end{array}$

500

500

490

$0,010 \quad 0,007245$

0,007245

490

0,010

0,007245

0,014490

480

0,020

0,014490

0,028979

490

0,010

0,007245

0,036224

470

0,040

0,028979

0,065204

490

0,010

0,007245

0,072449

$0,010 \quad 0,007245$

0,079694

490

0,010

0,007245

0,086938

$0,010 \quad 0,007245$

0,094183

490

0,010

0,007245

0,101428

$0,015 \quad 0,010867$

0,112295

490

0,010

0,007245

0,119540

$0,010 \quad 0,007245$

0,126785 


\begin{tabular}{|c|c|c|c|c|c|c|c|}
\hline $10: 22,5$ & 6,0 & 68,5 & 500 & 490 & 0,010 & 0,007245 & 0,134030 \\
\hline $10: 27,0$ & 4,5 & 73,0 & 500 & 490 & 0,010 & 0,007245 & 0,141275 \\
\hline 10:31,5 & 4,5 & 77,5 & 500 & 490 & 0,010 & 0,007245 & 0,148520 \\
\hline $10: 36,5$ & 5,0 & 82,5 & 500 & 490 & 0,010 & 0,007245 & 0,155765 \\
\hline $10: 42,0$ & 5,5 & 88,0 & 500 & 490 & 0,010 & 0,007245 & 0,163010 \\
\hline $10: 47,5$ & 5,5 & 93,5 & 505 & 490 & 0,010 & 0,007245 & 0,170254 \\
\hline $10: 54,0$ & 6,5 & 100,0 & 500 & 485 & 0,020 & 0,014490 & 0,184744 \\
\hline $11: 00,0$ & 6,0 & 106,0 & 500 & 485 & 0,015 & 0,010867 & 0,195611 \\
\hline $11: 06,0$ & 6,0 & 112,0 & 520 & 480 & 0,020 & 0,014490 & 0,210101 \\
\hline 11:13 & 15,5 & 127,5 & 520 & 480 & 0,040 & 0,028979 & 0,239081 \\
\hline $11: 38,0$ & 16,5 & 144,0 & 520 & 480 & 0,040 & 0,028979 & 0,268060 \\
\hline $11: 45,0$ & 7,0 & 151,0 & 520 & 490 & 0,030 & 0,021735 & 0,289795 \\
\hline 11:51,0 & 6,0 & 157,0 & 520 & 490 & 0,030 & 0,021735 & 0,311529 \\
\hline $11: 57,5$ & 6,5 & 163,5 & 520 & 490 & 0,030 & 0,021735 & 0,333264 \\
\hline $12: 04,0$ & 6,5 & 170,0 & 520 & 490 & 0,030 & 0,021735 & 0,354999 \\
\hline $12: 09,0$ & 5,0 & 175,0 & 520 & 490 & 0,030 & 0,021735 & 0,376733 \\
\hline 12:17,0 & 8,0 & 183,0 & 505 & 485 & 0,035 & 0,025357 & 0,402090 \\
\hline $12: 26,0$ & 9,0 & 192,0 & 520 & 485 & 0,020 & 0,014490 & 0,416580 \\
\hline $13: 10,0$ & 44,0 & 236,0 & 500 & 430 & 0,090 & 0,065204 & 0,481784 \\
\hline $13: 19,5$ & 9,5 & 245,5 & 500 & 485 & 0,015 & 0,010867 & 0,492651 \\
\hline $13: 26,5$ & 7,0 & 252,5 & 500 & 490 & 0,010 & 0,007245 & 0,499896 \\
\hline $13: 36,0$ & 9,5 & 262,0 & 500 & 480 & 0,020 & 0,014490 & 0,514386 \\
\hline $13: 42,5$ & 6,5 & 268,5 & 500 & 485 & 0,015 & 0,010867 & 0,525253 \\
\hline $13: 49,5$ & 7,0 & 275,5 & 500 & 490 & 0,010 & 0,007245 & 0,532498 \\
\hline $13: 54,0$ & 4,5 & 280,0 & 500 & 490 & 0,010 & 0,007245 & 0,539743 \\
\hline $14: 01,0$ & 7,0 & 287,0 & 500 & 485 & 0,015 & 0,010867 & 0,550610 \\
\hline $14: 06,5$ & 5,5 & 292,5 & 500 & 490 & 0,010 & 0,007245 & 0,557855 \\
\hline $14: 14,0$ & 17,5 & 310,0 & 500 & 490 & 0,010 & 0,007245 & 0,565100 \\
\hline $14: 31,0$ & 17,0 & 327,0 & 500 & 470 & 0,030 & 0,021735 & 0,586834 \\
\hline $14: 39,0$ & 18,0 & 345,0 & 500 & 485 & 0,015 & 0,010867 & 0,597702 \\
\hline $14: 48,0$ & 9,0 & 354,0 & 500 & 485 & 0,015 & 0,010867 & 0,608569 \\
\hline $14: 55,0$ & 7,0 & 361,0 & 500 & 490 & 0,010 & 0,007245 & 0,615814 \\
\hline $15: 03,0$ & 8,0 & 369,0 & 500 & 485 & 0,015 & 0,010867 & 0,626681 \\
\hline $15: 11,0$ & 8,0 & 377,0 & 500 & 490 & 0,010 & 0,007245 & 0,633926 \\
\hline $15: 18,5$ & 7,5 & 384,5 & 500 & 490 & 0,010 & 0,007245 & 0,641171 \\
\hline
\end{tabular}

Trdamento

: $(v+V)$; Vinhaça in natura corno redutor, seguida de vinhaça in natura como infivante.

\begin{tabular}{|c|c|c|c|c|c|c|c|}
\hline hh:mm & $\prod_{(\mathrm{min})}$ & $\begin{array}{l}\text { TAC } \\
\text { (min) }\end{array}$ & $\underset{(\mathrm{mm})}{d 0}$ & $\begin{array}{c}\mathrm{d} 1 \\
(\mathrm{~mm})\end{array}$ & $\begin{array}{l}\text { do-d1 } \\
\text { (m) }\end{array}$ & $\begin{array}{c}\mathrm{PI} \\
\left(\mathrm{m}^{3} / \mathrm{m}^{2}\right)\end{array}$ & $\begin{array}{l}\text { PLAC } \\
\left(\mathrm{m}^{3} / \mathrm{m}^{2}\right)\end{array}$ \\
\hline & & \multicolumn{6}{|c|}{ Repetição I } \\
\hline $\begin{array}{l}19: 54 \\
21: 23\end{array}$ & 89,0 & 89,0 & $\begin{array}{l}500 \\
500\end{array}$ & 490 & 0,010 & 0,007245 & 0,007245 \\
\hline
\end{tabular}




\section{Repetiçäo V}

$15: 45,0$

$18: 25,0$

21:06,5

$\begin{array}{lll}280,0 & 280,0 & 505 \\ 162,0 & 442,0 & 540\end{array}$

495

520

$$
\begin{array}{ll}
0,010 & 0,007245 \\
0,000 & 0,000000
\end{array}
$$

0,007245

0,007245

\section{Repetição III}

10:44

$11: 02$

$11: 35$

$12: 55$

13:37

$14: 25$

$15: 21$

15:53

16:44

$\begin{array}{lrll}18 & 18 & 500 & \\ 33 & 51 & 500 & 490 \\ 80 & 131 & 505 & 490 \\ 42 & 173 & 500 & 490 \\ 48 & 221 & 505 & 490 \\ 56 & 277 & 500 & 490 \\ 31 & 308 & 500 & 480 \\ 51 & 359 & 500 & 470\end{array}$

$$
0,010
$$

$$
0,010
$$

0,020

0,007245

0,007245

0,015

0,007245

0,014490

0,010867

0,028980

$0,010 \quad 0,007245$

0,039847

0,015

0,010867

0,047092

0,020

0,014490

0,057959

0,030

0,021735

0,072449

0,094183

\section{Repetição II}

10:42

11:25

$11: 47,5$

$13: 06$

$14: 47$

$16: 42$

$$
\begin{array}{r}
43,0 \\
22,5 \\
18,5 \\
101,0 \\
115,0
\end{array}
$$

$\begin{array}{rr} & 500 \\ 43,0 & 500 \\ 65,5 & 500 \\ 84,0 & 500 \\ 185,0 & 505 \\ 300,0 & 500\end{array}$

490
490
480
490
495

0,010

0,007245

0,007245

$0,010 \quad 0,007245$

0,014490

$0,020 \quad 0,014490$

0,028980

$0,010 \quad 0,007245$

0,036224

$0,010 \quad 0,007245$

0,043469

\section{Repetiçāo N}

$12: 58$

$13: 24,5$

13:44,5

$14: 16$

15:01,5

16:10

18:01,5

$18: 58,5$

26,5
20,0
31,5
45,5
68,5
111,5
57,0

$\begin{array}{rr} & 500 \\ 26,5 & 500 \\ 46,5 & 500 \\ 78,0 & 500 \\ 123,5 & 500 \\ 192,0 & 500 \\ 303,5 & 500 \\ 360,5 & 500\end{array}$

490
490
490
490
490
485
500

0,010

0,010

0,010

0,010

0,010

0,015

0,000

0,007245

0,007245

0,014490

0,021735

0,028979

0,036224

0,047092

$500 \quad 500$

0,047092
Trotamento

hh:mm

\section{: (A); Água comum como infituante.}

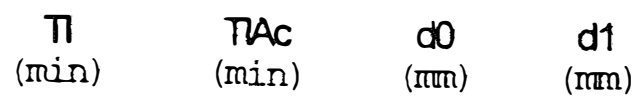

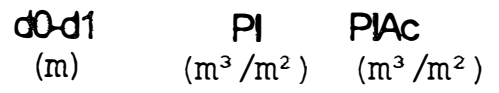


Repeţção I

\begin{tabular}{|c|c|c|c|c|c|c|c|}
\hline $12: 31$ & & & 500 & & & & \\
\hline $12: 32,5$ & 1,5 & 1,5 & 500 & 460 & 0,040 & 0,028979 & 0,028979 \\
\hline $12: 34$ & 1,5 & 3,0 & 500 & 480 & 0,020 & 0,014490 & 0,043469 \\
\hline $12: 35$ & 1,0 & 4,0 & 500 & 480 & 0,020 & 0,014490 & 0,057958 \\
\hline $12: 37$ & 2,0 & 6,0 & 505 & 480 & 0,020 & 0,014490 & 0,072448 \\
\hline $12: 39$ & 2,0 & 8,0 & 500 & 480 & 0,025 & 0,018112 & 0,090560 \\
\hline $12: 40$ & 1,0 & 9,0 & 500 & 480 & 0,020 & 0,014490 & 0,105050 \\
\hline 12:42 & 2,0 & 11,0 & 500 & 480 & 0,020 & 0,014490 & 0,119540 \\
\hline $12: 43,5$ & 1,5 & 12,5 & 500 & 480 & 0,020 & 0,014490 & 0,134030 \\
\hline $12: 45,5$ & 2,0 & 14,5 & 510 & 480 & 0,020 & 0,014490 & 0,148519 \\
\hline $12: 50$ & 4,5 & 19,0 & 500 & 480 & 0,030 & 0,021735 & 0,170254 \\
\hline $12: 52$ & 2,0 & 21,0 & 500 & 480 & 0,020 & 0,014490 & 0,184744 \\
\hline $12: 54$ & 2,0 & 23,0 & 500 & 480 & 0,020 & 0,014490 & 0,199233 \\
\hline $12: 55$ & 3,0 & 26,0 & 500 & 480 & 0,020 & 0,014490 & 0,213723 \\
\hline $12: 57$ & 2,0 & 28,0 & 500 & 480 & 0,020 & 0,014490 & 0,228213 \\
\hline $12: 59$ & 2,0 & 30,0 & 500 & 480 & 0,020 & 0,014490 & 0,242703 \\
\hline 13:01 & 2,0 & 32,0 & 500 & 480 & 0,020 & 0,014490 & 0,257192 \\
\hline 13:03 & 2,0 & 34,0 & 500 & 480 & 0,020 & 0,014490 & 0,271682 \\
\hline $13: 05$ & 2,0 & 36,0 & 505 & 480 & 0,020 & 0,014490 & 0,286172 \\
\hline 13:07 & 2,0 & 38,0 & 500 & 480 & 0,025 & 0,018112 & 0,304284 \\
\hline $13: 08,5$ & 1,5 & 39,5 & 500 & 480 & 0,020 & 0,014490 & 0,318774 \\
\hline 13:10 & 1,5 & 41,0 & 500 & 480 & 0,020 & 0,014490 & 0,333264 \\
\hline 13:15 & 5,0 & 46,0 & 500 & 475 & 0,025 & 0,018112 & 0,351376 \\
\hline 13:17 & 2,0 & 48,0 & 500 & 480 & 0,020 & 0,014490 & 0,365865 \\
\hline 13:19 & 2,0 & 50,0 & 500 & 480 & 0,020 & 0,014490 & 0,380355 \\
\hline $13: 21$ & 2,0 & 52,0 & 500 & 480 & 0,020 & 0,014490 & 0,394845 \\
\hline $13: 23,5$ & 2,5 & 54,5 & 500 & 480 & 0,020 & 0,014490 & 0,409335 \\
\hline $13: 25$ & 1,5 & 56,0 & 500 & 475 & 0,025 & 0,018112 & 0,427447 \\
\hline $13: 27,5$ & 2,5 & 58,5 & 500 & 480 & 0,020 & 0,014490 & 0,441937 \\
\hline $13: 30$ & 2,5 & 61,0 & 500 & 480 & 0,020 & 0,014490 & 0,456426 \\
\hline $13: 35$ & 5,0 & 66,0 & 500 & 480 & 0,020 & 0,014490 & 0,470916 \\
\hline $13: 37,5$ & 2,5 & 68,5 & 510 & 475 & 0,025 & 0,018112 & 0,489028 \\
\hline $13: 42$ & 4,5 & 73,0 & 500 & 475 & 0,035 & 0,025357 & 0,514385 \\
\hline $13: 44,5$ & 2,5 & 75,5 & 500 & 475 & 0,025 & 0,018112 & 0,532497 \\
\hline $13: 47,5$ & 2,0 & 77,5 & 500 & 480 & 0,020 & 0,014490 & 0,546987 \\
\hline $13: 49$ & 2,5 & 80,0 & 500 & 480 & 0,020 & 0,014490 & 0,561477 \\
\hline 13:51 & 2,0 & 82,0 & 500 & 480 & 0,020 & 0,014490 & 0,575967 \\
\hline $13: 53,5$ & 2,5 & 84,5 & 500 & 480 & 0,020 & 0,014490 & 0,590456 \\
\hline $13: 56$ & 2,5 & 87,0 & 500 & 480 & 0,020 & 0,014490 & 0,604946 \\
\hline $14: 01$ & 5,0 & 92,0 & 505 & 480 & 0,020 & 0,014490 & 0,619436 \\
\hline $14: 05$ & 4,0 & 96,0 & 500 & 475 & 0,030 & 0,021735 & 0,641171 \\
\hline $14: 07$ & 2,0 & 98,0 & 500 & 480 & 0,020 & 0,014490 & 0,655660 \\
\hline $14: 10,5$ & 3,5 & 101,5 & 515 & 475 & 0,025 & 0,018112 & 0,673772 \\
\hline $14: 14,5$ & 4,0 & 105,5 & 500 & 480 & 0,035 & 0,025357 & 0,699129 \\
\hline $14: 16,5$ & 2,0 & 107,5 & 500 & 480 & 0,020 & 0,014490 & 0,713619 \\
\hline $14: 19,5$ & 3,0 & 110,5 & 500 & 480 & 0,020 & 0,014490 & 0,728109 \\
\hline $14: 22,5$ & 3,0 & 113,5 & 500 & 480 & 0,020 & 0,014490 & 0,742599 \\
\hline
\end{tabular}




$\begin{array}{llllllll}14: 26,5 & 4,0 & 117,5 & 500 & 470 & 0,030 & 0,021735 & 0,764333 \\ 14: 29 & 2,5 & 120,0 & 500 & 475 & 0,025 & 0,018112 & 0,782445 \\ 14: 31,5 & 2,5 & 122,5 & 500 & 480 & 0,020 & 0,014490 & 0,796935 \\ 14: 34,5 & 3,0 & 125,5 & 500 & 475 & 0,025 & 0,018112 & 0,815047 \\ 14: 37,5 & 3,0 & 128,5 & 500 & 475 & 0,025 & 0,018112 & 0,833160 \\ 14: 40,5 & 3,0 & 131,5 & 500 & 480 & 0,020 & 0,014490 & 0,847649 \\ 14: 44 & 3,5 & 135,0 & 500 & 480 & 0,020 & 0,014490 & 0,862139 \\ 14: 46,5 & 2,5 & 137,5 & 505 & 480 & 0,020 & 0,014490 & 0,876629 \\ 14: 50 & 3,5 & 141,0 & 510 & 480 & 0,025 & 0,018112 & 0,894741 \\ 14: 55 & 5,0 & 146,0 & 500 & 480 & 0,030 & 0,021735 & 0,916476 \\ 14: 58,5 & 3,5 & 149,5 & 500 & 480 & 0,020 & 0,014490 & 0,930965 \\ 15: 01 & 2,5 & 152,0 & 500 & 480 & 0,020 & 0,014490 & 0,945455 \\ 15: 06 & 5,0 & 157,0 & 500 & 480 & 0,020 & 0,014490 & 0,959945 \\ 15: 08 & 3,0 & 160,0 & 500 & 480 & 0,020 & 0,014490 & 0,974435 \\ 15: 12 & 4,0 & 164,0 & 500 & 480 & 0,020 & 0,014490 & 0,988924 \\ 15: 16 & 4,0 & 168,0 & 500 & 475 & 0,025 & 0,018112 & 1,007036 \\ 15: 19 & 3,0 & 171,0 & 500 & 480 & 0,020 & 0,014490 & 1,021526 \\ 15: 22 & 3,0 & 174,0 & 500 & 480 & 0,020 & 0,014490 & 1,036016 \\ 15: 26 & 4,0 & 178,0 & 500 & 480 & 0,020 & 0,014490 & 1,050506 \\ 15: 30,5 & 4,5 & 182,5 & 500 & 480 & 0,020 & 0,014490 & 1,064995 \\ 15: 34 & 3,5 & 186,0 & 500 & 480 & 0,020 & 0,014490 & 1,079485 \\ 15: 37 & 3,0 & 189,0 & 520 & 480 & 0,020 & 0,014490 & 1,093975 \\ 15: 43,5 & 6,5 & 195,5 & 500 & 480 & 0,040 & 0,028979 & 1,122954 \\ 15: 46,5 & 3,0 & 198,5 & 500 & 480 & 0,020 & 0,014490 & 1,137444 \\ 15: 50 & 3,5 & 202,0 & 500 & 480 & 0,020 & 0,014490 & 1,151934 \\ 15: 54,5 & 4,5 & 206,5 & 500 & 475 & 0,025 & 0,018112 & 1,170046 \\ 15: 59,5 & 5,0 & 211,5 & 500 & 480 & 0,020 & 0,014490 & 1,184536 \\ 16: 01 & 1,5 & 213,0 & 500 & 480 & 0,020 & 0,014490 & 1,199026 \\ 16: 08 & 7,0 & 220,0 & 500 & 480 & 0,020 & 0,014490 & 1,213515 \\ 16: 12 & 4,0 & 224,0 & 500 & 475 & 0,025 & 0,018112 & 1,231627 \\ 16: 15,5 & 3,5 & 227,5 & 500 & 480 & 0,020 & 0,014490 & 1,246117 \\ 16: 20 & 4,5 & 232,0 & 500 & 475 & 0,025 & 0,018112 & 1,264229 \\ 16: 24 & 4,0 & 236,0 & 500 & 480 & 0,020 & 0,014490 & 1,278719\end{array}$

\section{Repeticão V}

9:53

9:54

10:00

10:01,5

10:05

10:08,5

10:11,5

10:15

10:18,5

$10: 24,5$

$10: 28,5$

$10: 33,5$

$10: 38,5$

$\begin{array}{rrr}1,0 & 1,0 & 500 \\ 6,0 & 7,0 & 500 \\ 1,5 & 8,5 & 500 \\ 3,5 & 12,0 & 500 \\ 3,5 & 15,5 & 500 \\ 3,0 & 18,5 & 500 \\ 3,5 & 22,0 & 500 \\ 3,5 & 25,5 & 500 \\ 6,0 & 31,5 & 500 \\ 4,0 & 35,5 & 500 \\ 5,0 & 40,5 & 500 \\ 5,0 & 45,5 & 500\end{array}$

485
490
490
490
490
490
490
490
485
490
490
490

0,015

0,010

0,010

0,010

0,010

0,010

0,010

0,010

0,015

0,010

0,010

0,010

0,010867

0,007245

0,007245

0,007245

0,007245

0,007245

0,007245

0,007245

0,010867

0,007245

0,007245

0,007245

0,010867

0,018112

0,025357

0,032602

0,039846

0,047091

0,054336

0,061581

0,072448

0,079693

0,086938

0,094183 


$\begin{array}{lrrrrrrr}10: 44 & 5,5 & 51,0 & 500 & 490 & 0,010 & 0,007245 & 0,101428 \\ 10: 51 & 7,0 & 58,0 & 500 & 490 & 0,010 & 0,007245 & 0,108673 \\ 10: 59,5 & 8,5 & 66,5 & 500 & 485 & 0,015 & 0,010867 & 0,11954 \\ 10: 11 & 13,5 & 80,0 & 500 & 485 & 0,015 & 0,010867 & 0,130407 \\ 10: 21 & 8,0 & 88,0 & 500 & 490 & 0,010 & 0,007245 & 0,137652 \\ 10: 31,5 & 10,5 & 98,5 & 500 & 490 & 0,010 & 0,007245 & 0,144897 \\ 10: 42 & 10,5 & 109,0 & 500 & 490 & 0,010 & 0,007245 & 0,152142 \\ 10: 54 & 12,0 & 121,0 & 500 & 490 & 0,010 & 0,007245 & 0,159387 \\ 12: 03 & 9,0 & 130,0 & 520 & 490 & 0,010 & 0,007245 & 0,166632 \\ 12: 48 & 45,0 & 175,0 & 520 & 465 & 0,055 & 0,039847 & 0,206478 \\ 13: 35 & 47,0 & 222,0 & 500 & 485 & 0,035 & 0,025357 & 0,231836 \\ 10: 48,5 & 13,5 & 235,5 & 500 & 485 & 0,015 & 0,010867 & 0,242703 \\ 14: 04 & 15,5 & 251,0 & 500 & 490 & 0,010 & 0,007245 & 0,249948 \\ 14: 21 & 17,0 & 268,0 & 500 & 490 & 0,010 & 0,007245 & 0,257193 \\ 14: 40 & 19,0 & 287,0 & 500 & 485 & 0,015 & 0,010867 & 0,26806 \\ 15: 00 & 20,0 & 307,0 & 505 & 485 & 0,015 & 0,010867 & 0,278927 \\ 15: 16 & 16,0 & 323,0 & 500 & 490 & 0,015 & 0,010867 & 0,289794 \\ 15: 32,5 & 16,5 & 339,5 & 500 & 490 & 0,010 & 0,007245 & 0,297039 \\ 15: 55 & 22,5 & 362,0 & 500 & 485 & 0,015 & 0,010867 & 0,307907\end{array}$

\section{Repetição III}

10:34

10:35,5

10:37,5

10:39

10:40,5

10:42

10:44,5

10:46

10:50

10:52,5

10:55

10:59

11:01

11:05

11:08,5

11:11

11:13,5

11:18

11:21

11:25

11:29

11:33

$11: 38,5$

$11: 43,5$

11:48

11:52,5

12:00

$\begin{array}{rrrr} & & 500 & \\ 1,5 & 1,5 & 500 & 490 \\ 2,0 & 3,5 & 500 & 490 \\ 1,5 & 5,0 & 500 & 490 \\ 1,5 & 6,5 & 500 & 490 \\ 1,5 & 8,0 & 500 & 490 \\ 2,5 & 10,5 & 500 & 490 \\ 1,5 & 12,0 & 500 & 490 \\ 4,0 & 16,0 & 500 & 480 \\ 2,5 & 18,5 & 500 & 490 \\ 2,5 & 21,0 & 500 & 490 \\ 4,0 & 25,0 & 500 & 485 \\ 2,0 & 27,0 & 500 & 490 \\ 4,0 & 31,0 & 500 & 485 \\ 3,5 & 34,5 & 500 & 490 \\ 2,5 & 37,0 & 500 & 490 \\ 2,5 & 39,5 & 500 & 490 \\ 4,5 & 44,0 & 500 & 485 \\ 3,0 & 47,0 & 500 & 490 \\ 4,0 & 51,0 & 500 & 490 \\ 4,0 & 55,0 & 500 & 490 \\ 4,0 & 59,0 & 500 & 490 \\ 5,5 & 64,5 & 500 & 480 \\ 5,0 & 69,5 & 500 & 490 \\ 4,5 & 74,0 & 500 & 490 \\ 4,5 & 78,5 & 505 & 490 \\ 7,5 & 86,0 & 520 & 490 \\ & & & \end{array}$

$$
\begin{array}{ll}
0,010 & 0,007245 \\
0,010 & 0,007245 \\
0,010 & 0,007245 \\
0,010 & 0,007245 \\
0,010 & 0,007245 \\
0,010 & 0,007245 \\
0,010 & 0,007245 \\
0,020 & 0,014490 \\
0,010 & 0,007245 \\
0,010 & 0,007245 \\
0,015 & 0,010867 \\
0,010 & 0,007245 \\
0,015 & 0,010867 \\
0,010 & 0,007245 \\
0,010 & 0,007245 \\
0,010 & 0,007245 \\
0,015 & 0,010867 \\
0,010 & 0,007245 \\
0,010 & 0,007245 \\
0,010 & 0,007245 \\
0,010 & 0,007245 \\
0,020 & 0,014490 \\
0,010 & 0,007245 \\
0,010 & 0,007245 \\
0,010 & 0,007245 \\
0,015 & 0,010867
\end{array}
$$

0,007245

0,014490

0,021735

0,028980

0,036224

0,043469

0,050714

0,065204

0,072449

0,079694

0,090561

0,097806

0,108673

0,115918

0,123163

0,130408

0,141275

0,148520

0,155765

0,163010

0,170255

0,184744

0,191989

0,199234

0,206479

0,217346 


$\begin{array}{lrllllll}12: 52 & 52,0 & 138,0 & 500 & 415 & 0,105 & 0,076071 & 0,293417 \\ 12: 57,5 & 5,5 & 143,5 & 500 & 490 & 0,010 & 0,007245 & 0,300662 \\ 13: 05 & 3,0 & 146,5 & 500 & 490 & 0,010 & 0,007245 & 0,307907 \\ 13: 26 & 21,0 & 167,5 & 500 & 465 & 0,035 & 0,025357 & 0,333264 \\ 13: 40 & 14,0 & 181,5 & 500 & 485 & 0,015 & 0,010867 & 0,344131 \\ 13: 49,5 & 9,5 & 191,0 & 500 & 490 & 0,010 & 0,007245 & 0,351376 \\ 14: 00 & 10,5 & 201,5 & 500 & 490 & 0,010 & 0,007245 & 0,358621 \\ 14: 08 & 8,0 & 209,5 & 500 & 485 & 0,015 & 0,010867 & 0,369489 \\ 14: 22 & 14,0 & 223,5 & 500 & 485 & 0,015 & 0,010867 & 0,380356 \\ 14: 35 & 13,0 & 236,5 & 500 & 485 & 0,015 & 0,010867 & 0,391223 \\ 14: 47 & 12,0 & 248,5 & 505 & 490 & 0,010 & 0,007245 & 0,398468 \\ 14: 59,5 & 12,5 & 261,0 & 505 & 490 & 0,015 & 0,010867 & 0,409335 \\ 15: 17 & 17,5 & 278,5 & 500 & 485 & 0,020 & 0,014490 & 0,423825 \\ 15: 31 & 14,0 & 292,5 & 500 & 490 & 0,010 & 0,007245 & 0,431070 \\ 15: 48 & 17,0 & 309,5 & 500 & 485 & 0,015 & 0,010867 & 0,441937 \\ 16: 04 & 16,0 & 325,5 & 500 & 490 & 0,010 & 0,007245 & 0,449182 \\ 16: 22,5 & 18,5 & 344,0 & 500 & 485 & 0,015 & 0,010867 & 0,460049 \\ 16: 39 & 17,5 & 361,5 & 500 & 485 & 0,015 & 0,010867 & 0,470917\end{array}$

\section{Repetição II}

$\begin{array}{lrrrr}10: 30 & & & 495 & \\ 10: 31 & 1,0 & 1,0 & 500 & 480 \\ 10: 34 & 3,0 & 4,0 & 500 & 480 \\ 10: 37,5 & 3,5 & 7,5 & 500 & 480 \\ 10: 42,5 & 5,0 & 12,5 & 500 & 480 \\ 10: 48 & 5,5 & 18,0 & 500 & 480 \\ 10: 54 & 6,0 & 24,0 & 500 & 480 \\ 11: 01 & 7,0 & 31,0 & 500 & 480 \\ 11: 09 & 8,0 & 39,0 & 500 & 480 \\ 11: 20 & 11,0 & 50,0 & 500 & 475 \\ 11: 27 & 7,0 & 57,0 & 500 & 490 \\ 11: 35 & 8,0 & 65,0 & 500 & 485 \\ 11: 45 & 10,0 & 75,0 & 500 & 480 \\ 11: 54,5 & 9,5 & 84,5 & 500 & 490 \\ 12: 02 & 7,5 & 92,0 & 500 & 490 \\ 12: 12 & 10,0 & 102,0 & 525 & 490 \\ 13: 04 & 52,0 & 154,0 & 500 & 445 \\ 13: 20 & 16,0 & 170,0 & 500 & 485 \\ 13: 33 & 13,0 & 183,0 & 500 & 490 \\ 13: 47 & 14,0 & 197,0 & 500 & 490 \\ 14: 00 & 13,0 & 210,0 & 500 & 490 \\ 14: 16 & 16,0 & 226,0 & 500 & 490 \\ 14: 32,5 & 16,5 & 242,5 & 500 & 490 \\ 14: 50 & 18,0 & 260,5 & 500 & 485 \\ 15: 05 & 14,5 & 275,0 & 500 & 490 \\ 15: 19,5 & 14,5 & 289,5 & 500 & 490 \\ 15: 36 & 16,5 & 306,0 & 500 & 490 \\ 16: 10 & 34,0 & 340,0 & 500 & 475\end{array}$

$\begin{array}{lll}0,015 & 0,010867 & 0,010867 \\ 0,020 & 0,014490 & 0,025357 \\ 0,020 & 0,014490 & 0,039846 \\ 0,020 & 0,014490 & 0,054336 \\ 0,020 & 0,014490 & 0,068826 \\ 0,020 & 0,014490 & 0,083316 \\ 0,020 & 0,014490 & 0,097805 \\ 0,020 & 0,014490 & 0,112295 \\ 0,025 & 0,018112 & 0,130407 \\ 0,010 & 0,007245 & 0,137652 \\ 0,015 & 0,010867 & 0,148520 \\ 0,020 & 0,014490 & 0,163009 \\ 0,010 & 0,007245 & 0,170254 \\ 0,010 & 0,007245 & 0,177499 \\ 0,010 & 0,007245 & 0,184744 \\ 0,080 & 0,057959 & 0,242703 \\ 0,015 & 0,010867 & 0,253570 \\ 0,010 & 0,007245 & 0,260815 \\ 0,010 & 0,007245 & 0,268060 \\ 0,010 & 0,007245 & 0,275305 \\ 0,010 & 0,007245 & 0,282550 \\ 0,010 & 0,007245 & 0,289794 \\ 0,015 & 0,010867 & 0,300662 \\ 0,010 & 0,007245 & 0,307907 \\ 0,010 & 0,007245 & 0,315152 \\ 0,010 & 0,007245 & 0,322396 \\ 0,025 & 0,018112 & 0,340509\end{array}$


16:39

17:04
29,0

25,0

369,0

394,0

\begin{abstract}
500
500
\end{abstract}
485

480

0,015

0,020

0,010867

0,014490

0,351376

0,365866

\section{Repetição N}

12:18,5

$12: 20,0$

$12: 21,0$

$12: 24,5$

$12: 26,5$

$12: 28,5$

$12: 30,5$

$12: 40,0$

$12: 43,0$

$12: 46,5$

$12: 50,0$

$12: 53,5$

$12: 58,0$

$13: 01,5$

13:05,5

$13: 09,0$

13:14,5

13:18,5

$13 \cdot 23,5$

$13: 29,0$

13:35,5

$13: 42,0$

$13: 47,5$

13:54,0

$14: 01,5$

$14: 07,5$

$14: 15,0$

$14: 22,5$

$14: 29,0$

$14: 37,0$

$14: 47,0$

$14: 56,5$

$15: 06,0$

15:15,0

$15: 23,0$

$15: 37,0$

$15: 52,0$

16:05,5

16:16,5

16:30,5

16:44,0

16:59,5

$17: 12,0$

1,5

1,5

1,0

3,5

2,0

2,0

2,0

9,5

3,0

3,5

3,5

3,5

4,5

3,5

4,0

3,5

5,5

4,0

5,0

5,5

6,5

6,5

5,5

6,5

7,5

2,5
6,0

\section{0}

8,0

10,0

12,0

21,5

24,5

28,0

31,5

35,0

39,5

500

505

$$
500
$$

500

500

510

500

500

500

500

500

43,0

500

47,0

500

$50,5 \quad 500$

$56,0 \quad 500$

$60,0 \quad 500$

$65,0 \quad 500$

70,5

500

500

500

500

500

500

6,0

500

500

7,5

500

500

500

500

500

500

500

500

500

500

500

500

500

500

500

500

$17: 28,0$

13,5

228,0

242,0

13,5

255,5

271,0

12,5

283,5

500

0,020

0,020

0,040

0,020

0,020

0,020

0,090

0,020

0,020

0,020

0,020

0,020

0,020

0,020

0,020

0,020

0,020

0,020

0,020

0,020

0,020

0,020

0,020

0,020

0,020

0,020

0,020

0,020

0,020

0,020

0,020

0,020

0,020

0,030

0,030

0,025

0,020

0,020

0,020

0,025

0,020

0,025

480
0,014490

0,014490

0,028979

0,014490

0,014490

0,014490

0,065204

0,014490

0,014490

0,014490

0,014490

0,014490

0,014490

0,014490

0,014490

0,014490

0,014490

0,014490

0,014490

0,014490

0,014490

0,014490

0,014490

0,014490

0,014490

0,014490

0,014490

0,014490

0,014490

0,014490

0,014490

0,014490

0,014490

0,021735

0,021735

0,018112

0,014490

0,014490

0,014490

0,018112

0,014490

0,018112
0,014490

0,028979

0,057959

0,072449

0,086938

0,101428

0,166632

0,181122

0,195611

0,210101

0,224591

0,239081

0,253570

0,268060

0,282550

0,297040

0,311529

0,326019

0,340509

0,354999

0,369488

0,383978

0,398468

0,412958

0,427447

0,441937

0,456427

0,470917

0,485406

0,499896

0,514386

0,528876

0,543365

0,565100

0,586834

0,604947

0,619436

0,633926

0,648416

0,666528

0,681018

0,699130 


$\begin{array}{llllllll}17: 45,0 & 17,0 & 316,5 & 500 & 475 & 0,025 & 0,018112 & 0,717242 \\ 18: 14,5 & 29,5 & 346,0 & 500 & 480 & 0,020 & 0,014490 & 0,731732 \\ 18: 27,5 & 13,0 & 359,0 & 500 & 480 & 0,020 & 0,014490 & 0,746222\end{array}$

Trotamento

hh:mm

: (M); Virhaça in natura como intotrante.

$\underset{(m i n)}{\pi}$

TLC

(min)

\begin{tabular}{|c|c|c|}
\hline $\begin{array}{l}T \\
\min )\end{array}$ & $\begin{array}{l}\text { THAc } \\
\text { (min) }\end{array}$ & $\begin{array}{c}\infty 0 \\
(\mathrm{~mm})\end{array}$ \\
\hline & & 500 \\
\hline 24,5 & 24,5 & 500 \\
\hline 54,5 & 79,0 & 500 \\
\hline 100,0 & 179,0 & 500 \\
\hline 97,0 & 276,0 & 500 \\
\hline 4,0 & 360,0 & 500 \\
\hline
\end{tabular}

10:00 $10: 24,5$

$11: 19$

12:59

$14: 36$

16:00

d1



490
490
485
490
495

dod1

PI

$\left(m^{3} / m^{2}\right) \quad\left(m^{3} / m^{2}\right)$

Repetção I

0,010

0,007245

$0,010 \quad 0,007245$

0,015

0,010867

0,010

0,007245

0,005

0,003622

$15: 12$

15:21

$15: 43,5$

16:21

17:47

20:27

$\begin{array}{rrr}9,0 & 9,0 & 500 \\ 22,5 & 31,5 & 500 \\ 37,5 & 69,0 & 500 \\ 86,0 & 155,0 & 500 \\ 160,0 & 315,0 & 505\end{array}$

490
490
490
485
485

0,007245

0,014490

0,025357

0,032602

0,036224

\section{Repetção V}

500

500

500

505

$$
\begin{array}{ll}
0,010 & 0,007245 \\
0,010 & 0,007245 \\
0,010 & 0,007245 \\
0,015 & 0,010867 \\
0,015 & 0,010867
\end{array}
$$

0,007245

0,014490

0,021735

0,032602

0,043469

\section{Repetção III}

13:56

$14: 00$

14:06,5

14:17

$14: 26$

$14: 33,5$

$14: 44,5$

$14: 55$

15:13

15:31

15:59

$16: 27$

17:01

17:30

18:17

19:26

19:54

$\begin{array}{rrrr}4,0 & 4,0 & 500 & \\ 6,5 & 10,5 & 500 & 485 \\ 11,5 & 22,0 & 500 & 485 \\ 9,0 & 31,0 & 500 & 490 \\ 7,5 & 38,5 & 500 & 490 \\ 11,0 & 49,5 & 500 & 490 \\ 10,5 & 60,0 & 500 & 490 \\ 18,0 & 78,0 & 500 & 490 \\ 18,0 & 96,0 & 500 & 490 \\ 28,0 & 124,0 & 500 & 490 \\ 28,0 & 152,0 & 500 & 490 \\ 34,0 & 186,0 & 500 & 490 \\ 38,0 & 224,0 & 500 & 490 \\ 38,0 & 262,0 & 505 & 490 \\ 69,0 & 331,0 & 505 & 490 \\ 28,0 & 359,0 & 505 & 505\end{array}$

0,010867

0,021734

0,032602

0,039846

0,047091

0,054336

0,061581

0,068826

0,076071

0,083316

0,090561

0,097805

0,105050

0,112295

0,123162

0,123162 
Repetição II

\begin{tabular}{|c|c|c|c|c|c|c|c|}
\hline $16: 34$ & & & 510 & & & & \\
\hline $16: 42$ & 8,0 & 8,0 & 510 & 495 & 0,015 & 0,010867 & 0,010867 \\
\hline $16: 53$ & 19,0 & 27,0 & 510 & 495 & 0,015 & 0,010867 & 0,021734 \\
\hline $17: 05$ & 12,0 & 39,0 & 510 & 490 & 0,020 & 0,014490 & 0,036224 \\
\hline $17: 39$ & 34,0 & 73,0 & 510 & 470 & 0,040 & 0,028979 & 0,065204 \\
\hline 18:02 & 23,0 & 96,0 & 510 & 490 & 0,020 & 0,014490 & 0,079693 \\
\hline $18: 30,5$ & 28,5 & 124,5 & 510 & 490 & 0,020 & 0,014490 & 0,094183 \\
\hline $19: 22$ & 51,5 & 176,0 & 510 & 490 & 0,020 & 0,014490 & 0,108673 \\
\hline 21:11 & 49,0 & 225,0 & 510 & 495 & 0,015 & 0,010867 & 0,119540 \\
\hline $22: 35$ & 84,0 & 309,0 & 510 & 505 & 0,005 & 0,003622 & 0,123162 \\
\hline
\end{tabular}

Trotamento

: (a+A); Água cornum corno redutor de infittração, seguida de água co mum corno intivante.

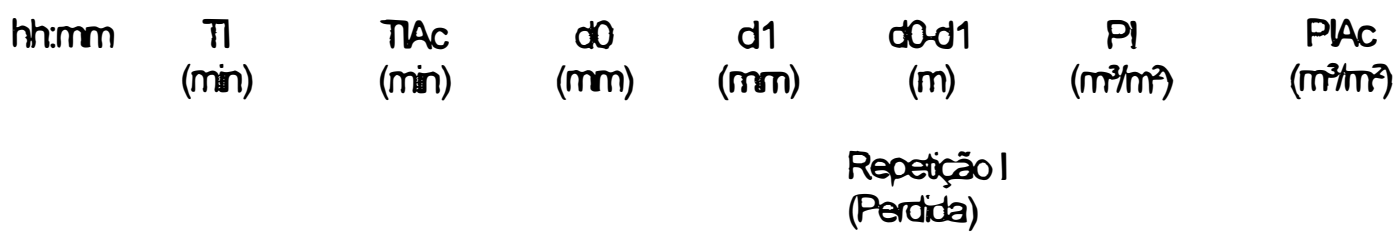

$\begin{array}{lrrrrrrr}15: 35 & & & 505 & & & & \\ 15: 41 & 6,0 & 6,0 & 500 & 490 & 0,015 & 0,010867 & 0,010867 \\ 15: 53,5 & 12,5 & 18,5 & 500 & 480 & 0,020 & 0,014490 & 0,025357 \\ 16: 00 & 6,5 & 25,0 & 500 & 490 & 0,010 & 0,007245 & 0,032602 \\ 16: 07 & 7,0 & 32,0 & 500 & 490 & 0,010 & 0,007245 & 0,039846 \\ 16: 14 & 7,0 & 39,0 & 500 & 490 & 0,010 & 0,007245 & 0,047091 \\ 16: 21,5 & 7,5 & 46,5 & 500 & 490 & 0,010 & 0,007245 & 0,054336 \\ 16: 30 & 8,5 & 55,0 & 500 & 490 & 0,010 & 0,007245 & 0,061581 \\ 16: 35 & 5,0 & 60,0 & 520 & 495 & 0,005 & 0,003622 & 0,065204 \\ 16: 53 & 8,0 & 68,0 & 500 & 480 & 0,040 & 0,028979 & 0,094183 \\ 17: 05 & 12,0 & 80,0 & 500 & 490 & 0,010 & 0,007245 & 0,101428 \\ 17: 17,5 & 12,5 & 92,5 & 500 & 485 & 0,015 & 0,010867 & 0,112295 \\ 17: 30 & 12,5 & 105,0 & 500 & 490 & 0,010 & 0,007245 & 0,119540 \\ 17: 44 & 14,0 & 119,0 & 500 & 490 & 0,010 & 0,007245 & 0,126785 \\ 17: 55,5 & 11,5 & 130,5 & 500 & 490 & 0,010 & 0,007245 & 0,134030 \\ 18: 05 & 9,5 & 140,0 & 500 & 490 & 0,010 & 0,007245 & 0,141275 \\ 18: 16 & 11,0 & 151,0 & 500 & 490 & 0,010 & 0,007245 & 0,148520 \\ 18: 27 & 11,0 & 162,0 & 500 & 490 & 0,010 & 0,007245 & 0,155764\end{array}$


$18: 40$

$18: 53$
$19: 05$
$19: 37,5$
$19: 57,5$
$20: 08$
$20: 44$
$21: 15$
$21: 35$

$13,0 \quad 175,0 \quad 500$

\section{3,0}

13,0

32,5

20,0

10,5

36,0

31,0

20,0

$\begin{array}{ll}188,0 & 500 \\ 201,0 & 500 \\ 233,5 & 500 \\ 253,5 & 505 \\ 264,0 & 505 \\ 300,0 & 500 \\ 331,0 & 505 \\ 351,0 & 500\end{array}$

500

500

505
505

500

505

500
13:37

13:41

13:44,5

13:54,5

13:58,5

14:03

$14: 09,5$

$14: 17,5$

$14: 22,5$

$14: 27$

$14: 35$

$14: 41,5$

$14: 49$

$14: 57,5$

15:06

15:16,5

15:27

15:37

15:45,5

15:55

16:10

16:25

16:38

16:48,5

16:57

17:10

17:24

17:33

$17: 44,5$

$17: 56,5$

18:05

18:15

18:55

19:25

19:51

$\begin{array}{rrr} & & 500 \\ 4,0 & 4,0 & 500 \\ 3,5 & 7,5 & 510 \\ 10,0 & 17,5 & 500 \\ 4,0 & 21,5 & 500 \\ 4,5 & 26,0 & 500 \\ 6,5 & 32,5 & 500 \\ 8,0 & 40,5 & 500 \\ 5,0 & 45,5 & 500 \\ 4,5 & 50,0 & 500 \\ 8,0 & 58,0 & 500 \\ 6,5 & 64,5 & 500 \\ 7,5 & 72,0 & 500 \\ 8,5 & 80,5 & 500 \\ 9,5 & 90,0 & 500 \\ 10,5 & 100,5 & 500 \\ 10,5 & 111,0 & 500 \\ 10,0 & 121,0 & 500 \\ 8,5 & 129,5 & 500 \\ 9,5 & 139,0 & 500 \\ 15,0 & 154,0 & 500 \\ 15,0 & 169,0 & 500 \\ 13,0 & 182,0 & 500 \\ 10,5 & 192,5 & 500 \\ 8,5 & 201,0 & 500 \\ 13,0 & 214,0 & 500 \\ 14,0 & 228,0 & 500 \\ 9,5 & 237,5 & 500 \\ 11,0 & 248,5 & 500 \\ 12,0 & 260,5 & 500 \\ 8,5 & 269,0 & 500 \\ 10,0 & 279,0 & 520 \\ 40,0 & 319,0 & 500 \\ 30,0 & 349,0 & 500 \\ 26,0 & 375,0 & 500 \\ & & \end{array}$

500
490

$0,010 \quad 0,007245$

0,163009

490
490
470
490
480
485
480
490

0,010

0,010

0,007245

$0,030 \quad 0,021735$

$0,010 \quad 0,007245$

$0,025 \quad 0,018112$

$0,020 \quad 0,014490$

$0,020 \quad 0,014490$

$0,015 \quad 0,010867$

0,170254
0,177499
0,199234
0,206478
0,224591
0,239080
0,253570
0,264437

Repetiçāo III

$500 \quad 485$

485

0,015

0,010867

0,010867

0,015

0,010867

0,021734

490

490

490

490

485

490

490

490

490

490

485

490

480

490

490

490

490

480

485

490

490

490

480

490

490

490

490

490

490

460

480

470
0,020

0,010

0,010

0,014490

0,007245

0,010

0,015

0,010

0,010

0,010

0,010

0,010

0,015

0,010

0,020

0,010

0,010

0,010

0,010

0,020

0,015

0,010

0,010

0,010

0,020

0,010

0,010

0,010

0,010

0,010

0,010

0,060

0,020

0,030

0,007245

0,007245

0,010867

0,007245

0,007245

0,007245

0,007245

0,007245

0,010867

0,007245

0,014490

0,007245

0,007245

0,007245

0,007245

0,014490

0,010867

0,007245

0,007245

0,007245

0,014490

0,007245

0,007245

0,007245

0,007245

0,007245

0,007245

0,043469

0,014490

0,021735
0,036224

0,043469

0,050714

0,057959

0,068826

0,076071

0,083316

0,090561

0,097805

0,105050

0,115918

0,123162

0,137652

0,144897

0,152142

0,159387

0,166632

0,181121

0,191989

0,199234

0,206478

0,213723

0,228213

0,235458

0,242703

0,249948

0,257193

0,264437

0,271682

0,315152

0,329641

0,351376 
Repetição II

\begin{tabular}{|c|c|c|c|c|c|c|c|}
\hline $14: 00$ & & & 495 & & & 336 & \\
\hline $14: 01$ & 1,0 & 1,0 & 500 & 480 & 0,015 & 0,010867 & 0,010867 \\
\hline $14: 02,5$ & 1,5 & 2,5 & 500 & 480 & 0,020 & 0,014490 & 0,025357 \\
\hline $14: 04$ & 2,5 & 5,0 & 500 & 480 & 0,020 & 0,014490 & 0,039846 \\
\hline $14: 05,5$ & 1,5 & 6,5 & 500 & 480 & 0,020 & 0,014490 & 0,054336 \\
\hline $14: 07$ & 2,5 & 9,0 & 500 & 480 & 0,020 & 0,014490 & 0,068826 \\
\hline $14: 10$ & 3,0 & 12,0 & 500 & 480 & 0,020 & 0,014490 & 0,083316 \\
\hline $14: 12,5$ & 2,5 & 14,5 & 500 & 480 & 0,020 & 0,014490 & 0,097805 \\
\hline $14: 14,5$ & 2,0 & 16,5 & 500 & 480 & 0,020 & 0,014490 & 0,112295 \\
\hline $14: 19$ & 4,5 & 21,0 & 500 & 480 & 0,020 & 0,014490 & 0,126785 \\
\hline $14: 21$ & 2,0 & 23,0 & 500 & 480 & 0,020 & 0,014490 & 0,141275 \\
\hline $14: 23$ & 2,0 & 25,0 & 520 & 480 & 0,020 & 0,014490 & 0,155764 \\
\hline $14: 29$ & 6,0 & 31,0 & 520 & 449 & 0,071 & 0,051439 & 0,207203 \\
\hline $14: 32,5$ & 3,5 & 34,5 & 530 & 465 & 0,055 & 0,039847 & 0,247050 \\
\hline $14: 36,5$ & 4,0 & 38,5 & 510 & 460 & 0,070 & 0,050714 & 0,297764 \\
\hline $14: 38,5$ & 2,0 & 40,5 & 500 & 475 & 0,035 & 0,025357 & 0,323121 \\
\hline $14: 40$ & 1,5 & 42,0 & 500 & 470 & 0,030 & 0,021735 & 0,344856 \\
\hline $14: 42$ & 2,0 & 44,0 & 500 & 480 & 0,020 & 0,014490 & 0,359345 \\
\hline $14: 43$ & 1,0 & 45,0 & 505 & 480 & 0,020 & 0,014490 & 0,373835 \\
\hline $14: 45$ & 2,0 & 47,0 & 500 & 480 & 0,025 & 0,018112 & 0,391947 \\
\hline $14: 47$ & 2,0 & 49,0 & 500 & 480 & 0,020 & 0,014490 & 0,406437 \\
\hline $14: 49$ & 2,0 & 51,0 & 500 & 475 & 0,025 & 0,018112 & 0,424549 \\
\hline $14: 51$ & 2,0 & 53,0 & 500 & 475 & 0,025 & 0,018112 & 0,442661 \\
\hline $14: 53,5$ & 2,5 & 55,5 & 500 & 470 & 0,030 & 0,021735 & 0,464396 \\
\hline $14: 54,5$ & 6,0 & 61,5 & 500 & 480 & 0,020 & 0,014490 & 0,478886 \\
\hline 15:01 & 6,0 & 67,5 & 500 & 480 & 0,020 & 0,014490 & 0,493375 \\
\hline $15: 03$ & 2,0 & 69,5 & 500 & 480 & 0,020 & 0,014490 & 0,507865 \\
\hline $15: 05,5$ & 1,5 & 71,0 & 500 & 480 & 0,020 & 0,014490 & 0,522355 \\
\hline $15: 06$ & 1,5 & 72,5 & 500 & 480 & 0,020 & 0,014490 & 0,536845 \\
\hline $15: 07,5$ & 1,5 & 74,0 & 500 & 480 & 0,020 & 0,014490 & 0,551334 \\
\hline $15: 09$ & 1,5 & 75,5 & 500 & 480 & 0,020 & 0,014490 & 0,565824 \\
\hline 15:11 & 2,0 & 77,5 & 500 & 480 & 0,020 & 0,014490 & 0,580314 \\
\hline $15: 21$ & 10,0 & 87,5 & 500 & 480 & 0,020 & 0,014490 & 0,594804 \\
\hline 15:26 & 5,0 & 92,5 & 500 & 445 & 0,055 & 0,039847 & 0,634650 \\
\hline $15: 28$ & 2,0 & 94,5 & 500 & 470 & 0,030 & 0,021735 & 0,656385 \\
\hline $15: 29,5$ & 1,5 & 96,0 & 500 & 475 & 0,025 & 0,018112 & 0,674497 \\
\hline 15:31 & 1,5 & 97,5 & 500 & 480 & 0,020 & 0,014490 & 0,688987 \\
\hline 15:33 & 2,0 & 99,5 & 500 & 480 & 0,020 & 0,014490 & 0,703477 \\
\hline 15:35 & 2,0 & 101,5 & 500 & 480 & 0,020 & 0,014490 & 0,717966 \\
\hline $15: 42$ & 7,0 & 108,5 & 500 & 480 & 0,020 & 0,014490 & 0,732456 \\
\hline $15: 44$ & 2,0 & 110,5 & 500 & 480 & 0,020 & 0,014490 & 0,746946 \\
\hline $15: 46$ & 2,0 & 112,5 & 500 & 480 & 0,020 & 0,014490 & 0,761436 \\
\hline $15: 48$ & 2,0 & 114,5 & 500 & 480 & 0,020 & 0,014490 & 0,775925 \\
\hline 15:50 & 2,0 & 116,5 & 500 & 480 & 0,020 & 0,014490 & 0,790415 \\
\hline 15:52 & 2,0 & 118,5 & 500 & 480 & 0,020 & 0,014490 & 0,804905 \\
\hline $15: 54$ & 2,0 & 120,5 & 500 & 480 & 0,020 & 0,014490 & 0,819394 \\
\hline
\end{tabular}




\begin{tabular}{|c|c|c|c|c|c|c|c|}
\hline $15: 57$ & 3,0 & 123,5 & 500 & 475 & 0,025 & 0,018112 & 0,837507 \\
\hline 16:02 & 5,0 & 128,5 & 500 & 445 & 0,055 & 0,039847 & 0,877353 \\
\hline $16: 06,5$ & 4,5 & 133,0 & 500 & 480 & 0,020 & 0,014490 & 0,891843 \\
\hline $16: 09,5$ & 3,0 & 136,0 & 500 & 475 & 0,025 & 0,018112 & 0,909955 \\
\hline $16: 12,5$ & 3,0 & 139,0 & 500 & 480 & 0,020 & 0,014490 & 0,924445 \\
\hline $16: 14$ & 1,5 & 140,5 & 500 & 480 & 0,020 & 0,014490 & 0,938935 \\
\hline $16: 16,5$ & 2,5 & 143,0 & 500 & 475 & 0,025 & 0,018112 & 0,957047 \\
\hline $16: 21$ & 4,5 & 147,5 & 500 & 460 & 0,040 & 0,028979 & 0,986027 \\
\hline $16: 22,5$ & 1,5 & 149,0 & 500 & 480 & 0,020 & 0,014490 & 1,000516 \\
\hline $16: 25$ & 2,5 & 151,5 & 500 & 480 & 0,020 & 0,014490 & 1,015006 \\
\hline $16: 27,5$ & 2,0 & 153,5 & 500 & 480 & 0,020 & 0,014490 & 1,029496 \\
\hline $16: 30,5$ & 3,0 & 156,5 & 500 & 460 & 0,040 & 0,028979 & 1,058475 \\
\hline $16: 36,5$ & 6,0 & 162,5 & 500 & 480 & 0,020 & 0,014490 & 1,072965 \\
\hline $16: 42$ & 5,5 & 168,0 & 500 & 480 & 0,020 & 0,014490 & 1,087455 \\
\hline $16: 52$ & 10,0 & 178,0 & 500 & 460 & 0,040 & 0,028979 & 1,116434 \\
\hline $16: 58,5$ & 6,5 & 184,5 & 500 & 480 & 0,020 & 0,014490 & 1,130924 \\
\hline $17: 02$ & 3,5 & 188,0 & 500 & 470 & 0,030 & 0,021735 & 1,152659 \\
\hline $17: 09$ & 7,0 & 195,0 & 500 & 480 & 0,020 & 0,014490 & 1,167148 \\
\hline $17: 17,5$ & 8,5 & 203,5 & 520 & 480 & 0,020 & 0,014490 & 1,181638 \\
\hline $18: 38$ & 20,5 & 224,0 & 500 & 375 & 0,145 & 0,105051 & 1,286689 \\
\hline $17: 43,5$ & 5,5 & 229,5 & 500 & 480 & 0,020 & 0,014490 & 1,301178 \\
\hline $17: 47$ & 4,0 & 233,5 & 500 & 480 & 0,020 & 0,014490 & 1,315668 \\
\hline $17: 50$ & 3,0 & 236,5 & 500 & 475 & 0,025 & 0,018112 & 1,333780 \\
\hline $17: 55,5$ & 5,5 & 242,0 & 500 & 480 & 0,020 & 0,014490 & 1,348270 \\
\hline $17: 59$ & 4,0 & 246,0 & 500 & 470 & 0,030 & 0,021735 & 1,370005 \\
\hline 18:06 & 7,0 & 253,0 & 500 & 480 & 0,020 & 0,014490 & 1,384494 \\
\hline 18:10,5 & 4,5 & 257,5 & 500 & 470 & 0,030 & 0,021735 & 1,406229 \\
\hline $18: 12,5$ & 2,5 & 260,0 & 500 & 480 & 0,020 & 0,014490 & 1,420719 \\
\hline $18: 14,5$ & 2,0 & 262,0 & 500 & 480 & 0,020 & 0,014490 & 1,435208 \\
\hline 18:17 & 2,5 & 264,5 & 500 & 480 & 0,020 & 0,014490 & 1,449698 \\
\hline $18: 19,5$ & 2,5 & 267,0 & 500 & 480 & 0,020 & 0,014490 & 1,464188 \\
\hline $18: 26$ & 6,5 & 273,5 & 500 & 480 & 0,020 & 0,014490 & 1,478678 \\
\hline $18: 28,5$ & 2,5 & 276,0 & 500 & 480 & 0,020 & 0,014490 & 1,493167 \\
\hline 18:33 & 4,5 & 280,5 & 500 & 470 & 0,030 & 0,021735 & 1,514902 \\
\hline 18:35,5 & 2,5 & 283,0 & 500 & 480 & 0,020 & 0,014490 & 1,529392 \\
\hline $18: 38,5$ & 3,0 & 286,0 & 500 & 470 & 0,030 & 0,021735 & 1,551126 \\
\hline $18: 48$ & 9,5 & 295,5 & 500 & 475 & 0,025 & 0,018112 & 1,569239 \\
\hline 19:02 & 4,0 & 299,5 & 500 & 470 & 0,030 & 0,021735 & 1,590973 \\
\hline $19: 05,5$ & 3,5 & 303,0 & 500 & 470 & 0,030 & 0,021735 & 1,612708 \\
\hline 19:16 & 10,5 & 313,5 & 500 & 430 & 0,070 & 0,050714 & 1,663422 \\
\hline $19: 20$ & 4,0 & 317,5 & 500 & 480 & 0,020 & 0,014490 & 1,677912 \\
\hline $19: 23,5$ & 3,5 & 321,0 & 500 & 480 & 0,020 & 0,014490 & 1,692401 \\
\hline 19:34 & 10,5 & 331,5 & 500 & 451 & 0,049 & 0,035500 & 1,727901 \\
\hline $19: 36,5$ & 2,5 & 334,0 & 500 & 471 & 0,029 & 0,021010 & 1,748911 \\
\hline 19:39,5 & 3,0 & 337,0 & 500 & 480 & 0,020 & 0,014490 & 1,763401 \\
\hline $19: 44,5$ & 5,0 & 342,0 & 500 & 460 & 0,040 & 0,028979 & 1,792381 \\
\hline $19: 52,5$ & 8,0 & 350,0 & 500 & 460 & 0,040 & 0,028979 & 1,821360 \\
\hline 20:03 & 10,5 & 360,5 & 500 & 425 & 0,075 & 0,054337 & 1,875697 \\
\hline
\end{tabular}


Repetição N

\begin{tabular}{|c|c|c|c|c|c|c|c|}
\hline $15: 49$ & 4,0 & 4,0 & 500 & & & & \\
\hline $15: 53,5$ & 4,5 & 8,5 & 500 & 480 & 0,020 & 0,014490 & 0,014490 \\
\hline $15: 57$ & 3,5 & 12,0 & 500 & 480 & 0,020 & 0,014490 & 0,028979 \\
\hline $16: 00$ & 3,0 & 15,0 & 500 & 480 & 0,020 & 0,014490 & 0,043469 \\
\hline $16: 04$ & 4,0 & 19,0 & 500 & 480 & 0,020 & 0,014490 & 0,057959 \\
\hline $16: 09$ & 5,0 & 24,0 & 500 & 480 & 0,020 & 0,014490 & 0,072449 \\
\hline $16: 15$ & 6,0 & 30,0 & 500 & 480 & 0,020 & 0,014490 & 0,086938 \\
\hline $15: 20,5$ & 5,5 & 35,5 & 505 & 480 & 0,020 & 0,014490 & 0,101428 \\
\hline $15: 28$ & 7,5 & 43,0 & 500 & 480 & 0,025 & 0,018112 & 0,119540 \\
\hline $15: 35$ & 7,0 & 50,0 & 500 & 480 & 0,020 & 0,014490 & 0,134030 \\
\hline $15: 42$ & 7,0 & 57,0 & 500 & 480 & 0,020 & 0,014490 & 0,148520 \\
\hline $15: 48$ & 6,0 & 63,0 & 500 & 480 & 0,020 & 0,014490 & 0,163010 \\
\hline $15: 55$ & 7,0 & 70,0 & 500 & 480 & 0,020 & 0,014490 & 0,177499 \\
\hline $17: 01$ & 6,0 & 76,0 & 500 & 480 & 0,020 & 0,014490 & 0,191989 \\
\hline $17: 07,5$ & 6,5 & 82,5 & 500 & 480 & 0,020 & 0,014490 & 0,206479 \\
\hline $17: 15$ & 7,5 & 90,0 & 520 & 480 & 0,020 & 0,014490 & 0,220969 \\
\hline $18: 10$ & 55,0 & 145,0 & 500 & 374 & 0,146 & 0,105775 & 0,326744 \\
\hline $18: 17$ & 7,0 & 152,0 & 500 & 480 & 0,020 & 0,014490 & 0,341233 \\
\hline $18: 24$ & 7,0 & 159,0 & 500 & 480 & 0,020 & 0,014490 & 0,355723 \\
\hline $18: 31,5$ & 7,5 & 166,5 & 500 & 480 & 0,020 & 0,014490 & 0,370213 \\
\hline $18: 38$ & 6,5 & 173,0 & 500 & 480 & 0,020 & 0,014490 & 0,384703 \\
\hline $18: 45$ & 7,0 & 180,0 & 500 & 480 & 0,020 & 0,014490 & 0,399192 \\
\hline $18: 51,5$ & 6,5 & 186,5 & 500 & 480 & 0,020 & 0,014490 & 0,413682 \\
\hline $19: 00$ & 8,5 & 195,0 & 500 & 480 & 0,020 & 0,014490 & 0,428172 \\
\hline $19: 10$ & 10,0 & 205,0 & 500 & 480 & 0,020 & 0,014490 & 0,442662 \\
\hline $19: 18$ & 8,0 & 213,0 & 500 & 480 & 0,020 & 0,014490 & 0,457151 \\
\hline $19: 56,5$ & 38,5 & 251,5 & 500 & 420 & 0,080 & 0,057959 & 0,515110 \\
\hline $20: 08$ & 11,5 & 263,0 & 500 & 480 & 0,020 & 0,014490 & 0,529600 \\
\hline $20: 19$ & 11,0 & 274,0 & 500 & 480 & 0,020 & 0,014490 & 0,544090 \\
\hline $20: 31$ & 12,0 & 286,0 & 500 & 480 & 0,020 & 0,014490 & 0,558579 \\
\hline $20: 43$ & 12,0 & 298,0 & 500 & 480 & 0,020 & 0,014490 & 0,573069 \\
\hline $20: 58,5$ & 15,5 & 313,5 & 500 & 475 & 0,025 & 0,018112 & 0,591181 \\
\hline $21: 14,5$ & 16,0 & 329,5 & 500 & 480 & 0,020 & 0,014490 & 0,605671 \\
\hline $21: 32$ & 17,5 & 347,0 & 500 & 470 & 0,030 & 0,021735 & 0,627406 \\
\hline $21: 44,5$ & 12,5 & 359,5 & 500 & 480 & 0,020 & 0,014490 & 0,641895 \\
\hline
\end{tabular}

Perda média de liquido por infituação no final de 6 horas.

$\begin{array}{ccc}\begin{array}{c}\text { Trata } \\ \text { mento }\end{array} & \begin{array}{c}\text { Repet- } \\ \text { ça }\end{array} & \begin{array}{c}\text { TAd } \\ \text { (min.) }\end{array} \\ \text { (v+A) } & I & 352,0 \\ & V & 375,5\end{array}$

\begin{tabular}{|c|c|}
\hline $\begin{array}{l}\text { PAdl } \\
\left(\mathrm{m}^{3} / \mathrm{m}^{2}\right)\end{array}$ & $\begin{array}{c}\text { PAd } \\
\text { (mintminnin) }\end{array}$ \\
\hline 0,365866 & 0,00103939 \\
\hline 0,293417 & 0,0007814 \\
\hline
\end{tabular}




$\begin{array}{ccc} & \text { III } & 349,0 \\ & \text { II } & 358,0 \\ & \text { N } & 384,5 \\ & \text { Média } & 363,8 \\ & \text { I } & 155,0 \\ & \text { V } & 442,0 \\ & \text { III } & 359,0 \\ & \text { II } & 300,0 \\ & \text { N } & 360,5 \\ \text { (A) } \quad \text { Média } & 323,3 \\ & \text { I } & 236,0 \\ & \text { V } & 362,0 \\ & \text { III } & 361,5 \\ & \text { II } & 394,0 \\ & \text { N } & 359,0 \\ & \text { Média } & 342,5 \\ \text { M I I } & 360,0 \\ & \text { V } & 315,0 \\ & \text { III } & 359,0 \\ & \text { II } & 309,0 \\ & \text { N } & - \\ & \text { Média } & 335,8 \\ & \text { I } & - \\ \text { (a+A) } & \text { V } & 351,0 \\ & \text { III } & 375,0 \\ & \text { II } & 360,5 \\ & \text { N } & 359,5 \\ & & 361,5\end{array}$

$\begin{array}{cc}0,246326 & 0,00070581 \\ 0,217346 & 0,00060711 \\ 0,641171 & 0,00166754 \\ 0,352825 & 0,000960 \\ 0,01087 & 0,00007 \\ 0,007245 & 0,00002 \\ 0,094183 & 0,00026235 \\ 0,043469 & 0,0001449 \\ 0,047092 & 0,00013063 \\ 0,040571 & 0,000125 \\ 1,278719 & 0,0054183 \\ 0,307907 & 0,00085057 \\ 0,470917 & 0,00130267 \\ 0,365866 & 0,00092859 \\ 0,746222 & 0,00207861 \\ 0,633926 & 0,002116 \\ 0,036224 & 0,00010062 \\ 0,043469 & 0,000138 \\ 0,123162 & 0,00034307 \\ 0,123162 & 0,00039858 \\ - & - \\ 0,081504 & 0,000245 \\ - & - \\ 0,264437 & 0,00075338 \\ 0,351376 & 0,000937 \\ 1,875697 & 0,00520304 \\ 0,641895 & 0,00178552 \\ 0,783351 & 0,002170 \\ & \end{array}$

